\title{
WestVirginiaUniversity
}

THE RESEARCH REPOSITORY @ WVU

Graduate Theses, Dissertations, and Problem Reports

2003

\section{Standardization of test methods for property evaluation of FRP bars}

Vijay Kumar Tripathi

West Virginia University

Follow this and additional works at: https://researchrepository.wvu.edu/etd

\section{Recommended Citation}

Tripathi, Vijay Kumar, "Standardization of test methods for property evaluation of FRP bars" (2003). Graduate Theses, Dissertations, and Problem Reports. 1403.

https://researchrepository.wvu.edu/etd/1403

This Thesis is protected by copyright and/or related rights. It has been brought to you by the The Research Repository @ WVU with permission from the rights-holder(s). You are free to use this Thesis in any way that is permitted by the copyright and related rights legislation that applies to your use. For other uses you must obtain permission from the rights-holder(s) directly, unless additional rights are indicated by a Creative Commons license in the record and/ or on the work itself. This Thesis has been accepted for inclusion in WVU Graduate Theses, Dissertations, and Problem Reports collection by an authorized administrator of The Research Repository @ WVU. For more information, please contact researchrepository@mail.wvu.edu. 


\title{
Standardization of Test Methods for
}

Property Evaluation of FRP Bars

\author{
Vijay Kumar Tripathi
}

\author{
Thesis submitted to the \\ College of Engineering and Mineral Resources \\ at West Virginia University \\ in partial fulfillment of the requirements \\ for the degree of
}

\author{
Master of Science \\ in \\ Civil Engineering
}

Department of Civil and Environmental Engineering

\author{
Dr. P.V. Vijay, Ph.D., Chair \\ Dr. Hota GangaRao, Ph.D., Co-Chair \\ Dr. Udaya Halabe, Ph.D.
}

Morgantown, West Virginia

2003

Keywords: FRP Bars, Rebars, FRP Test Methods, Tension, Flexure, Bending, Shear, Bond, Moisture Absorption, Aging. 


\section{ABSTRACT \\ Standardization of Test Methods for Property Evaluation of FRP Bars Vijay Kumar Tripathi}

The objective of this research is to verify/modify/develop standardized test methods for evaluating mechanical properties of Fiber Reinforced Polymer (FRP) bars by conducting limited complementary tests to determine/verify their mechanical properties. Both short and long-term tests were conducted as a part of this research. Short-term tests included tension, flexure, shear and bond property evaluations. Long-term tests included evaluation of moisture absorption and flexural tests on aged bars. A total of 229 FRP bars with different fibers (carbon, glass and aramid), varying diameters (\#3 to \#8) and surface textures (ribbed, sand-coated, and sand-coated with helical wraps) were tested under this research.

Tension tests were conducted using grips made of split schedule 80 steel pipes that were bonded to the bars using a commercially available resin. Grip lengths based on diameter of FRP bars were established to be varying from 8" to 13.3" for \#3 to \#8 bars, respectively. Average tensile strengths of FRP bars were found to be $256 \mathrm{ksi}$ (ribbed carbon), 83 to $77 \mathrm{ksi}$ (ribbed glass), 82 to $67 \mathrm{ksi}$ (sand coated glass), and $173 \mathrm{ksi}$ (sand coated aramid)

Three-point bending tests were conducted for different span to diameter (L/D) ratios (16, 20, 21 and 40), using two types of supports, i.e., type A (knife-edge) and type B (smooth roller). Type B support showed better consistency in test results with lower standard deviation. Flexural strengths of FRP bars were $151 \mathrm{ksi}$ (sand coated carbon), 145 to $117 \mathrm{ksi}$ (ribbed glass), 113 to $98 \mathrm{ksi}$ (sand coated glass), and $103 \mathrm{ksi}$ (sand coated aramid). Similarly, stiffness values were also evaluated for these bars in tension and flexure.

Single and double shear tests were conducted using two cutting tools having widths of 1 " and 1/2". Double shear tests with $1 / 2$ " wide tool gave the most consistent results. Shear strengths of ribbed carbon, ribbed glass and sand coated glass FRP bars were $47 \mathrm{ksi}, 27.2 \mathrm{ksi}$ and $27 \mathrm{ksi}$, respectively (in double shear with 1/2" wide cutting tool).

Concrete cylinder pullout tests were performed using carbon and glass FRP bars. Experimental bond strengths for ribbed carbon, ribbed glass and sand coated glass FRP bars were 1834 psi, 1712 psi and 1895 psi, respectively.

For moisture absorption tests, two-inch long bars were cut and sealed at the ends with a thin layer of epoxy. They were immersed in distilled water and monitored for change in weights. FRP bars showed low amount of moisture absorption $(<0.34 \%)$ over a period of 298 days. FRP bars immersed in water and 3\% salt solutions for over four years at room temperature and under fluctuations of freeze-thaw conditions were tested in three-point bending. FRP bars immersed in salt solution and subjected to freeze-thaw temperature fluctuations showed maximum stress reduction.

Maximum standard deviation values of test results were $7.11 \%, 7.6 \%, 6.4 \%$ and $8.76 \%$ of average strength/stiffness values for tension, flexure (support type B), double shear, and bond tests, respectively. Strains, deflections, and slips corresponding to specific test types were recorded using strain gages, deflection gages, LVDTs and data acquisition system. Based on the data from this research, specifications were developed and submitted to NCHRP-FHWA for consideration as draft AASHTO Standard Test Specifications. 


\section{ACKNOWLEDGEMENTS}

I would like to extend my sincere gratitude to a number of people for their contributions toward this thesis and my master's degree.

The professors at West Virginia University have been a wonderful source of guidance and encouragement. Dr. P.V. Vijay and Dr. Hota GangaRao, my thesis advisors, offered many helpful suggestions regarding the research and documentation of my master's thesis. My sincere thanks to them for being an integral part of this research work, their insights, guidance, time and most of all their patience. I also would like to thank Dr. Udaya Halabe, member of my thesis committee, for his precious time and guidance.

My sincere thanks to Dana Humberson and David Turner, at West Virginia University, who helped in the manufacture of equipments and fixtures required for the completion of this work. I would also like to express my gratitude to José Ricardo Basto, a fellow research student, for lending me a helping hand whenever possible. I would like to thank and acknowledge National Cooperative Highway Research Program, which sponsored this research on the development of draft for AASHTO Standard test specifications.

Finally, I would like to express my deepest gratitude to West Virginia University and my friends for the lovely experience at Morgantown. 


\section{LIST OF CONTENTS}

Abstract...

Acknowledgements.

List of Contents.

List of Figures.

List of Tables

CHAPTER 1

INTRODUCTION

1.1 INTRODUCTION.

1.2 OBJECTIVES.

$1.3 \mathrm{SCOPE}$.

1.4 OVERVIEW OF CHAPTERS

\section{CHAPTER 2}

LITERATURE REVIEW

2.1 INTRODUCTION.

2.2 SHORT TERM BEHAVIOR............................................................................ 9

2.2.1 TENSION ................................................................................... 10

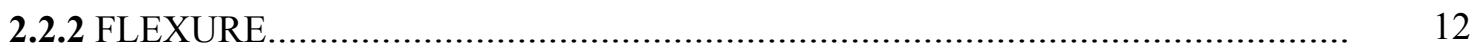

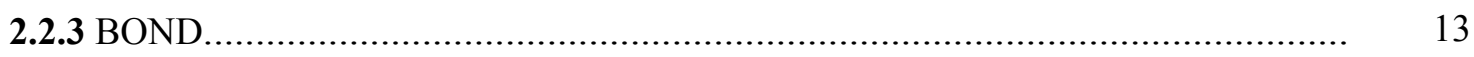

2.3 LONG TERM BEHAVIOR......................................................................... 16

2.3.1 MOISTURE ABSORPTION.................................................................... 16

2.3.2 EFFECT OF AGING ON FLEXURE............................................................. 18

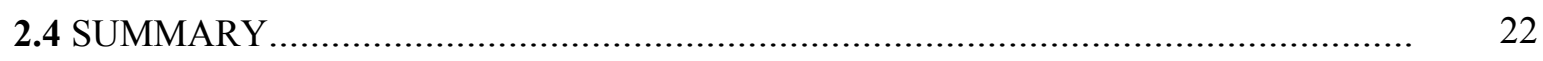

CHAPTER 3

TYPES OF TESTS AND SPECIMENS

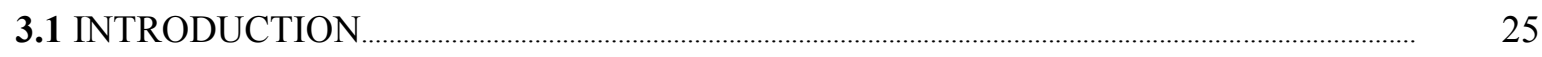

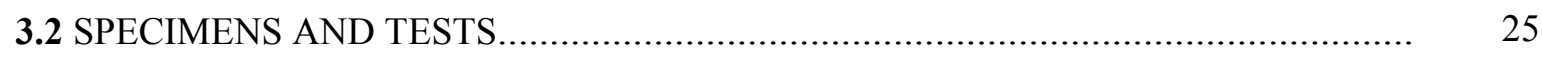

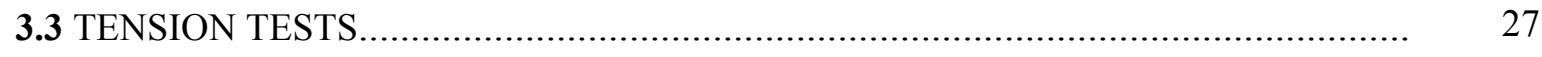

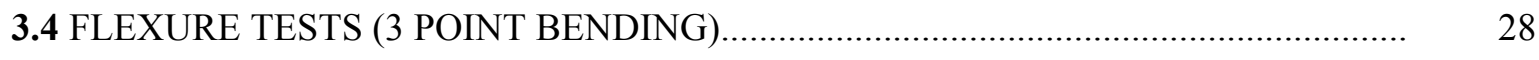

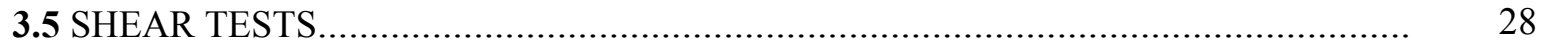




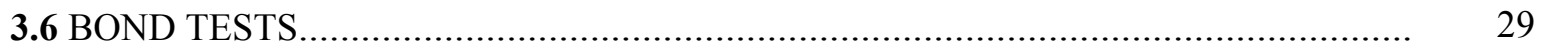

3.7 LONG TERM TESTING............................................................................ 29

3.7.1 MOISTURE ABSORPTION .................................................................................. 29

3.7.2 FLEXURE TEST ON AGED SPECIMENS....................................................................... 30

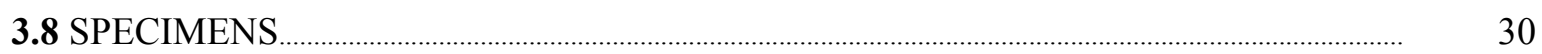

\section{CHAPTER 4 \\ TENSION TESTS}

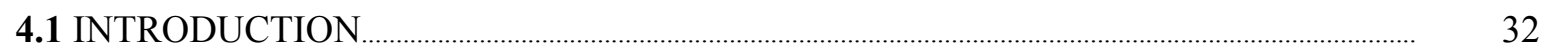

4.2 DEVELOPMENT OF THE TEST ............................................................... 33

4.2.1 REFERENCED DOCUMENTS.................................................................... 33

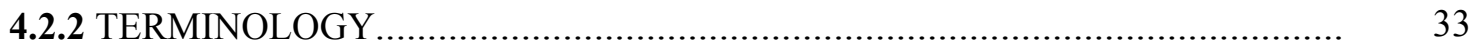

4.2.3 SPECIMEN PREPARATION ................................................................ 34

4.2.4 TEST EQUIPMENT ..........................................................................

4.2.5 TEST METHOD

4.2.6 CALCULATION .................................................................................... 36

4.3 TEST RESULTS

4.3.1 TENSION - CFRP - RIBBED - \#3 ........................................................... 38

4.3.2 TENSION - GFRP - RIBBED - \#4, \#6....................................................... 39

4.3.3 TENSION - GFRP - SAND COATED - \#4, \#5, \#8............................................ 42

4.3.4 TENSION - AFRP - SAND COATED - \#3 .....................................................

4.4 SUMMARY AND CONCLUSIONS - TENSION TESTS......................................... 46

4.5 TEST METHOD SUMMARY ........................................................................ 48

\section{CHAPTER 5 \\ FLEXURE TESTS}

5.1 INTRODUCTION

5.2 DEVELOPMENT OF THE TEST ..................................................................... 52

5.2.1 REFERENCED DOCUMENTS................................................................... 52

5.2.2 TERMINOLOGY ............................................................................. 52

5.2.3 SPECIMEN PREPARATION.............................................................. 52

5.2.4 TEST EQUIPMENT ............................................................................. 53 


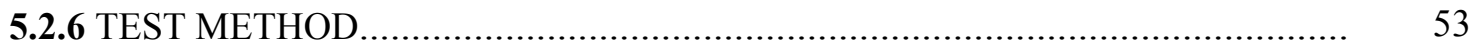

5.2.6 CALCULATION .................................................................................... 55

• METHOD I (STRESS-STRAIN PLOT) ................................................... 55

• METHOD II (LOAD-DEFLECTION PLOT).............................................. 56

5.3 TEST RESULTS - SUPPORT TYPE A........................................................... 57

5.3.1 FLEXURE - GFRP - RIBBED - \#4 - SUPPORT A.......................................... 57

5.3.2 FLEXURE - GFRP - SAND COATED - \#4 - SUPPORT A................................. 61

5.3.3 FLEXURE - CFRP - RIBBED - \#3 - SUPPORT A............................................ 66

5.4 SUMMARY - FLEXURE TESTS ON SUPPORT TYPE A.......................................... 71

5.5 TEST RESULTS - SUPPORT TYPE B.............................................................

5.5.1 FLEXURE - GFRP - RIBBED - \#3, \#4 \& \#5 - SUPPORT B................................ 73

5.5.2 FLEXURE - GFRP - SAND COATED - \#3, \#4, \#5 \& \#6 - SUPPORT B........... 76

5.5.3 FLEXURE - CFRP - SAND COATED - \#3 - SUPPORT B................................. 79

5.5.4 FLEXURE - AFRP - SAND COATED - \#3 - SUPPORT B................................. 81

5.6 SUMMARY AND CONCLUSIONS-FLEXURE TESTS ON SUPPORT TYPE B........ 83

5.7 TEST METHOD SUMMARY............................................................................

\section{CHAPTER 6}

SHEAR TESTS

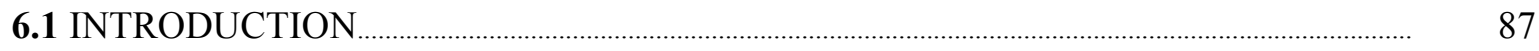

6.2 DEVELOPMENT OF THE TEST................................................................... 88

6.2.1 REFERENCED DOCUMENTS............................................................... 88

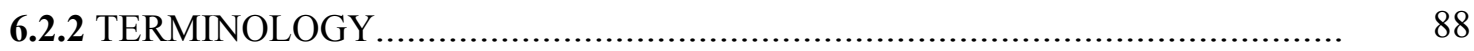

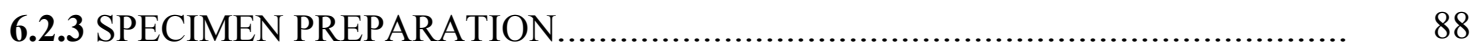

6.2.4 TEST EQUIPMENT AND REQUIREMENTS................................................ 89

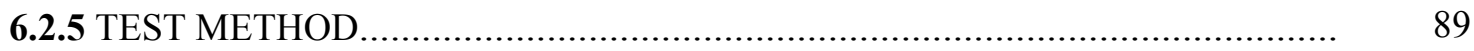

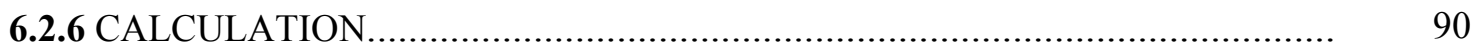

6.3 TEST RESULTS - 1" WIDE CUTTING TOOL........................................................

6.3.1 SHEAR - CFRP - RIBBED - \#3 - 1" WIDE CUTTING TOOL.......................... 91

6.3.2 SHEAR - GFRP - RIBBED - \#4 - 1" WIDE CUTTING TOOL........................... 93

6.3.3 SHEAR - GFRP - SAND COATED - \#4 - 1" WIDE CUTTING TOOL.............. 95

6.4 TEST RESULTS - 1/2" WIDE CUTTING TOOL.................................................... 96

6.4.1 SHEAR - CFRP - RIBBED - \#3 - 1/2" WIDE CUTTING TOOL......................... 96

6.4.2 SHEAR - GFRP - RIBBED - \#4 - 1/2” WIDE CUTTING TOOL....................... 98 
6.4.3 SHEAR - GFRP - SAND COATED - \#4 - 1/2” WIDE CUTTING TOOL............ 99

6.5 SUMMARY AND CONCLUSIONS - SHEAR TESTS........................................ 100

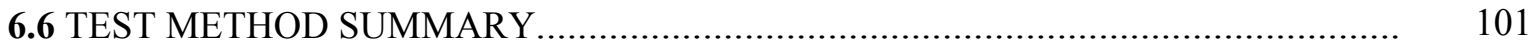

\section{CHAPTER 7 \\ BOND TESTS}

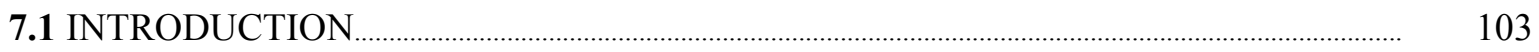

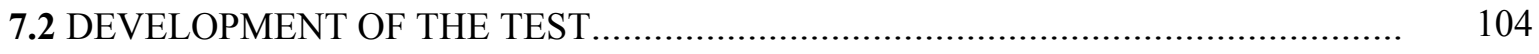

7.2.1 REFERENCED DOCUMENTS......................................................... 104

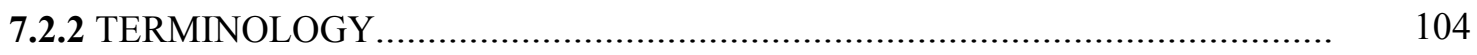

7.2.3 SPECIMEN PREPARATION................................................................ 105

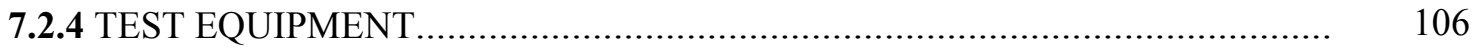

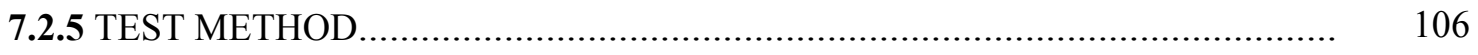

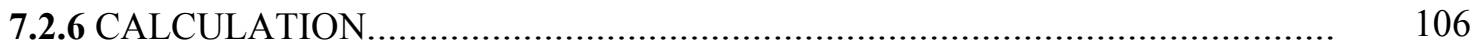

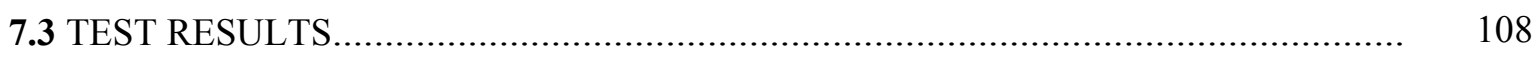

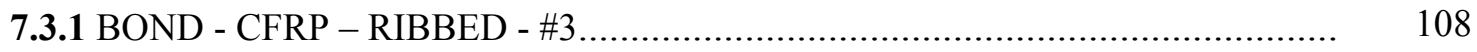

7.3.2 BOND - GFRP - RIBBED - \#4................................................................ 109

7.3.3 BOND - GFRP - SAND COATED - \#4..................................................... 110

7.4 SUMMARY AND CONCLUSIONS - BOND TESTS ON FRP BARS....................... 112

7.5 TEST METHOD SUMMARY ....................................................................... 113

\section{CHAPTER 8}

LONG TERM TESTS

8.1 INTRODUCTION

8.2 MOISTURE ABSORPTION ................................................................................................................. 115

8.2.1 SPECIMEN PREPARATION AND TEST METHOD. ...................................... 116

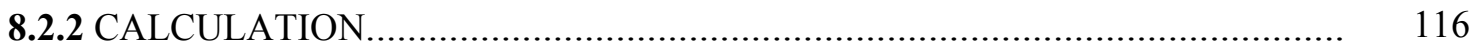

8.3 TEST RESULTS - MOISTURE ABSORPTION ..................................................... 117

8.4 FLEXURE TESTS ON AGED SPECIMENS...................................................... 118

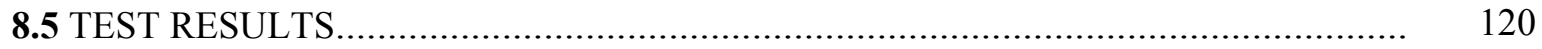

8.5.1 AGED FLEXURE - GFRP - RIBBED - \#4............................................ 120

8.5.2 AGED FLEXURE - GFRP - SAND COATED - \#4...................................... 123

8.6 SUMMARY AND CONCLUSIONS - FLEXURE TEST ON AGED BARS................ 127 


\section{CHAPTER 9 \\ SUMMARY AND CONCLUSIONS}

9.1 INTRODUCTION

9.2 SUMMARY AND CONLUSIONS- TENSION TESTS …....................................... 129

9.2.1 RESULTS SUMMARY AND CONCLUSIONS........................................... 129

9.2.2 TEST METHOD SUMMARY ................................................................ 131

9.3 SUMMARY AND CONCLUSIONS - FLEXURE TESTS...................................... 132

9.3.1 RESULTS SUMMARY AND CONCLUSIONS.............................................. 133

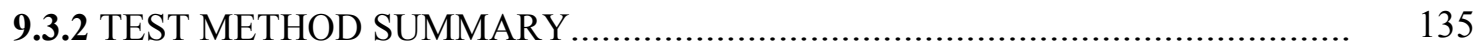

9.4 SUMMARY AND CONCLUSIONS - SHEAR TESTS............................................. 136

9.4.1 RESULTS SUMMARY AND CONCLUSIONS............................................... 136

9.4.2 TEST METHOD SUMMARY............................................................... 138

9.5 SUMMARY AND CONCLUSIONS - BOND TESTS .......................................... 139

9.5.1 RESULTS SUMMARY AND CONCLUSIONS........................................... 139

9.5.2 TEST METHOD SUMMARY............................................................. 140

9.6 SUMMARY AND CONCLUSIONS - MOISTURE ABOSORPTION....................... 140

9.7 SUMMARY AND CONCLUSIONS - FLEXURE ON AGED SAMPLES.................. 141

9.7.1 RESULTS SUMMARY AND CONCLUSIONS........................................ 141

9.8 RESEARCH SUMMARY - TEST METHODS................................................. 143

9.9 RESEARCH SUMMARY - TEST RESULTS................................................ 144

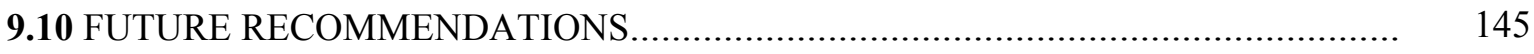

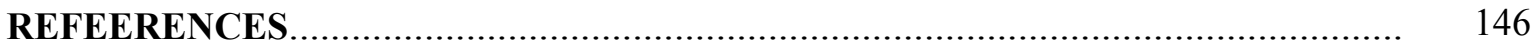

APPENDIX A: DRAFT AASHTO TEST PROTOCOLS...................................... 153

A.1 Draft Standard Test Method for Tensile Properties of FRP Rods.............................. 153

A.2 Draft Standard Test Method for Flexural Properties of FRP Rods............................. 156

A.3 Draft Standard Test Method for Shear Properties of FRP Rod.................................. 158

A.4 Draft Standard Test Method for Bond Strength of FRP Rods by Pullout Testing.......... 160

A.5 Draft Standard Test Method for Moisture Absorption of FRP Rods............................ 166

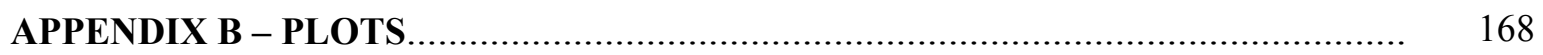

B.1 Stress-strain plots for tension tests - Ribbed CFRP - \#3 ..................................... 168

B.2 Stress-strain plots for tension tests - Ribbed GFRP - \#4 WVU................................. 169

B.3 Stress-strain plots for tension tests - Ribbed GFRP - \#4 FAU.................................. 170

B.4 Stress-strain plots for tension tests - Sand Coated GFRP - \#4 WVU......................... 170 
B.5 Stress-strain plots for tension tests - Sand Coated GFRP - \#5 FAU........................... 171

B.6 Stress-strain plots for tension tests - Sand Coated AFRP - \#3 FAU........................... 171

B.7 Load-deflection plots for flexure tests on support type A - Ribbed CFRP - \#3.............. 172

B.8 Load-deflection plots for flexure tests on support type A - Ribbed GFRP - \#4............. 173

B.9 Stress-strain plots for flexure tests on support type A - Ribbed GFRP - \#4................. 174

B.10 Load-deflection plots for flexure tests on support type A - Sand Coated GFRP - \#4.... 175

B.11 Stress-strain plots for flexure tests on support type A - Sand Coated GFRP - \#4......... 176

B.12 Load-deflection plots for flexure tests on aged bars - Ribbed GFRP - \#4................. 176

B.13 Load-deflection plots for flexure tests on aged bars - Sand Coated GFRP - \#4........... 177

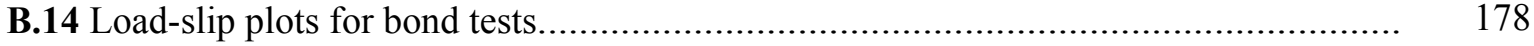

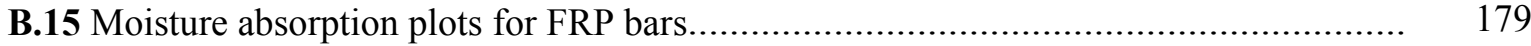

APPENDIX C: SHEAR DEFLECTIONS IN BARS UNDER FLEXURE...................... 180 


\section{LIST OF FIGURES}

Fig 1.1: Different Types of FRP Reinforcement Bars (top to bottom) (a) Sand Coated 5 GFRP; (b) Ribbed GFRP; (c) Sand Coated AFRP; and (d) Ribbed CFRP

Fig 4.1: Schematic Diagram of a Tension Test Specimen 32

Fig 4.2: (a) Typical test setup for tension tests; (b) failure of a CFRP bar 37

Fig 4.3: Typical Stress-Strain $(\sigma-\varepsilon)$ plot from a tension test 37

Fig 5.1: Schematic Diagram of Support Type B. $\quad 54$

Fig 5.2: Flexure Test Setup (a) support Type A; (b) support Type B. 54

Fig. 5.3: Typical (a) Test Setup and (b) Dial gage readings for Flexure Tests 56

Fig. 5.4: Typical (a) Stress-Strain $(\sigma-\varepsilon)$ plot and (b) Load-Deflection (P- $\delta$ ) plot 57

Fig. 6.1: Shear Testing Apparatus 91

Fig 7.1: Bond test apparatus $\quad 107$

Fig 7.2: Schematic diagram of the bond test test setup 108

Fig 7.3: Bond Stress-slip plots for varying surface textures (Sand Coated and Ribbed) 113

Fig 7.4: Bond Stress-slip plots for varying fiber type (Carbon and glass) 113

Fig 8.1: Ribbed CFRP, Ribbed GFRP and Sand Coated GFRP bars immersed in distilled $\quad 117$ water

Fig 8.2: Weight plots of (a) ribbed CFRP (b) ribbed GFRP and (c) sand coated GFRP bars 117 over 298 days

Fig 8.3: Schematic Diagram of supports used for flexure $\quad 119$

Fig 8.4: Flexure Test Setup using support Type B. $\quad 120$

Fig A.2.1 Test Setup $\quad 157$

Fig A.3.1 Double shear testing machine $\quad 159$

Fig A.4.1 Vertical bond test specimen $\quad 163$

Fig A.4.2 Horizontal bond test 164

Fig A.4.3 Schematic details of bond test setup 1 164

Fig A.4.4 Typical bond test setup 2 165

Fig A.4.5 Typical positions of LVDTs at the surface of the concrete cube 165

Fig C-1 L/D ratio vs Percentage Shear Deflections and Total Deflections 182 


\section{LIST OF TABLES}

Table 1.1: Number of FRP bars tested under short-term test categories 6

Table 1.2: Number of FRP bars tested under long-term test categories 7

Table 3.1: Numbers, types and diameters of FRP bars tested 27

Table 4.1: Specimens tested in Tension (28 Specimens) 33

Table 4.2: Length of steel grips used for tension tests 34

Table 4.3: Tensile test results for \#3 Ribbed CFRP bars (WVU Specimens) 38

Table 4.4: Tensile test results for \#4 Ribbed GFRP bars (WVU Specimens) 40

Table 4.5: Tensile test results for \#4 Ribbed GFRP bars (FAU Specimens) 40

Table 4.6: Tensile test results for \#6 Ribbed GFRP bars (FAU Specimens) 40

Table 4.7: Tensile test results for \#4 Sand Coated GFRP bars (WVU Specimens) 42

Table 4.8: Tensile test results for \#5 Sand-coated GFRP bars (FAU Specimens) 43

Table 4.9: Tensile test results for \#8 Sand Coated GFRP bars (FAU Specimens) 43

Table 4.10: Tensile test results for \#3 Sand Coated AFRP bars 45

Table 4.11: Summary of Tension Tests 46

Table 5.1: Specimens tested in Flexure (70 Specimens) 51

Table 5.2: Flexure test results for \#4 Ribbed GFRP bars on support Type A ( $/ \mathrm{D}=16)$ (WVU Specimens)

Table 5.3: Flexure test results for \#4 Ribbed GFRP bars on support Type A ( $/ \mathrm{D}=16)$ (Additional Tests, WVU Specimens)

Table 5.4: Flexure test results for \#4 Ribbed GFRP bars on support Type A ( $/ \mathrm{D}=40)$ (WVU Specimens)

Table 5.5: Flexure test results for \#4 Sand Coated GFRP bars on support Type A (L/D=16) 62 (WVU Specimens)

Table 5.6: Flexure test results for \#4 Sand Coated GFRP bars on support Type A (L/D=16) 63 (Additional Tests, WVU Specimens)

Table 5.7: Flexure test results for \#4 Sand Coated GFRP bars on support Type A (L/D=40) 65 (WVU Specimens)

Table 5.8: Flexure test results for \#3 Ribbed CFRP bars on support Type A (L/D=21) 66 (WVU Specimens)

Table 5.9: Flexure test results for \#3 Ribbed CFRP bars on support Type A (L/D=21) (Additional Tests, WVU Specimens)

Table 5.10: Flexure test results for \#3 Ribbed CFRP bars on support Type A (L/D=21) (FAU Specimens)

Table 5.11: Flexure test results for \#3 Ribbed CFRP bars on support Type A ( $L / D=21)$ (Additional Tests with tabs attached, WVU Specimens)

Table 5.12: Summary of Flexure test results for FRP bars on support Type A 71

Table 5.13: Flexure test results for \#3 Ribbed GFRP bars on support Type B ( $/ D=20)$ 
(FAU Specimens)

Table 5.14: Flexure test results for \#4 Ribbed GFRP bars on support Type B (L/D=20) (FAU Specimens)

Table 5.15: Flexure test results for \#5 Ribbed GFRP bars on support Type B (L/D=20) (FAU Specimens)

Table 5.16: Flexure test results for \#3 Sand Coated GFRP bars on support Type B $(L / D=20)$ (FAU Specimens)

Table 5.17: Flexure test results for \#4 Sand Coated GFRP bars on support Type B ( $/ \mathrm{D}=20)$ (FAU Specimens)

Table 5.18: Flexure test results for $\# 5$ Sand Coated GFRP bars on support Type B $(L / D=20)$ (FAU Specimens)

Table 5.19: Flexure test results for \#6 Sand Coated GFRP bars on support Type B (L/D=20) (FAU Specimens)

Table 5.20: Flexure test results for \#3 Sand Coated CFRP bars on support Type B $(L / D=20)$ (FAU Specimens)

Table 5.21: Flexure test results for \#3 Sand Coated AFRP bars on support Type B $(L / D=20)$ (FAU Specimens)

Table 5.22: Summary of Flexure test results for FRP bars on support Type B

Table 6.1: Specimens tested in Shear (45 Specimens)

Table 6.2: Single and Double Shear test results for \#3 Ribbed CFRP bars - 1" wide cutting tool (WVU Specimens)

Table 6.3: Single and Double Shear test results for \#4 Ribbed GFRP bars - 1" wide cutting tool (WVU Specimens)

Table 6.4: Single and Double Shear test results for \#4 Sand Coated GFRP bars - 1" wide cutting tool (WVU Specimens)

Table 6.5: Double Shear test results for \#3 Ribbed CFRP bars - 1/2" wide cutting tool (WVU Specimens)

Table 6.6: Double Shear test results for \#4 Ribbed GFRP bars - 1/2" wide cutting tool (WVU Specimens)

Table 6.7: Double Shear test results for \#4 Sand Coated GFRP bars - 1/2" wide cutting tool (WVU Specimens)

Table 6.8: Summary of shear test results for FRP bars (WVU Specimens)

100

Table 7.1: Specimens tested in Bond (9 Specimens)

Table 7.2: Bond test results for \#3 Ribbed CFRP bars (WVU Specimens)

Table 7.3: Bond test results for \#4 Ribbed GFRP bars (WVU Specimens)

Table 7.4: Bond test results for \#4 Sand Coated GFRP bars (WVU Specimens)

Table 7.5: Summary of bond test results on FRP bars (WVU Specimens)

Table 7.6: Bar slip inside concrete cylinders for various FRP bars.

Table 8.1: FRP bars tested for moisture absorption (27 Specimens)

Table 8.2: Weights in grams (sum of 9 specimens) of bars for moisture absorption 117

Table 8.3: Aged Specimens tested in Flexure (50 Specimens) 
Table 8.4: Maximum stress results from flexure tests for \#4 Ribbed GFRP bars under different aging conditions (WVU Specimens)

Table 8.5: Stiffness results from flexure tests for \#4 Ribbed GFRP bars under different aging conditions (WVU Specimens)

Table 8.6: Maximum stress results from flexure tests for \#4 sand coated GFRP bars under different aging conditions (WVU Specimens)

Table 8.7: Stiffness results from flexure tests for \#4 sand coated GFRP bars under different aging conditions (WVU Specimens)

Table 8.8: Summary of flexural tests performed on \#4 ribbed and \#4 sand coated GFRP bars under different aging conditions (WVU Specimens)

Table 9.1: Summary of Tension Test Results

Table 9.2: Summary of Flexure test results for FRP bars on support Type B

Table 9.3: Summary of shear test results for FRP bars (WVU Samples)

Table 9.4: Summary of bond test results on FRP bars (WVU Samples)

Table 9.5: Summary of flexural tests performed on \#4 ribbed and \#4 sand coated GFRP bars under different aging conditions (WVU Specimens)

Table C-1: Theoretical flexure and shear deflections 


\section{CHAPTER 1 \\ INTRODUTION}

\subsection{INTRODUCTION}

Historically, steel reinforcing bars (rebars, from hereon referred to as bars) have been effectively used as concrete reinforcement. Steel bars perform well under chloride-free environment. Under chloride-free environment, properly designed concrete structures can theoretically last for decades without any significant signs of deterioration. However, some structures are constantly subjected to chloride attack. Some examples for such exposures include,

(a) Roads/highways, where salts are used for deicing;

(b) Coastal areas, where there is a good concentration of chloride ions in the surrounding moist environment;

(c) Manufacturing/process plants, where such aggressive chemical environments prevail;

(d) Fine and coarse aggregates of concrete with salt contamination.

When reinforcing bars undergo oxidation due to chloride attack, oxidation products of steel with considerably larger volume are produced. This oxidation product volume increase in turn generates additional radial tensile stresses around the bar in concrete. The surrounding concrete eventually cracks exposing the steel bars to the harsh (chloride) environment, accelerating the corrosion process. Replacement/rehabilitation of a part or whole of a concrete structure is expensive, and at times expensive than the cost of the original structure itself. A remedial measure to overcome the corrosion of steel bar is to use epoxy-coated steel 
bars. However, such measures have provided only short-term relief in alleviating the corrosion problems.

With the advent of fiber reinforced polymers (FRP) consisting of high-strength fibers in a polymer matrix, an alternative has been found for reinforcing concrete structures to address corrosion problems. Glass FRPs offer strengths equal to or higher than those of steel bars and at the same time exhibit non-corrosive property. Carbon FRP bars have higher tensile strengths as compared to steel reinforcement bars.

The fibers in FRP composites are the main load-carrying elements. The polymer matrix (cured resin) protects the fibers from damage, ensures good alignment of fibers, and allows load distribution among individual fibers. Fibers are selected based on the strength, stiffness, and durability requirement for specific applications. Resins are selected based on the function and manufacture of the FRP bar. Fiber types that are typically used in the construction industry are carbon and glass, with thermoset epoxy, vinyl ester, polyester, and urethane resins, even though aramid has been used occasionally. Some advantages of FRP bars include: non-corrosiveness, high strength to weight ratio, non-conductiveness and good thermal insulation, magnetic transparency, good impact resistance, and light weight. FRP bars find a variety of applications in the construction industry, especially as concrete reinforcement. 


\subsection{OBJECTIVES}

In this research carbon, glass and aramid bars have been evaluated for developing standardized test methods and to determine their mechanical properties. The objective of this work is to verify/modify/develop test methods (standards) to determine the mechanical properties of FRP bars. This is achieved by reviewing existing research literature and relevant standards and conducting limited numbers of additional tests to determine/verify the mechanical properties of FRP bars. Specifically, ranges of variation (standard deviations) in test results were considered during the standardization of a particular test method.

\subsection{SCOPE}

Static tests are performed to characterize the mechanical properties of FRP bars. The two main categories of tests performed to establish mechanical properties of the bars are: shortterm and long-term tests. The tests conducted on unaged specimens are termed as short-term tests and the tests carried out on aged specimens are termed long-term tests. Specimens exposed to constant water, salt and/or temperature conditions are referred to herein as aged specimens. A total of 229 FRP specimens were tested in this research.

Types of bars tested in this research are - Carbon FRP (CFRP) bars, Glass FRP (GFRP) bars, and Aramid FRP (AFRP) bars. Short-term tests are carried out to determine the basic strength properties of FRP bars which include tensile, bending, shear and the bond strength. Stiffness (Young's Modulus, E) of the bars is also evaluated. Generally, bars with different diameters are used within the same categories of tests to establish the effect of bar-diameter on the test results. The bar diameters tested in this research are: 3/8" (\#3), 1/2" (\#4), 5/8" 
(\#5), 3/4" (\#6) and 1" (\#8). Tables 1.1 and 1.2 provide a summary of the types, diameters and number of specimens tested under short-term and long-term test category. Figure 1.1 shows different types of bars used for testing.

Scope for each type of short-term test is summarized below.

(a) Tension tests: This test comprises of monotonic tensile loading up to failure to establish ultimate strength and stiffness of the bar using strain gage data and data acquisition system.

(b) Flexure tests: This test is performed to determine the flexural tensile strength of the FRP bars. Span of 16, 20, 21 and/or 40 times the diameter of the bar are used during testing. Stiffness evaluation is done using load-deflection and/or stress-strain plot methods.

(c) Shear tests: This test is performed to evaluate the strength of the bars in shear. Two different shearing widths -1 " and $1 / 2$ " are used to determine the effect of bending on shear strength. Single and double shear tests are also performed to determine the effect of anchoring the specimens to the fixture in each method with respect to stress values.

(d) Bond tests: Cylinder pull-out tests are performed to evaluate the bond strength of the FRP bars. Slip measurements at the unloaded end are also noted.

Limited numbers of long-term tests are carried out to evaluate durability of the FRP bars. Tests performed in this category are:

(a) Moisture Absorption: 2" long samples sealed at the ends with a thin coat of epoxy are immersed in water and monitored for weight gain over a period of 298 days. 
(b) Flexure Tests: Samples were kept in water and salt solution at room and freeze-thaw temperature conditions (for over 4 years), and flexure tests (as described in short-term tests) are performed on these samples.

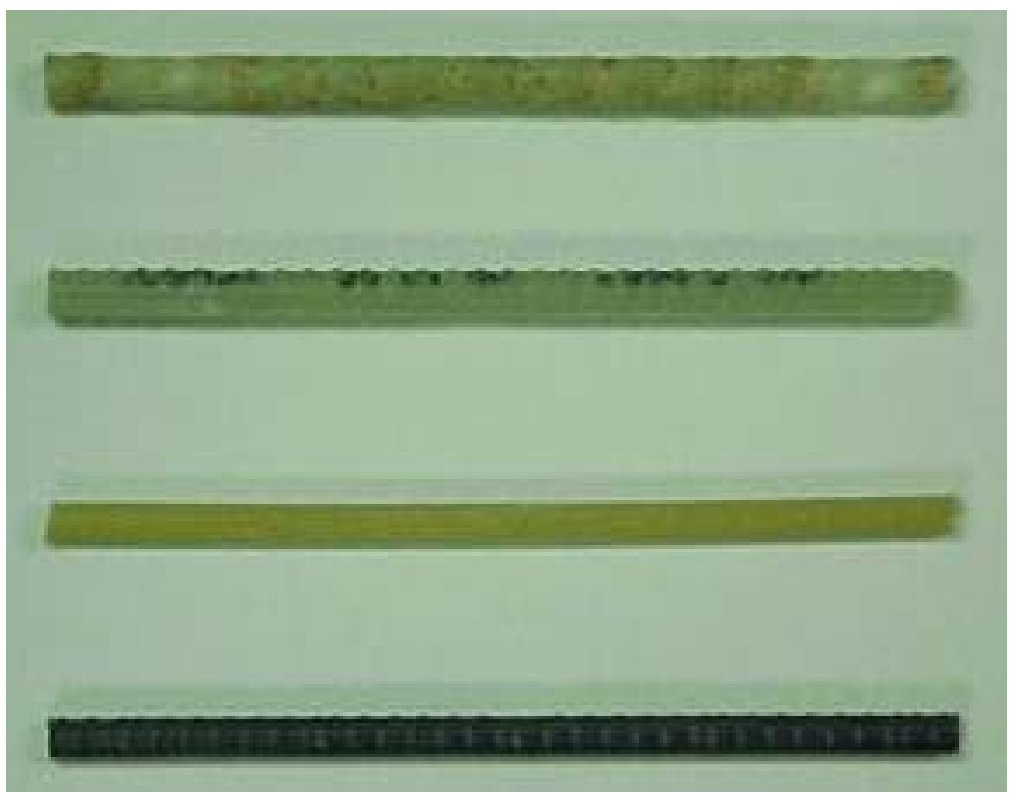

Fig 1.1: Different Types of FRP Reinforcement Bars (top to bottom) (a) Sand Coated GFRP; (b) Ribbed GFRP; (c) Sand Coated AFRP; and (d) Ribbed CFRP 
Table 1.1: Number of FRP bars tested under short-term test category

\begin{tabular}{|c|c|c|c|c|c|c|}
\hline \multicolumn{2}{|c|}{$\mathrm{R}=$ Ribbed; $\mathrm{S}=$ Sand Coated } & 3/8" (\#3) & $1 / 2 ”(\# 4)$ & $5 / 8 "(\# 5)$ & 6/8" (\#6) & $1 "(\# 8)$ \\
\hline \multicolumn{7}{|c|}{ 1a TENSION } \\
\hline & Carbon(R) & 5 & - & - & - & - \\
\hline & Glass(R) & - & 8 & - & 3 & - \\
\hline & Glass(S) & - & 3 & 3 & - & 3 \\
\hline & Aramid(S) & 3 & - & - & - & - \\
\hline \multicolumn{7}{|c|}{$1 \mathrm{~b}$ FLEXURE } \\
\hline & $\operatorname{Carbon}(\mathrm{R})$ & 15 & - & - & - & - \\
\hline & Carbon(S) & 3 & - & - & - & - \\
\hline & Glass(R) & 3 & 18 & 3 & - & - \\
\hline & Glass $(\mathrm{S})$ & 3 & 16 & 3 & 3 & - \\
\hline & Aramid(S) & 3 & - & - & - & - \\
\hline \multicolumn{7}{|c|}{ 1c SHEAR - SINGLE } \\
\hline & Carbon(R) & 5 & - & - & - & - \\
\hline & Glass(R) & - & 5 & - & - & - \\
\hline & Glass $(\mathrm{S})$ & - & 5 & - & - & - \\
\hline \multicolumn{7}{|c|}{ 1c SHEAR - DOUBLE } \\
\hline & Carbon(R) & 10 & - & - & - & - \\
\hline & Glass(R) & - & 10 & - & - & - \\
\hline & Glass(S) & - & 10 & - & - & - \\
\hline \multicolumn{7}{|c|}{ 1d BOND } \\
\hline & Carbon(R) & 3 & - & - & - & - \\
\hline & Glass(R) & - & 3 & - & - & - \\
\hline & Glass(S) & - & 3 & - & - & - \\
\hline & TOTAL & 53 & 81 & 9 & 6 & 3 \\
\hline & GRAND TOTAL & 152 & & & & \\
\hline
\end{tabular}


Table 1.2: Number of FRP bars tested under long-term test category

\begin{tabular}{|c|c|c|c|c|c|c|}
\hline \multicolumn{2}{|c|}{$\mathrm{R}=$ Ribbed; $\mathrm{S}=$ Sand Coated } & $3 / 8 "(\# 3)$ & $1 / 2 "(\# 4)$ & $5 / 8 "(\# 5)$ & 6/8" (\#6) & $1 "(\# 8)$ \\
\hline \multicolumn{7}{|c|}{ 2a MOISTURE } \\
\hline & Carbon(R) & 9 & - & - & - & - \\
\hline & Glass(R) & - & 9 & - & - & - \\
\hline & Glass(S) & - & 9 & - & - & - \\
\hline \multicolumn{7}{|c|}{ 2b FLEXURE } \\
\hline & Glass(R) & - & 25 & - & - & - \\
\hline & Glass(S) & - & 25 & - & - & - \\
\hline & TOTAL & 9 & 68 & - & - & - \\
\hline & GRAND TOTAL & 77 & & & & \\
\hline
\end{tabular}

\subsection{OVERVIEW OF CHAPTERS}

$\rightarrow$ Chapter 2 contains review of research findings, performance data, and current practices on FRPs. The technical data on FRPs are reviewed from the viewpoint of short-term and longterm behavior. Short-term behavior includes review of tensile, flexural and bond strength of FRP rebars. Long-term behavior includes review of technical data with respect to environmental durability.

$\rightarrow$ Chapter 3 gives an introduction to the tests conducted/developed during the course of this research. It also gives information on materials used in the manufacture of FRP bars.

$\rightarrow$ Chapter 4 through Chapter 8 contain the test and sample descriptions, analytical procedure, test data, discussion of test data with respect to their standard deviations for tension (Chapter 4), flexure (Chapter 5), shear (Chapter 6), bond (Chapter 7) and long-term tests (Chapter 8). Long term tests in Chapter 8 include moisture absorption in FRP bars and flexure tests on aged FRP specimens. These chapters also contain appropriate test setup 
photographs, schematic diagrams of test apparatus, and stiffness plots from load-deflection or stress-strain data.

$\rightarrow$ Summaries and conclusions from each test group are included in Chapter 9 with brief discussions.

$\rightarrow$ Appendix A: Data from this research were drafted into possible test standards, to be adopted by AASHTO, with technical collaboration between other project participants. Draft specifications developed through this research collaboration for different tests on FRP bars are included in Appendix A of this document.

$\rightarrow$ Appendix B contains load-deflection and stress-strain plots of some of the FRP specimens tested in this research work

$\rightarrow$ Appendix C gives a brief discussion of shear deflection in FRP bars subjected to 3-point bending. 


\section{CHAPTER 2}

\section{LITERATURE REVIEW}

\subsection{INTRODUCTION}

This chapter contains review of published domestic and foreign research findings, performance data, and current practices on FRP composites. Review information is supplemented from unpublished reports and personal contacts with state transportation agencies, state and federal research laboratories, and FRP composites manufacturers. The available technical data on FRPs are reviewed from the viewpoint of: short-term and longterm behavior. Section 2.2 (Short-term behavior) has been reviewed with emphasis on tensile, flexural, shear and bond strength of FRP bars. Section 2.3 has been emphasized with respect to aging mechanisms including varying temperatures, alkaline conditions and freezethaw cycles.

\subsection{SHORT TERM BEHAVIOR}

Extensive research on FRP reinforcement has been reported in literature [1 to 5]. Current FRP composites for structural applications mainly use three types of continuous fibers: carbon, glass, and aramid, designated as CFRP, GFRP, and AFRP composites respectively. Recent structural applications of FRP materials include reinforcing bars for concrete structures, typically with E-glass fibers embedded in vinylester or epoxy matrix [6 to 10$]$. 
Aramid FRP (AFRP) composites are mostly used as reinforcement for prestressing and posttensioning rods in Japan and Europe. The performance/cost ratios of CFRP and AFRP composites are nearly identical. However, carbon fibers are known to be the most stable fibers in aggressive environments. Research in North America has been focused primarily on GFRP and CFRP composites due to their better physical and mechanical properties. Aramid fibers are organic and dimensionally unstable because of greater moisture absorption than glass and carbon. High moisture absorption leads to swelling of the bars resulting in internal cracking and progressive loss of bond between concrete and aramid bars. This behavior is similar to the undesirable cracking and spalling of concrete in conventional steel reinforced concrete due to corrosion [11, 12] and related expansion of steel and consequent cracking of concrete. Sasaki et al. [13] conducted laboratory tests under seawater on the durability of cables made up of carbon, aramid, glass, and vinylon. All of the unstressed aramid/vinylester cables submerged in seawater broke during the exposure period of 32 months. Therefore, in this research, the emphasis on AFRP has been less than that on GFRP and CFRP.

\subsubsection{TENSION}

Several types of FRP bars have been commercially produced, and each has distinct strength and durability depending on the type of resin, fiber, and other constituents in the composite. Fibers in the bars may be made of glass, aramid, carbon, and their combination. Surface of the bars may be smooth, sand-coated, deformed through helical wraps or lugs (ribs). The ribbed surface texture is similar to that of a steel bar. 
The properties and behavior of FRP bars do vary significantly based on the type of fibers and resins, fiber volume fraction, fiber orientation, manufacturing process, and quality control during manufacturing. Tension, compression, bending, and torsion tests were conducted on GFRP bars at the Constructed Facilities Center (CFC), West Virginia University, to characterize the strength and stiffness properties [14]. Different failure modes were observed for bars in tension depending on the type of bar. Smooth bars had fiber breakage, while, wrapped or ribbed bars exhibited matrix cracking before the fiber breakage, accompanied by the failure and peeling of outer fibers before breakage [14].

FRP bars also exhibit shear lag phenomenon, which is due to higher stresses carried by outer fibers as compared to core fibers. As the bar size increases, ultimate failure stress decreases. For example, it has been reported [14] that \#8 GFRP bars have about 70 ksi mean tensile strength as compared to $130 \mathrm{ksi}$ mean tensile strength of $\# 3$ bars with fiber volume fraction, $\mathrm{V}_{\mathrm{f}}$ equals to 0.7 . Similar research results on FRP bars are available in the literature, including semi-empirical correlations for failure strength and stiffness of the bars.

Benmokrane and Masmoudi [15] tested glass fiber reinforced bars of 0.5" diameter with a fiber volume fraction of $55 \%$ and reported tensile strength of $112.2 \mathrm{ksi}$ with a failure strain of $2.05 \%$. Young's modulus has been measured to be $5.46 \times 10^{6}$ psi which was based on strain gage readings.

Otsuki, et al. [16] and committee members of the Japan Society of Civil Engineers (JSCE) tested carbon, aramid, glass, and polyvinyl FRP specimens. These specimens were of circular 
cross section and of different shapes - deformed, flat, twisted, braided, and cable type. Tanano, et al. [17] conducted high temperature tensile modulus tests on braided and stranded carbon, and braided aramid FRP bars. The carbon FRP bars showed little decrease in tensile elastic modulus due to temperature rise, whereas the braided and stranded type aramid FRP bars of different cross sectional shapes showed sharp decreases in tensile elastic modulus at around $250^{\circ} \mathrm{C}$.

\subsubsection{FLEXURE}

This section contains review of literature of flexural strength of FRP bars. Emphasis herein has been to compare the response of concrete beam reinforced with FRP versus steel bars.

Bending tests have been conducted [14] on KODIAK (KD) and MARSHAL VEGA (MV) GFRP bars under 3-point bending using \#7 and \#8 diameter bars. The dominant failure mode for smooth and ribbed specimens was fiber/matrix debonding, whereas some ribbed specimens reportedly had rib fracture. The failures were initiated on compression side [14]. Support span-to-depth ratio of 20 was used for three-point bending tests. Bending moduli have been obtained based on the standard deflection equation from three-point bending test data excluding shear deflection term. Mean value of the Young's modulus measured from bending tests was $6.78 \times 10^{6} \mathrm{psi}$ as compared to $7.01 \times 10^{6} \mathrm{psi}$ from the axial tension tests, where the fiber volume fraction percent was of the order of $70 \%$.

Available test results on the flexural behavior of concrete beams reinforced with FRP bars and the on-going research [1 to 5] suggest that the search is still on for refining existing 
mathematical models. Research in early 1990 suggested a conservative estimation of flexural strength of FRP bar reinforced concrete beams using modified working stress equations, and limiting the concrete compressive strength [18]. This conservative approach was of major concern due to lack of the validation of mathematical models with reference to the test results and conventionally unacceptable compression failure modes.

Several tests have been conducted by Benmokrane, et al. [15], Hosny, et al [19], Abdallah, et al. [20], Matthys and Taerwe [21], Razaqpur and Ali [22] and Faza and GangaRao [23] to investigate the bending behavior of concrete beams reinforced with GFRP bars. Flexural strength of a concrete beam failing in tension and compression has been evaluated in a member similar to those in steel reinforced concrete beam members. It was found that use of simplified moment equilibrium and strain compatibility equations similar to those in steel reinforced beams provide fairly accurate predictions for bending resistance, i.e., within $10 \%$ of the experimental values [24].

Maji et al. [25] carried out flexural tests on concrete beams reinforced with carbon/epoxy FRP bars. The beams were subjected to static and cyclic three point bending. Evaluation of the fracture energy showed that ductility of the beams was due to a large fraction of the total strain energy released in the formation of distributed cracks in concrete.

\subsubsection{BOND}

Several researchers [26 to 30] have conducted studies on bond behavior. Published research findings indicate that bond performance of FRP bars is dependent on surface texture, 
manufacturing process, mechanical properties of the bar, and the environmental conditions [31 to 33].

Pullout tests were conducted by Vijay and GangaRao [24] on cylinders with embedded steel reinforcement and GFRP C-BAR ${ }^{\mathrm{TM}}$ (M1 type) and sand coated GFRP bars. \#4 bars were chosen for comparison and three replications tested for each bar type. Both types of GFRP bars exhibited superior bond properties over steel bar. Compared to steel bar, bond strengths of $\mathrm{C}-\mathrm{BAR}^{\mathrm{TM}}$ and sand coated bar were $33.5 \%$ and $55.5 \%$ higher, respectively. In addition, Faza and GangaRao [37] investigated the bond characteristics of GFRP bars by testing 20 concrete specimens with different configurations of FRP reinforcement size, type (ribbed, sand-coated) and embedment lengths. To emulate the beam portion adjacent to a diagonal crack, specimens were tested as cantilever beams. Twelve pullout cylinder specimens were tested and a design equation to determine the development length of GFRP bars recommended. Slightly higher bond strength resistance was noted for GFRP bars than that with steel bars.

Fukuyama, et al. [34] investigated bond-splitting strength of concrete members reinforced with FRP bars. Bar pullout and cantilever type bond tests were conducted in this study. The cantilever type bond test was carried out to obtain the load conditions existing in the shear span of beams, and to investigate the bond splitting strength of reinforced concrete beams. A simple test method was proposed to investigate the bond splitting strength without lateral reinforcement. In addition, effects of surface deformation, size, type, and shape of FRP bars were studied by several researchers $[27,29,30,35,36,37]$. Pleiman [27] conducted more 
than 70 pullout tests to examine the bond strength of GFRP reinforcing bars (E-glass fiber), Kevlar 49 bars (AFRP), and steel bars. It was concluded that AFRP and GFRP bars exhibited similar behavior; however, their performance level was below steel bars. Daniali [29] investigated the bond strength of GFRP bars (E-glass fibers and vinylester resin) by testing 30 beams with varying bar diameters and embedment lengths. Daniali identified the occurrence of premature bond failure under sustained load. Laboratory results indicated that ultimate bond strength of FRP reinforced concrete beams was lower than that of beams with conventional steel bars.

Chaallal, et al. [38, 39] investigated the bond strength of glass FRP bars in concrete. Twentyfour pullout tests were carried out according to ASTM C234-91. The use of sand grains adhered to the surface of rods increased the bond significantly. However, no gain was achieved when using closer pitch of embossments for rods with sand grains. It was also concluded that the development length recommended for steel has to be increased by a third when using glass fiber rods.

Benmokrane, et al. [35] investigated bond performance of FRP bars for developing guidelines for bond and anchorage of FRP bars. The study indicated that the size effect observed for steel bars is also present for FRP bars. It was concluded that the development length of FRP bars to attain an ultimate tensile force varied from 15 to 30 times the diameter of the bar. The bond strength of FRP bars was found to be lower than that of steel bars, and approximately $60 \%$ to $90 \%$ of that of steel bars, depending on bar sizes. 
Malvar [40] investigated bond stress-slip characteristics of four types of glass FRP bars. A family of bond stress-slip curves for five levels of constant radial confining stress was obtained for each FRP bar. Bond stress-radial deformation curves were also obtained to characterize the radial expansion at the interface. It was concluded that small surface deformations, about $5.4 \%$ of the nominal bar diameter (i.e. similar to that of steel), are sufficient to cause bond stresses up to five times the concrete tensile strength. Either surface deformations or indentations obtained by stressing an external helicoidal strand are acceptable for bond purposes. It was observed that, for same amount of confinement, the bond strength in a steel bar is 1.2 to 1.5 times greater than the bond strength of an FRP bar. Bond strength can usually be increased threefold by increasing confining pressure.

\subsection{Long Term Behavior}

Though FRP bars under harsh environmental conditions provide superior mechanical, thermal, and chemical properties over conventional materials, reduction in properties with time is evident under service conditions, affecting safety and effectiveness of these composite systems. Extent of degradation is accelerated under harsh conditions. This section provides a review of degradation mechanisms affecting thermo-mechanical properties under exposure to alkaline environment, alternate wet/dry cycles including corrosive medium, freeze-thaw conditions, and temperature and humidity variations.

\subsubsection{Moisture Absorption}

Water penetrates FRPs through two processes; diffusion through the resin, and flow through cracks or other material flaws. During diffusion, absorbed water is not in the liquid form, but 
consists of molecules or groups of molecules that are linked together by hydrogen bonds to the polymer. They are dissolved in the surface layer of the polymer and migrate into the bulk of the material under a concentration gradient. Water penetration into cracks or other flaws occurs by capillary flow. Water also penetrates at the interface of fiber-matrix. Water penetration at resin-glass interface of E-glass epoxy composite is reportedly 450 times faster than the penetration through resin alone. It is reported that the primary mechanism of moisture pickup is diffusion through resin, and transfer of moisture through the cracks is an after effect [50]. Moisture pickup leads to loss of chemical energy, which is attributed to hydrolytic scission of ester groups. However, increased hydrostatic pressure reduces water uptake due to closing of micro-cracks. The influence of varying environmental conditions can lead to diffusion of water into the resin causing swelling stresses. The equilibrium content of water determines the magnitude of swelling stresses. The chemical composition of resin influences the solubility of water in the resin and its susceptibility to hydrolysis.

Vijay, et al. [44] investigated moisture absorption of GFRP bars under tap water, salt water, and alkaline water considering temperature variations including freeze-thaw cycles. Moisture absorption tests were conducted to determine diffusivity rates under different moisture conditioning schemes. The amount and rate of diffusivity were related to the strength and stiffness degradation in FRP bars based on the experimental data. Moisture absorption tests were conducted on $13 \mathrm{~mm}$ diameter FRP bar specimens measuring $50 \mathrm{~mm}$ long and their ends sealed using durable resin to allow moisture penetration along radial direction only. The degradation rate and magnitude of the strength and stiffness of GFRP bars in alkaline environment were quite significant when compared with the effects of plain and salt water. 
On an average, alkaline conditioning produced about twice the percent increase in moisture content by weight as compared to tap- and salt-water conditioning. The authors concluded that the higher absorption of alkaline solution in relation to other solutions is an indication of high degradation in tensile strength of GFRP bars under accelerated aging involving solutions with $\mathrm{pH}$ of about 13 .

\subsubsection{Effect of aging on flexure}

Research results from the aerospace industry indicate that the degradation mechanisms operating at the molecular level are varied depending on the type of environment and the type of material and include photo-oxidation, thermal oxidation, thermal degradation, high energy radiation damage, hydrolytic degradation, stress cracking, and electro-chemical corrosion [41]. For structural applications, however, most of the environmental degradation is due to a combination of temperature, moisture, and humidity. The absorbed moisture not only plasticizes the matrix, but can also change the stress due to cracking through swelling. At the fiber-matrix interface, moisture may reduce the bond by breaking the chemical bond [42].

GangaRao, et al. [43] presented test results on accelerated aging (mechanical and hygrothermal properties) of structural composites (GFRP) bars and plates to establish their long-term strength and stiffness degradation trends through correlation of the property degradation to natural weathering. Accelerated testing procedure was provided to establish strength and stiffness degradation (mechanical properties) in terms of compliance shift factors, power-law coefficients for different times, temperature, moisture, and sustained 
stress condition. Accelerated aging factors of FRPs included sustained stress, $\mathrm{pH}$, temperature, and humidity variations. Accelerated tests with GFRP bars indicated that strength reduction (about 15\% in strength and stiffness for GFRP bar made of urethane modified vinylester, whereas, $75 \%$ and $30 \%$ in strength and stiffness for bars made of isocyanurate vinylester) was more of a problem than stiffness reduction.

Uomoto, et al. [45] presented the experimental results on a new high alkali resistant GFRP rods using both aramid fibers and glass fibers (AGFRP). The results of the alkaline solution tests indicated that GFRP rods show reduction in their strength rapidly (more than $70 \%$ of their strength is reduced after 120 days exposure). Both AFRP and AGFRP rods did not exhibit strength reduction even after 120 days of exposure to alkali solution. AGFRP rods showed higher alkali resistance compared with GFRP.

Arockiasamy, et al. [46] conducted experimental studies on AFRP specimens to determine the durability characteristics in alkaline solution heated to about $113^{\circ} \mathrm{F}$. Detailed scanning electron microscopic analysis indicated damage of the matrix in the specimen exposed to alkaline solution. Arockiasamy, et al. [47] presented the experimental studies on the durability of CFRP tendons. The loss of tensile strength and elastic modulus, if any, due to degradation in both tensioned and untensioned carbon composite cables subjected to wet/dry cycles of sea- water/alkaline solution were examined and discussed. The exposure periods in seawater and alkaline solutions varied from 3 to 9 months. The Young's modulus of carbon composite cables was reduced due to sustained tension and the values from the cables 
exposed to seawater and alkaline environment showed a reduction of about $12 \%$. However, exposure to harsh environment did not affect the ultimate strength [46].

Tannous and Saadatmanesh [48] examined the durability of AR glass FRP bars in eight different environments. In addition, ten beam specimens reinforced with AR glass FRP bars were exposed to deicing salt solutions for a period of two years and then tested in flexure. The following conclusions were based on the results of the tests performed in the study: i) diffusion in the FRP bars is dependent on temperature and the type and the concentration of the solution, ii) the AR glass did not improve the behavior of bars in the alkaline environment of the concrete, iii) loss in strength was observed when AR glass FRP bars were exposed to a simulated marine environment, and iv) Fick's law generally applies to relatively short term prediction of accelerated test results, as long as microcracking is not excessive.

Chaallal, et al. [39] carried out freezing and thawing tests on three $75 \times 100 \times 400 \mathrm{~mm}$ concrete specimens reinforced with an ordinary \#3 steel bar, epoxy coated \#3 steel bar, and glass fiber rods $($ diameter $=0.3$ "). The tests were performed according to ASTM C666. Flexure tests were performed on the specimens at 0,200, 400, and 600 freeze-thaw cycles. The specimens with glass fiber rod showed similar behavior to other specimens, as the strength decay curves were almost parallel.

The freeze-thaw durability of an isophthalic polyester and vinylester pultruded fiberglass composite was examined by Gomez, et al. [49]. The rectangular coupon specimens measuring 0.375 " thick, 12 " long, and 1 " wide were exposed to freezing and thawing cycles 
between $0^{\circ} \mathrm{F}$ and $40^{\circ} \mathrm{F}$ after initial exposure to a $2 \% \mathrm{NaCl}$ - water solution. Periodically, the coupons were removed and tested in flexure to failure and the results compared with that of the control specimens. Water absorbed into polymeric composite causes delamination between composite plies reducing its load bearing capacity. The reinforcing fiber and resin matrix interface is also weakened by water absorption resulting in loss of strength and rigidity. Freezing and thawing temperatures contribute towards delamination of the plies and interfacial failure.

Vijay and GangaRao [24] studied the effect of temperature and stress on the strength of GFRP bars made of urethane modified vinylester resins, by subjecting the bars to freeze-thaw temperature, having an average temperature of $94^{0} \mathrm{~F}$ as opposed to room temperature of $72^{0} \mathrm{~F}$. For sand coated bars, maximum strength reductions in salt and alkaline conditioning coupled with freeze-thaw conditioning were $21.9 \%$ and $37.5 \%$ respectively, over 15 -month duration with zero sustained stress. Under freeze-thaw condition and sustained stress, maximum strength reductions in salt and alkaline conditioning were $25.6 \%$ (12 months of $35 \%$ applied stress) and $82.1 \%$ (12 months of $40 \%$ stress application) respectively. Stress reduction in sand coated bars at $65.6{ }^{0} \mathrm{C}\left(150{ }^{0} \mathrm{~F}\right)$ and immersed in alkaline solution was $84.7 \%$ within 4 months under $40 \%$ sustained stress. For C-BAR ${ }^{\mathrm{TM}}$ bars, maximum strength reductions in salt and alkaline conditioning with freeze-thaw conditioning were $51.5 \%$ and $55 \%$ respectively, over 30-month duration.

Vijay and GangaRao [24] have also studied the effect of moisture with different $\mathrm{pH}$ level and stress on GFRP bars made of urethane modified vinylester resins. For sand-coated GFRP 
bars, maximum strength reductions in salt and alkaline conditioning at room temperature

were $18.5 \%$ and $32.2 \%$ respectively, over 15 -month duration. For C-BAR ${ }^{\mathrm{TM}}$ bars, maximum strength reductions in salt and alkaline conditioning at room temperature were $24.5 \%$ and $30 \%$ respectively, over 30 -month duration.

\subsection{Summary}

The available literature on fiber reinforced polymer composite bars has been synthesized in terms of their short-term behavior, environmental and mechanical durability, and physical and chemical aging. The following summary emphasizes failure mechanisms under varying environmental conditions and provides an explanation for physical and chemical aging of FRPs.

Short-Term Behavior: The short-term behavior has been evaluated in terms of axial tensile, flexural and bond strengths of FRP bars. The properties and behavior of FRP bars can vary significantly based on the types of fibers and resin, fiber volume fraction, fiber orientation and manufacturing process. In addition, failure stress of a bar decreases with increase in bar size. Bars with about $55 \%$ of fiber volume fraction and 0.5 " diameter exhibited tensile strength of $100 \mathrm{MPa}$ with a failure strain of about $2 \%$. Mean values of strength and stiffness under bending are typically lower in tension.

Available test results on the flexural behavior of concrete beams reinforced with FRP bars revealed that moment equilibrium and strain compatibility equations, similar to those in steel reinforced concrete beams, provide accurate predictions for bending resistance. Deflection 
equations of concrete beams with GFRP bars reflect their lower stiffness in relation to steel bars. Therefore, modification factors while calculating the effective moment of inertia for concrete beams (accounting for the post-cracking behavior of concrete beams) is suggested by many researchers.

Several researchers conducted studies on the bond behavior of FRP bars embedded in concrete, including pullout testing. However, a few researchers investigated the bond characteristics of GFRP bars in concrete using cantilever beam set-up. Some researchers found that the bond strength of FRP bars is about 20\% lower than that of steel bars, while others have reported about $20 \%$ higher bond strength. Pullout testing of concentrically placed GFRP bars with full confinement showed no significant influence of concrete strength on bar stress to failure.

FRP bars under harsh environments provide better mechanical, thermal, and chemical properties than conventional materials; however, reduction in properties is evident with time. Under highly alkaline environments glass fibers may react to form expansive silica gel leading to cracking in concrete. Durability of GFRP bars based on the resin type is more critical than that of CFRP or AFRP bars exposed to alkaline environment.

Water absorption into polymeric composites can cause delamination of plies, thus reducing the mechanical properties of FRP composite. The reinforcing fibers and the resin matrix interface are weakened by water absorption, and freeze-thaw effects do contribute towards delamination of plies. Therefore, during manufacturing, void ratio of the finished FRP 
product must be minimized to the extent possible. The freeze-thaw damage can be magnified, if the cut edges or drilled holes are not sealed with a durable resin. 


\section{CHAPTER 3}

\section{TYPES OF TESTS AND SPECIMENS}

\subsection{INTRODUCTION}

Tests were conducted on FRP bars to determine appropriate properties while designing concrete structures. The tests performed on FRP bars, namely, tension, flexure, shear, bond, and long-term tests including moisture absorption and flexure tests on aged specimens are described briefly with reference to test procedures, equipment, results, analytical calculations and discussions. These are elaborated in Chapters 4 through 8 , respectively. The test methods were developed for possible AASHTO specifications. Available literature on the existing test methods from ACI, AASHTO and ASTM were utilized. Limited numbers of additional tests were conducted to standardize the modified test methods based on the standard deviations of the test results. Modifications or new additions to each test procedure are described under the test procedure section in Chapters 4 through 8 .

\subsection{SPECIMENS AND TESTS}

The specimens tested in this research were classified based on laboratory aging conditions:

(a) Aged Specimens: Specimens immersed in water or salt solution and exposed to room temperature or freeze-thaw temperature conditions for a specified period of time.

(b) Unaged Specimens: Specimens under room temperature without exposure to any solutions.

The tests performed on these specimens were broadly categorized on the basis of laboratory aging conditions as: 
(I) Short term tests - tests performed on unaged specimens; and

(II) Long term tests - tests performed on specimens aged in water or salt at room or freezethaw temperatures.

Tests performed under the short-term test category were:

(a) Tension - To determine the ultimate tensile strength of bars, they were bonded with split steel pipe grips at both ends and subjected to tension. Strain gages were attached at the center of the specimens to measure the strain.

(b) Flexure - 3-point bending tests were performed on the bars to determine the maximum flexural strength. Bars were supported at each end and load was applied at the center span. A strain gage and/or a dial gage were/was used to measure strains and/or deflections respectively.

(c) Shear - The shear strength of the bars was determined using an apparatus (shown in Fig 6.1), which has an anchoring base and a cutting tool. Load was applied on the cutting tool to shear the specimen in one or two cross-sections of the bar depending on the type of test performed (single or double shear test as discussed in Chapter 6).

(d) Bond - Pull-out tests were performed to evaluate the bond strength of the bars. Bars were cast in concrete cylinders at one end and attached with split steel pipe grips at the other end. Slip at the lower end (unloaded end) of the bar was measured using an LVDT.

\section{WVU and FAU Samples:}

The samples from West Virginia University, Morgantown are hereon referred to in this document as WVU Samples and those provided by Florida Atlantic University are referred to as FAU samples. 
Following tests were performed in the long-term test category:

(a) Moisture Absorption - 2" long specimens were cut from the bars and sealed at the cut ends with a thin coat of epoxy resin. They were then immersed in distilled water and their weights were monitored regularly to determine the amount of moisture absorption.

(b) Flexure tests - Specimens were aged in water and salt solutions at room and freeze-thaw temperatures for a period of over 4 years. These specimens were then tested in 3-point bending, similar to "Flexure Tests" under short-term tests.

Table 3.1 gives a summary of the numbers, types and diameters of FRP specimens tested during this research.

Table 3.1: Numbers, types and diameters of FRP bars tested

\begin{tabular}{|c|c|c|c|c|c|}
\hline Dia (in) & AFRP & \multicolumn{2}{|c|}{ CFRP } & \multicolumn{2}{c|}{ GFRP } \\
\hline & Sand Coated & Ribbed & Sand Coated & Ribbed & Sand Coated \\
\hline $0.375(\# 3)$ & 6 & 47 & 3 & 3 & 3 \\
\hline $0.500(\# 4)$ & - & - & - & 78 & 71 \\
\hline $0.625(\# 5)$ & - & - & - & 3 & 6 \\
\hline $0.750(\# 5)$ & - & - & - & 3 & 3 \\
\hline $1.000(\# 5)$ & - & - & - & - & 3 \\
\hline
\end{tabular}

\subsection{TENSION TESTS}

Chapter 4 describes the axial tension tests performed on FRP bars. Schedule 80 steel pipes split along the length at center were used as grips at each end of the test specimen. These split pipes were bonded to the specimen using Pliogrip ${ }^{\mathrm{TM}}$, a commercially available resin. A minimum curing time of 24 hours was allowed for the resin to set. These grips were simple to work with and were extremely effective. This can be noticed from the failure modes of the tension specimen (Section 4.3, Chapter 4), where almost all the specimens failed at the 
center. The length of the grips was decided based on the diameter of the rebar specimen to be tested as described in Section 4.2.3(b) and Table 4.2.

\subsection{FLEXURE TESTS (3 point bending)}

Flexure tests performed on FRP bars are described in this section. 3-point bending test was performed on these specimens. \#3 ribbed CFRP, \#4 ribbed GFRP and \#4 sand-coated GFRP bars were tested using Type A Supports (as shown in Fig.5.2).The supports were modified to Type B (as shown in Figs 5.1 and 5.2). The reference material used for the modification of supports was ASTM D4476-97: Standard test method for flexural properties of fiber reinforced pultruded plastic rods. Also different span to diameter ratios (mainly 20 and 40) were used to determine the effect of span to diameter ratios on flexure test results.

\subsection{SHEAR TESTS}

Shear tests performed on FRP bars is described in Chapter 6. The shear testing apparatus used is shown in Fig. 6.1. Shear tests were performed with two different cutting tool widths: 1" and 1/2". Also two different types of shear tests: single and double shear tests were performed. In single shear tests only one cross section of the specimen was subjected to shear, while in double shear two parallel cross sections were subjected to shear. In single shear, the specimen was anchored only at one end, while in double shear the specimen was anchored at both the ends. Shear tests were initially performed with a cutting tool 1" wide, in other words a span of 1". It was observed that bending effects play an important role in the results, another set of tests for double shear was performed with a cutting tool $1 / 2$ " wide, thereby reducing the span to half. Shear tests results are given Chapter 6. 


\subsection{BOND TESTS}

Pull-out tests were performed on FRP bars to evaluate bond strength. The FRP bar was embedded in a concrete cylinder 6"in diameter and 12" long. The length of contact of bar with concrete was 3.5", while the remaining length of the bar was debonded from concrete using foam tubes around the bar. The slip at the lower end of the bar was measured using an LVDT.

\subsection{LONG TERM TESTING}

The tests performed on specimens exposed to different laboratory aging conditions are termed as long-term tests. Long-term tests were categorized into two different types,

(a) Moisture absorption,

(b) Flexure tests on aged specimens

(i) Immersed in water at room temperature

(ii) Immersed in salt water at room temperature

(iii) Immersed in water and subjected to freeze-thaw temperature

(iv) Immersed in salt water and subjected to freeze-thaw temperature

(v) Unaged samples (for test results comparison)

\subsubsection{MOISTURE ABSORPTION}

Two-inch long specimens were cut and sealed at the ends with a suitable resin to avoid penetration of water during the aging process. The specimens were then immersed in distilled water. The initial weight of the specimens before immersion was recorded for reference. The 
weight of the specimens was then monitored at regular intervals. Moisture gain of the specimens was recorded and the percentage absorption was calculated.

\subsubsection{FLEXURE TEST ON AGED SPECIMENS}

The specimens were immersed in water and salt solutions and aged under room temperature and freeze-thaw temperatures $\left(12^{\circ} \mathrm{F}-120^{\circ} \mathrm{F}\right)$. The test specimens, sample preparation, test apparatus, testing method and calculations are the same as described in Chapter 5 of this document. Support Type B was used in these tests.

\subsection{SPECIMENS}

Fibers are selected based on the strength, stiffness, and durability required for an application. Based on the fiber types the specimens tested under this research are: Carbon FRP (CFRP) bars, Glass FRP (GFRP) bars, and Aramid FRP (AFRP) bars.

The polymer matrix (resin) protects the fibers from damage, ensures that the fibers remain aligned, and allows loads to be distributed among the individual fibers. Resins are selected based on the environment the FRP will be exposed to as well as the method by which the FRP is being manufactured. Resins used in FRP materials are generally classified as either thermosetting or thermoplastic resins. Epoxy and vinyl ester are the most commonly used thermosetting resins because of durability and adhesion properties. Most thermosetting resins are sensitive to heat and ultra-violet light exposure. Polyurethane modified vinyl-ester resin constituted the resin-matrix of the rebars tested in this research. 
Fiber volume fraction (fvf) is a measure of volume of fibers present in the bar with respect to its entire volume. Since fibers are the main load carrying elements of the FRP bar, higher fvf results in higher load carrying capacity of the bar. However, due to manufacturing process limitations, it is difficult to achieve more than $70 \%$ fvf under present manufacturing methods. FRP rebar specimens tested in this work had a fiber volume fraction ranging from $\mathbf{5 0 - 6 0 \% .}$

The surface texture of the bar plays a critical role in the bond strength a bar will display if used as reinforcement in concrete. The bars were categorized based on surface textures as:

(a) Ribbed: ribs or lugs (similar to those in steel rebars) on the surface of the rebar (b) Sand-coated: sand particles bonded to the surface of the rebar

(c) Sand-coated with helical wraps: sand particles bonded on the surface of the bar and fibers of the bar held together by helically wrapped fibers on the circumference and along the length of the bar. 


\section{CHAPTER 4}

\section{TENSION TESTS}

\subsection{INTRODUCTION}

Axial tension tests were conducted on different types of FRP bars as shown in Table 4.1. Tension test procedure and analytical calculations adopted are given in Section 4.2. A schematic diagram of the tension test specimen is shown in Fig. 4.1. The specimens were bonded with steel grips on both the ends using a commercially available resin PLIOGRIPTM. Grips were made of Schedule 80 steel pipes which were split along the length in half. The internal diameter of the grips was same as the external diameter of the bar to be tested. A minimum of 24 hours curing time was allowed for the resin to set before the specimens were tested. Length of the grips was based on the diameter of the bars tested as shown in Table 4.2. Table 4.1 gives different specimens tested for tension in this research.
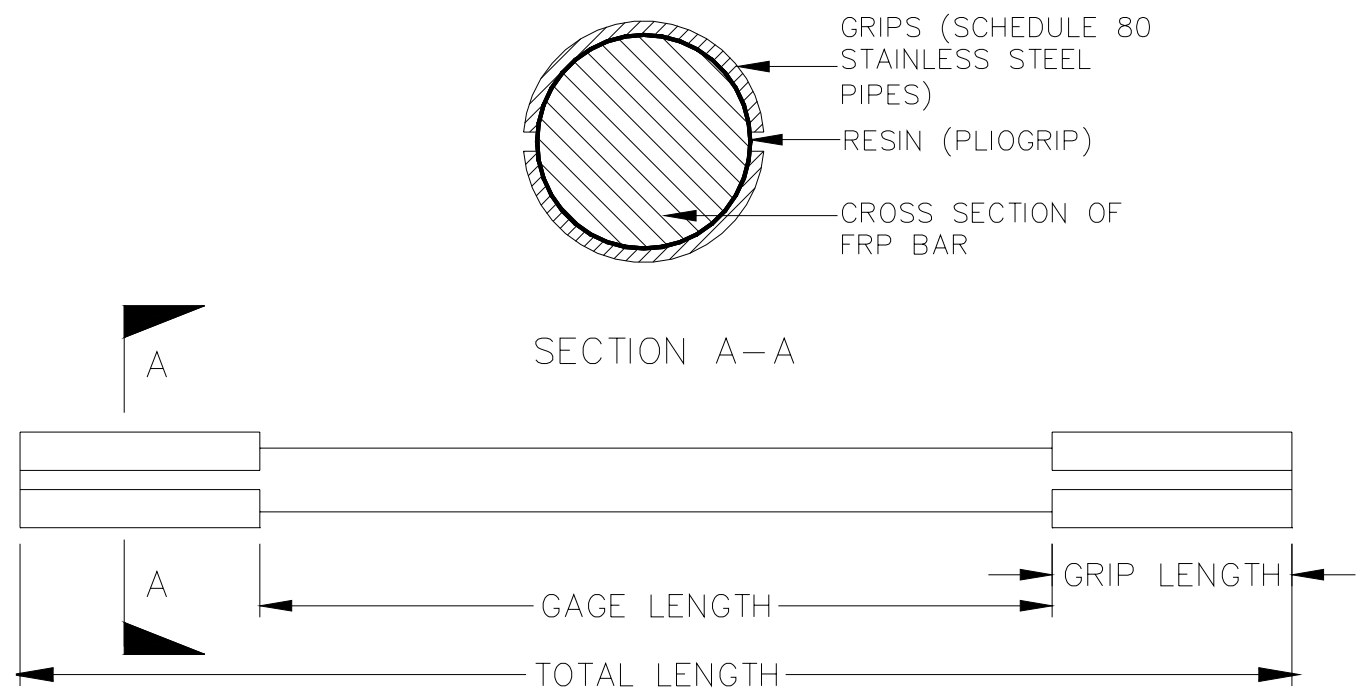

Fig 4.1: Schematic Diagram of a Tension Test Specimen 
Table 4.1: Specimens tested in Tension (28 Specimens)

\begin{tabular}{|c|c|c|c|c|c|}
\hline Dia (in) & AFRP & \multicolumn{2}{|c|}{ CFRP } & \multicolumn{2}{c|}{ GFRP } \\
\hline & Sand Coated & Ribbed & Sand Coated & Ribbed & Sand Coated \\
\hline $0.375(\# 3)$ & 3 & 5 & - & - & - \\
\hline $0.500(\# 4)$ & - & - & - & $3+5$ & 3 \\
\hline $0.625(\# 5)$ & - & - & - & - & 3 \\
\hline $0.750(\# 5)$ & - & - & - & 3 & - \\
\hline $1.000(\# 5)$ & - & - & - & - & 3 \\
\hline
\end{tabular}

\subsection{DEVELOPMENT OF THE TEST}

\subsubsection{Referenced Documents}

Japan Society of Civil Engineers (JSCE) 1997. Recommendation for Design and Construction of Concrete Structures Using Continuous Fiber Reinforced Materials, Concrete Engineering Series 23, Ed. A. Machida, Research Committee on Continuous Fiber Reinforcing Materials, Tokyo, Japan, p. 325

\subsubsection{Terminology}

(a) Test section: The portion of a specimen to be tested between the anchoring sections of the test specimen.

(b) Grip length (anchoring section): The end part of the test specimen where an anchorage is fitted to transmit the load from the testing machine to the test section.

(c) Gauge length: The distance between two gage points on the test section providing a reference length to the test specimen.

(d) Anchorage: Device fitted to the anchoring section of a test specimen to transmit loads from the testing machine to the test specimen.

(e) Tensile capacity: The tensile load at the failure of the test specimen. 
(f) Guaranteed tensile capacity: Guaranteed value for the tensile capacity; if none is specified, the manufacturer's guaranteed tensile capacity was adopted.

\subsubsection{Specimen Preparation}

(a) Preparation: Care was taken so that the specimen was not subjected to any processing. During the sampling and preparation of test specimens, all deformation, heating, outdoor exposure to ultraviolet light etc., causing changes to the material properties of the test specimen was avoided.

(b) Test section length \& Grip length: A test section length of 20-24 in was adopted with a grip length of 8in (for \#3-\#5 bars), 10 in (for \#6 bars) and 13.3 in (for \#8 bars) on each side. A preferable grip length of $15 "$ is suggested for \#8 bars [Vijay and GangaRao, 1999]. However, in this test a grip length of $\# 8$ bars was taken to be 13.3 in due to specimen length restrictions. The total length of the specimens including the grip lengths was 40 in for FAU Specimens and 42 in for WVU Specimens.

Table 4.2: Length of steel grips used for tension tests

\begin{tabular}{|c|c|}
\hline $\begin{array}{c}\text { Internal Diameter of the } \\
\text { Test Specimen (in) }\end{array}$ & $\begin{array}{c}\text { Length of steel pipe } \\
\text { grip (in) }\end{array}$ \\
\hline $0.375(\# 3)$ & 8 \\
\hline $0.500(\# 4)$ & 8 \\
\hline $0.625(\# 5)$ & 8 \\
\hline $0.750(\# 6)$ & 10 \\
\hline $1.000(\# 8)$ & 13.3 \\
\hline
\end{tabular}

(c) Anchorages (Grips): Steel pipes of appropriate diameter and length (as mentioned above) were split and bonded to each end of the FRP rebar using Pliogrip ${ }^{\mathrm{TM}}$, a commercially 
available resin. The resin was allowed to cure for a minimum of 24 hours, before the specimens were tested.

(d) Number of Specimens: Number of specimens tested was either three or five, depending upon the availability of the specimens.

\subsubsection{Test Equipment}

The tension specimens were tested on a universal testing machine with a maximum load capacity of 200 kips. A computerized data acquisition system was used to automatically log in the load and strain data for analysis.

\subsubsection{Test Method}

(a) Strain Gage: In order to determine the Young's modulus of the test specimen, a strain gauge was mounted in the center of the test section in the direction of tension.

(b) Mounting: When mounting the test specimen on the testing machine, care was taken to ensure that the longer axis of the test specimen coincides with the imaginary line joining the two end anchors fitted to the testing machine.

(c) Loading Rate: The applied rate of loading for the tension test specimen was between 1570 ksi per minute.

(d) Testing Temperature: The test temperature was generally within the range of $40-100^{\circ} \mathrm{F}$.

(e) Loading: The load was applied until tensile failure, and the measurements were recorded until the load reaches at least $60 \%$ of the tensile capacity or the guaranteed tensile capacity. 


\subsubsection{Calculation}

The material properties of FRP bar were assessed only on the basis of the test specimen undergoing failure in the test section. In cases where there was tensile failure or slippage in anchoring section, the data was disregarded and/or additional tests were performed.

(a) Tensile Stress, $\sigma$ : The tensile stress was calculated according to Eq. (4.1),

$$
\sigma=\mathrm{F} / \mathrm{A}
$$

Where,

$$
\sigma=\text { Tensile stress }(\mathrm{ksi})
$$

$\mathrm{F}=$ Load at which the stress is being calculated (kips)

$A=$ cross sectional area of test specimen $\left(i^{2}\right)-$ based on manufacturer specified die diameter.

(b) Strain, $\varepsilon$ : The load and the corresponding strain was automatically recorded from the strain gage to a computer using the computerized data acquisition system.

(c) Stiffness, E (Young's Modulus): The stresses calculated in (a) and the corresponding strains were then plotted to get the stress-strain curve. A typical stress-strain plot is shown in Fig. 4.3, with stress on the y-axis and strain on the x-axis. The slope of this curve then gives the stiffness of the test specimen. The data points used for the calculation of the stiffness were between $20 \%$ to $60 \%$ of the tensile capacity of the specimen. 


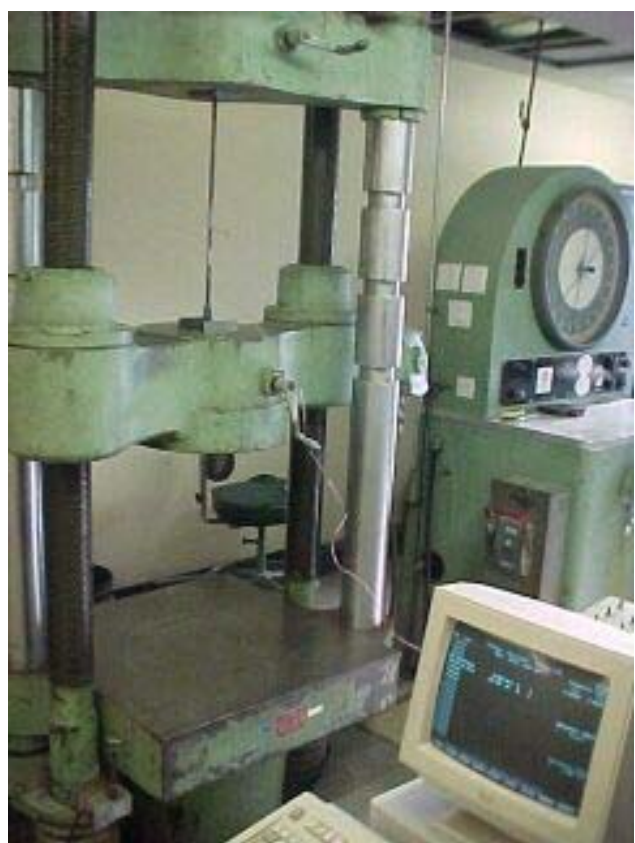

(a)

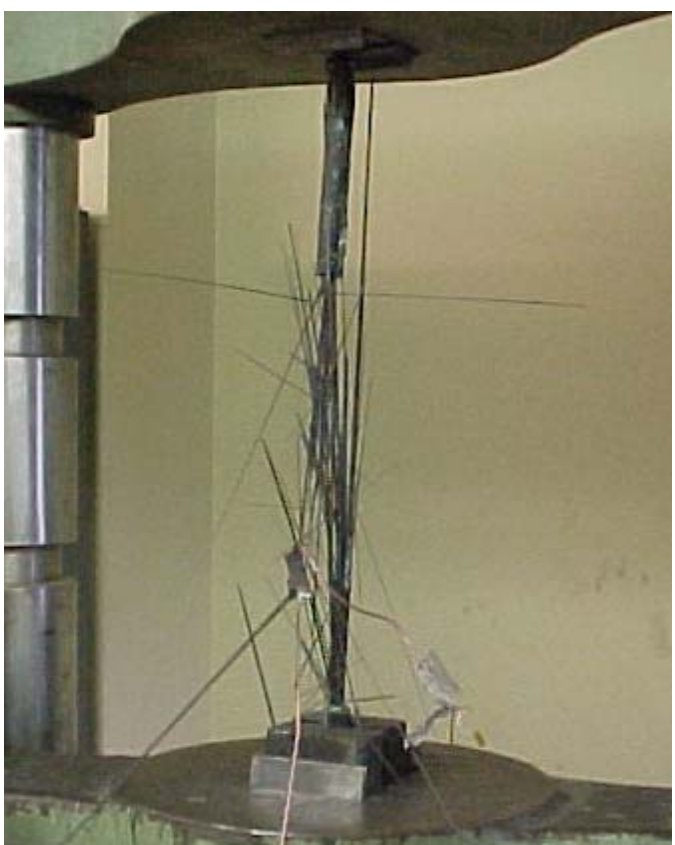

(b)

Fig 4.2: (a) Typical test setup for tension tests; (b) failure of a CFRP bar

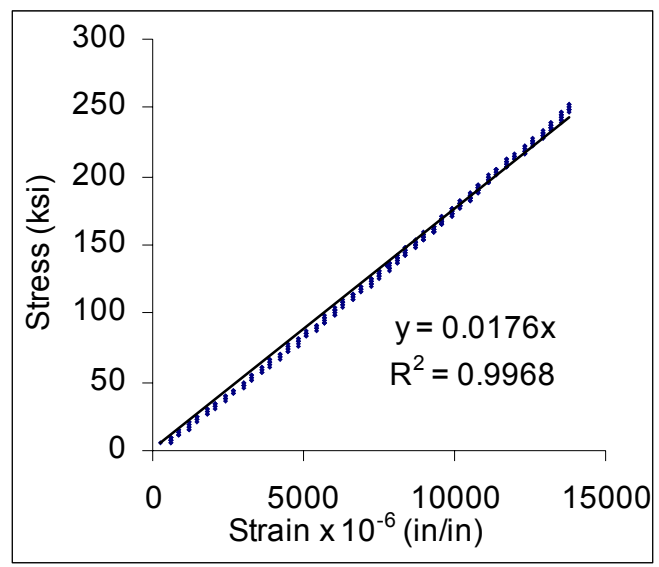

Fig 4.3: Typical Stress-Strain $(\sigma-\varepsilon)$ plot from a tension test 


\subsection{TEST RESULTS}

\subsubsection{TENSION - CFRP - RIBBED - \#3}

\section{$\rightarrow$ Test and Specimen Details}

- Fiber type - Carbon

- Surface texture - Ribbed

- Diameter of Bars tested - 0.375” (\#3)

- Length of the specimens -42 "

- Grip length on each end - 8"

- Number of specimens tested -5

- Strains were measured at the center of the specimen using a strain gage

- Stiffness values were calculated using stress-strain plots

\section{$\rightarrow$ Test Results}

Table 4.3: Tensile test results for \#3 Ribbed CFRP bars (WVU Specimens)

\begin{tabular}{|c|c|c|c|c|}
\hline$\#$ & Dia (in) & Max Stress (ksi) & Stiffness (msi) & Failure \\
\hline 1 & 0.375 & 267.77 & 17.586 & At Center \\
\hline 2 & 0.375 & 263.2 & 17.397 & At Center \\
\hline 3 & 0.375 & 232.15 & 17.6 & At Center \\
\hline 4 & 0.375 & 253.28 & 17.5 & At Center \\
\hline 5 & 0.375 & 265.16 & 17.9 & At Center \\
\hline Average & & $\mathbf{2 5 6 . 3 1}$ & $\mathbf{1 7 . 6 0}$ & \\
\hline Std dev & & $\mathbf{1 4 . 5 8}$ & $\mathbf{0 . 1 9}$ & \\
\hline \% & & $\mathbf{5 . 6 9}$ & $\mathbf{1 . 0 7}$ & \\
\hline
\end{tabular}

\section{$\rightarrow$ Discussion of Test Results}

- Avg. tensile stress $=256.31 \pm 14.58 \mathrm{ksi}($ Std. dev. was $5.69 \%$ of avg. value) 
- Average Stiffness $=17.6 \pm 0.19 \mathrm{msi}$ (Std. dev. was $1.07 \%$ of avg. value)

- Failure Mode - Failure in all the specimens was observed at the center. The failure was initiated with the splitting of fibers in the outer layer as observed during the test. At the end of the test, the fibers failed at the center by splitting into a conical mesh pattern as shown in Fig. 4.2 (b). The failure mode suggested that the stress distribution across the cross-section of the bar is not uniform. Failure occurred in outer fibers first and moved towards the core. This demonstrated that the stresses were higher in the peripheral region of the cross-section as compared to the core. This phenomenon is called shear lag [Wu, 1990].

\subsubsection{TENSION - GFRP - RIBBED - \#4, \#6}

\section{$\rightarrow$ Test and Specimen Details}

- Fiber type - Glass

- Surface texture - Ribbed

- Diameter of Bars tested - 0.5” (\#4), 0.75” (\#6)

- Length of the specimens - 42" (WVU Specimens), 40" (FAU Specimens)

- Grip length on each end - 8" for \#4, 10" for \#6

- Number of specimens tested $-5+3+3-11$

- Strains were measured at the center of the specimen using a strain gage

- Stiffness values were calculated using stress-strain plots 


\section{Test Results}

Table 4.4: Tensile test results for \#4 Ribbed GFRP bars (WVU Specimens)

\begin{tabular}{|c|c|c|c|c|}
\hline$\#$ & Dia (in) & Max Stress (ksi) & Stiffness (msi) & Failure \\
\hline 1 & 0.5 & 89.93 & 5.305 & At Center \\
\hline 2 & 0.5 & 80.61 & 5.267 & At Center \\
\hline 3 & 0.5 & 84.47 & 5.23 & At Center \\
\hline 4 & 0.5 & 82.86 & 5.879 & At Center \\
\hline 5 & 0.5 & 73.87 & 5.414 & At Center \\
\hline Average & & $\mathbf{8 2 . 3 5}$ & $\mathbf{5 . 4 2}$ & \\
\hline Std dev & & $\mathbf{5 . 8 6}$ & $\mathbf{0 . 2 7}$ & \\
\hline \% & & $\mathbf{7 . 1 1}$ & $\mathbf{4 . 9 1}$ & \\
\hline
\end{tabular}

Table 4.5: Tensile test results for \#4 Ribbed GFRP bars (FAU Specimens)

\begin{tabular}{|c|c|c|c|c|}
\hline$\#$ & Dia (in) & Max. Stress (Ksi) & Stiffness (msi) & Failure \\
\hline TC1 & 0.5 & 87.1 & 5.181 & At Center \\
\hline TC2 & 0.5 & 84.4 & 5.04 & At Center \\
\hline TC3 & 0.5 & 79.4 & 5.516 & At Center \\
\hline Average & & $\mathbf{8 3 . 6 3}$ & $\mathbf{5 . 2 5}$ & \\
\hline Std Dev & & $\mathbf{3 . 9 1}$ & $\mathbf{0 . 2 4}$ & \\
\hline \% & & $\mathbf{4 . 6 8}$ & $\mathbf{4 . 5 7}$ & \\
\hline
\end{tabular}

Table 4.6: Tensile test results for \#6 Ribbed GFRP bars (FAU Specimens)

\begin{tabular}{|c|c|c|c|c|}
\hline$\#$ & Dia (in) & Max. Stress (Ksi) & Stiffness (msi) & Failure \\
\hline TB1 & 0.75 & 32.12 & 4.1 & Grip Failure \\
\hline TB2 & 0.75 & 74.4 & 5.5 & At Center \\
\hline TB3 & 0.75 & 79.45 & 5.2 & At Center \\
\hline Average & & $\mathbf{7 6 . 9 3}$ & $\mathbf{5 . 3 5}$ & \\
\hline Std Dev & & $\mathbf{3 . 5 8}$ & $\mathbf{0 . 2 2}$ & \\
\hline \% & & $\mathbf{4 . 6 5}$ & $\mathbf{4 . 1 1}$ & \\
\hline
\end{tabular}




\section{$\rightarrow$ Discussion of Test Results}

- WVU Specimens (\#4)

$\rightarrow$ Avg. Tensile Stress $=82.35 \pm 5.86 \mathrm{ksi}($ Std. dev. was $7.11 \%$ of avg. value $)$

$\rightarrow$ Avg. Stiffness $=5.42 \pm 0.27 \mathrm{msi}$ (Std. dev. was $4.91 \%$ of avg. value)

\section{- FAU Specimens (\#4)}

$\rightarrow$ Avg. Tensile Stress $=83.63 \pm 3.91 \mathrm{ksi}($ Std. dev. was $4.68 \%$ of avg. value $)$

$\rightarrow$ Avg. Stiffness $=5.25 \pm 0.24$ msi (Std. dev. was $4.57 \%$ of avg. value)

\section{- FAU Specimens (\#6)}

$\rightarrow$ Avg. Tensile Stress $=76.93 \pm 3.58 \mathrm{ksi}($ Std. dev. was $4.65 \%$ of avg. value $)$

$\rightarrow$ Avg. Stiffness $=5.35 \pm 0.22 \mathrm{msi}$ (Std. dev. was $4.11 \%$ of avg. value)

- Failure Mode - Except for one \#6 specimen (Specimen \# TB1 in Table: 5.2.6), all other specimens failed at the center. The failure was initiated with the splitting of fibers in the outer layer. At the end of test, the fibers split at the center into a conical mesh pattern.

- Stress and Stiffness - \#6 diameter bars showed 8.7\% (76.93 ksi vs $83.63 \mathrm{ksi}$ ) lesser avg. stress as compared to \#4 diameter bars, which suggested increased shear lag in larger diameter bars. The maximum variation in the avg. stiffness values between \#4 ribbed GFRP bars and \#6 ribbed GFRP bars was 1.9\% (5.25 ksi vs $5.35 \mathrm{ksi}$ ), which was lesser as compared to the variation in the stress values $(8.7 \%)$.

- Standard Deviation - Tensile stress results showed standard deviations lesser than $7.11 \%$ of the average. Stiffness results showed standard deviations were lesser than $4.91 \%$ of the average value for all ribbed GFRP bars. 
- WVU \#4 and FAU \#4 specimens - Results of \#4 diameter specimens from WVU and those supplied by FAU (as a part of round robin testing) showed close resemblance in terms of avg. tensile stress and standard deviations.

\subsubsection{TENSION - GFRP - SAND COATED - \#4, \#5, \#8}

\section{$\rightarrow$ Test and Specimen Details}

- Fiber type - Glass

- Surface texture - Sand Coated

- Diameter of Bars tested - 0.5” (\#4), 0.625” (\#5), 0.75” (\#6)

- Length of the specimens - 42" (WVU Specimens), 40" (FAU Specimens)

- Grip length on each end - 8" for \#4, 8" for \#5, 13.3" for \#8

- Number of specimens tested $-5+(3+3)$

- Strains were measured at the center of the specimen using a strain gage

- Stiffness values were calculated using stress-strain plots

$\rightarrow$ Test Results

Table 4.7: Tensile test results for \#4 Sand Coated GFRP bars (WVU Specimens)

\begin{tabular}{|c|c|c|c|c|}
\hline$\#$ & Dia (in) & Max Stress (ksi) & Stiffness (msi) & Failure \\
\hline 1 & 0.5 & 80.61 & 5.192 & At Center \\
\hline 2 & 0.5 & 83.18 & 6.613 & At Center \\
\hline 3 & 0.5 & 82.53 & 6.11 & At Center \\
\hline Average & & $\mathbf{8 2 . 1 1}$ & $\mathbf{5 . 9 7}$ & \\
\hline Std dev & & $\mathbf{1 . 3 4}$ & $\mathbf{0 . 7 2}$ & \\
\hline \% & & $\mathbf{1 . 6 3}$ & $\mathbf{1 2 . 0 7}$ & \\
\hline
\end{tabular}


Table 4.8: Tensile test results for \#5 Sand-coated GFRP bars (FAU Specimens)

\begin{tabular}{|c|c|c|c|c|}
\hline$\#$ & Dia (in) & Max. Stress (Ksi) & Stiffness (msi) & Failure \\
\hline TA1 & 0.625 & 90 & 5.654 & At Center \\
\hline TA2 & 0.625 & 87.4 & 5.219 & At Center \\
\hline TA3 & 0.625 & 82.5 & 5.925 & At Center \\
\hline Average & & $\mathbf{8 6 . 6 3}$ & $\mathbf{5 . 6}$ & \\
\hline Std Dev & & $\mathbf{3 . 8 1}$ & $\mathbf{0 . 3 6}$ & \\
\hline$\%$ & & $\mathbf{4 . 4}$ & $\mathbf{6 . 4 3}$ & \\
\hline
\end{tabular}

Table 4.9: Tensile test results for \#8 Sand Coated GFRP bars (FAU Specimens)

\begin{tabular}{|c|c|c|c|c|}
\hline$\#$ & Dia (in) & Max. Stress (Ksi) & Stiffness (msi) & Failure \\
\hline TE1 & 1 & 42.7 & 5.8 & Grip Failure \\
\hline TE2 & 1 & 68.1 & 6.1 & At Center \\
\hline TE3 & 1 & 66.27 & 6.3 & At Center \\
\hline Average & & $\mathbf{6 7 . 1 9}$ & $\mathbf{6 . 2}$ & \\
\hline Std Dev & & $\mathbf{1 . 3}$ & $\mathbf{0 . 1 5}$ & \\
\hline$\%$ & & $\mathbf{1 . 9 3}$ & $\mathbf{2 . 4 2}$ & \\
\hline
\end{tabular}

\section{$\rightarrow$ Discussion of Test Results}

- WVU Specimens (\#4)

$\rightarrow$ Avg. Tensile Stress $=82.11 \pm 1.34 \mathrm{ksi}($ Std. dev. was $1.63 \%$ of avg. value $)$

$\rightarrow$ Avg. Stiffness $=5.97 \pm 0.72 \mathrm{msi}($ Std. dev. was $12.07 \%$ of avg. value $)$

\section{- FAU Specimens (\#5)}

$\rightarrow$ Avg. Tensile Stress $=86.63 \pm 3.81 \mathrm{ksi}($ Std. dev. was $4.4 \%$ of avg. value $)$

$\rightarrow$ Avg. Stiffness $=5.6 \pm 0.36 \mathrm{msi}$ (Std. dev. was $6.43 \%$ of avg. value)

\section{- FAU Specimens (\#8)}

$\rightarrow$ Avg. Tensile Stress $=67.19 \pm 1.3 \mathrm{msi}$ (Std. dev. was $1.93 \%$ of avg. value $)$

$\rightarrow$ Avg. Stiffness $=6.2 \pm 0.15 \mathrm{msi}$ (Std. dev. was $2.42 \%$ of avg. value) 
- Failure Mode - Except for one \#8 specimen (Specimen TE1 in Table 5.2.9, which failed in the grips), all other specimens failed at the center. The failure was initiated with some sand particles popping followed by splitting of fibers in the outer layer as observed during the test. At the end of test, the fibers split at the center into a conical mesh pattern.

- Stress and Stiffness - \#8 FAU specimens showed 29\% (67.19 ksi vs 86.63 ksi) lesser avg. stress as compared to $\# 5$ diameter bars from FAU. This was due to the increased shear lag phenomenon in larger dia bars as compared to smaller dia bars. The variation in the avg. stiffness values of \#5 GFRP bars and \#8 GFRP bars was 10.7\% (5.6 msi vs 6.2 msi), which was lower as compared to the variation in avg. stress values. However, this variation was still higher as compared to those of ribbed GFRP bars and it was concluded that results of sand coated bars are less consistent than ribbed GFRP bars.

- Standard Deviation - Tensile stress standard deviations were lesser than $4.4 \%$ of the average for all the sand coated GFRP specimens. Stiffness results for WVU \#4 specimens varied a lot with $12.07 \%$ standard deviation of the average. This was due to the presence of helical ribs which made the failure and behavior of the specimens very unpredictable. However, stiffness values of FAU specimens showed comparatively lower standard deviation values that were lesser than the average value (6.43\%).

- WVU and FAU specimens - WVU specimens were sand-coated bars with helical ribs, while FAU specimens were sand-coated and did not have any helical ribs. Hence the results of WVU Specimens were not compared with FAU Specimens. 


\subsubsection{TENSION - AFRP - SAND COATED - \#3}

$\rightarrow$ Test and Specimen Details

- Fiber type - Aramid

- Surface texture - Ribbed

- Diameter of Bars tested - 0.375" (\#3)

- Length of the specimens - 42"

- Grip length on each end - 8"

- Number of specimens tested - 5

- Strains were measured at the center of the specimen using a strain gage

- Stiffness values were calculated using stress-strain plots

\section{Test Results}

Table 4.10: Tensile test results for \#3 Sand Coated AFRP bars

\begin{tabular}{|c|c|c|c|c|}
\hline $\begin{array}{c}\text { Specimen } \\
\#\end{array}$ & Dia (in) & Max. Stress (Ksi) & Stiffness (msi) & Failure \\
\hline TD1 & 0.375 & 175.6 & 8.366 & At Center \\
\hline TD2 & 0.375 & 173 & 8.593 & At Center \\
\hline TD3 & 0.375 & 172.4 & 8.58 & At Center \\
\hline Average & & $\mathbf{1 7 3 . 6 7}$ & $\mathbf{8 . 5 1}$ & \\
\hline Std Dev & & $\mathbf{1 . 7}$ & $\mathbf{0 . 1 3}$ & \\
\hline \% & & $\mathbf{0 . 9 8}$ & $\mathbf{1 . 5 3}$ & \\
\hline
\end{tabular}

\section{$\rightarrow$ Discussion of Test Results}

- Average Tensile Stress $=173.67 \pm 1.7 \mathrm{ksi}($ Std. dev. was $0.98 \%$ of avg. value)

- Average Stiffness $=8.5 \pm 0.13 \mathrm{msi}$ (Std. dev. was $1.53 \%$ of avg. value) 
- Failure Mode - Failure in all the specimens was observed at the center of the specimens. It was initiated with some sand particles popping followed by splitting of fibers in the outer layer as observed during the test. At the end of test, the fibers failed at the center forming a conical mesh pattern. The failure mode suggested that the stress distribution across the cross-section of the bar was not uniform. Failure occurred in outer fibers first and moved towards the core. This demonstrated that stresses were higher in the peripheral region of the cross-section as compared to the core.

- Standard Deviation - Stress and Stiffness results were consistent with a standard deviation of $1 \%$ and $1.5 \%$ of the average values respectively.

\subsection{SUMMARY AND CONCLUSIONS - TENSION TESTS}

Table 4.11: Summary of Tension Tests

\begin{tabular}{|l|c|c|c|}
\hline \multicolumn{1}{|c|}{ Bar Type } & Dia & Avg. Max. Stress (ksi) & Stiffness $\sigma-\varepsilon(m s i)$ \\
\hline CFRP Ribbed (WVU) & $\# 3$ & $256.31 \pm 14.58(5.69 \%)$ & $17.60 \pm 0.19(1.07 \%)$ \\
\hline GFRP Ribbed (WVU) & $\# 4$ & $82.35 \pm 5.86(7.11 \%)$ & $5.42 \pm 0.27(4.91 \%)$ \\
\hline GFRP Ribbed (FAU) & $\# 4$ & $83.63 \pm 3.91(4.68 \%)$ & $5.25 \pm 0.24(4.57 \%)$ \\
\hline GFRP Ribbed (FAU) & $\# 6$ & $76.93 \pm 3.58(4.65 \%)$ & $5.35 \pm 0.22(4.11 \%)$ \\
\hline GFRP Sand Coated (WVU) & $\# 4$ & $82.11 \pm 1.34(1.63 \%)$ & $5.97 \pm 0.72(12.07 \%)$ \\
\hline GFRP Sand Coated (FAU) & $\# 5$ & $86.63 \pm 3.81(4.4 \%)$ & $5.60 \pm 0.36(6.43 \%)$ \\
\hline GFRP Sand Coated (FAU) & $\# 8$ & $67.19 \pm 1.3(1.93 \%)$ & $6.20 \pm 0.15(2.42 \%)$ \\
\hline AFRP Sand Coated (FAU) & $\# 3$ & $173.67 \pm 1.7(0.98 \%)$ & $8.51 \pm 0.13(1.53 \%)$ \\
\hline
\end{tabular}

(Values in parenthesis indicate standard deviations as a percentage of the average value)

- Stress - Of the three types of bars tested (carbon, glass, and aramid fibers), carbon bars gave a maximum average tensile stress of $256.31 \mathrm{ksi}$ ( $\# 3$ bars), aramid bars gave an 
average tensile stress of $173.67 \mathrm{ksi}$ ( $\# 3$ bars), followed by glass bars showing an average stress range of 67.19-86.63 ksi (\#3-\#8 bars). Both types of glass bars tested (ribbed and sand coated), displayed similar stresses in tension for \#4 bars.

- Stiffness - Of the three types of bars tested (carbon, glass, and aramid fibers), carbon bars had the average stiffness of $17.6 \mathrm{msi}$ (\#3 bars). Aramid bars gave an average stiffness of $8.51 \mathrm{msi}$ (\#3 bars), followed by glass bars showing an average stiffness range of 5.25-6.2 msi (\#3-\#8 bars). Of both types of glass bars tested (ribbed and sand coated), sand coated bars showed slightly higher stiffness values in tension.

- Standard Deviation - Standard deviation values for tensile stress were observed to be a maximum of $7.11 \%$ of the average values for all the bars. Standard deviations for stiffness values were observed to be less than $6.43 \%$ except in case of \#4 WVU sand coated GFRP bars with helical wraps which showed $12.07 \%$ standard deviation in stiffness values. Hence, it was concluded that sand coated GFRP bars with helical wraps show the most inconsistent results among all the FRP bars tested in tension. This inconsistency is attributed mainly to the helical wrapping scheme, which causes stress concentration along the path of helical wraps.

- Failure Mode and Effect of Diameter on Stresses - Failures in all specimens (except two which failed in the grips) were observed to be at the center. At the end of each test, the bar fibers split into a conical mesh pattern. The failure was initiated with popping of sand particles in sand coated bars and splitting of fibers on the outer surface in case of ribbed bars, indicating the failure initiation was in the outer fibers of the bars, with higher stresses. Thus, the stress variation across the cross-section of the bar is not uniform which is referred to as shear lag [Wu, 1991]. This stress variation results in reduction of average 
tensile stress in the bar. The stress variation increases with the increase in bar diameter, resulting in reduced average stresses in higher diameter bars.

\subsection{TEST METHOD SUMMARY}

- Grip Lengths and Adhesive - Variable lengths of steel grips with Pliogrip ${ }^{\mathrm{TM}}$ adhesive were used depending on the diameter of the FRP bar to be tested. A grip length of 8in (for \#3-\#5 bars), 10 in (for \#6 bars) and 13.3 in (for \#8 bars) was found sufficient to be used on each end of the bar. A preferable grip length of 15 " is suggested for \#8 bars [Vijay and GangaRao, 1991]. However, in this test a grip length of \#8 bars was taken to be 13.3 in due to specimen length restrictions. These optimum grip lengths for different diameter of bars are summarized in Table 4.2 of this document.

- Bar Diameters - Variable diameters for the same type of bars were tested in tension to determine the effect of diameter on tensile stresses. It was observed that in general, bars with larger diameters show lower tensile stresses due to shear lag effect.

- Loading rate - The loading rates were adjusted and determined for tension such that the load application and failure of the specimen was gradual. The loading rate for all the tension tests ranged between $15-70 \mathrm{ksi}$ per minute, such that the failure of the specimen was reached between 30 seconds to 5 minutes. Loading rates were lower for glass bars and higher for carbon bars based on higher ultimate tensile strength of carbon bars. Suggested loading rate helps in minimizing stress concentration effects due to quick loading and creep effects due to slow loading.

- Standard Deviations - Lower standard deviation values indicate higher consistency in test results associated with a particular test methodology. Due to lower standard 
deviations $(<7.11 \%)$, this test methodology can be considered as a standardized tension test procedure. 


\section{CHAPTER 5}

\section{FLEXURE TESTS}

\subsection{INTRODUCTION}

Three-point bending tests were conducted on FRP bars. The test procedure adopted is given in Section 5.2. Bending tests were performed on two types of supports - Type A and Type B as shown in Figs 5.1 and 5.2. Different span-to-diameter ratios (16, 20, 21 and 40) were adopted during the tests to evaluate the effect of bending spans on the test results. Following types of bars with different span-to-depth ratios (heron referred to as L/D) were tested on support Type A:

- \#3 Ribbed CFRP bars (L/D = 21)

- \#4 Ribbed GFRP bars (L/D = 16 \& 40)

- \#4 Sand Coated GFRP bars with helical ribs (L/D = $16 \& 40)$

(Note: ASTM D790M-93: "Standard test methods for flexural properties of unreinforced and reinforced plastics and electrical insulating materials" recommends four L/D ratios of 16, 32, 40 and 60 for three point bending tests for high stress reinforced orthotropic laminates and laminated thermosetting materials)

The main drawback of support type A was the sharp edges at support locations which resulted in the punching of bars at those locations. Secondly, while applying the load, the bars slipped along the supports. Thirdly, Support type A had a base span limitation of maximum 8.5". Hence only \#3 and \#4 bars could be tested with L/D ratios of 21 and 16 respectively. For $\mathrm{L} / \mathrm{D}$ ratios of 40 , the specimens had to be tested on a different testing machine with some support fixture modifications. And finally, test results obtained from 
support Type A showed higher variations. All these factors led to the modification of the support type, and hence support Type B was developed. Support type B was developed in accordance to ASTM D4476-97: Standard test method for flexural properties of fiber reinforced pultruded plastic rods. Support Type B had smooth round contact points at support locations, which prevented the bars from punching at those locations. The specimens stayed in place while the load was applied. Support Type B was also capable of a maximum span of 42", which allowed an L/D ratio in excess of 40 for bar diameters upto \#8. It was however observed from the tests on support Type A that tests performed with a $\mathrm{L} / \mathrm{D}$ ratio of 16 or 21 gave lesser standard deviations as compared to L/D of 40 . Hence, all the remaining flexure tests were conducted for a constant L/D ratio of 20 with a minimum overhang of $10 \%$ of the testing span on each side on support Type B. Following types of bars were tested on support Type B with an L/D of 20:

- \#3, \#4, \#5 \& \#6 Sand Coated GFRP bars

- \#3, \#4 \& \#5 Ribbed GFRP bars

- \#3 Sand Coated CFRP bars

- \#3 Sand Coated AFRP bars

Table 5.1 gives a list of various specimens tested in flexure on both support types.

Table 5.1: Specimens tested in Flexure (70 Specimens)

\begin{tabular}{|c|c|c|c|c|c|c|}
\hline \multirow{2}{*}{ Dia (in) } & \multirow{2}{*}{$\begin{array}{c}\text { Support } \\
\text { Type }\end{array}$} & AFRP & \multicolumn{2}{|c|}{ CFRP } & \multicolumn{2}{|c|}{ GFRP } \\
\cline { 3 - 7 } & Sand Coated & Ribbed & Sand Coated & Ribbed & Sand Coated \\
\hline \multirow{2}{*}{$0.375(\# 3)$} & A & - & 15 & - & - & - \\
\cline { 2 - 7 } & B & 3 & - & 3 & 3 & 3 \\
\hline \multirow{2}{*}{$0.500(\# 4)$} & A & - & - & - & 15 & 13 \\
\cline { 2 - 7 } & B & - & - & - & 3 & 3 \\
\hline $0.625(\# 5)$ & B & - & - & - & 3 & 3 \\
\hline $0.750(\# 6)$ & B & - & - & - & - & 3 \\
\hline
\end{tabular}




\subsection{DEVELOPMENT OF THE TEST}

\subsubsection{Referenced Documents}

(a) ASTM D-790M-93: Standard test methods for flexural properties of unreinforced and reinforced plastics and electrical insulating materials.

(b) ASTM D4476-97: Standard test method for flexural properties of fiber reinforced pultruded plastic rods.

(c) Japan Society of Civil Engineers (JSCE) 1997. Recommendation for Design and Construction of Concrete Structures Using Continuous Fiber Reinforced Materials, Concrete Engineering Series 23, Ed. A. Machida, Research Committee on Continuous Fiber Reinforcing Materials, Tokyo, Japan, p. 325.

\subsubsection{Terminology}

(a) Test section: The portion of a specimen to be tested between the overhang sections of the test specimen.

(b) Overhang section: The end parts of the test specimen, i.e., the overhangs beyond the supports.

(c) Loading edge: The fixture used to apply the load at the center of the test section.

(d) Bending Tensile Failure: Tensile failure at the bottom of the specimen in bending.

(e) Bending Tensile Capacity: Load at the time of failure of the specimen, due to tension at the bottom.

\subsubsection{Specimen Preparation}

(a) Preparation: Care was taken so that the specimen was not subjected to any processing. During the sampling and preparation of test specimens, all deformation, heating, outdoor 
exposure to ultraviolet light etc., causing changes to the material properties of the test specimen was avoided.

(b) Overhangs: The overhang section adopted was a minimum of $10 \%$ of the test section on each side of the specimen.

(c) Length: The length of the test specimen was the length of the test section added to the length of the overhang sections. Bending tests were performed on different lengths of the test sections corresponding to L/D ratios of 16, 20, 21 and 40 .

(d) Number of Specimens: Number of specimens tested was three or five.

\subsubsection{Test Equipment}

Two testing machines with maximum load capacities of 200 kips and 22 kips were used for this test group. A computerized data acquisition system was used for 200 kips machine to automatically log in the data for analysis. The testing machine with 22 kips capacity had an inbuilt computerized load control and deflection monitoring mechanism.

\subsubsection{Test Method}

(a) Strain Gage: In order to determine the Young's modulus of the test specimen, a strain gauge was mounted in the center of the test section at the bottom surface of the specimen (tension face).

(b) Dial Gage: To determine the maximum deflections, a dial gage (accuracy $0.0001 \% / 0.0005 ")$ was placed at the center of the specimen.

(c) Mounting: When mounting the test specimen on the testing machine, care was taken to ensure that the specimen is placed at the center across the supports with equal overhangs on each side. It was also ensured that the loading edge was perpendicular to the axis of the specimen. 
(d) Testing Temperature: The test temperature was generally within the range of $40-100^{\circ} \mathrm{F}$.

(e) Loading Rate: loading rate for the tension tests was between 15-70 ksi per minute.

(f) Loading: The load was applied until failure, and the measurements were recorded until the load reaches at least $60 \%$ of the bending tensile capacity of the specimen.

(g) Supports: The bending specimens were tested on two different types of supports as shown in Figs 5.1 and 5.2 (both supports A and B could be adjusted for variable spans):

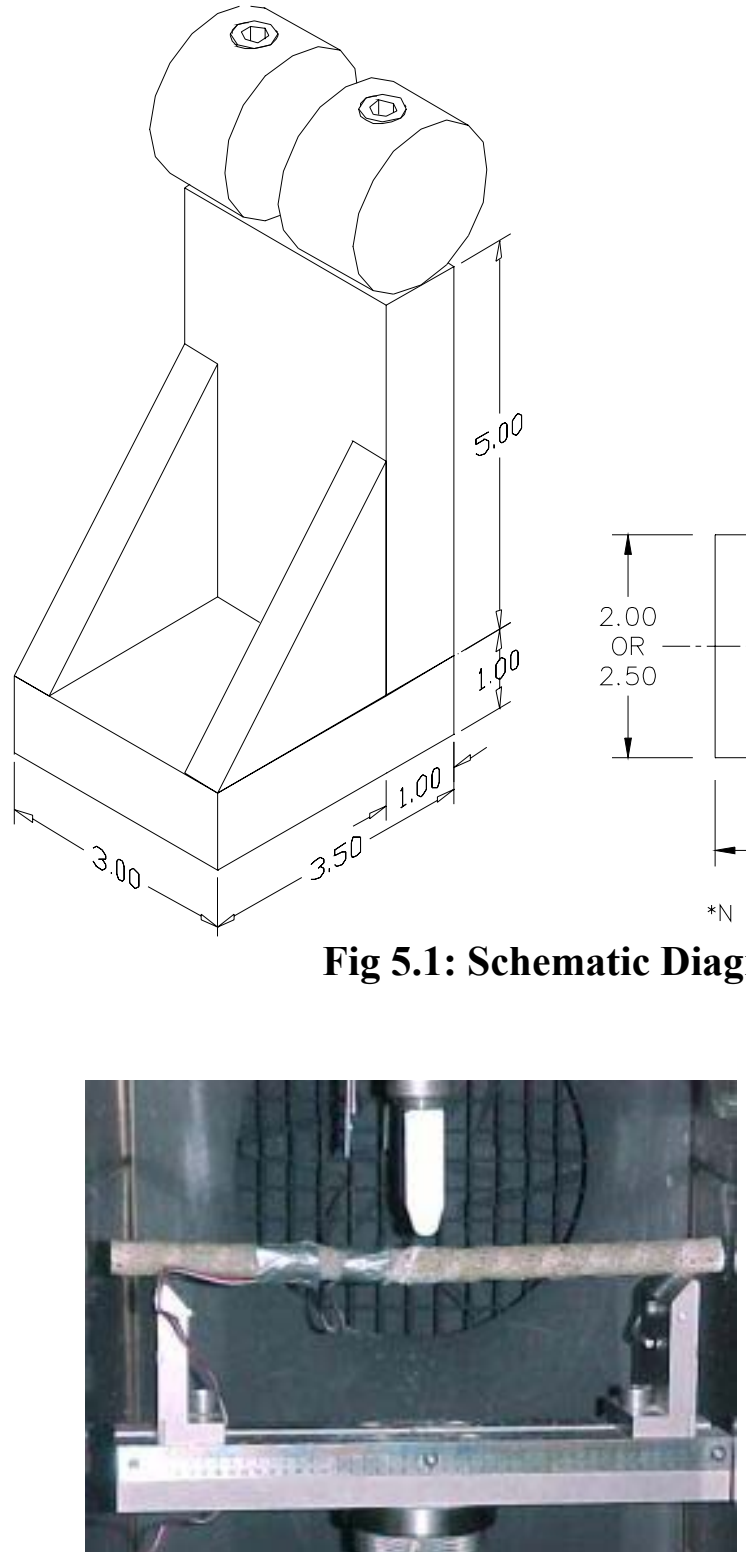

(a)

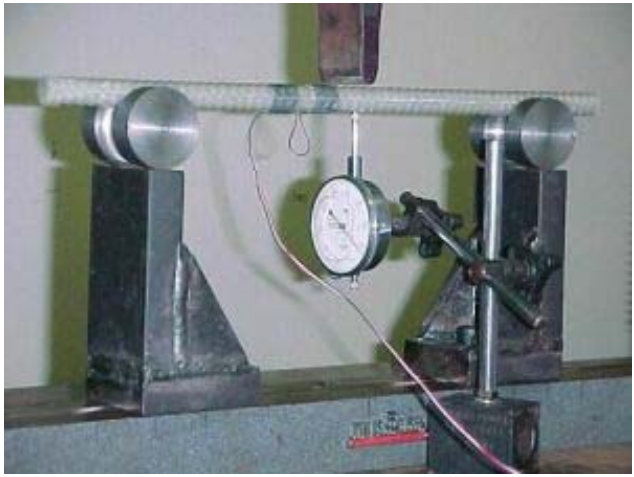

(b)

Fig 5.2: Flexure Test Setup (a) support Type A; (b) support Type B. 


\subsubsection{Calculation}

The material properties of FRP bar were assessed only on the basis of the test specimen undergoing failure in the test section. In cases where there was tensile failure or slippage in anchoring section, the data was disregarded and additional tests were performed. The stiffness (E) of the material can be calculated by two methods as given below,

\section{- Method I (Stress-Strain Plot):}

(a) Tensile Stress, $\sigma$ : The tensile stress was calculated according to Eq. (5.1),

$$
\sigma=(\text { M . c }) / I
$$

Where,

$\sigma=$ Tensile stress $(\mathrm{Ksi})$

$\mathrm{M}=$ Maximum Moment (at midspan) from Eq. (5.2) (Kip-in)

$\mathrm{c}=$ Location of the extreme fiber in tension from the neutral axis (in)

$I=$ Moment of Inertia of the FRP rebar from Eq. (5.3) $\left(\right.$ in $\left.^{4}\right)$

(b) Moment, M: Moment at the center span of the bar in 3-point bending can be calculated as,

$$
\mathrm{M}=\mathrm{PL} / 4
$$

Where,

$\mathrm{P}=$ Maximum load applied at the center span (Kips)

$\mathrm{L}=$ Length of Testing section (in)

(c) Moment of Inertia, I: Moment of inertia of a circular cross-section can be calculated as,

$$
\mathrm{I}=\pi \mathrm{D}^{4} / 64
$$

Where, $\mathrm{D}=$ manufacture specified die diameter of the FRP bar (in)

(d) Strain, ع: The load and the corresponding strain was automatically recorded from the strain gage to a computer using the computerized data acquisition system. 
(e) Stiffness, E (Young's Modulus): The stresses calculated in (a) and the corresponding strains were then plotted to get the stress-strain curve. A typical stress-strain plot is shown in Fig. 5.4(a), with stress on the y-axis and strain on the x-axis. The slope of this curve then gives the stiffness of the test specimen. The data points used for the calculation of the stiffness were between $20 \%$ to $60 \%$ of the tensile capacity of the specimen.

\section{- Method II (Load-Deflection Plot):}

(a) Stiffness, E : Alternatively, stiffness can be calculated according to Eq. (5.4),

$$
\mathrm{E}=(\mathrm{P} / \delta)\left[\mathrm{L}^{3} /(48 . \mathrm{I})\right]
$$

Where,

$\mathrm{P}=$ Maximum Load which is applied the center span of the bar (Kips)

$\delta=$ Corresponding Deflection at the center span of the bar (in)

$\mathrm{L}=$ Length of the testing section (in)

$\mathrm{I}=$ Moment of Inertia of the FRP rebar from Eq. (5.3) $\left(\mathrm{in}^{4}\right)$

The ratio $(\mathrm{P} / \delta$ ) can be directly obtained from the load-deflection plot with load on the yaxis and the deflection on the x-axis as shown in Fig 5.4(b).

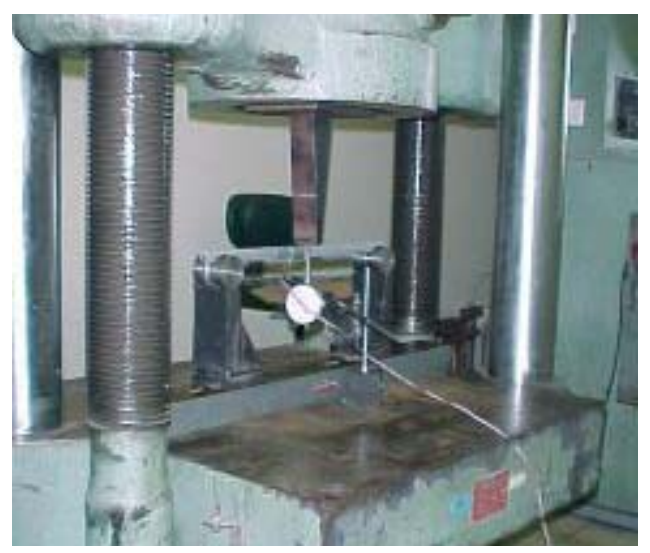

(a)

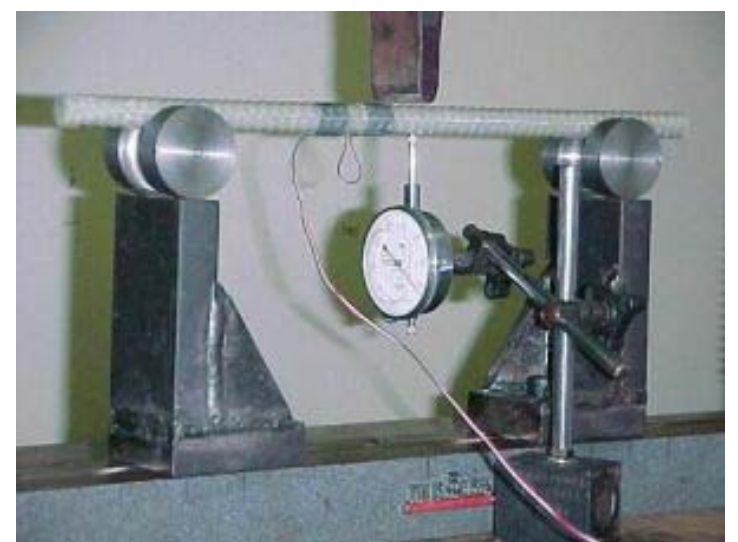

(b)

Fig. 5.3 Typical (a) Test Setup and (b) Dial gage readings for Flexure Tests 


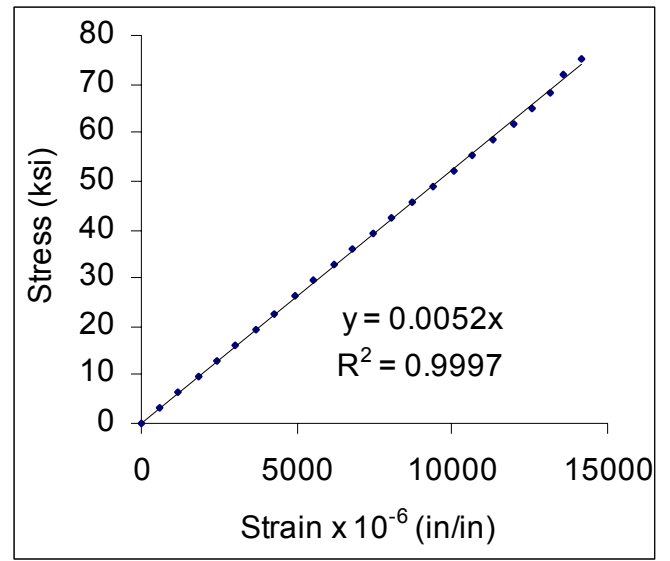

(a)

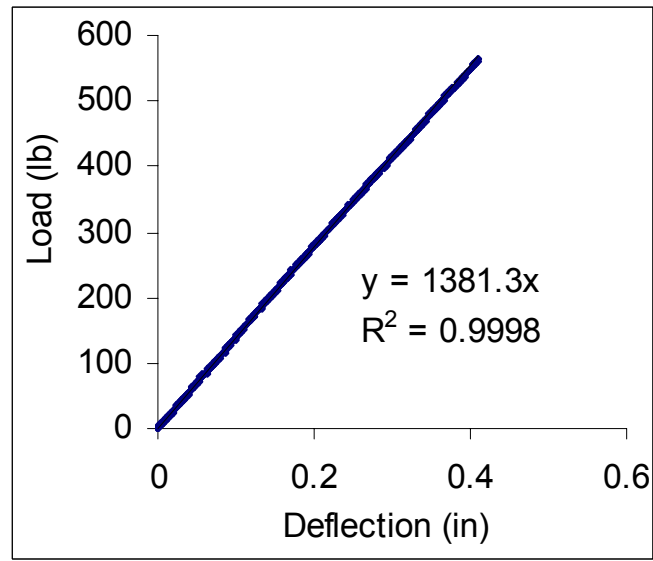

(b)

Fig. 5.4: Typical (a) Stress-Strain $(\sigma-\varepsilon)$ plot and (b) Load-Deflection (P- $\delta$ ) plot

\subsection{TEST RESULTS - SUPPORT TYPE A}

This section gives the results of bending tests conducted using support Type A. These results were observed to show higher test result variations and inconsistencies. It should be noted that support Type A testing and the subsequent results were discarded in favor of support Type B testing. The flexure tests on support Type A were intended to be performed on an L/D ratio of 20 . However, due to span restrictions on the testing machine (max span of 8.5 in), tests were performed with an L/D ratio of 16 and 21 for \#4 GFRP and \#3 CFRP bars.

\subsubsection{FLEXURE - GFRP - RIBBED - \#4 - SUPPORT A}

\section{$\rightarrow$ Test and Specimen Details}

- Fiber type - Glass

- Surface texture - Ribbed

- Diameter of Bars tested - 0.500” (\#4)

- Flexure test span / total length of specimens - 8" / 9.5" $(\mathrm{L} / \mathrm{D}=16)$

- Number of specimens tested - 15 
- Deflections were automatically recorded by the computerized testing machine

- Stiffness values were calculated using load-deflection plots

$\rightarrow$ Test Results

Table 5.2: Flexure test results for \#4 Ribbed GFRP bars on support Type A (L/D=16) (WVU Specimens)

\begin{tabular}{|c|c|c|c|}
\hline$\#$ & Dia (in) & Max Stress (ksi) & Stiffness P- $\boldsymbol{\delta}$ (msi) \\
\hline 1 & 0.5 & 140.02 & 5.72 \\
\hline 2 & 0.5 & 138.18 & 6.12 \\
\hline 3 & 0.5 & 130.91 & 5.03 \\
\hline 4 & 0.5 & 110.79 & 5.29 \\
\hline 5 & 0.5 & 118.3 & 5.07 \\
\hline Average & & $\mathbf{1 2 7 . 6 4}$ & $\mathbf{5 . 4 5}$ \\
\hline Std Dev & & $\mathbf{1 2 . 7 1}$ & $\mathbf{0 . 4 7}$ \\
\hline \% & & $\mathbf{9 . 9 6}$ & $\mathbf{8 . 6 2}$ \\
\hline
\end{tabular}

$\rightarrow$ Discussion of Test Results

- Average Bending Stress $=127.64 \pm 12.71 \mathrm{ksi}$ (Std. dev. was $9.96 \%$ of avg. value)

- Average Stiffness $=5.45 \pm 0.47 \mathrm{msi}$ (Std. dev. was $8.62 \%$ of avg. value)

- Failure Mode - Tension failure was observed at the bottom mid-span of the bar followed by compression failure at top.

- Standard Deviation - Flexural stress and Stiffness standard deviations were 9.96\% and $8.62 \%$ respectively, which were slightly higher. Hence a set of additional tests were performed on these bars.

\section{ADDITIONAL TESTS}

It was observed from the results in Table 5.2 that the standard deviations were on the higher side $(9.96 \%$ of the avg. stress, $8.62 \%$ of the avg. stiffness results). Hence additional tests on 
the same supports and testing machine were conducted with a few modifications. During the earlier tests, the specimens were observed to move and adjust while the initial $20-30 \%$ of the load was applied. Hence in the additional tests, the specimens were slightly grinded at the load application and support points (this slightly reduced the cross-sectional area of the bar) to prevent them from moving. Also the specimens were manually held in place till $20-30 \%$ of the load had already been applied. Strain gages were also bonded on the tension face at midspan of the specimen to determine the stiffness values from stress-strain plots. The results from the tests are given in Table 5.3.

\section{$\rightarrow$ Test Results}

Table 5.3: Flexure test results for \#4 Ribbed GFRP bars on support Type A (L/D=16) (Additional Tests, WVU Specimens)

\begin{tabular}{|c|c|c|c|c|}
\hline$\#$ & Dia (in) & $\begin{array}{c}\text { Max Stress } \\
(\mathbf{k s i})\end{array}$ & $\begin{array}{c}\text { Stiffness P- } \boldsymbol{\delta} \\
(\mathbf{m s i})\end{array}$ & $\begin{array}{c}\text { Stiffness } \sigma-\varepsilon \\
(\mathbf{m s i})\end{array}$ \\
\hline 6 & 0.5 & 99.39 & 4.61 & 4.73 \\
\hline 7 & 0.5 & 108.54 & 4.89 & 5.04 \\
\hline 8 & 0.5 & 117.18 & 4.81 & 5.19 \\
\hline 9 & 0.5 & 112.76 & 4.68 & 5.04 \\
\hline 10 & 0.5 & 119.6 & 4.97 & 5.5 \\
\hline Average & & $\mathbf{1 1 1 . 4 9}$ & $\mathbf{4 . 7 9}$ & $\mathbf{5 . 1}$ \\
\hline Std Dev & & $\mathbf{7 . 9 8}$ & $\mathbf{0 . 1 5}$ & $\mathbf{0 . 2 8}$ \\
\hline \% & & $\mathbf{7 . 1 6}$ & $\mathbf{3 . 1 3}$ & $\mathbf{5 . 4 9}$ \\
\hline
\end{tabular}

\section{Discussion of Test Results (Additional tests)}

- Average Bending Stress $=111.49 \pm 7.98 \mathrm{ksi}($ Std. dev. was $7.16 \%$ of avg. value $)$

- Average Stiffness $(\mathbf{P}-\delta)=4.79 \pm 0.15 \mathrm{msi}($ Std. dev. was $3.13 \%$ of avg. value) 
- Average Stiffness $(\sigma-\varepsilon)=5.1 \pm 0.28 \mathrm{msi}$ (Std. dev. was $5.49 \%$ of avg. value)

- Failure Mode - The failure mode observed was however the same, i.e., tension failure at bottom mid-span followed by compression failure at top.

- Stress and stiffness - \#4 Ribbed GFRP bars additional test results displayed an average stress of $111.49 \mathrm{ksi}$, which is lower as compared to $127.64 \mathrm{ksi}$ obtained in the earlier tests. This was due to the grinding at the load application point, due to which the effective cross sectional area of the bar was reduced slightly and hence lesser stress values. The average stiffness from load-deflection plots obtained was $4.79 \mathrm{msi}$ as compared to $5.45 \mathrm{msi}$ in the earlier test. Average stiffness obtained from stress-strain plots was $5.1 \mathrm{msi}$.

- Standard Deviation - Standard deviation values for tensile stress were lower as compared to the earlier tests. Flexural stress values show a standard deviation of $7.16 \%$ as compared to $9.98 \%$ in earlier test. The stiffness values from load-deflection plots also show lower standard deviation of $3.13 \%$ as compared to $8.62 \%$ in the earlier test. However, stress-strain plot for stiffness calculation show higher stiffness (5.1 msi as compared to $4.79 \mathrm{msi}$ ) and higher standard deviation (5.49\% as compared to $3.13 \%)$. It should be noted that the load and strain values are noted manually for stress-strain plots.

\section{FLEXURE TESTS ON LONG SPAN $(L / D=40)$}

To test the specimens using support Type A with a higher L/D ratio, a different testing machine supporting a longer base fixture was used. Results obtained are given in Table 5.4. These specimens too were grinded at support and load application locations which resulted in a slight decrease in the effective cross-sectional area of the bar. 
$\rightarrow$ Test Results

Table 5.4: Flexure test results for \#4 Ribbed GFRP bars on support Type A (L/D=40) (WVU Specimens)

\begin{tabular}{|c|c|c|}
\hline$\#$ & Dia (in) & Max Stress (ksi) \\
\hline 1 & 0.5 & 149.4 \\
\hline 2 & 0.5 & 101.85 \\
\hline 3 & 0.5 & 99.85 \\
\hline 4 & 0.5 & 89.66 \\
\hline 5 & 0.5 & 110.04 \\
\hline Average & & $\mathbf{1 1 0 . 1 6}$ \\
\hline Std Dev & & $\mathbf{2 3 . 1 1}$ \\
\hline \% & & $\mathbf{2 0 . 9 8}$ \\
\hline
\end{tabular}

$\rightarrow$ Discussion of Test Results (L/D ratio=40)

- Average Bending Stress $=110.16 \pm 23.11 \mathrm{ksi}$ (Std. dev. was $20.98 \%$ of avg. value)

- Stress - \#4 ribbed GFRP bars tested on support type A with an L/D ratio of 40 showed an average tensile stress of $110.16 \mathrm{ksi}$ as compared to $111.49 \mathrm{ksi}$ with L/D ratio of 16 . Though the average stress results are almost the same, the standard deviations observed in case of $\mathrm{L} / \mathrm{D}$ ratio of 40 is higher $(20.98 \%$ of average as compared to $7.16 \%$ for $\mathrm{L} / \mathrm{D}$ ratio of 16).

- Failure Mode - The failure mode observed was similar to those in tests with L/D ratio of 16, i.e., tension failure at bottom mid-span followed by compression failure at top.

\subsubsection{FLEXURE - GFRP - SAND COATED - \#4 - SUPPORT A}

$\rightarrow$ Test and Specimen Details

- Fiber type - Glass 
- Surface texture - Sand Coated

- Diameter of Bars tested - 0.500” (\#4)

- Flexure test span / total length of specimens - 8" / 9.5" $(\mathrm{L} / \mathrm{D}=16)$

- Number of specimens tested - 13

- Deflections were automatically recorded by the computerized testing machine

- Stiffness values were calculated using load-deflection plots

\section{$\rightarrow$ Test Results}

Table 5.5: Flexure test results for \#4 Sand Coated GFRP bars on support Type A (L/D=16) (WVU Specimens)

\begin{tabular}{|c|c|c|c|}
\hline$\#$ & Dia (in) & Max Stress (ksi) & Stiffness P- $\boldsymbol{\delta}$ (msi) \\
\hline 1 & 0.5 & 70.93 & 4.85 \\
\hline 2 & 0.5 & 95.32 & 5.13 \\
\hline 3 & 0.5 & 83.37 & 5.19 \\
\hline 4 & 0.5 & 67.58 & 4.87 \\
\hline 5 & 0.5 & 83.23 & 4.92 \\
\hline Average & & $\mathbf{8 0 . 0 9}$ & $\mathbf{4 . 9 9}$ \\
\hline Std Dev & & $\mathbf{1 1 . 1}$ & $\mathbf{0 . 1 6}$ \\
\hline \% & & $\mathbf{1 3 . 8 6}$ & $\mathbf{3 . 2 1}$ \\
\hline
\end{tabular}

\section{Discussion of Test Results}

- Average Bending Stress $=80.09 \pm 11.1 \mathrm{ksi}$ (Std. dev. was $13.86 \%$ of avg. value)

- Average Stiffness $=4.99 \pm 0.16 \mathrm{msi}$ (Std. dev. was $3.21 \%$ of avg. value)

- Failure Mode - Tension failure was observed at the bottom mid-span, followed by compression failure at top. The failure was always observed along the helical rib of the bars. 
- Standard Deviation - Avg. stress and stiffness standard deviations were 13.86\% and $3.21 \%$ respectively. Stress values therefore show a variation in excess of $10 \%$. Hence a set of additional tests were performed on these bars similar to the tests performed on ribbed GFRP bars in section 5.3.1.

\section{ADDITIONAL TESTS}

Additional tests, as described in Section 5.3.1, were performed on sand coated GFRP bars. These tests were performed due to the higher standard deviation values $(13.86 \%$ of average flexural tensile stress). The results obtained from the tests are given in Table 5.6.

$\rightarrow$ Test Results

Table 5.6: Flexure test results for \#4 Sand Coated GFRP bars on support Type A (L/D=16) (Additional Tests, WVU Specimens)

\begin{tabular}{|c|c|c|c|c|}
\hline$\#$ & Dia (in) & $\begin{array}{c}\text { Max Stress } \\
\text { (ksi) }\end{array}$ & $\begin{array}{c}\text { Stiffness P- } \boldsymbol{\delta} \\
(\mathbf{m s i})\end{array}$ & $\begin{array}{c}\text { Stiffness } \sigma-\boldsymbol{\varepsilon} \\
(\mathbf{m s i})\end{array}$ \\
\hline 6 & 0.5 & 65.41 & 4.91 & 5.71 \\
\hline 7 & 0.5 & 66.51 & 4.91 & 6.29 \\
\hline 8 & 0.5 & 75.13 & 4.87 & 7.34 \\
\hline Average & & $\mathbf{6 9 . 0 2}$ & $\mathbf{4 . 9}$ & $\mathbf{6 . 4 5}$ \\
\hline Std Dev & & $\mathbf{5 . 3 2}$ & $\mathbf{0 . 0 2}$ & $\mathbf{0 . 8 3}$ \\
\hline \% & & $\mathbf{7 . 7 1}$ & $\mathbf{0 . 4 1}$ & $\mathbf{1 2 . 8 7}$ \\
\hline
\end{tabular}

\section{$\rightarrow$ Discussion of Test Results (Additional Tests)}

- Average Bending Stress $=69.02 \pm 5.32 \mathrm{ksi}($ Std. dev. was $7.71 \%$ of avg. value)

- Average Stiffness $(\mathbf{P}-\delta)=4.9 \pm 0.02 \mathrm{msi}$ (Std. dev. was $0.41 \%$ of avg. value)

- Average Stiffness $(\sigma-\varepsilon)=6.45 \pm 0.83 \mathrm{msi}$ (Std. dev. was $12.87 \%$ of avg. value) 
- Failure Mode - The failure mode observed was however the same, i.e., tension failure at bottom mid-span, followed by compression failure. The failure was always observed along the helical wrap of the bars.

- Stress and stiffness - Additional tests on \#4 Sand Coated GFRP bars gave an average stress of $69.02 \mathrm{ksi}$, which was lower as compared to $80.09 \mathrm{ksi}$ obtained in earlier tests (tests without grinding the specimens). This was due to the grinding at the load application point, due to which the effective cross sectional area of the bar was reduced slightly and hence lesser stress values. Average stiffness from load-deflection plots obtained was $4.9 \mathrm{msi}$ as compared to $4.99 \mathrm{msi}$ in the earlier test. The average stiffness obtained from stress-strain plots is $6.45 \mathrm{msi}$.

- Standard Deviation - The standard deviation values for tensile stress were lower than the earlier tests. Average stress values show a standard deviation of $7.71 \%$ as compared to $13.86 \%$ from earlier tests. The stiffness values from load-deflection plot also show lower standard deviation of $0.41 \%$ as compared to $3.21 \%$. However, stress-strain plot for stiffness calculation show higher stiffness (6.45 msi as compared to $4.9 \mathrm{msi})$ and higher standard deviation ( $12.87 \%$ as compared to $0.41 \%)$. It should be noted that the load and strain values are noted manually for stress-strain plots. Also, values form strain gages are a better local measure of strain without shear deflection effect.

\section{FLEXURE TESTS ON LONG SPAN $(L / D=40)$}

Table 5.7 gives the results of Sand coated GFRP bars tested on L/D ratio of 40 . This test is discussed in Section 5.3.1. 
Table 5.7: Flexure test results for \#4 Sand Coated GFRP bars on support Type A $(\mathrm{L} / \mathrm{D}=40)(\mathrm{WVU}$ Specimens)

\begin{tabular}{|c|c|c|}
\hline$\#$ & Dia (in) & Max Stress (ksi) \\
\hline 1 & 0.5 & 73.34 \\
\hline 2 & 0.5 & 69.26 \\
\hline 3 & 0.5 & 61.07 \\
\hline 4 & 0.5 & 59.14 \\
\hline 5 & 0.5 & 57.1 \\
\hline Average & & $\mathbf{6 3 . 9 8}$ \\
\hline Std Dev & & $\mathbf{6 . 9 8}$ \\
\hline \% & & $\mathbf{1 0 . 9 1}$ \\
\hline
\end{tabular}

\section{$\rightarrow$ Discussion of Test Results $(\mathrm{L} / \mathrm{D}$ ratio $=40)$}

- Average Bending Stress $=63.98 \pm 6.98 \mathrm{ksi}$ (Std. dev. was $10.91 \%$ of avg. value)

- Stress - \#4 sand coated GFRP bars tested on support type A with an L/D ratio of 40 showed an average tensile stress of $63.98 \mathrm{ksi}$ as compared to $69.02 \mathrm{ksi}$ with L/D ratio of 16. Though the average stress results are almost comparable, the standard deviation observed in case of $\mathrm{L} / \mathrm{D}$ ratio of 40 is higher than that from $\mathrm{L} / \mathrm{D}$ of $16(10.91 \%$ of average as compared to $7.71 \%$ for $\mathrm{L} / \mathrm{D}$ ratio of 16$)$.

- Failure Mode - The failure mode observed was similar to that observed in tests with $\mathrm{L} / \mathrm{D}$ ratio of 16 , i.e., tension failure at bottom mid-span, followed by compression failure. The failure was always observed along the helical rib of the bars. 


\subsubsection{FLEXURE - CFRP - RIBBED - \#3 - SUPPORT A}

$\rightarrow$ Test and Specimen Details

- Fiber type - Carbon

- Surface texture - Ribbed

- Diameter of Bars tested - 0.375" (\#3)

- Flexure test span / total length of specimens $-8 " / 9.5 "(\mathrm{~L} / \mathrm{D} \approx 21)$

- Number of specimens tested - 15

- Deflections were automatically recorded by the computerized testing machine

- Stiffness values were calculated using load-deflection plots

\section{Test Results}

Table 5.8: Flexure test results for \#3 Ribbed CFRP bars on support Type A ( $L / D=21)$

(WVU Specimens)

\begin{tabular}{|c|c|c|c|}
\hline$\#$ & Dia (in) & Max Stress (ksi) & Stiffness P- $\delta$ (msi) \\
\hline 1 & 0.375 & 140.21 & 16.49 \\
\hline 2 & 0.375 & 146.67 & 16.3 \\
\hline 3 & 0.375 & 152.97 & 19.16 \\
\hline 4 & 0.375 & 159.27 & 19.03 \\
\hline 5 & 0.375 & 166.54 & 20.47 \\
\hline Average & & $\mathbf{1 5 3 . 1 3}$ & $\mathbf{1 8 . 2 9}$ \\
\hline Std Dev & & $\mathbf{1 0 . 3 2}$ & $\mathbf{1 . 8 2}$ \\
\hline \% & & $\mathbf{6 . 7 4}$ & $\mathbf{9 . 9 5}$ \\
\hline
\end{tabular}

$\rightarrow$ Discussion of Test Results

- Average Bending Stress $=153.13 \pm 10.32 \mathrm{ksi}$ (Std. dev. was $6.74 \%$ of avg. value) 
- Average Stiffness $=18.29 \pm 1.82 \mathrm{msi}$ (Std. dev. was $9.95 \%$ of avg. value)

- Failure Mode - Slight punching was observed at the load application and the support points. The failure initiated with punching in the compression zone followed by tension failure at bottom of the specimen.

- Standard Deviation - Flexural stress and stiffness standard deviations were 6.74\% and $9.95 \%$, respectively. Stiffness values showed higher variation than the stress values. Additional tests were performed on these bars similar to those on ribbed GFRP bars in section 5.3.1.

\section{ADDITIONAL TESTS}

Additional tests, as described in Section 5.3.1, were performed on ribbed GFRP bars. The results obtained from the tests are given in Table 5.9.

\section{Test Results}

Table 5.9: Flexure test results for \#3 Ribbed CFRP bars on support Type A (L/D=21) (Additional Tests, WVU Specimens)

\begin{tabular}{|c|c|c|c|c|}
\hline$\#$ & Dia (in) & $\begin{array}{c}\text { Max Stress } \\
(\mathbf{k s i})\end{array}$ & $\begin{array}{c}\text { Stiffness P- } \delta \\
(\mathbf{m s i})\end{array}$ & $\begin{array}{c}\text { Stiffness } \\
\sigma-\varepsilon(\mathbf{m s i})\end{array}$ \\
\hline 6 & 0.375 & 142.55 & 13.59 & 15.54 \\
\hline 7 & 0.375 & 132.11 & 13.88 & 15.36 \\
\hline 8 & 0.375 & 133.27 & 13.3 & 15.91 \\
\hline 9 & 0.375 & 129.02 & 11.96 & 13.93 \\
\hline 10 & 0.375 & 129.41 & 11.96 & 16.99 \\
\hline Average & & $\mathbf{1 3 3 . 2 7}$ & $\mathbf{1 2 . 9 4}$ & $\mathbf{1 5 . 5 5}$ \\
\hline Std Dev & & $\mathbf{5 . 4 9}$ & $\mathbf{0 . 9 2}$ & $\mathbf{1 . 1}$ \\
\hline \% & & $\mathbf{4 . 1 2}$ & $\mathbf{7 . 1 1}$ & $\mathbf{7 . 0 7}$ \\
\hline
\end{tabular}




\section{$\rightarrow$ Discussion of Test Results (Additional Tests)}

- Average Bending Stress $=133.27 \pm 5.49 \mathrm{ksi}$ (Std. dev. was $4.12 \%$ of avg. value)

- Average Stiffness $(\mathbf{P}-\delta)=12.94 \pm 0.92 \mathrm{msi}$ (Std. dev. was $7.11 \%$ of avg. value)

- Average Stiffness $(\sigma-\varepsilon)=15.55 \pm 1.1 \mathrm{msi}($ Std. dev. was $7.07 \%$ of avg. value)

- Failure Mode - The failure mode observed similar as in earlier case, i.e., the failure initiated with punching in the compression zone followed by tension failure at bottom of the specimen.

- Stress and stiffness-Additional tests on \#3 Ribbed CFRP bars gave an average stress of $133.27 \mathrm{ksi}$, which was lower as compared to $153.13 \mathrm{ksi}$ obtained in the earlier test. This was due to the grinding at the load application point and hence, a reduction in the effective cross-sectional area of the bar. The average stiffness from load-deflection plots obtained was $12.94 \mathrm{msi}$ as compared to $18.29 \mathrm{msi}$ in the earlier test. The average stiffness obtained from stress-strain plots is $15.55 \mathrm{msi}$.

- Standard Deviation - Standard deviation values observed were lower as compared to the earlier tests. Flexural stress values showed a standard deviation of $4.12 \%$ as compared to $6.74 \%$ in earlier test. The stiffness values from load-deflection plot also show lower standard deviation of $7.11 \%$ as compared to $9.95 \%$ in the earlier test.

\section{ADDITIONAL TESTS ON SPECIMENS FROM FAU}

Additional tests, as described in Section 5.3.1, were performed on ribbed GFRP specimens received from Florida Atlantic University. These specimens were similar to the WVU specimens tested in this section. The results obtained from the tests are given in Table 5.10. 
$\rightarrow$ Test Results

Table 5.10: Flexure test results for \#3 Ribbed CFRP bars on support Type A (L/D=21) (FAU Specimens)

\begin{tabular}{|c|c|c|}
\hline$\#$ & Dia (in) & Max Stress (ksi) \\
\hline CR1 & 0.375 & 121.6 \\
\hline CR2 & 0.375 & 119.76 \\
\hline CR3 & 0.375 & 125.17 \\
\hline Average & & $\mathbf{1 2 2 . 1 8}$ \\
\hline Std Dev & & $\mathbf{2 . 7 5}$ \\
\hline \% & & $\mathbf{2 . 2 5}$ \\
\hline
\end{tabular}

\section{$\rightarrow$ Discussion of Test Results (Additional Tests)}

- Average Bending Stress $=122.18 \pm 2.75 \mathrm{ksi}($ Std. dev. was $2.25 \%$ of avg. value $)$

- Failure Mode - The failure mode observed similar as in earlier case, i.e., the failure initiated with punching in the compression zone followed by tension failure at bottom of the specimen.

- The FAU \#3 ribbed CFRP bars additional test results gave an average stress $122.18 \mathrm{ksi}$ as compared to $133.27 \mathrm{ksi}$ of WVU specimens under the same testing conditions. Standard deviation is $2.25 \%$ of the average stress value.

\section{ADDITIONAL TESTS WITH TABS}

Punching at the load application points and support locations was observed in the failure mode observed in the \#3 CFRP bars. Another set of tests with FRP tabs attached at the load application point ( 1 " long) and support locations (1/2" long) were performed. This test was a 
modification of the additional tests described in Section 5.2.2.1. The results obtained from the test are given in Table 5.2.25.

$\rightarrow$ Test Results

Table 5.11: Flexure test results for \#3 Ribbed CFRP bars on support Type A (L/D=21) (Additional Tests with tabs attached, WVU Specimens)

\begin{tabular}{|c|c|c|}
\hline$\#$ & Dia (in) & Max Stress (ksi) \\
\hline CT1 & 0.375 & 186.97 \\
\hline CT2 & 0.375 & 194.69 \\
\hline Average & & $\mathbf{1 9 0 . 8 3}$ \\
\hline Std Dev & & $\mathbf{5 . 4 6}$ \\
\hline \% & & $\mathbf{2 . 8 6}$ \\
\hline
\end{tabular}

\section{$\rightarrow$ Discussion of Test Results (Additional tests with tabs)}

- Average Bending Stress $=190.83 \pm 5.46 \mathrm{ksi}$ (Std. dev. was $2.86 \%$ of avg. value)

- Failure Mode - The addition of the tabs avoided the punching observed in earlier cases. The failure mode observed in this case was tension failure at the bottom.

- \#3 ribbed CFRP bars with tabs gave an average flexural stress of $190.83 \mathrm{ksi}$ as compared to $133.27 \mathrm{ksi}$ observed in case of additional tests of WVU specimens. This was due to the 1" long tab bonded at the load application point on the test specimen. The tab caused the point load to be distributed over a length of 1 " and resulted in a strength increase. 


\subsection{SUMMARY - FLEXURE TESTS ON SUPPORT TYPE A}

Table 5.12: Summary of Flexure test results for FRP bars on support Type A

\begin{tabular}{|l|c|c|c|}
\hline & $\begin{array}{c}\text { Avg. Max. Stress } \\
\text { (ksi) }\end{array}$ & $\begin{array}{c}\text { Stiffness P- } \delta \\
\text { (msi) }\end{array}$ & $\begin{array}{c}\text { Stiffness } \sigma-\varepsilon \\
(\mathbf{m s i})\end{array}$ \\
\hline \#4 Ribbed GFRP (L/D=16) & $\begin{array}{c}127.64 \pm 12.71 \\
(9.96 \%)\end{array}$ & $\begin{array}{c}5.45 \pm 0.47 \\
(8.62 \%)\end{array}$ & - \\
\hline \#4 Ribbed GFRP (L/D=16, & $\begin{array}{c}111.49 \pm 7.98 \\
(7.16 \%)\end{array}$ & $\begin{array}{c}4.79 \pm 0.15 \\
(3.13 \%)\end{array}$ & $\begin{array}{c}5.1 \pm 0.28 \\
(5.49 \%)\end{array}$ \\
\hline Additional tests) & $\begin{array}{c}110.16 \pm 23.11 \\
(20.98 \%)\end{array}$ & - & - \\
\hline \#4 Ribbed GFRP (L/D=40) & $\begin{array}{c}80.09 \pm 11.1 \\
(13.86 \%)\end{array}$ & $\begin{array}{c}4.99 \pm 0.16 \\
(3.21 \%)\end{array}$ & - \\
\hline \#4 Sand Coated GFRP \\
(L/D=16) & $\begin{array}{c}69.02 \pm 5.32 \\
(7.71 \%)\end{array}$ & $\begin{array}{c}4.9 \pm 0.02 \\
(0.41 \%)\end{array}$ & $6.45 \pm 0.83$ \\
\hline \#4 Sand Coated GFRP \\
(L/D=16, Additional tests)
\end{tabular}

(Values in brackets indicate standard deviations as a percentage of the average value)

- Flexural Stress - The "additional tests" were performed by grinding the specimens at the load application point and the support locations to prevent the specimens from sliding along the supports and under load application head. Due to this grinding, the effective cross-sectional area of the bars was reduced. Hence, maximum stress values obtained 
from "additional tests" were lower than those obtained from tests on specimens that were not grinded. Additional tests with tabs (on CFRP bars only) indicated an increase in stress from $133.27 \mathrm{ksi}$ to $190.83 \mathrm{ksi}$. This was due to the 1 " tab at load application point which converted the point load into a uniformly distributed load over 1". Of the two types of glass bars tested (ribbed and sand coated), sand coated bars gave lesser bending strength value as compared to ribbed bars. This was due to the pinching effect along the helical wrap of sand coated bars causing stress concentration along the helical ribs leading to earlier failure of the bars.

- Standard Deviation - Standard deviations observed in "additional tests" were observed to be less than those tested without grinding.

- L/D ratio - The stress results obtained from specimens tested on L/D ratio of 40 are slightly lesser than those obtained from specimens tested on L/D ratio of 16 or 21 . However, the standard deviations observed in tests with $\mathrm{L} / \mathrm{D}=40$ are higher as compared to those observed in "additional tests" with $\mathrm{L} / \mathrm{D}=16$ or 21 .

- Stiffness Methods - Stiffness values obtained from stress-strain plots are higher than the values obtained by load-deflection methods. The maximum variation between these values is as high as $32 \%$ (4.9 msi vs $6.45 \mathrm{msi}$ ) in case of \#4 sand coated GFRP bars. This variation in the stiffness results obtained from load-deflection and stress-strain plots needs to be evaluated with higher number of specimens. 


\subsection{TEST RESULTS - SUPPORT TYPE B}

5.5.1 FLEXURE - GFRP - RIBBED - \#3, \#4 \& \#5 - SUPPORT B

$\rightarrow$ Test and Specimen Details

- Fiber type - Glass

- Surface texture - Ribbed

- Diameters of Bars tested - \#3, \#4 \& \#5

- $\mathrm{L} / \mathrm{D}$ ratio -20

- Number of specimens tested -9

- Deflections were automatically recorded by deflection gage ( 0.0005 " sensitivity)

- Strain gage was bonded at mid-span tension side of each specimen to record strains.

- Stiffness values were calculated using load-deflection and stress-strain plots.

\section{$\rightarrow$ Test Results}

Table 5.13: Flexure test results for \#3 Ribbed GFRP bars on support Type $B(L / D=20)$ (FAU Specimens)

\begin{tabular}{|c|c|c|c|c|}
\hline & Dia & Max Stress & Stiffness & Stiffness \\
\hline$\#$ & (in) & $\mathbf{( k s i )}$ & $\mathbf{( P -} \boldsymbol{\delta}) \mathbf{m s i}$ & $(\boldsymbol{\sigma}-\varepsilon) \mathbf{~ m s i}$ \\
\hline BI1 & 0.375 & 141.6 & 6.189 & 6.083 \\
\hline BI2 & 0.375 & 149.3 & 6.558 & 6.664 \\
\hline BI3 & 0.375 & 145.1 & 7.162 & 6.616 \\
\hline Average & & $\mathbf{1 4 5 . 3 4}$ & $\mathbf{6 . 6 4}$ & $\mathbf{6 . 4 6}$ \\
\hline Std Dev & & $\mathbf{3 . 8 6}$ & $\mathbf{0 . 5}$ & $\mathbf{0 . 3 3}$ \\
\hline \% & & $\mathbf{2 . 7}$ & $\mathbf{7 . 6}$ & $\mathbf{5 . 2}$ \\
\hline
\end{tabular}


Table 5.14: Flexure test results for \#4 Ribbed GFRP bars on support Type B (L/D=20)

(FAU Specimens)

\begin{tabular}{|c|c|c|c|c|}
\hline & Dia & Max Stress & Stiffness & Stiffness \\
\hline$\#$ & (in) & $\mathbf{( k s i )}$ & $\mathbf{( P -} \delta$ ) $\mathbf{~ m s i}$ & $(\sigma-\varepsilon)$ msi \\
\hline BD1 & 0.5 & 135.4 & 6.183 & 6.374 \\
\hline BD2 & 0.5 & 124.1 & 6.127 & 6.8 \\
\hline BD3 & 0.5 & 124.2 & 6.289 & 6.687 \\
\hline Average & & $\mathbf{1 2 7 . 9}$ & $\mathbf{6 . 2}$ & $\mathbf{6 . 6 3}$ \\
\hline Std Dev & & $\mathbf{6 . 5}$ & $\mathbf{0 . 0 9}$ & $\mathbf{0 . 2 3}$ \\
\hline \% & & $\mathbf{5 . 1}$ & $\mathbf{1 . 5}$ & $\mathbf{3 . 5}$ \\
\hline
\end{tabular}

Table 5.15: Flexure test results for \#5 Ribbed GFRP bars on support Type B (L/D=20) (FAU Specimens)

\begin{tabular}{|c|c|c|c|c|}
\hline & Dia & Max Stress & Stiffness & Stiffness \\
\hline$\#$ & (in) & $\mathbf{( k s i )}$ & $\mathbf{( P -} \boldsymbol{\delta}) \mathbf{m s i}$ & $(\boldsymbol{\sigma}-\boldsymbol{\varepsilon}) \mathbf{m s i}$ \\
\hline BB1 & 0.625 & 115.3 & 6.371 & 6.057 \\
\hline BB2 & 0.625 & 117.1 & 6.546 & 6.4 \\
\hline BB3 & 0.625 & 119.2 & 6.578 & 6.561 \\
\hline Average & & $\mathbf{1 1 7 . 2}$ & $\mathbf{6 . 5}$ & $\mathbf{6 . 3 4}$ \\
\hline Std Dev & & $\mathbf{1 . 9 6}$ & $\mathbf{0 . 1 2}$ & $\mathbf{0 . 2 6}$ \\
\hline \% & & $\mathbf{1 . 7}$ & $\mathbf{1 . 9}$ & $\mathbf{4 . 2}$ \\
\hline
\end{tabular}

$\rightarrow$ Discussion of Test Results

- Average Flexural Stress and standard deviations of Ribbed GFRP bars

$\rightarrow$ \#3 bars: $145.34 \pm 3.86 \mathrm{ksi}(\mathrm{Std}$. Dev. was $2.7 \%$ of average)

$\rightarrow$ \#4 bars: $127.9 \pm 6.5 \mathrm{ksi}($ Std. Dev. was $5.1 \%$ of average)

$\rightarrow$ \#5 bars: $117.2 \pm 1.96 \mathrm{ksi}$ (Std. Dev. was $1.7 \%$ of average) 
- Avg. Stiffness of Sand Coated GFRP bars from load-deflection and stress-strain plots

$\rightarrow$ \#3 bars: $\boldsymbol{P}-\delta: 6.64 \pm 0.5 \mathrm{ksi}$ (Std. Dev. was $7.6 \%$ of average)

$$
\sigma-\varepsilon: 6.46 \pm 0.33 \mathrm{ksi}(\mathrm{Std} \text {. Dev. was } 5.2 \% \text { of average) }
$$

$\rightarrow$ \#4bars: $\boldsymbol{P}$ - $\delta: 6.2 \pm 0.09 \mathrm{ksi}($ Std. Dev. was $1.5 \%$ of average)

$$
\sigma-\varepsilon: 6.63 \pm 0.23 \mathrm{ksi}(\mathrm{Std} \text {. Dev. was } 3.5 \% \text { of average) }
$$

$\rightarrow$ \#5bars: $\boldsymbol{P}$ - $\delta: 6.5 \pm 0.12 \mathrm{ksi}($ Std. Dev. was $1.9 \%$ of average)

$$
\sigma-\varepsilon: 6.34 \pm 0.26 \mathrm{ksi}(\mathrm{Std} \text {. Dev. was } 4.2 \% \text { of average) }
$$

- Failure Mode - Slight punching in the compression zone initially followed by tension failure at bottom. The same failure mode was observed in all the specimens.

- Stress and stiffness - The average stress of ribbed GFRP bars reduces with increase in diameter. This is due to increased shear lag in larger diameter bars. The maximum variation in flexural stress of the bars is $24 \%$ (145.34 ksi vs $117.2 \mathrm{ksi})$ between \#3 and \#5 bar diameters. Stiffness values for all the diameters of bars tested, from both loaddeflection and stress-strain plots, display less variations as compared to the variations in stress. The maximum variation in stiffness values is $7.1 \%(6.64 \mathrm{msi}$ vs $6.2 \mathrm{msi})$ when load-deflection plots were used and 4.6\% (6.63 msi vs $6.34 \mathrm{msi})$ when stress-strain plots were used for computations. The maximum variation in stiffness values obtained from load-deflection and stress-strain plots is 7\% (6.63 msi vs $6.2 \mathrm{msi}$ ) for \#4 bars.

- Standard Deviation - The maximum standard deviation for flexural stress among all ribbed GFRP bars tested was 5.1\% percentage of average for \#4 bars. Maximum standard deviation for stiffness among all ribbed GFRP bars tested was 7.6\% percentage of average for \#3 bars. 
5.5.2 FLEXURE - GFRP - SAND COATED - \#3, \#4, \#5 \& \#6 - SUPPORT B

$\rightarrow$ Test and Specimen Details

- Fiber type - Glass

- Surface texture - Sand Coated

- Diameters of Bars tested - \#3, \#4, \#5 \& \#6

- L/D ratio - 20

- Number of specimens tested - 12

- Deflections were automatically recorded by deflection gage ( 0.0005 ” sensitivity)

- A strain gage was bonded at mid-span tension side of each specimen to record strains.

- Stiffness values were calculated using load-deflection and stress-strain plots.

\section{Test Results}

Table 5.16: Flexure test results for \#3 Sand Coated GFRP bars on support Type B (L/D=20) (FAU Specimens)

\begin{tabular}{|c|c|c|c|c|}
\hline & Dia & Max Stress & Stiffness & Stiffness \\
\hline$\#$ & (in) & $\mathbf{( k s i )}$ & $\mathbf{( P - \delta ) ~} \mathbf{m s i}$ & $(\boldsymbol{\sigma}-\boldsymbol{\varepsilon}) \mathbf{m s i}$ \\
\hline BG1 & 0.375 & 105.1 & 5.923 & 6.819 \\
\hline BG2 & 0.375 & 101.1 & 5.389 & 7.069 \\
\hline BG3 & 0.375 & 116.2 & 5.875 & 7.407 \\
\hline Average & & $\mathbf{1 0 7 . 4 7}$ & $\mathbf{5 . 7 3}$ & $\mathbf{7 . 1}$ \\
\hline Std Dev & & $\mathbf{7 . 8 3}$ & $\mathbf{0 . 3}$ & $\mathbf{0 . 3}$ \\
\hline \% & & $\mathbf{7 . 3}$ & $\mathbf{5 . 3}$ & $\mathbf{4 . 3}$ \\
\hline
\end{tabular}


Table 5.17: Flexure test results for \#4 Sand Coated GFRP bars on support Type B $(\mathrm{L} / \mathrm{D}=20)$ (FAU Specimens)

\begin{tabular}{|c|c|c|c|c|}
\hline & Dia & Max Stress & Stiffness & Stiffness \\
\hline$\#$ & (in) & $\mathbf{( k s i )}$ & $\mathbf{( P - \delta ) ~ m s i ~}$ & $(\sigma-\varepsilon)$ msi \\
\hline BE1 & 0.5 & 114.6 & 5.843 & 5.979 \\
\hline BE2 & 0.5 & 112.2 & 6.016 & 6.867 \\
\hline BE3 & 0.5 & 112.8 & 6.279 & 6.346 \\
\hline Average & & $\mathbf{1 1 3 . 2}$ & $\mathbf{6 . 0 5}$ & $\mathbf{6 . 4}$ \\
\hline Std Dev & & $\mathbf{1 . 2 5}$ & $\mathbf{0 . 2 2}$ & $\mathbf{0 . 4 5}$ \\
\hline \% & & $\mathbf{1 . 2}$ & $\mathbf{3 . 7}$ & $\mathbf{7 . 1}$ \\
\hline
\end{tabular}

Table 5.18: Flexure test results for \#5 Sand Coated GFRP bars on support Type B $(\mathrm{L} / \mathrm{D}=20)$ (FAU Specimens)

\begin{tabular}{|c|c|c|c|c|}
\hline & Dia & Max Stress & Stiffness & Stiffness \\
\hline$\#$ & (in) & $\mathbf{( k s i )}$ & $(\mathbf{P}-\delta) \mathbf{~ m s i}$ & $(\sigma-\varepsilon)$ msi \\
\hline BC1 & 0.625 & 110.2 & 5.93 & 6.285 \\
\hline BC2 & 0.625 & 110.5 & 6.155 & 6.296 \\
\hline BC3 & 0.625 & 111.2 & 6.014 & 6.422 \\
\hline Average & & $\mathbf{1 1 0 . 6 4}$ & $\mathbf{6 . 0 4}$ & $\mathbf{6 . 3 4}$ \\
\hline Std Dev & & $\mathbf{0 . 5 2}$ & $\mathbf{0 . 1 2}$ & $\mathbf{0 . 0 8}$ \\
\hline \% & & $\mathbf{0 . 5}$ & $\mathbf{2}$ & $\mathbf{1 . 3}$ \\
\hline
\end{tabular}


Table 5.19: Flexure test results for \#6 Sand Coated GFRP bars on support Type B $(\mathrm{L} / \mathrm{D}=20)$ (FAU Specimens)

\begin{tabular}{|c|c|c|c|c|}
\hline & Dia & Max Stress & Stiffness & Stiffness \\
\hline$\#$ & (in) & $\mathbf{( k s i )}$ & $(\mathbf{P}-\boldsymbol{\delta}) \mathbf{m s i}$ & $(\boldsymbol{\sigma}-\boldsymbol{\varepsilon}) \mathbf{m s i}$ \\
\hline BA1 & 0.75 & 99.6 & 5.521 & 5.704 \\
\hline BA2 & 0.75 & 97.8 & 5.548 & 5.72 \\
\hline BA3 & 0.75 & 97.8 & 5.525 & 6.408 \\
\hline Average & & $\mathbf{9 8 . 4}$ & $\mathbf{5 . 5 4}$ & $\mathbf{5 . 9 5}$ \\
\hline Std Dev & & $\mathbf{1 . 0 4}$ & $\mathbf{0 . 0 2}$ & $\mathbf{0 . 4 1}$ \\
\hline \% & & $\mathbf{1 . 1}$ & $\mathbf{0 . 4}$ & $\mathbf{6 . 9}$ \\
\hline
\end{tabular}

\section{Discussion of Test Results}

- Average Flexural Stress and standard deviations of Sand Coated GFRP bars

$\rightarrow$ \#3 bars: $107.47 \pm 7.83 \mathrm{ksi}(\mathrm{Std}$. Dev. was $7.3 \%$ of average)

$\rightarrow$ \#4bars: $113.2 \pm 1.25 \mathrm{ksi}$ (Std. Dev. was $1.2 \%$ of average)

$\rightarrow$ \#5bars: $110.64 \pm 0.52 \mathrm{ksi}(\mathrm{Std}$. Dev. was $0.5 \%$ of average)

$\rightarrow$ \#6bars: $98.4 \pm 1.04$ ksi (Std. Dev. was 1.1\% of average)

- Avg. Stiffness of Sand Coated GFRP bars from load-deflection and stress-strain plots

$\rightarrow$ \#3 bars: $\boldsymbol{P}$ - $\delta: 5.73 \pm 0.3 \mathrm{msi}(\mathrm{Std}$. Dev. was $5.3 \%$ of average)

$$
\sigma-\varepsilon: 7.1 \pm 0.3 \mathrm{msi}(\mathrm{Std} \text {. Dev. was } 4.3 \% \text { of average) }
$$

$\rightarrow$ \#4bars: $\boldsymbol{P}$ - $\delta: 6.05 \pm 0.22 \mathrm{msi}($ Std. Dev. was $3.7 \%$ of average)

$$
\sigma-\varepsilon: 6.4 \pm 0.45 \mathrm{msi}(\mathrm{Std} \text {. Dev. was } 7.1 \% \text { of average) }
$$

$\rightarrow$ \#5bars: $\boldsymbol{P}$ - $\delta: 6.04 \pm 0.12 \mathrm{msi}($ Std. Dev. was $2 \%$ of average)

$$
\sigma-\varepsilon: 6.34 \pm 0.08 \mathrm{msi}(\text { Std. Dev. was } 1.3 \% \text { of average) }
$$


$\rightarrow$ \#6bars: $\boldsymbol{P}$ - $\delta: 5.54 \pm 0.02 \mathrm{msi}$ (Std. Dev. was $0.4 \%$ of average)

$\sigma-\varepsilon: 5.95 \pm 0.41 \mathrm{msi}$ (Std. Dev. was $6.9 \%$ of average)

- Failure Mode - Tension failure at bottom in all the specimens.

- Stress and stiffness - For sand coated bars there was a reduction of $9.22 \%(107.47 \mathrm{ksi}$ vs $98.4 \mathrm{ksi})$ in stress between $\# 3$ and \#6 bars. However, the intermediate bar diameters (\#4 and \#5) did not show a pattern of continuous stress reduction with increase in diameter as was observed in case of ribbed GFRP bars. The maximum variation in stiffness values is $9.2 \%$ (6.05 msi vs $5.54 \mathrm{msi}$ ) for obtained from load-deflection plots and $19.33 \%$ ( $7.1 \mathrm{msi}$ vs $5.95 \mathrm{msi})$ for values obtained from stress-strain plots. Hence, the variation observed in stiffness values between different diameters of sand coated GFRP bars is high as compared to that of ribbed GFRP bars. The maximum variation in stiffness values obtained from load-deflection and stress-strain plots is $24 \%$ (7.1 msi vs $5.73 \mathrm{msi})$ for \#3 bars.

- Standard Deviation - The maximum standard deviation for flexural stress among all sand coated GFRP bars tested was $7.3 \%$ percentage of average for \#3 bars. Maximum standard deviation for stiffness among all sand coated GFRP bars tested was 7.1\% percentage of average for \#4 bars.

\subsubsection{FLEXURE - CFRP - SAND COATED - \#3 - SUPPORT B}

\section{$\rightarrow$ Test and Specimen Details}

- Fiber type - Carbon

- Surface texture - Sand Coated

- Diameters of Bars tested - \#3 
- $\mathrm{L} / \mathrm{D}$ ratio -20

- Number of specimens tested - 3

- Deflections were automatically recorded by deflection gage $(0.0005$ " sensitivity)

- A strain gage was bonded at mid-span tension side of each specimen to record strains.

- Stiffness values were calculated using load-deflection and stress-strain plots.

\section{Test Results}

Table 5.20: Flexure test results for \#3 Sand Coated CFRP bars on support Type B

$$
(\mathrm{L} / \mathrm{D}=20) \text { (FAU Specimens) }
$$

\begin{tabular}{|c|c|c|c|c|}
\hline & Dia & Max Stress & Stiffness & Stiffness \\
\hline$\#$ & (in) & $\mathbf{( k s i )}$ & $\mathbf{( P -} \delta$ ) $\mathbf{m s i}$ & $(\sigma-\varepsilon)$ msi \\
\hline BF1 & 0.375 & 152.5 & 14.756 & 16.711 \\
\hline BF2 & 0.375 & 145.6 & 14.887 & 18.01 \\
\hline BF3 & 0.375 & 156.1 & 14.808 & 15.82 \\
\hline Average & & $\mathbf{1 5 1 . 4}$ & $\mathbf{1 4 . 8 2}$ & $\mathbf{1 6 . 8 5}$ \\
\hline Std Dev & & $\mathbf{5 . 3 4}$ & $\mathbf{0 . 0 7}$ & $\mathbf{1 . 1 1}$ \\
\hline \% & & $\mathbf{3 . 6}$ & $\mathbf{0 . 5}$ & $\mathbf{6 . 6}$ \\
\hline
\end{tabular}

\section{Discussion of Test Results}

- Avg. flexural stress: $151.4 \pm 5.34 \mathrm{ksi}$ (Std. Dev. was 3.6\% of average)

- Avg. Stiffness (P- $\delta$ ): $14.82 \pm 0.07 \mathrm{msi}$ (Std. Dev. was 0.5\% of average)

- Avg. Stiffness ( $\sigma-\varepsilon): 16.85 \pm 1.11 \mathrm{msi}($ Std. Dev. was $6.6 \%$ of average)

- Failure Mode - Tension failure at bottom in all the specimens.

- Stiffness - Variation in stiffness values obtained from load-deflection and stress-strain plots was $13.7 \%$. 
- Standard Deviation - Standard deviation for flexural stress as a percentage of average was $3.6 \%$ and max std. dev. for stiffness was $6.6 \%$.

\subsubsection{FLEXURE - AFRP - SAND COATED - \#3 - SUPPORT B}

\section{$\rightarrow$ Test and Specimen Details}

- Fiber type - Aramid

- Surface texture - Sand Coated

- Diameters of Bars tested - \#3

- $\mathrm{L} / \mathrm{D}$ ratio -20

- Number of specimens tested -3

- Deflections were automatically recorded by deflection gage ( 0.0005 " sensitivity)

- A strain gage was bonded at mid-span tension side of each specimen to record strains.

- Stiffness values were calculated using load-deflection and stress-strain plots.

\section{$\rightarrow$ Test Results}

Table 5.21: Flexure test results for \#3 Sand Coated AFRP bars on support Type B (L/D=20) (FAU Specimens)

\begin{tabular}{|c|c|c|c|c|}
\hline & Dia & Max Stress & Stiffness & Stiffness \\
\hline$\#$ & $\mathbf{( i n )}$ & $\mathbf{( k s i )}$ & $\mathbf{( P -} \delta \mathbf{~} \mathbf{~ m s i}$ & $(\sigma-\varepsilon) \mathbf{~ m s i}$ \\
\hline BH1 & 0.375 & 105.2 & 8.493 & 8.679 \\
\hline BH2 & 0.375 & 101.3 & 8.553 & 9.725 \\
\hline BH3 & 0.375 & 101.9 & 7.935 & 8.743 \\
\hline Average & & $\mathbf{1 0 2 . 8}$ & $\mathbf{8 . 3 3}$ & $\mathbf{9 . 0 5}$ \\
\hline Std Dev & & $\mathbf{2 . 1 1}$ & $\mathbf{0 . 3 5}$ & $\mathbf{0 . 5 9}$ \\
\hline \% & & $\mathbf{2 . 1}$ & $\mathbf{4 . 3}$ & $\mathbf{6 . 6}$ \\
\hline
\end{tabular}




\section{$\rightarrow$ Discussion of Test Results}

- Avg. flexural stress: $102.8 \pm 2.11 \mathrm{ksi}$ (Std. Dev. was $2.1 \%$ of average)

- Avg. Stiffness (P- $\mathbf{\delta}): 8.33 \pm 0.35 \mathrm{msi}$ (Std. Dev. was 4.3\% of average)

- Avg. Stiffness ( $\sigma-\varepsilon): 9.05 \pm 0.59 \mathrm{msi}$ (Std. Dev. was 6.6\% of average)

- Failure Mode - Tension failure at bottom in all the specimens.

- Stiffness - Variation in stiffness values obtained from load-deflection and stress-strain plots was $8.6 \%$.

- Standard Deviation - Standard deviation for flexural stress as a percentage of average was $2.1 \%$ and max std. dev. for stiffness was $6.6 \%$. 
5.6 SUMMARY AND CONCLUSIONS - FLEXURE TESTS ON SUPPORT TYPE B

Table 5.22: Summary of Flexure test results for FRP bars on support Type $B(L / D=20)$

\begin{tabular}{|c|c|c|c|c|}
\hline & $\begin{array}{l}\text { Avg. Max. } \\
\text { Stress (ksi) }\end{array}$ & $\begin{array}{c}\text { Stiffness P- } \delta \\
\text { (msi) }\end{array}$ & $\begin{array}{l}\text { Stiffness } \sigma-\varepsilon \\
\quad(\mathrm{msi})\end{array}$ & $\begin{array}{l}\text { Stiff } \% \text { diff } \\
\text { P- } \delta \text { v/s } \sigma-\varepsilon\end{array}$ \\
\hline \#3 Ribbed GFRP & $\begin{array}{c}145.34 \pm 3.86 \\
(2.7 \%)\end{array}$ & $\begin{array}{c}6.64 \pm 0.5 \\
\quad(7.6 \%)\end{array}$ & $\begin{array}{c}6.46 \pm 0.33 \\
(5.2 \%)\end{array}$ & $+2.8 \%$ \\
\hline \#4 Ribbed GFRP & $\begin{array}{c}127.9 \pm 6.5 \\
(5.1 \%)\end{array}$ & $\begin{array}{c}6.2 \pm 0.09 \\
(1.5 \%)\end{array}$ & $\begin{array}{c}6.63 \pm 0.23 \\
(3.5 \%)\end{array}$ & $-6.5 \%$ \\
\hline \#5 Ribbed GFRP & $\begin{array}{c}117.2 \pm 1.96 \\
(1.7 \%)\end{array}$ & $\begin{array}{c}6.5 \pm 0.12 \\
(1.9 \%)\end{array}$ & $\begin{array}{c}6.34 \pm 0.26 \\
(4.2 \%)\end{array}$ & $+2.5 \%$ \\
\hline \#3 Sand Coated GFRP & $\begin{array}{c}107.47 \pm 7.83 \\
(7.3 \%)\end{array}$ & $\begin{array}{l}5.73 \pm 0.3 \\
(5.3 \%)\end{array}$ & $\begin{array}{c}7.1 \pm 0.3 \\
(4.3 \%)\end{array}$ & $-19.3 \%$ \\
\hline \#4 Sand Coated GFRP & $\begin{array}{c}113.2 \pm 1.25 \\
(1.2 \%)\end{array}$ & $\begin{array}{c}6.05 \pm 0.22 \\
(3.7 \%)\end{array}$ & $\begin{array}{c}6.4 \pm 0.45 \\
(7.1 \%)\end{array}$ & $-5.5 \%$ \\
\hline \#5 Sand Coated GFRP & $\begin{array}{c}110.64 \pm 0.52 \\
(0.5 \%)\end{array}$ & $\begin{array}{c}6.04 \pm 0.12 \\
(2.0 \%)\end{array}$ & $\begin{array}{c}6.34 \pm 0.08 \\
(1.3 \%)\end{array}$ & $-4.7 \%$ \\
\hline \#6 Sand Coated GFRP & $\begin{array}{c}98.4 \pm 1.04 \\
(1.1 \%)\end{array}$ & $\begin{array}{c}5.54 \pm 0.02 \\
(0.4 \%)\end{array}$ & $\begin{array}{c}5.95 \pm 0.41 \\
(6.9 \%)\end{array}$ & $-6.9 \%$ \\
\hline \#3 Sand Coated CFRP & $\begin{array}{c}151.4 \pm 5.34 \\
(3.6 \%)\end{array}$ & $\begin{array}{c}14.82 \pm 0.07 \\
(0.5 \%)\end{array}$ & $\begin{array}{c}16.85 \pm 1.11 \\
(6.6 \%)\end{array}$ & $-12.04 \%$ \\
\hline \#3 Sand Coated AFRP & $\begin{array}{c}102.8 \pm 2.11 \\
(2.1 \%)\end{array}$ & $\begin{array}{c}8.33 \pm 0.35 \\
(4.3 \%)\end{array}$ & $\begin{array}{c}9.05 \pm 0.59 \\
(6.6 \%)\end{array}$ & $-7.9 \%$ \\
\hline
\end{tabular}

( $\rightarrow$ Values in parenthesis indicate standard deviations as a percentage of the average value)

- Flexural Stress - Of the three types of bars tested (carbon, glass and aramid) in flexure, carbon bars provided a maximum flexural stress of $151.4 \mathrm{ksi}$ (\#3 bars). Aramid bars provided an average flexural stress $102.8 \mathrm{ksi}$ (\#3 bars). GFRP bars provided an average stress range of $145-98$ ksi (\#3-\#6 bars). Of the two types of GFRP bars tested (ribbed and sand coated), ribbed bars gave higher flexural stress values. Ribbed GFRP bars showed reduction in stress with the increase in bar diameter (145 ksi for \#3 to 117 
ksi for \#5). This was due to the shear lag phenomenon. However, in case of sand coated GFRP bars, only \#3 and \#6 bars showed this trend, whereas \#4 and \#5 bars showed higher stresses than \#3 and \#6 bars. This may be due to asymmetrical distribution of the fibers in $\# 4$ and $\# 5$ bars as compared to $\# 3$ and $\# 6$ bars.

- Flexural Stiffness - Of the three types of bars tested in flexure (carbon, glass and aramid), carbon bars provided maximum flexural stiffness of 14.82 with P- $\delta$ method and 16.85 msi with $\sigma-\varepsilon$ method. Aramid bars provided stiffness values of 8.33 with P$\delta$ method and 9.05 msi with $\sigma-\varepsilon$ method. GFRP bars provided the stiffness value range of $5.54-6.64 \mathrm{msi}$ with P- $\delta$ method and $5.95-7.1 \mathrm{msi}$ with $\sigma-\varepsilon$ method. Of the two types of GFRP bars tested (ribbed and sand coated), ribbed bars displayed slightly higher stiffness values. In general, stiffness values obtained from stress-strain plots were higher than the values obtained by load-deflection methods. The maximum variation between these values is as high as $19.3 \%$ in case of \#3 sand coated GFRP bars and $12.04 \%$ in case of \#3 sand coated CFRP bar. For bars with \#4-\#6 diameters this variation was lesser than $7.9 \%$.

- Standard Deviation - The maximum standard deviation for all flexure tests on support Type B was $7.6 \%$. This variation was less when compared to the $20.98 \%$ maximum variation in test results observed from tests on support Type A (Table 5.22, Chapter 5).

- Tensile/Flexure stress comparison - Carbon and aramid FRP bars show lower flexural stresses (151.4 and 102.8 ksi respectively), as compared to tensile stresses (256.31 and $173.67 \mathrm{ksi}$ respectively). In general, higher stresses are expected in tensile values under flexure when compared to pure tension. In line with this trend, ribbed and sand coated glass bars (with \#3-\#6 diameter) show higher flexural stresses (98.4-145.34 
ksi) as compared to their tensile stresses (67.19-86.63 ksi). The combination of tensile and shear stresses under flexural tests of \#3 CFRP and AFRP bars need to be further investigated including additional tests on higher diameter CFRP and AFRP bars.

- Tensile/Flexure stiffness comparison - Carbon bars show lower (4.3\%) flexural stiffness values (16.85 msi) when compared to tensile stiffness (17.6 msi). Aramid bars, however, show higher $(6.3 \%)$ flexural stiffness values $(9.05 \mathrm{msi})$ as compared to their tensile stiffness $(8.51 \mathrm{msi})$. Glass bars show higher (\% increase varies for specific bar) stiffness values $(5.95-7.1 \mathrm{msi})$ when compared to their tensile stiffness $(5.25-6.8 \mathrm{msi})$.

\subsection{TEST METHOD SUMMARY}

- Supports - Two different types of supports - Type A and Type B were used for testing FRP bars in flexure. Tests using Support Type B were finally accepted due to more consistent test results and flexibility of use of the supports. It was noted that support Type B did not cause punching of the specimens at support locations as observed in the case of support Type A.

- L/D ratio - FRP bars were tested in flexure with different L/D ratios (16, 20, 21 and 40). L/D ratio of 20 provided consistent results. This is within ASTM D790M-93 designated limits of $16-40$.

- Bar Diameters - Variable diameters for the same type of bars were tested in flexure to determine the effect of diameter on flexural stresses. It was observed that in general, bars with larger diameters show lower flexural stresses.

- Loading rate - The loading rates were adjusted and determined for flexure tests such that the load application and failure of the specimen was gradual. The loading rate for all 
the flexure tests ranged between 15-70 ksi per minute, such that the failure of the specimen was reached between 30 seconds to 5 minutes. Loading rates were lower for glass bars and higher for carbon bars as carbon bars have higher ultimate tensile strength. Suggested loading rate helps in minimizing stress concentration effects due to quick loading and creep effects due to slow loading.

- Standard Deviations - Lower standard deviation values indicate higher consistency in test results associated with a particular test methodology. Due to lower standard deviations $(<7.6 \%)$ of flexure test results conducted using support Type $\mathrm{B}$, this test methodology can be considered as a standardized flexure test procedure. 


\section{CHAPTER 6}

\section{SHEAR TESTS}

\subsection{INTRODUCTION}

Shear tests were performed on three types of FRP bars - ribbed CFRP, ribbed GFRP, and sand coated GFRP bars. Table 6.1 gives the type and number of bars tested in shear. Shear test procedure adopted and analytical calculations are given in section 6.2. Fig 6.1 shows a photograph and schematic diagrams of the shear test apparatus and the cutting tool used. Two different types of shear tests were performed on the FRP bars - single shear and double shear. Also, two different widths of cutting tools ( 1 " and 1/2" wide) were used to perform the shear tests. Single shear tests were conducted using only 1" wide cutting tool while double shear tests were performed using both 1 " and $1 / 2$ " wide cutting tools. Initial tests performed in single shear using 1" tools showed a higher variation in results (as observed from the test results provided in this Chapter) as compared to double shear tests conducted using 1" wide cutting tool. Further, the double shear tests were performed using the $1 / 2$ " wide cutting tool to minimize bending effects.

Table 6.1: Specimens tested in Shear (45 Specimens)

\begin{tabular}{|c|c|c|c|c|}
\hline $\begin{array}{c}\text { Cutting } \\
\text { Tool Width }\end{array}$ & $\begin{array}{c}\text { Shear Test } \\
\text { Type }\end{array}$ & $\begin{array}{c}\text { Ribbed } \\
\text { CFRP }\end{array}$ & $\begin{array}{c}\text { Ribbed } \\
\text { GFRP }\end{array}$ & $\begin{array}{c}\text { Sand Coated } \\
\text { GFRP }\end{array}$ \\
\hline \multirow{2}{*}{ 1 “ } & Single Shear & 5 & 5 & 5 \\
\cline { 2 - 5 } & Double Shear & 5 & 5 & 5 \\
\hline $1 / 2$ “ & Double Shear & 5 & 5 & 5 \\
\hline
\end{tabular}




\subsection{DEVELOPMENT OF THE TEST}

\subsubsection{Referenced Documents}

Japan Society of Civil Engineers (JSCE) 1997. Recommendation for Design and Construction of Concrete Structures Using Continuous Fiber Reinforced Materials, Concrete Engineering Series 23, Ed. A. Machida, Research Committee on Continuous Fiber Reinforcing Materials, Tokyo, Japan, p. 325

\subsubsection{Terminology}

(a) Test section: The portion of a specimen to be tested between the anchoring sections.

(b) Anchoring section: The end parts of the test specimen where the test specimen is anchored to the shear apparatus.

(c) Shear Apparatus: Apparatus used to conduct the shear test as shown in Fig 6.1.

(d) Anchor Length: The length of the FRP bar anchored to the shear fixture on each end of the bar (One end in case of single shear test)

(e) Cutting tool: The device which is used to transfer the load from the testing machine to the test specimen.

(f) Single Shear Test: In this test only one cross-section of the bar was tested in shear.

(g) Double Shear Test: In this test two cross-sections of the bar was tested in shear.

\subsubsection{Specimen Preparation}

(a) Preparation: Care was taken so that the specimen was not subjected to any processing. During the sampling and preparation of test specimens, all deformation, heating, outdoor 
exposure to ultraviolet light etc., causing changes to the material properties of the test specimen was avoided.

(b) Test section length \& Anchor length: The shear tests were performed with cutting tools with two different widths, 1 " and 1/2". Hence the test section length is 1 " and $1 / 2$ " for respective cases. The remaining length of the bar was anchored (Both ends for Double shear test and one end for single shear test). The total length of the specimen including the anchor lengths for Single and Double shear tests were 4 in and 7in respectively.

(c) Anchorages: Bolts were used to anchor the specimen to the shear fixture to minimize bending effects.

(e) Cutting Tool: Cutting tools of two different widths were used, 1" and 1/2". Fig 6.1(c) shows a schematic representation of the cutting tool.

(f) Number of Specimens: Number of specimens tested five for each test condition.

\subsubsection{Test Equipment and Requirements}

The Shear specimens were tested on a universal testing machine with a miximum load capacity of 22 kips. It had an in-built computerized mechanism to record deflections and loads.

\subsubsection{Test Method}

(a) Shear Apparatus: The shear testing apparatus was be constructed so that a rod-shaped test specimen is sheared on two planes more or less simultaneously by two blades (edges) converging along the faces perpendicular to the axis direction of the test specimen. The 
discrepancy in the axis direction between the upper and lower blades was kept as small as possible.

(b) Mounting: The test specimen was mounted in the center of the shear apparatus, touching the cutting tool such that no gap should was visible between the contact surface of the cutting tool and the test specimen.

(c) Loading Rate: The applied rate of loading for the tension test specimen was between 5-15 ksi per minute.

(d) Testing Temperature: Test temperature was generally within the range of $40-100^{\circ} \mathrm{F}$.

(e) Loading: The load was applied until tensile failure, and the measurements were recorded until the load reaches at least $60 \%$ of the tensile capacity or the guaranteed tensile capacity.

\subsubsection{Calculation}

Shear stress of the specimens was calculated according to Eq. (6.1),

$$
\begin{aligned}
& \tau=\mathrm{P} /(\mathrm{nA}) \\
& \text { Where, } \\
& \tau=\text { shear stress }(\mathrm{ksi}) \\
& P=\text { shear failure load (kips) } \\
& A=\text { cross sectional area of test specimen }\left(\mathrm{in}^{2}\right)-\text { based on manufacturer specified die } \\
& \text { diameter. } \\
& n=1 \text { for single shear test and } 2 \text { for double shear test. }
\end{aligned}
$$




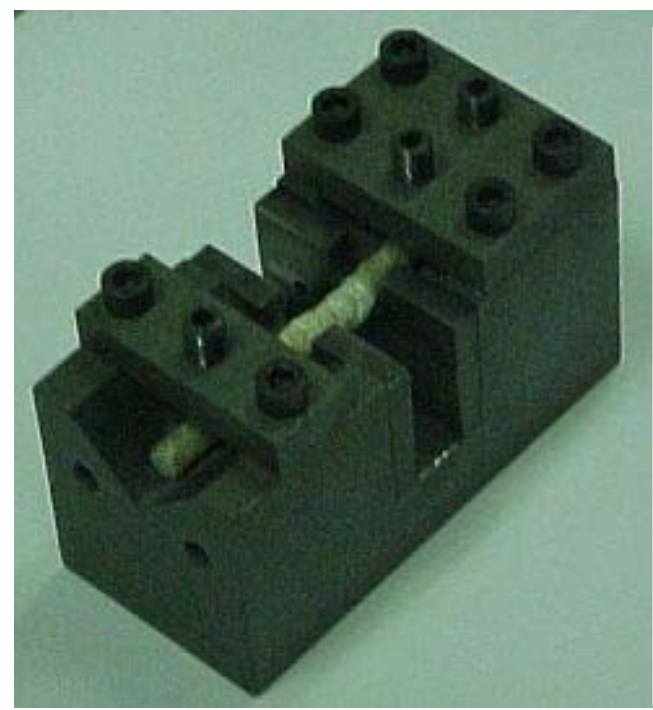

(a)

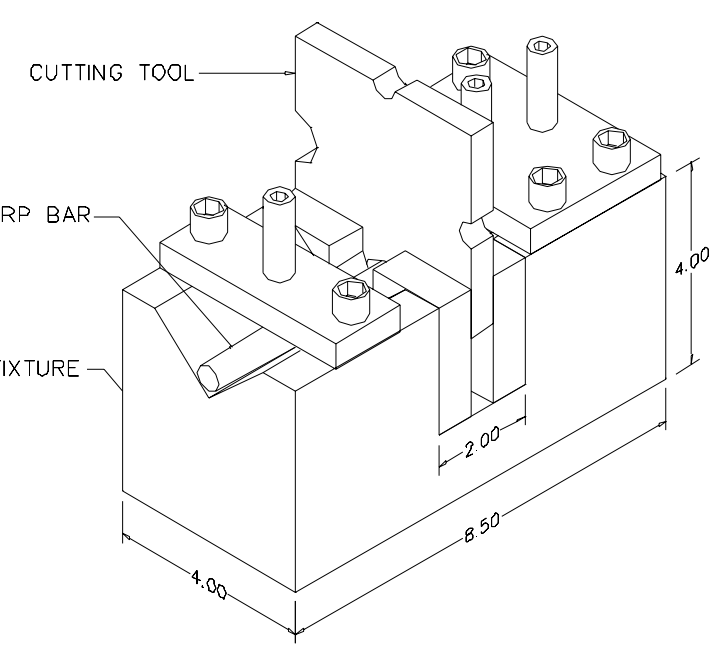

(b)

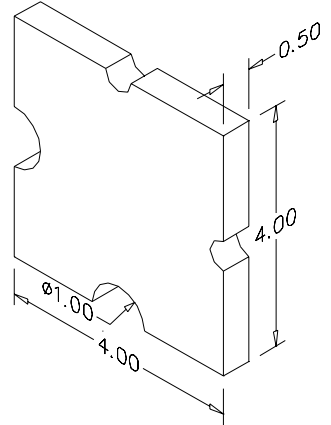

(c)

Fig. 6.1 Shear Testing Apparatus

\subsection{TEST RESULTS - 1" WIDE CUTTING TOOL}

\subsubsection{SHEAR - CFRP - RIBBED - \#3 - 1" WIDE CUTTING TOOL}

$\rightarrow$ Test and Specimen Details

- Fiber type - Carbon

- Surface texture - Ribbed

- Diameter of Bars tested - 0.375" (\#3)

- Length of the specimens - 7.5"

- Cutting tool width - 1 " 
- Number of specimens tested -5

- Specimen was anchored at one end for single shear and both ends for double shear tests.

$\rightarrow$ Test Results

Table 6.2: Single and Double Shear test results for \#3 Ribbed CFRP bars - 1" wide cutting tool (WVU Specimens)

\begin{tabular}{|c|c|c|c|}
\hline$\#$ & Dia (in) & Single Shear Stress (ksi) & Double Shear Stress (ksi) \\
\hline 1 & 0.375 & 24.29 & 36.6 \\
\hline 2 & 0.375 & 32.89 & 39.39 \\
\hline 3 & 0.375 & 29.27 & 39.07 \\
\hline 4 & 0.375 & 34.35 & 42.14 \\
\hline 5 & 0.375 & 25.32 & 39.02 \\
\hline Average & & $\mathbf{2 9 . 2 3}$ & $\mathbf{3 9 . 2 5}$ \\
\hline Std. Dev. & & $\mathbf{4 . 4 6}$ & $\mathbf{1 . 9 7}$ \\
\hline \% & & $\mathbf{1 5 . 2 6}$ & $\mathbf{5 . 0 2}$ \\
\hline
\end{tabular}

\section{Discussion of Test Results}

- Average Single Shear Stress $=29.23 \pm 4.46 \mathrm{ksi}$ (Std. Dev. was $15.26 \%$ of average)

- Average Double Shear Stress = $39.25 \pm 1.97$ ksi (Std. Dev. was 5.02\% of average)

- Failure Mode - All the specimens failed at the shear edge of the cutting tool.

- Standard deviation values were higher in single shear stress $(15.26 \%)$ as compared to $5.02 \%$ of average value in double shear tests.

- Double shear stress was $34.28 \%$ higher than single shear stress. Double shear test results showed higher stress as compared to the single shear test results due to the anchoring methods adopted in the test methods. In single shear the specimen was anchored to the test apparatus at one end and hence behaved more like a cantilever beam 
loaded with a uniformly distributed load spread over 1" (width of the cutting tool) at the free end. In double shear the specimen was anchored at both the ends to the apparatus and hence behaved more like a fixed beam with uniformly distributed load spread over 1" (width of the cutting tool) at the center. A cantilever beam has higher bending moment at the fixed support as compared to a fixed beam under the same loading conditions. Hence bending effects were more in a single shear test. As a result, the shear stress of a bar was lower under single shear than double shear loading.

\subsubsection{SHEAR - GFRP - RIBBED - \#4 - 1" WIDE CUTTING TOOL}

$\rightarrow$ Test and Specimen Details

- Fiber type - Glass

- Surface texture - Ribbed

- Diameter of Bars tested - 0.5" (\#4)

- Length of the specimens - 7.5"

- Cutting tool width - 1"

- Number of specimens tested -5

- Specimen was anchored at one end for single shear and both ends for double shear tests. 
$\rightarrow$ Test Results

Table 6.3: Single and Double Shear test results for \#4 Ribbed GFRP bars - 1" wide cutting tool (WVU Specimens)

\begin{tabular}{|c|c|c|c|}
\hline$\#$ & Dia (in) & Single Shear Stress (ksi) & Double Shear Stress (ksi) \\
\hline 1 & 0.5 & 19.2 & 22.2 \\
\hline 2 & 0.5 & 20.4 & 24.8 \\
\hline 3 & 0.5 & 23 & 22.84 \\
\hline 4 & 0.5 & 19.4 & 22.2 \\
\hline 5 & 0.5 & 13.6 & 25.3 \\
\hline Average & & $\mathbf{1 9 . 1 2}$ & $\mathbf{2 3 . 4 7}$ \\
\hline Std. Dev. & & $\mathbf{3 . 4 4}$ & $\mathbf{1 . 4 8}$ \\
\hline \% & & $\mathbf{1 8}$ & $\mathbf{6 . 3 1}$ \\
\hline
\end{tabular}

\section{$\rightarrow$ Discussion of Test Results}

- Average Single Shear Stress $=19.12 \pm 3.44$ ksi (Std. Dev. was 18\% of average)

- Average Double Shear Stress $=23.47 \pm 1.48$ ksi (Std. Dev. was $6.31 \%$ of average)

- Failure Mode - All the specimens failed at the shear edge of the cutting tool.

- Standard deviation values are higher in single shear stress (18\%) as compared to $6.31 \%$ of average value in double shear tests.

- Double shear stress is $22.75 \%$ higher than single shear stress. Double shear test results show higher stress as compared to the single shear test results due to the anchoring methods adopted in the test methods as described in section 6.3.1. 


\subsubsection{SHEAR - GFRP - SAND COATED - \#4 - 1" WIDE CUTTING TOOL}

$\rightarrow$ Test and Specimen Details

- Fiber type - Glass

- Surface texture - Sand Coated with helical wraps

- Diameter of Bars tested - 0.5" (\#4)

- Length of the specimens - 7.5"

- Cutting tool width $-1 "$

- Number of specimens tested - 5

- Specimen was anchored at one end for single shear and both ends for double shear tests.

$\rightarrow$ Test Results

Table 6.4: Single and Double Shear test results for \#4 Sand Coated GFRP bars - 1" wide cutting tool (WVU Specimens)

\begin{tabular}{|c|c|c|c|}
\hline$\#$ & Dia (in) & Single Shear Stress (ksi) & Double Shear Stress (ksi) \\
\hline 1 & 0.5 & 21.8 & 26.5 \\
\hline 2 & 0.5 & 27.3 & 23.35 \\
\hline 3 & 0.5 & 30.76 & 24.45 \\
\hline 4 & 0.5 & 30.3 & 23.76 \\
\hline 5 & 0.5 & 22.2 & 26.64 \\
\hline Average & & $\mathbf{2 6 . 4 8}$ & $\mathbf{2 4 . 9 4}$ \\
\hline Std. Dev. & & $\mathbf{4 . 3}$ & $\mathbf{1 . 5 4}$ \\
\hline \% & & $\mathbf{1 6 . 2 4}$ & $\mathbf{6 . 1 8}$ \\
\hline
\end{tabular}

$\rightarrow$ Discussion of Test Results

- Average Single Shear Stress $=26.48 \pm 4.3 \mathrm{ksi}$ (Std. Dev. was 16.24\% of average)

- Average Double Shear Stress $=24.94 \pm 1.54$ ksi (Std. Dev. was 6.18\% of average) 
- Failure Mode - All the specimens failed at the shear edge of the cutting tool.

- Standard deviation values are higher in single shear stress (16.24\%) as compared to $6.18 \%$ of average value in double shear tests. Unlike ribbed CFRP and GFRP bars, sand coated GFRP bars show almost the same stress in both single and double shear. However, the standard deviation values are still lower in case of double shear tests.

\section{SINGLE SHEAR TEST v/s DOUBLE SHEAR TEST}

As observed from the results, it was concluded that bending effects played an important role in the test results. Higher bending effect resulted in lower shear stress. Hence, it was decided to reduce the effective bending span for the specimens, i.e., the width of the cutting tool was reduced. The cutting tool was reduced to half its width, i.e. to $1 / 2$ ", and the fixtures were accordingly modified to reduce the effective bending span to $1 / 2$ " as compared to 1 " in earlier tests. Also, it was observed that the standard deviations in single shear tests were higher (more than 16\%) as compared to those obtained for double shear tests (lesser than $6.3 \%$ ). Hence, it was concluded that double shear test is a more consistent method to determine the shear stress of FRP bars. Therefore, only double shear tests were conducted using $1 / 2$ " wide cutting tool.

\subsection{TEST RESULTS - 1/2" WIDE CUTTING TOOL}

\subsubsection{SHEAR - CFRP - RIBBED - \#3 - 1/2" WIDE CUTTING TOOL}

\section{$\rightarrow$ Test and Specimen Details}

- Fiber type - Carbon

- Surface texture - Ribbed 
- Diameter of Bars tested - 0.375" (\#3)

- Length of the specimens - 7.5"

- Cutting tool width $-1 / 2$ "

- Number of specimens tested -5

\section{$\rightarrow$ Test Results}

Table 6.5: Double Shear test results for \#3 Ribbed CFRP bars - 1/2" wide cutting tool (WVU Specimens)

\begin{tabular}{|c|c|c|}
\hline$\#$ & Dia (in) & Double Shear Stress (ksi) \\
\hline 1 & 0.375 & 49.45 \\
\hline 2 & 0.375 & 48.78 \\
\hline 3 & 0.375 & 42.87 \\
\hline 4 & 0.375 & 45.57 \\
\hline 5 & 0.375 & 47.96 \\
\hline Average & & $\mathbf{4 6 . 9 3}$ \\
\hline Std. Dev. & & $\mathbf{2 . 7 1}$ \\
\hline \% & & $\mathbf{5 . 7 8}$ \\
\hline
\end{tabular}

\section{$\rightarrow$ Discussion of Test Results}

- Average Double Shear Stress $=46.93 \pm 2.71 \mathrm{ksi}($ Std. Dev. was $5.78 \%$ of average)

- Failure Mode - All the specimens failed at the shear edge of the cutting tool.

- Standard deviation values are 5.02\% and 5.78\% for double shear results with 1 " and $1 / 2$ " cutting tool.

- Ribbed CFRP bars have an average shear stress of 46.93 ksi in double shear with 1/2" cutting tool as compared to $39.25 \mathrm{ksi}$ in double shear with 1" wide cutting tool, an increase of $19.57 \%$. 


\subsubsection{SHEAR - GFRP - RIBBED - \#4 - 1/2" WIDE CUTTING TOOL}

$\rightarrow$ Test and Specimen Details

- Fiber type - Glass

- Surface texture - Ribbed

- Diameter of Bars tested - 0.5" (\#4)

- Length of the specimens - 7.5"

- Cutting tool width - 1/2"

- Number of specimens tested - 5

$\rightarrow$ Test Results

Table 6.6: Double Shear test results for \#4 Ribbed GFRP bars - 1/2" wide cutting tool (WVU Specimens)

\begin{tabular}{|c|c|c|}
\hline$\#$ & Dia (in) & Double Shear Stress (ksi) \\
\hline 1 & 0.5 & 28.5 \\
\hline 2 & 0.5 & 27.2 \\
\hline 3 & 0.5 & 25.59 \\
\hline 4 & 0.5 & 26.66 \\
\hline 5 & 0.5 & 28.28 \\
\hline Average & & $\mathbf{2 7 . 2 5}$ \\
\hline Std. Dev. & & $\mathbf{1 . 2}$ \\
\hline \% & & $\mathbf{4 . 4 1}$ \\
\hline
\end{tabular}

$\rightarrow$ Discussion of Test Results

- Average Double Shear Stress $=27.25 \pm 1.2 \mathrm{ksi}$ (Std. Dev. was $4.41 \%$ of average)

- Failure Mode - All the specimens failed at the shear edge of the cutting tool. 
- Standard deviation values are $6.31 \%$ and $4.41 \%$ for double shear results with 1 " and $1 / 2$ " cutting tool.

- Ribbed GFRP bars have an average shear stress of $27.25 \mathrm{ksi}$ in double shear with 1/2" cutting tool as compared to $23.47 \mathrm{ksi}$ in double shear with 1" wide cutting tool, an increase of $16.11 \%$.

\subsubsection{SHEAR - GFRP - SAND COATED - \#4 - 1/2" WIDE CUTTING TOOL}

\section{$\rightarrow$ Test and Specimen Details}

- Fiber type - Glass

- Surface texture - Sand Coated with helical wraps

- Diameter of Bars tested - 0.5” (\#4)

- Length of the specimens - 7.5"

- Cutting tool width - 1/2"

- Number of specimens tested - 5

$\rightarrow$ Test Results

Table 6.7: Double Shear test results for \#4 Sand Coated GFRP bars - 1/2" wide cutting tool (WVU Specimens)

\begin{tabular}{|c|c|c|}
\hline$\#$ & Dia (in) & Double Shear Stress (ksi) \\
\hline 1 & 0.5 & 25.79 \\
\hline 2 & 0.5 & 26.14 \\
\hline 3 & 0.5 & 26.64 \\
\hline 4 & 0.5 & 27.57 \\
\hline 5 & 0.5 & 28.79 \\
\hline Average & & $\mathbf{2 6 . 9 9}$ \\
\hline Std. Dev. & & $\mathbf{1 . 2 2}$ \\
\hline \% & & $\mathbf{4 . 5 3}$ \\
\hline
\end{tabular}




\section{$\rightarrow$ Discussion of Test Results}

- Average Double Shear Stress $=26.99 \pm 1.22 \mathrm{ksi}($ Std. Dev. was $4.53 \%$ of average)

- Failure Mode - All of the test specimens failed at the shear edge of the cutting tool.

- Standard deviation values are $6.18 \%$ and $4.53 \%$ for double shear results with 1 " and $1 / 2$ " cutting tool, a reduction of $36.4 \%$.

- Ribbed GFRP bars have an average shear stress of 26.99 ksi in double shear with 1/2" cutting tool as compared to $24.94 \mathrm{ksi}$ in double shear with 1" wide cutting tool, an increase of $8.22 \%$.

\subsection{SUMMARY AND CONCLUSIONS - SHEAR TESTS}

Table 6.8: Summary of shear test results for FRP bars (WVU Specimens)

\begin{tabular}{|l|c|c|c|}
\hline Bar Type & $\begin{array}{c}\text { Single Shear } \\
\text { Stress (ksi) }\end{array}$ & $\begin{array}{c}\text { Double Shear } \\
\text { Stress (ksi) }\end{array}$ & $\begin{array}{c}\text { Double Shear } \\
\text { Stress (ksi) }\end{array}$ \\
\hline (Tool Width) & $\mathbf{1} \boldsymbol{1}$ & $\mathbf{1} \%$ & $\mathbf{1 / 2} \%$ \\
\hline \#3 Ribbed CFRP & $29.23 \pm 4.46$ & $39.25 \pm 1.97$ & $46.93 \pm 2.71$ \\
& $(15.26 \%)$ & $(5.02 \%)$ & $(5.78 \%)$ \\
\hline \#4 Ribbed GFRP & $19.12 \pm 3.44$ & $23.47 \pm 1.48$ & $27.25 \pm 1.2$ \\
& $(18 \%)$ & $(6.31 \%)$ & $(4.41 \%)$ \\
\hline \#4 Sand Coated & $26.48 \pm 4.3$ & $24.94 \pm 1.54$ & $26.99 \pm 1.22$ \\
GFRP & $(16.24 \%)$ & $(6.18 \%)$ & $(4.53 \%)$ \\
\hline
\end{tabular}

(Values in parenthesis indicate standard deviations as a percentage of the average value)

- Cutting Tool Width - The width of the cutting tool constitutes the effective shear cutting region and determines the effective bending span. Higher width of the cutting tool resulted in lower shear stress due to increased bending effects. Two different widths of cutting tool -1 " and $1 / 2$ " were used. The results with $1 / 2$ " cutting tool gave higher and consistent shear stress when compared to those with the use of 1 " wide cutting tool. 
- Single and Double Shear - Single shear results gave lower shear stress (except sand coated GFRP bars) and higher standard deviations as compared to double shear stress results. This was due to the anchor mechanism adopted for each test - anchoring at one end in single shear (similar to a cantilever beam) compared to anchoring at both ends (similar to a fixed beam) for double shear. Due to the anchor mechanisms, bending effects in single shear were more when compared to double shear tests and resulted in lower shear stresses (in single shear).

- Shear Stress - Ribbed CFRP bars showed the maximum shear stress of the three types of bars tested. Ribbed GFRP and sand coated bars showed similar shear stresses in double shear. However, in single shear, sand coated bars showed higher shear stresses as compared to ribbed GFRP bars. There was an increase in shear stress (in double shear) of the bars by $8-20 \%$, when $1 / 2$ " wide cutting tool was used as compared to 1 " wide cutting tool.

- Standard Deviation - Standard deviation values were in the range of $15-18 \%$ for single shear tests, whereas for double shear tests this range was $4.4-6.4 \%$ with both 1 " and $1 / 2$ " wide cutting tools. Hence, it was concluded that double shear tests were comparatively more consistent and accurate of the two shear test methods.

\subsection{TEST METHOD SUMMARY}

- Cutting Tool Width - Two different shearing tool widths - 1" and 1/2" were used for testing FRP bars in shear. Bending response played an important role in the shear strength test data in this research program. Higher bending effect resulted in lower shear strength. Hence it was decided to reduce the effective bending span for the specimens, 
i.e., by reducing the width of the cutting tool. The cutting tool was reduced to half its width, i.e. to $1 / 2 "$, and the fixtures were accordingly modified.

- Single and Double Shear - FRP bars were tested in single (one cross-section in shear) and double (two cross-sections in shear) shear. Due to increased bending effects, single shear tests gave lower shear stress values as compared to double shear stress values. Standard deviations in single shear tests were higher as compared to those obtained from double shear tests. Hence, double shear test is a more consistent method to determine the shear strength of FRP bars.

- Loading Rate - The loading rates were adjusted and determined for shear tests such that the load application and failure of the specimen was gradual. The loading rate for all the shear tests ranged between 5-15 ksi per minute, such that the failure of the specimen was reached between 30 seconds to 5 minutes. Suggested loading rate helps in minimizing stress concentration effects due to quick loading and creep effects due to slow loading.

- Standard Deviations - Lower standard deviation values indicate higher consistency in test results associated with a particular test methodology. Due to lower standard deviations $(<5.78 \%)$, double shear tests with $1 / 2$ " cutting tool can be considered as a standardized shear test procedure. 


\section{CHAPTER 7}

\section{BOND TESTS}

\subsection{INTRODUCTION}

Bond tests were performed on - ribbed CFRP, ribbed GFRP, and sand coated GFRP bars. Table 7.1 gives the types and number of bars tested. Bond test procedure and analytical calculation procedures adopted are given in section 7.2. Fig 7.1 shows test setup for bond tests. A schematic diagram of the test specimen and the cross section of the FRP bar with the concrete cylinder are shown in Fig 7.2. The FRP bars were embedded in a concrete cylinder (8.5 ksi, 12" long and 6" in diameter) for a length of 3.5". A foam tube was applied equally $\left(12-3.5=8.5 ; 8.5 / 2=4.25^{\prime \prime}\right)$ on either side (both at top and bottom) of the length of FRP bar in contact with the concrete. A thin coat of Vaseline ${ }^{\mathrm{TM}}$ was applied on the surface of the bars to reduce friction between the foam tube and the FRP bar over the area which was not in contact with concrete. An LVDT was used to record the slip at the lower end of the bar while load was applied at the end away from the concrete cylinder. The far end was bonded with schedule 80 steel split pipes (8" long) using a commercially available resin, PLIOGRIPTM, similar to the tension test specimens as described in Section 4.2. The total length of the FRP bar including the length inside the cylinder was 42". Figs 7.3 through 7.5 show the stress vs slip for different bars tested.

Table 7.1: Specimens tested in Bond (9 Specimens)

\begin{tabular}{|c|c|c|}
\hline Bar Type & Dia (in) & \# of specimens tested \\
\hline Ribbed CFRP & $0.375(\# 3)$ & 3 \\
\hline Ribbed GFRP & $0.375(\# 3)$ & 3 \\
\hline Sand Coated GFRP & $0.375(\# 3)$ & 3 \\
\hline
\end{tabular}




\subsection{DEVELOPMENT OF THE TEST}

\subsubsection{Referenced Documents}

(a) ASTM Standards:

C234-91a Standard Test Method for Comparing Concrete on the Basis of the Bond Developed with Reinforcing Steel

C293-79 Standard Test Method for Flexural strength of Concrete (Using Simple Beam With Center-Point Loading)

C511-85 Standard Specification for Moist Cabinets, Moist Rooms, and Water Storage Tanks Used in the testing of Hydraulic Cements and Concrete

C 617 - 87 Standard Practice for Capping Cylindrical Concrete Specimens

(b) Japan Society of Civil Engineers (JSCE) 1997. Recommendation for Design and Construction of Concrete Structures Using Continuous Fiber Reinforced Materials, Concrete Engineering Series 23, Ed. A. Machida, Research Committee on Continuous Fiber Reinforcing Materials, Tokyo, Japan, p. 325

\subsubsection{Terminology}

(a) Test section: The portion of a specimen to be tested between the anchoring section on one side and the concrete cylinder on the other side.

(b) Grip length (anchoring section): The end part of the test specimen where an anchorage is fitted to transmit the load from the testing machine to the test section.

(c) Anchorage: Device fitted to the anchoring section of a test specimen to transmit loads from the testing machine to the test specimen.

(d) Embedment Length: The length of the FRP bar embedded in the embedment cylinder. 
(e) Embedment cylinder: The concrete cylinder in which the FRP bar is embedded.

\subsubsection{Specimen Preparation}

(a) Preparation: Care was taken so that the specimen was not subjected to any processing. During the sampling and preparation of test specimens, all deformation, heating, outdoor exposure to ultraviolet light etc., causing changes to the material properties of the test specimen was avoided.

(b) Test section length \& Grip length: A test section length of 22 in was adopted with a grip length of 8in on one end of the bar. The total length of the specimen including the grip lengths was $42 \mathrm{in.}$

(c) Anchorages (Grips): Steel pipes of appropriate diameter and length (as mentioned above) were split and bonded to each end of the FRP rebar using Pliogrip ${ }^{\mathrm{TM}}$, a commercially available resin. The resin was allowed to cure for a minimum of 24 hours, before the specimens were tested.

(d) Embedment Cylinder: The FRP bar was cast, embedded in a concrete cylinder 12" in length and 6" in diameter.

(e) Embedment length and Debonding Element: An embedment length of 3.5 in was adopted. The remaining length of the FRP bar was debonded from the concrete using foam tubes between the bar and the concrete.

(f) Number of Specimens: Number of specimens tested was three in each group. 


\subsubsection{Test Equipment}

The specimens were tested on a universal testing machine with a maximum load capacity of 200 kips. A computerized data acquisition system was used to automatically log in the data for analysis.

\subsubsection{Test Method}

(a) Mounting: When mounting the test specimen on the testing machine, care was taken to ensure that the longer axis of the test specimen coincides with the imaginary line joining the two end anchors fitted to the testing machine.

(b) Loading Rate: The applied rate of loading for the tension test specimen was between 250750 psi per minute.

(c) Testing Temperature: Test temperature was generally within the range of $40-100^{\circ} \mathrm{F}$.

(d) Loading: The load was applied until tensile failure, and the measurements were recorded until the load reaches at least $60 \%$ of the tensile capacity or the guaranteed tensile capacity.

\subsubsection{Calculation}

The material properties of FRP bar were assessed only on the basis of the test specimen undergoing failure in the test section. In cases where there was tensile failure or slippage in anchoring section, the data was disregarded and additional tests were performed.

(a) Bond Stress, $\sigma$ : The bond stress was calculated according to Eq. (7.1),

$\sigma=\mathrm{F} / \mathrm{S}$

Where,

$$
\sigma=\text { Bond stress }(\mathrm{Ksi})
$$


$\mathrm{F}=$ Load at which bond failure occurs (Kips)

$\mathrm{S}=$ The surface area of the FRP bar in contact with the concrete calculated from Eq. (7.2) $\left(\right.$ in $\left.^{2}\right)$

(b) Contact Surface Area, S: The contact surface area was calculated as below,

$\mathrm{S}=\pi \mathrm{d}_{\mathrm{x}} \cdot \mathrm{l}_{\mathrm{x}}$

Where,

$\mathrm{S}=$ Contact surface area $\left(\mathrm{in}^{2}\right)$

$d_{x}=$ manufacturer specified die diameter of the FRP bar (in)

$1_{\mathrm{x}}=$ Length of embedment (in)

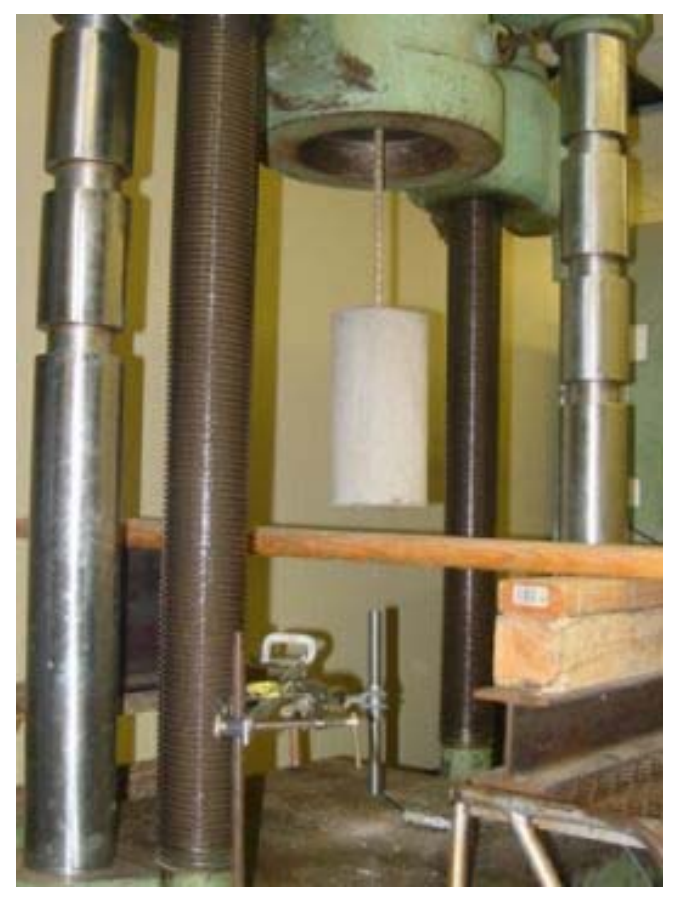

Fig 7.1: Bond test apparatus 


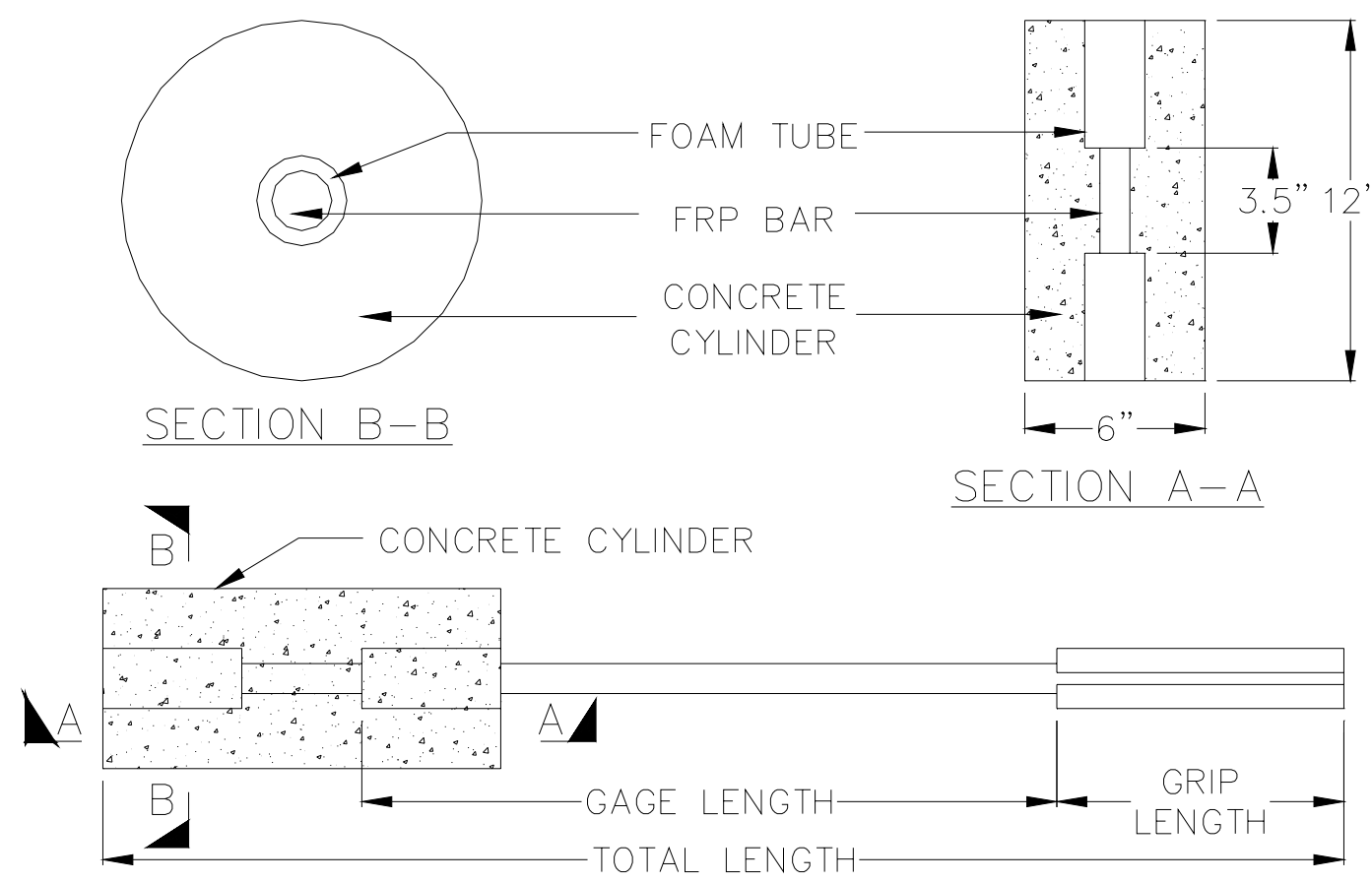

Fig 7.2: Schematic diagram of the bond test test setup

\subsection{TEST RESULTS}

\subsubsection{BOND - CFRP - RIBBED - \#3}

$\rightarrow$ Test and Specimen Details

- Fiber type-Carbon

- Surface texture - Ribbed

- Diameter of Bars tested - 0.375” (\#3)

- Total length of the specimens -42 "

- Length of FRP bar embedded in concrete - 3.5"

- Concrete Cylinder strength and dimensions - 8.5 ksi, 12" long and 6" diameter

- Number of specimens tested - 3

- Slip at the lower end of the bars recorded using an LVDT. 
$\rightarrow$ Test Results

Table 7.2: Bond test results for \#3 Ribbed CFRP bars (WVU Specimens)

\begin{tabular}{|c|c|c|c|c|}
\hline$\#$ & Dia (in) & Max Load (lbs) & Bond Stress (psi) & Failure \\
\hline 1 & 0.375 & 7503 & 1819 & Bar Slip \\
\hline 2 & 0.375 & 7614 & 1846 & Bar Slip \\
\hline 3 & 0.375 & 7582 & 1839 & Bar Slip \\
\hline Average & & $\mathbf{7 5 6 6}$ & $\mathbf{1 8 3 4}$ & \\
\hline Std dev & & $\mathbf{5 7 . 2}$ & $\mathbf{1 4 . 0 2}$ & \\
\hline \% & & $\mathbf{0 . 7 6}$ & $\mathbf{0 . 7 7}$ & \\
\hline
\end{tabular}

\section{$\rightarrow$ Discussion of Test Results}

- Average Bond Stress $=1834 \pm 14.02$ psi (Std. Dev. was $0.77 \%$ of average)

- Failure Mode - All the specimens failed due to bar slip inside concrete. Before failure, there was continuous slippage of the bar inside the concrete cylinder. The ribs on the surface served as resistance to slip. The max slip measured was 0.075 ".

\subsubsection{BOND - GFRP - RIBBED - \#4}

\section{$\rightarrow$ Test and Specimen Details}

- Fiber type - Glass

- Surface texture - Ribbed

- Diameter of Bars tested - 0.500” (\#4)

- Total length of the specimens - 42"

- Length of FRP bar embedded in concrete - 3.5"

- Concrete Cylinder strength and dimensions - 8.5 ksi, 12" long and 6" diameter

- Number of specimens tested - 3

- Slip at the lower end of the bars recorded using an LVDT. 
$\rightarrow$ Test Results

Table 7.3: Bond test results for \#4 Ribbed GFRP bars (WVU Specimens)

\begin{tabular}{|c|c|c|c|c|}
\hline$\#$ & Dia (in) & Max Load (lbs) & Bond Stress (psi) & Failure \\
\hline 1 & 0.5 & 9647 & 1754 & Bar Slip \\
\hline 2 & 0.5 & 9096 & 1654 & Bar Slip \\
\hline 3 & 0.5 & 9512 & 1730 & Bar Slip \\
\hline Average & & $\mathbf{9 4 1 8}$ & $\mathbf{1 7 1 2}$ & \\
\hline Std dev & & $\mathbf{2 8 7 . 2}$ & $\mathbf{5 2 . 2}$ & \\
\hline \% & & $\mathbf{3 . 0 5}$ & $\mathbf{3 . 0 5}$ & \\
\hline
\end{tabular}

\section{$\rightarrow$ Discussion of Test Results}

- Average Bond Stress $=1712 \pm 52.2$ psi (Std. Dev. was $3.05 \%$ of average)

- Failure Mode - All the specimens failed due to bar slip inside concrete. Before failure, there was continuous slippage of the bar inside the concrete cylinder. The ribs on the surface served as resistance to slip. The max slip measured was 0.068 ".

\subsubsection{BOND - GFRP - SAND COATED - \#4}

\section{$\rightarrow$ Test and Specimen Details}

- Fiber type - Glass

- Surface texture - Sand Coated with helical wraps.

- Diameter of Bars tested - 0.500” (\#4)

- Total length of the specimens - 42"

- Length of FRP bar embedded in concrete - 3.5"

- Concrete Cylinder strength and dimensions - 8.5 ksi, 12" long and 6" diameter

- Number of specimens tested - 3

- Slip at the lower end of the bars recorded using an LVDT. 
$\rightarrow$ Test Results

Table 7.4: Bond test results for \#4 Sand Coated GFRP bars (WVU Specimens)

\begin{tabular}{|c|c|c|c|c|}
\hline$\#$ & Dia (in) & Max Load (lbs) & Bond Stress (psi) & Failure \\
\hline $\mathbf{1}$ & 0.5 & 16331 & 2970 & Cylinder split \\
\hline $\mathbf{2}$ & 0.5 & 11066 & 2013 & Bar Slip \\
\hline $\mathbf{3}$ & 0.5 & 9774 & 1777 & Bar Slip \\
\hline Average & & $\mathbf{1 0 4 2 0}$ & $\mathbf{1 8 9 5}$ & \\
\hline Std dev & & $\mathbf{9 1 3 . 5}$ & $\mathbf{1 6 6}$ & \\
\hline \% & & $\mathbf{8 . 7 7}$ & $\mathbf{8 . 7 6}$ & \\
\hline
\end{tabular}

(Specimen \#1 not used to calculate average or std. dev. as failure occurred due to splitting of cylinder)

\section{$\rightarrow$ Discussion of Test Results}

- Average Bond Stress $=1895 \pm 166$ psi (Std. Dev. was $8.76 \%$ of average)

- Failure Mode - All the specimens failed due to bar slip inside concrete. The max slip measured was 0.084 " before failure.

\subsection{SUMMARY AND CONCLUSIONS - BOND TESTS ON FRP BARS.}

Table 7.5: Summary of bond test results on FRP bars (WVU Specimens)

\begin{tabular}{|l|c|}
\hline \multicolumn{1}{|c|}{ Bar Type } & Bond Stress (psi) \\
\hline \#3 Ribbed CFRP & $1834 \pm 14.02(0.77 \%)$ \\
\hline \#4 Ribbed GFRP & $1712 \pm 52.2(3.05 \%)$ \\
\hline \#4 Sand Coated GFRP & $1895 \pm 166(8.76 \%)$ \\
\hline
\end{tabular}

(Values in parenthesis indicate standard deviations as a percentage of the average value)

- Bond Stress - Sand coated GFRP bars had the maximum bond stress (1.895 ksi) among the three types of bars tested. The ribbed CFRP (1.834 ksi) and GFRP (1.712 ksi) bars show comparatively lower bond stress. 
- Standard Deviation - Though the sand coated bars displayed the maximum bond stress, the standard deviation was $8.76 \%$. Ribbed CFRP bars had the least standard deviation of $0.77 \%$, followed by ribbed GFRP bars with a standard deviation of 3.05\%.

- Failure Mode and Bar Slip- All bond test samples failed due to slipping of the FRP bar inside the concrete cylinder, except for one sample where the failure was observed due to splitting of the concrete cylinder. The maximum bar slip inside the concrete recorded was observed to range from 0.068 to 0.084 inches. Slip at the unloaded end of the bars at different stress levels are given in Table 7.6. Comparison of slips for varying surface texture and fiber type of the bars is plotted in Fig. 7.3 and 7.4 respectively. It was observed that bars with ribbed surface had more slip (maximum of 52.59\%, 33.94\% and $11.84 \%$ for load ranges $0-500,500-1000$ and $1000-1500 \mathrm{lbs}$ respectively) inside the concrete cylinder as compared to bars with sand coated surface. Comparing bars with carbon and glass fibers, it was observed that ribbed GFRP bars give more slip (maximum of $14.52 \%, 35.12 \%$ and $36.97 \%$ for load ranges $0-500,500-1000$ and $1000-1500 \mathrm{lbs}$ respectively) as compared to ribbed CFRP bars.

Table 7.6: Bar slip inside concrete cylinders for various FRP bars.

\begin{tabular}{|c|c|c|c|c|c|}
\hline \multirow{2}{*}{$\begin{array}{c}\text { Stress } \\
\text { (psi) }\end{array}$} & \multicolumn{3}{|c|}{ Slip x $10^{-3}$ (in) } & \multirow{2}{*}{$\begin{array}{c}\text { \% less slip } \\
\text { of S-GFRP } \\
\text { wrt R-GFRP }\end{array}$} & \multirow{2}{*}{$\begin{array}{l}\text { \% more slip } \\
\text { of R-GFRP } \\
\text { wrt R-CFRP }\end{array}$} \\
\hline & S-GFRP & R-GFRP & R-CFRP & & \\
\hline 0 & 0 & 0 & 0 & - & - \\
\hline 250 & 7.14 & 15.06 & 13.15 & 52.59 & 14.52 \\
\hline 500 & 15.1 & 22.58 & 23.9 & 33.13 & -5.52 \\
\hline 750 & 22.7 & 34.36 & 27.03 & 33.94 & 27.12 \\
\hline 1000 & 36.87 & 43.82 & 32.43 & 15.87 & 35.12 \\
\hline 1250 & 50.19 & 53.28 & 38.9 & 5.8 & 36.97 \\
\hline 1500 & 53.28 & 60.43 & 50.21 & 11.84 & 20.35 \\
\hline 1700 & 59.08 & 67.76 & 71.07 & 12.81 & -4.65 \\
\hline
\end{tabular}

(S-GFRP: Sand Coated GFRP; R-GFRP: Ribbed GFRP; R-CFRP: Ribbed CFRP; wrt: with respect to) 


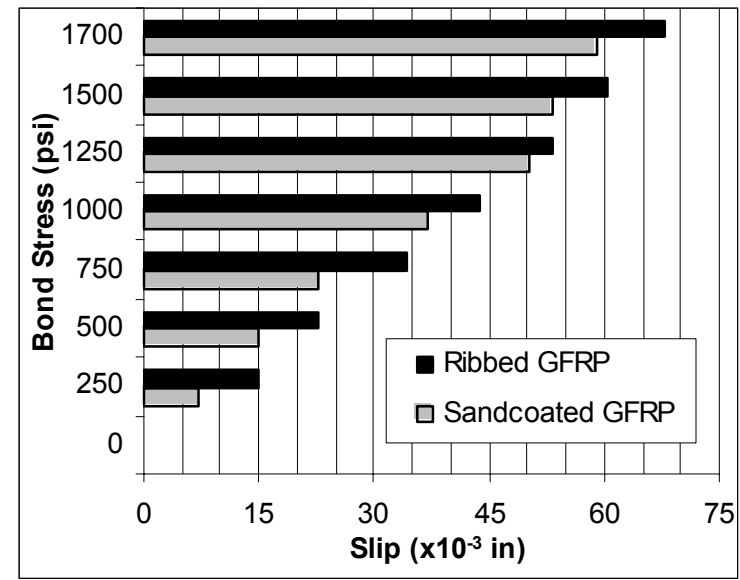

Fig 7.3: Bond Stress-slip plots for varying surface textures (Sand Coated and Ribbed)

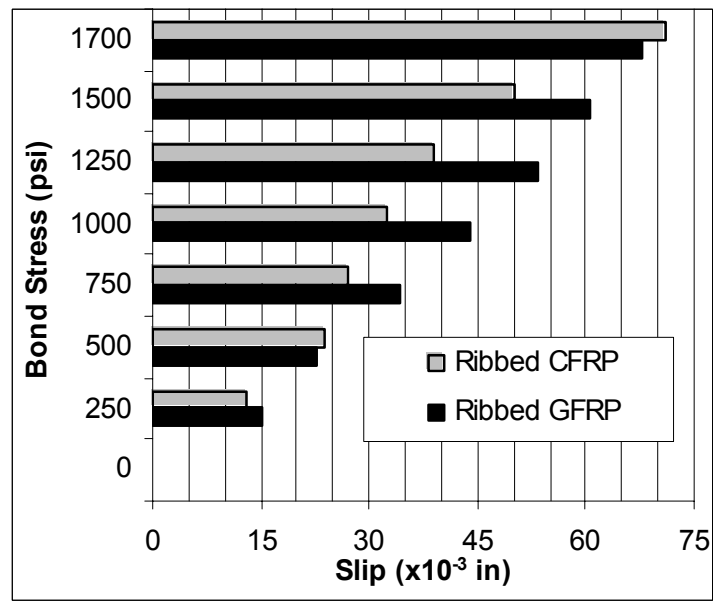

Fig 7.4: Bond Stress-slip plots for varying fiber type (Carbon and glass)

\subsection{TEST METHOD SUMMARY}

- Embedment of Bars in Concrete - FRP bars were embedded in the concrete cylinders for a length of 3.5 " by bonding foam tubes equally on either sides of the remaining length of the bar not in contact with concrete. Before bonding the foam tubes the non bonded zone of the bar surface was applied with a thin coat of Vaseline ${ }^{\mathrm{TM}}$ to minimize friction with foam and any type of bonding with concrete. The embedment length of 3.5 " was chosen because, with a higher embedment length there is a possibility of tension failure of the FRP bar before bond failure. 
- Loading Rate - The loading rate for all the bond tests ranged between 250-750 psi per minute, such that the failure was reached between 30 seconds to 5 minutes. Suggested loading rate helps in minimizing stress concentration effects due to quick loading and creep effects due to slow loading.

- Standard Deviations - Lower standard deviation values indicate higher consistency in test results associated with a particular test methodology. Due to lower standard deviations $(<8.76 \%)$, this test methodology can be considered as a standardized bond test procedure.

- Standard Deviations - Standard deviations for bond tests were evaluated to ascertain the consistency of the test results. Due to low standard deviations this test can be standardized for conducting shear tests. 


\section{CHAPTER 8}

\section{LONG TERM TESTS}

\subsection{INTRODUCTION}

The tests performed on aged specimens are termed as long-term tests. Long-term tests were categorized into two different types of tests,

(a) Moisture absorption,

(b) Flexure tests on aged specimens immersed in

(i) water at room temperature

(ii) salt water subjected to room temperature

(iii) water subjected to freeze-thaw temperature

(iv) salt water subjected to freeze-thaw temperature

\subsection{MOISTURE ABSORPTION}

Moisture tests were conducted on three types of FRP bars - ribbed CFRP, ribbed GFRP, and sand coated GFRP bars. The tests were conducted at room temperature. The test specimen preparation is described in Section 8.2.1. Table 8.1 gives the type and number of specimens of different types of bars tested. The specimens were immersed in distilled water and their weights were monitored at regular intervals for a period of 298 days. Fig 8.2 shows the weight against moisture immersion duration plot for the different bars tested. Table 8.2 shows the initial and final weight and the percentage gain in the weight of the specimens tested. 
Table 8.1 FRP bars tested for moisture absorption (27 Specimens)

\begin{tabular}{|c|c|c|}
\hline Bar Type & Dia (in) & $\begin{array}{c}\text { \# of } \\
\text { specimens }\end{array}$ \\
\hline Ribbed CFRP & 0.375 & 9 \\
\hline Ribbed GFRP & 0.500 & 9 \\
\hline Sand Coated GFRP & 0.500 & 9 \\
\hline
\end{tabular}

\subsubsection{Specimen Preparation and Test Method.}

Two-inch long specimens were cut and sealed at the ends with a thin coat of epoxy to avoid penetration of water during the aging process. The specimens were then immersed in distilled water. The initial weight of the specimens before immersion was recorded for reference. The weight of the specimens was then monitored at regular intervals over a period of 298 days. Gain in weights of the specimens was recorded and the percentage absorption was calculated.

\subsubsection{Calculation}

The percentage gain in moisture absorption was calculated using Eq. (4.2.1),

$$
\mathrm{g}=\left[\left(\mathrm{W}_{\mathrm{d}}-\mathrm{W}\right) / \mathrm{W}\right] \times 100
$$

Where,

$\mathrm{g}=$ percentage gain in moisture,

$\mathrm{W}_{\mathrm{d}}=$ Weight of the specimens after $\mathrm{d}$ days

$\mathrm{W}=$ Weight of the specimens before immersion in water 


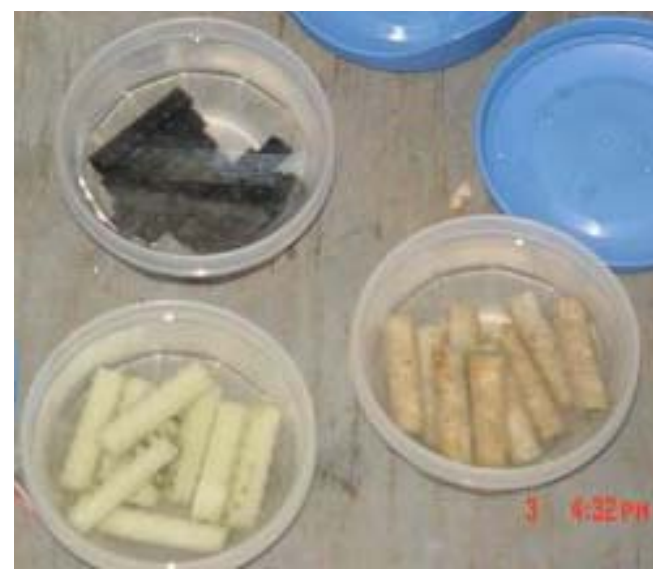

Fig 8.1: Ribbed CFRP, Ribbed GFRP and Sand Coated GFRP bars immersed in distilled water

\subsection{TEST RESULTS - MOISTURE ABSORPTION}

Table 8.2 Weights in grams (sum of 9 specimens) of bars for moisture absorption

\begin{tabular}{|l|c|c|l|}
\hline \multicolumn{1}{|c|}{ Date } & $\mathbf{7 / 1 7 / 2 0 0 1}$ & $\mathbf{5 / 1 6 / 2 0 0 2}$ & \%gain \\
\hline Days & 0 & 298 & \\
\hline \#3 Ribbed CFRP & 57.8101 & 58.0062 & 0.338067 \\
\hline \#4 Ribbed GFRP & 128.7425 & 128.9986 & 0.198529 \\
\hline \#4 Sand Coated GFRP & 112.9126 & 113.2054 & 0.258645 \\
\hline
\end{tabular}

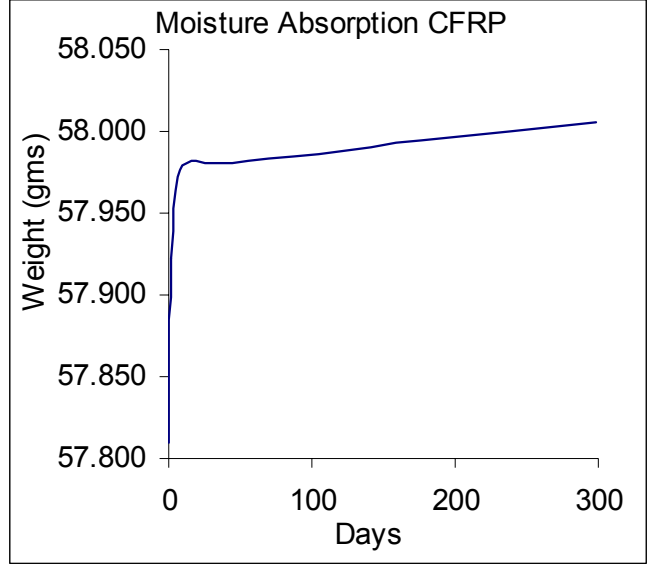

(a)

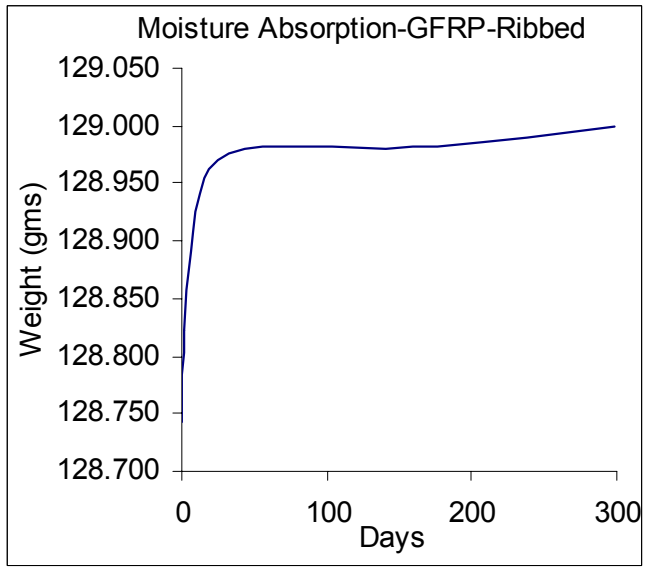

(b) 


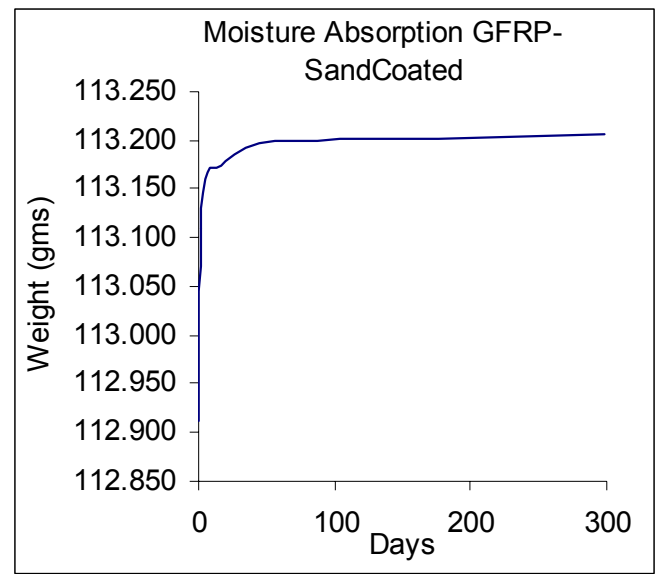

(c)

Fig 8.2 Weight plots of (a) ribbed CFRP (b) ribbed GFRP and (c) sand coated GFRP bars over 298 days

\section{$\rightarrow$ Discussion of Test Results}

- It was observed that the maximum moisture absorption in FRP bars was $0.34 \%$ for CFRP bars and the minimum was $0.2 \%$ for the ribbed GFRP bars over a period of 298 days. It was also observed that the major portion of absorption occurred during the first week. The absorption reduced after this period coming down to almost a stable state of no absorption after a month as also evident from the plots in Fig 8.2. The absorption behavior will change at higher temperatures or under stress, particularly, when matrix cracking occurs.

\subsection{FLEXURE TESTS ON AGED SPECIMENS}

Three-point bending tests were conducted on FRP bars aged for a period over four years. The test procedure and analytical calculations adopted are given in Section 4.2. These flexure tests were performed on support Type B as described in Chapter 4. Deflections were recorded, using a 0.0001 " precision dial gage, at the center span of the bar to calculate the stiffness using load-deflection plots. Fig. 8.3 gives a schematic diagram of support Type B used for testing. Fig 8.4 gives the test setup. Bars tested in this group were ribbed GFRP bars 
and sand coated GFRP with helical ribs. Table 8.3 gives a list of the specimens tested in flexure.

\section{AGING OF BARS}

The FRP bars were immersed in water and 3\% salt solutions under room temperature and freeze-thaw temperature conditions for over four years. Unaged bars from the same manufacturer and of the same make were also tested to compare the results obtained.

Table 8.3: Aged Specimens tested in Flexure (50 Specimens)

\begin{tabular}{|l|c|c|}
\hline \multicolumn{1}{|c|}{ Aging Condition } & $\begin{array}{c}\text { \#4 Ribbed } \\
\text { GFRP bar }\end{array}$ & $\begin{array}{c}\text { \#4 Sand coated } \\
\text { GFRP bar }\end{array}$ \\
\hline Unaged & 5 & 5 \\
\hline Water - Room Temp & 5 & 5 \\
\hline 3\% Salt soln. - Room Temp & 5 & 5 \\
\hline Water - Freeze-Thaw Temp & 5 & 5 \\
\hline 3\% Salt soln. - Freeze-Thaw Temp & 5 & 5 \\
\hline
\end{tabular}

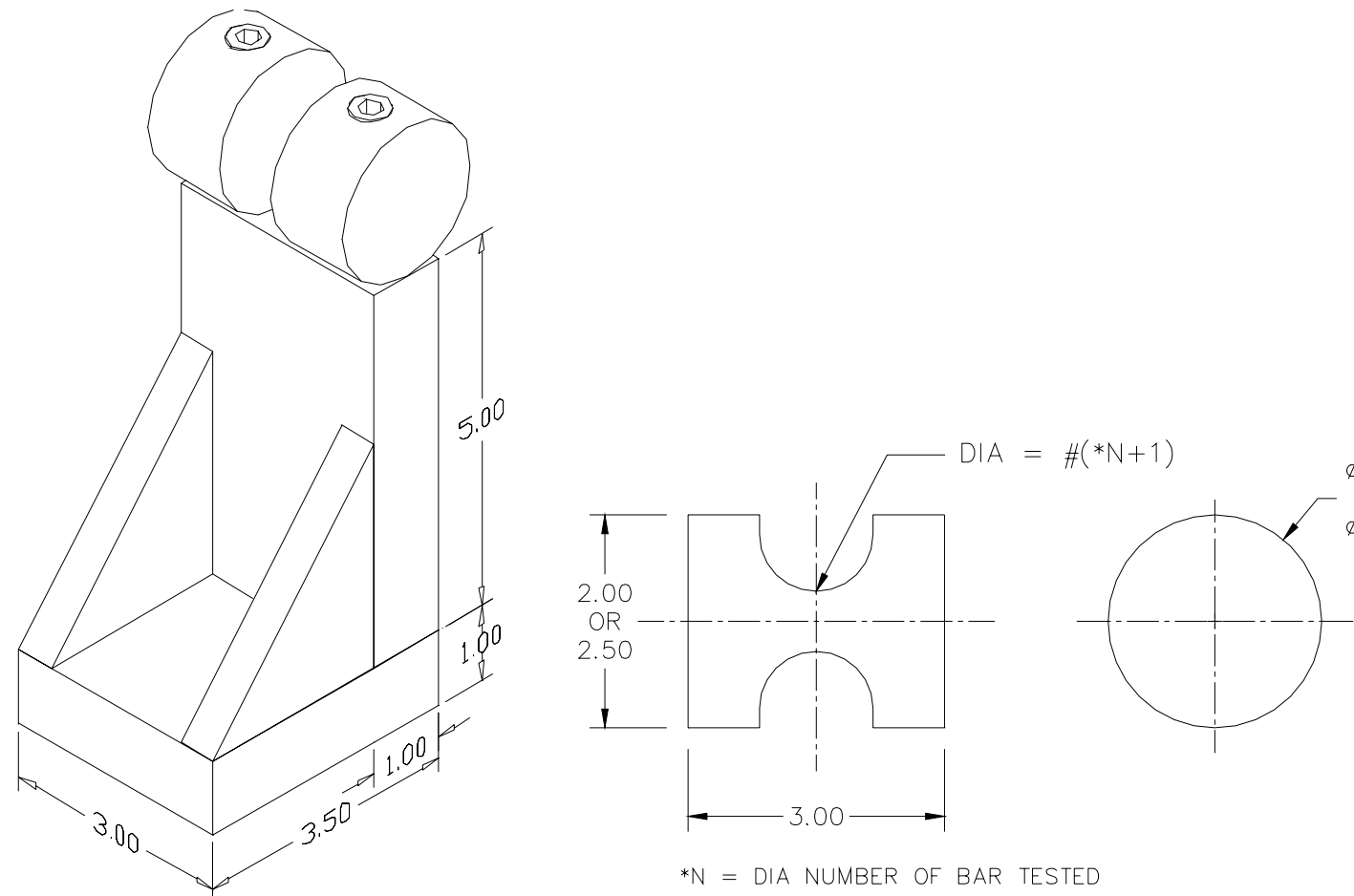

Fig 8.3: Schematic Diagram of supports used for flexure 


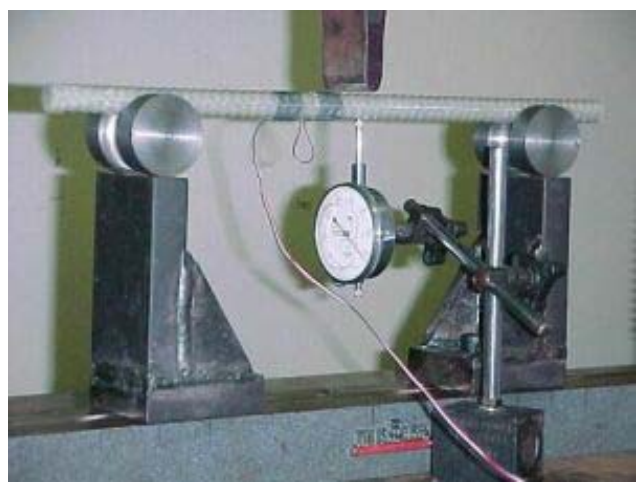

Fig 8.4: Flexure Test Setup using support Type B.

\subsection{TEST RESULTS}

\subsubsection{AGED FLEXURE - GFRP - RIBBED - \#4}

$\rightarrow$ Test and Specimen Details

- Fiber type - Glass

- Surface texture - Ribbed

- Diameters of Bars tested - 0.500” (\#4)

- $1 / \mathrm{d}$ ratio -20

- Number of specimens tested $-5+5+5$

- Deflections were recorded by deflection gage (0.0001" sensitivity)

- Stiffness values were calculated using load-deflection plots. 
Table 8.4: Maximum stress results from flexure tests for \#4 Ribbed GFRP bars under different aging conditions (WVU Specimens)

\begin{tabular}{|c|c|c|c|c|c|c|}
\hline \multirow{2}{*}{$\begin{array}{c}\text { Specimen } \\
\#\end{array}$} & \multirow{2}{*}{ Dia (in) } & \multicolumn{5}{|c|}{ Max Stress (ksi) } \\
\cline { 3 - 7 } & & Unaged & W+RT & S+RT & W+FT & S + FT \\
\hline 1 & 0.5 & 138.6 & 138.6 & 128.16 & 141.37 & 97.86 \\
\hline 2 & 0.5 & 130.39 & 122.25 & 122.32 & 112.11 & 108.01 \\
\hline 3 & 0.5 & 140.66 & 124.3 & 130.44 & 122.27 & 108 \\
\hline 4 & 0.5 & 116.2 & 122.32 & 138.57 & 127.14 & 108 \\
\hline 5 & 0.5 & 116.23 & 132.46 & 129.4 & 130.32 & 116.15 \\
\hline Average & & $\mathbf{1 2 8 . 4 2}$ & $\mathbf{1 2 7 . 9 9}$ & $\mathbf{1 2 9 . 7 8}$ & $\mathbf{1 2 6 . 6 4}$ & $\mathbf{1 0 7 . 6}$ \\
\hline Std Dev & & $\mathbf{1 1 . 7 8}$ & $\mathbf{7 . 2 7}$ & $\mathbf{5 . 8 3}$ & $\mathbf{1 0 . 7 4}$ & $\mathbf{6 . 4 9}$ \\
\hline \% & & $\mathbf{9 . 1 7}$ & $\mathbf{5 . 6 8}$ & $\mathbf{4 . 4 9}$ & $\mathbf{8 . 4 8}$ & $\mathbf{6 . 0 3}$ \\
\hline
\end{tabular}

(Note W: Water, S: Salt water; RT: Room temp.; FT: Freeze-thaw temp.)

Table 8.5: Stiffness results from flexure tests for \#4 Ribbed GFRP bars under different aging conditions (WVU Specimens)

\begin{tabular}{|c|c|ccccc|}
\hline \multirow{2}{*}{$\begin{array}{c}\text { Specimen } \\
\#\end{array}$} & \multirow{2}{*}{ Dia (in) } & \multicolumn{5}{|c|}{ Stiffness P- $\delta$ (msi) } \\
\cline { 3 - 7 } & & Unaged & W+RT & S+RT & W+FT & S+FT \\
\hline 1 & 0.5 & 5.75 & 5.16 & 5.28 & 5.63 & 5.77 \\
\hline 2 & 0.5 & 5.63 & 4.86 & 4.98 & 4.92 & 5.28 \\
\hline 3 & 0.5 & 5.53 & 5.95 & 6.05 & 5.17 & 5.66 \\
\hline 4 & 0.5 & 5.37 & 5.4 & 5.76 & 5.53 & 5.53 \\
\hline 5 & 0.5 & 5.62 & 5.58 & 5.09 & 5.59 & 5.57 \\
\hline Average & & $\mathbf{5 . 5 8}$ & $\mathbf{5 . 3 9}$ & $\mathbf{5 . 4 3}$ & $\mathbf{5 . 3 7}$ & $\mathbf{5 . 5 6}$ \\
\hline Std Dev & & $\mathbf{0 . 1 4}$ & $\mathbf{0 . 4 1}$ & $\mathbf{0 . 4 6}$ & $\mathbf{0 . 3 1}$ & $\mathbf{0 . 1 8}$ \\
\hline \% & & $\mathbf{2 . 5 1}$ & $\mathbf{7 . 6 1}$ & $\mathbf{8 . 4 7}$ & $\mathbf{5 . 7 7}$ & $\mathbf{3 . 2 4}$ \\
\hline
\end{tabular}

(Note W: Water, S: Salt water; RT: Room temp.; FT: Freeze-thaw temp.)

\section{$\rightarrow$ Discussion of Test Results}

- Average Bending Stress and standard deviations of ribbed GFRP bars

$$
\rightarrow \text { Unaged bars } \quad 128.42 \pm 11.78 \mathrm{ksi}(9.17 \%)
$$


$\rightarrow$ Specimens in water at room temp.

$127.99 \pm 7.27 \mathrm{ksi}(5.68 \%)$

$\rightarrow$ Specimens in salt water at room temp.

$129.78 \pm 5.83 \mathrm{ksi}(4.49 \%)$

$\rightarrow$ Specimens in water with freeze-thaw temp. $\quad 126.64 \pm 10.74 \mathrm{ksi}(8.48 \%)$

$\rightarrow$ Specimens in salt water with freeze-thaw temp. $107.6 \pm 6.49 \mathrm{ksi}(6.03 \%)$

- Average Stiffness and standard deviations of ribbed GFRP bars

$\rightarrow$ Unaged bars

$\rightarrow$ Specimens in water at room temp.

$\rightarrow$ Specimens in salt water at room temp.

$\rightarrow$ Specimens in water with freeze-thaw temp.

$\rightarrow$ Specimens in salt water with freeze-thaw temp. $5.56 \pm 0.18 \mathrm{msi}$ (3.24\%)

$5.58 \pm 0.14 \mathrm{msi}(2.51 \%)$

$5.39 \pm 0.41 \mathrm{msi}(7.61 \%)$

$5.43 \pm 0.46 \mathrm{msi}(8.47 \%)$

$5.37 \pm 0.31 \mathrm{msi}(5.77 \%)$

- Failure Mode - Slight punching in the compression zone initially followed by tension failure at bottom.

- Stress and stiffness - The maximum variation in the flexure stress of ribbed GFRP bars under different aging conditions was $20.6 \%$, with the maximum stress being 129.78 ksi and the minimum stress being $107.6 \mathrm{ksi}$ under different aging conditions. The maximum variation in stiffness values of the ribbed GFRP bars was $3.91 \%$, with a maximum of $5.58 \mathrm{msi}$ and a minimum of $5.37 \mathrm{msi}$ under different aging conditions. This variation in stiffness was less as compared to the variation in flexural stress.

- Standard Deviation - The standard deviations were in the range of $9.17 \%-2.51 \%$ for all the test results.

- Effect of Water - Specimens immersed in water at room temperature displayed no variation in stress, whereas specimens immersed in water at freeze-thaw temperature 
showed a small decrease of $1.6 \%(128.42 \mathrm{ksi}$ vs $126.64 \mathrm{ksi})$ in flexural stress as compared to unaged specimens.

- Effect of Salt water - Specimens immersed in salt solution at room temperature showed an increase of $1.06 \%$ (128.42 ksi vs $129.78 \mathrm{ksi})$ in stress, whereas specimens immersed in salt solution at freeze-thaw temperature show reduction a of $19.35 \%(128.42$ ksi vs $107.6 \mathrm{ksi}$ ) in flexural stress as compared to unaged specimens.

- Effect of Freeze-thaw temperature fluctuations - It was observed that freeze-thaw temperature fluctuations reduce the stress of the bars more as compared to room temperature conditions. This is because freeze-thaw variations results in contraction and expansion of the fiber-matrix interface due to the difference in thermal coefficient of expansions of fiber $\left(\mathrm{E}\right.$ glass fibers $\left.=2.6 \times 10^{-6} \mathrm{~F}^{-1}[52]\right)$ and matrix $\left(\right.$ Epoxy $=45-60 \mathrm{~F}^{-1}$; Polyester $\left.=30-55 \mathrm{~F}^{-1}[52]\right)$. Specimens immersed in salt solution coupled with freezethaw temperature conditions provided the most reduction in flexural stress as compared to unaged specimens.

\subsubsection{AGED FLEXURE - GFRP - SAND COATED - \#4}

\section{$\rightarrow$ Test and Specimen Details}

- Fiber type - Glass

- Surface texture - Sand Coated

- Diameters of Bars tested - 0.500” (\#4)

- $1 / \mathrm{d}$ ratio -20

- Number of specimens tested $-5+5+5$

- Deflections were recorded by deflection gage ( 0.0001 " sensitivity) 
- Stiffness values were calculated using load-deflection plots.

\section{Test Results}

Table 8.6: Maximum stress results from flexure tests for \#4 sand coated GFRP bars under different aging conditions (WVU Specimens)

\begin{tabular}{|c|c|c|c|c|c|c|}
\hline \multirow{2}{*}{$\begin{array}{c}\text { Specimen } \\
\#\end{array}$} & \multirow{2}{*}{ Dia (in) } & \multicolumn{5}{|c|}{ Max Stress (ksi) } \\
\cline { 3 - 7 } & & Unaged & W+RT & S+RT & W+FT & S + FT \\
\hline 1 & 0.5 & 77.49 & 77.44 & 63.23 & 67.33 & 57.04 \\
\hline 2 & 0.5 & 65.25 & 79.54 & 61.22 & 65.26 & 77.49 \\
\hline 3 & 0.5 & 77.5 & 69.34 & 77.48 & 81.59 & 69.35 \\
\hline 4 & 0.5 & 79.5 & 83.53 & 61.21 & 73.34 & 73.39 \\
\hline 5 & 0.5 & 75.48 & 75.48 & 59.17 & 67.26 & 61.19 \\
\hline Average & & $\mathbf{7 5 . 0 4}$ & $\mathbf{7 7 . 0 7}$ & $\mathbf{6 4 . 4 6}$ & $\mathbf{7 0 . 9 6}$ & $\mathbf{6 7 . 6 9}$ \\
\hline Std Dev & & $\mathbf{5 . 6 6}$ & $\mathbf{5 . 2 5}$ & $\mathbf{7 . 4 2}$ & $\mathbf{6 . 6 7}$ & $\mathbf{8 . 4 7}$ \\
\hline \% & & $\mathbf{7 . 5 4}$ & $\mathbf{6 . 8 1}$ & $\mathbf{1 1 . 5 1}$ & $\mathbf{9 . 4}$ & $\mathbf{1 2 . 5 1}$ \\
\hline
\end{tabular}

(Note W: Water, S: Salt water; RT: Room temp.; FT: Freeze-thaw temp.)

Table 8.7: Stiffness results from flexure tests for \#4 sand coated GFRP bars under different aging conditions (WVU Specimens)

\begin{tabular}{|c|c|ccccc|}
\hline \multirow{2}{*}{$\begin{array}{c}\text { Specimen } \\
\#\end{array}$} & \multirow{2}{*}{ Dia (in) } & \multicolumn{5}{|c|}{ Stiffness P- $\delta$ (msi) } \\
\cline { 3 - 7 } & & Unaged & W+RT & S+RT & W+FT & S+FT \\
\hline 1 & 0.5 & 5.64 & 5.05 & 5.25 & 5.18 & 5.13 \\
\hline 2 & 0.5 & 6.13 & 5.8 & 5.27 & 5.33 & 4.8 \\
\hline 3 & 0.5 & 5.37 & 5.21 & 5.15 & 6.14 & 4.86 \\
\hline 4 & 0.5 & 5.4 & 5.76 & 4.69 & 5.81 & 5.16 \\
\hline 5 & 0.5 & 5.64 & 5.18 & 5.06 & 5 & 4.86 \\
\hline Average & & $\mathbf{5 . 6 4}$ & $\mathbf{5 . 4}$ & $\mathbf{5 . 0 8}$ & $\mathbf{5 . 4 9}$ & $\mathbf{4 . 9 6}$ \\
\hline Std Dev & & $\mathbf{0 . 3}$ & $\mathbf{0 . 3 5}$ & $\mathbf{0 . 2 4}$ & $\mathbf{0 . 4 7}$ & $\mathbf{0 . 1 7}$ \\
\hline \% & & $\mathbf{5 . 3 2}$ & $\mathbf{6 . 4 8}$ & $\mathbf{4 . 7 2}$ & $\mathbf{8 . 5 6}$ & $\mathbf{3 . 4 3}$ \\
\hline
\end{tabular}

(Note W: Water, S: Salt water; RT: Room temp.; FT: Freeze-thaw temp.) 


\section{$\rightarrow$ Discussion of Test Results}

- Average Bending Stress and standard deviations of sand coated GFRP bars

$\rightarrow$ Unaged bars

$\rightarrow$ Specimens in water at room temp.

$\rightarrow$ Specimens in salt water at room temp.

$\rightarrow$ Specimens in water with freeze-thaw temp.

$\rightarrow$ Specimens in salt water with freeze-thaw temp.
$75.04 \pm 5.66 \mathrm{ksi}(7.54 \%)$

$77.07 \pm 5.25 \mathrm{ksi}(6.81 \%)$

$64.46 \pm 7.42 \mathrm{ksi}(11.51 \%)$

$70.96 \pm 6.67 \mathrm{ksi}(9.4 \%)$

$67.69 \pm 8.47 \mathrm{ksi}(12.51 \%)$

- Average Stiffness and standard deviations of ribbed GFRP bars

$\rightarrow$ Unaged bars

$\rightarrow$ Specimens in water at room temp.

$\rightarrow$ Specimens in salt at room temp.

$\rightarrow$ Specimens in water with freeze-thaw temp.

$\rightarrow$ Specimens in salt water at freeze-thaw temp.
$5.64 \pm 0.3 \mathrm{msi}(5.32 \%)$

$5.4 \pm 0.35 \mathrm{msi}(6.48 \%)$

$5.08 \pm 0.24 \mathrm{msi}(4.72 \%)$

$5.49 \pm 0.47 \mathrm{msi}(8.56 \%)$

$4.96 \pm 0.17 \mathrm{msi}(3.43 \%)$

- Failure Mode - Compression failure at top center span along the helical ribs.

- Stress and stiffness - The maximum variation in the flexure stress of ribbed GFRP bars was $19.56 \%$, with the maximum stress being $77.07 \mathrm{ksi}$ and the minimum stress being 64.46 ksi under different aging conditions. The maximum variation in stiffness values of the ribbed GFRP bars was $13.71 \%$, with a maximum of 5.64 msi and a minimum of 4.96 msi under different aging conditions. This variation was similar to the variation in flexural stress.

- Standard Deviation - The standard deviations were in the range of $12.51 \%-3.43 \%$ for all the test results. 
- Effect of Water - Specimens immersed in water at room temperature showed a slight increase of $2.71 \%$ (75.04 ksi vs $77.07 \mathrm{ksi})$ in stress and a reduction of $4.44 \%$ (5.64 msi vs $5.4 \mathrm{msi}$ ) in stiffness, whereas specimens immersed in water under freeze-thaw temperature fluctuations displayed a reduction of $5.75 \%$ (75.04 ksi vs $70.96 \mathrm{ksi})$ in flexural stress and a reduction of $2.74 \%$ (5.64 msi vs $5.49 \mathrm{msi}$ ) in stiffness, as compared to unaged specimens.

- Effect of Salt water - Specimens immersed in salt solution at room temperature showed a reduction of $16.43 \%$ ( $75.04 \mathrm{ksi}$ vs $64.46 \mathrm{ksi})$ in stress $11.02 \%$ (5.64 msi vs 5.08 msi) in stiffness, whereas specimens immersed in salt solution at freeze-thaw temperature showed a reduction of $10.86 \%$ (75.04 ksi vs $67.69 \mathrm{ksi})$ in flexural stress and $13.71 \%$ (5.64 msi vs $4.96 \mathrm{msi}$ ) in stiffness as compared to unaged specimens.

- Effect of Freeze-thaw temperature fluctuations - It was observed that freeze-thaw temperature fluctuations reduce the stress and stiffness of the bars more as compared to room temperature conditions as discussed in Section 8.5.1. 


\subsection{SUMMARY AND CONCLUSIONS - FLEXURE TEST ON AGED BARS}

Table 8.8: Summary of flexural tests performed on \#4 ribbed and \#4 sand coated GFRP bars under different aging conditions (WVU Specimens)

\begin{tabular}{|c|c|c|c|c|}
\hline \multirow{2}{*}{ Bar Type } & \multicolumn{2}{|c|}{ Aging Conditions } & Maximum Stress (ksi) & Stiffness (msi) \\
\cline { 2 - 5 } & Solution & Temp. & & \\
\hline \multirow{4}{*}{$\begin{array}{c}\text { \#4 Ribbed } \\
\text { GFRP }\end{array}$} & Unaged & RT & $128.42 \pm 11.78(9.17 \%)$ & $5.58 \pm 0.14(2.51 \%)$ \\
\cline { 2 - 5 } & Water & RT & $127.99 \pm 7.27(5.68 \%)$ & $5.39 \pm 0.41(7.61 \%)$ \\
\cline { 2 - 5 } & 3\% Salt & RT & $129.78 \pm 5.83(4.49 \%)$ & $5.43 \pm 0.46(8.47 \%)$ \\
\cline { 2 - 5 } & Water & FT & $126.64 \pm 10.74(8.48 \%)$ & $5.37 \pm 0.31(5.77 \%)$ \\
\cline { 2 - 5 } & 3\% Salt & FT & $107.6 \pm 6.49(6.03 \%)$ & $5.56 \pm 0.18(3.24 \%)$ \\
\hline \multirow{4}{*}{$\begin{array}{c}\text { \#4 Sand } \\
\text { GFRP }\end{array}$} & Unaged & RT & $75.04 \pm 5.66(7.54 \%)$ & $5.64 \pm 0.3(5.32 \%)$ \\
\cline { 2 - 5 } & Water & RT & $77.07 \pm 5.25(6.81 \%)$ & $5.4 \pm 0.35(6.48 \%)$ \\
\cline { 2 - 5 } & 3\% Salt & RT & $64.46 \pm 7.42(11.51 \%)$ & $5.08 \pm 0.24(4.72 \%)$ \\
\cline { 2 - 5 } & Water & FT & $70.96 \pm 6.67(9.4 \%)$ & $5.49 \pm 0.47(8.56 \%)$ \\
\cline { 2 - 5 } & $3 \%$ Salt & FT & $67.69 \pm 8.47(12.51 \%)$ & $4.96 \pm 0.17(3.43 \%)$ \\
\hline
\end{tabular}

(Values in parenthesis indicate standard deviations as a percentage of the average value. Freeze-thaw temperature $=12$ to $120^{\circ} \mathrm{F}$ )

- Stress and Stiffness - The maximum variation in the flexural strength and stiffness of \#4 ribbed GFRP bars due to aging was 20.6\% (129.78 ksi vs $107.6 \mathrm{ksi})$ and $3.91 \%$ (5.58 msi vs $5.37 \mathrm{msi}$ ). The maximum variation in the flexural strength and stiffness of \#4 sand coated GFRP bars due to aging was $19.56 \%$ (77.07 ksi vs $64.46 \mathrm{ksi})$ and $13.71 \%$ (5.64 msi vs $4.96 \mathrm{msi}$ ). Hence, it was concluded that stress values deteriorate more as compared to stiffness under aging conditions. Among both types of bars tested, ribbed bars show lesser reduction in stiffness values as compared to sand coated GFRP bars. Both bars however, show similar variations in flexural stress. 
- Standard Deviation - The maximum standard deviation for flexural stress values was 9.17\% (except \#4 sand coated GFRP bars in 3\% salt solutions that had $12.51 \%$ of standard deviation). The maximum standard deviation for stiffness results was $8.56 \%$ for all the GFRP bars.

- Effect of Water - \#4 ribbed GFRP bars showed negligible variation in flexural stress values in water solutions both at room temperature and freeze-thaw temperature. Howecer, \#4 sand coated GFRP bars showed a reduction of 5.75\% (75.04 ksi vs 70.96 ksi) in flexure stress when immersed in water at freeze-thaw temperature.

- Effect of Salt water - \#4 ribbed GFRP specimens immersed in salt solution at freezethaw temperature showed a reduction of $19.35 \%$ (128.42 ksi vs $107.6 \mathrm{ksi})$ in stress, and \#4 sand coated specimens immersed in salt solution at freeze-thaw temperature showed a reduction of $16.43 \%$ (75.04 ksi vs $64.46 \mathrm{ksi})$ in flexural stress values.

- Effect of Freeze-thaw temperature fluctuations - It was observed that freeze-thaw temperature fluctuations reduce the stress and stiffness of the bars more as compared to room temperature conditions. This is attributed to different coefficient of thermal expansions of fiber and matrix as discussed in Section 8.5.1. 


\section{CHAPTER 9}

\section{SUMMARY AND CONCLUSIONS}

\subsection{INTRODUCTION}

This chapter summarizes all the test methods developed/modified/verified in this research based on test results. Test results from tension, flexure, shear, bond and long-term tests (moisture and flexure tests on aged samples) are summarized in Sections 9.2 through 9.7. Each section also gives a brief summary of the work done towards the development of the test method and the subsequent study to standardize respective test methods.

\subsection{SUMMARY AND CONLUSIONS- TENSION TESTS}

Tension tests were conducted on three types of FRP bars - carbon, glass and aramid. Surface textures of those bars tested were either sand coated (with or without helical wraps) or ribbed. Diameters of bars tested varied from \#3 to \#8 with fiber volume fraction varying between $50-60 \%$. The test results are summarized in Table 9.1.

\subsubsection{Results Summary and Conclusions}

- Stress - Of the three types of bars tested (carbon, glass, and aramid fibers), carbon bars gave a maximum average tensile stress of $256.31 \mathrm{ksi}$ (\#3 bars), aramid bars gave an average tensile stress of $173.67 \mathrm{ksi}$ (\#3 bars), followed by glass bars showing an average stress range of 67.19-86.63 ksi (\#3-\#8 bars). Both types of glass bars tested (ribbed and sand coated), displayed similar stresses in tension for \#4 bars. 
- Stiffness - Of the three types of bars tested (carbon, glass, and aramid fibers), carbon bars had the average stiffness of $17.6 \mathrm{msi}$ (\#3 bars). Aramid bars gave an average stiffness of $8.51 \mathrm{msi}$ (\#3 bars), followed by glass bars showing an average stiffness range of 5.25-6.2 msi (\#3-\#8 bars). Of both types of glass bars tested (ribbed and sand coated), sand coated bars showed slightly higher stiffness values in tension.

Table 9.1: Summary of Tension Test Results

\begin{tabular}{|l|c|c|c|}
\hline \multicolumn{1}{|c|}{ 'Bar Type } & Dia & $\begin{array}{c}\text { Avg. Max. } \\
\text { Stress (ksi) }\end{array}$ & $\begin{array}{c}\text { Stiffness } \sigma-\varepsilon \\
(\mathbf{m s i})\end{array}$ \\
\hline CFRP Ribbed (WVU) & $\# 3$ & $256.31(5.69 \%)$ & $17.60(1.07 \%)$ \\
\hline AFRP Sand Coated (FAU) & $\# 3$ & $173.67(0.98 \%)$ & $8.51(1.53 \%)$ \\
\hline GFRP Ribbed (WVU) & $\# 4$ & $82.35(7.11 \%)$ & $5.42(4.91 \%)$ \\
\hline GFRP Ribbed (FAU) & $\# 4$ & $83.63(4.68 \%)$ & $5.25(4.57 \%)$ \\
\hline GFRP Ribbed (FAU) & $\# 6$ & $76.93(4.65 \%)$ & $5.35(4.11 \%)$ \\
\hline GFRP Sand Coated (WVU) & $\# 4$ & $82.11(1.63 \%)$ & $5.97(12.07 \%)$ \\
\hline GFRP Sand Coated (FAU) & $\# 5$ & $86.63(4.4 \%)$ & $5.60(6.43 \%)$ \\
\hline GFRP Sand Coated (FAU) & $\# 8$ & $67.19(1.93 \%)$ & $6.20(2.42 \%)$ \\
\hline
\end{tabular}

(Values in parenthesis are standard deviations as percentage of avg. stress/stiffness values)

- Standard Deviation - Standard deviation values for tensile stress were observed to be a maximum of $7.11 \%$ of the average values for all the bars. Standard deviations for stiffness values were observed to be less than $6.43 \%$ except in case of \#4 WVU sand coated GFRP bars with helical wraps which showed $12.07 \%$ standard deviation in stiffness values. Hence, it was concluded that sand coated GFRP bars with helical wraps show the most inconsistent results among all the FRP bars tested in tension. This inconsistency is attributed mainly to the helical wrapping scheme, which causes stress concentration along the path of helical wraps. 
- Failure Mode and Effect of Diameter on Stresses - Failures in all specimens (except two which failed in the grips) were observed to be at the center. At the end of each test, the bar fibers split into a conical mesh pattern. The failure was initiated with popping of sand particles in sand coated bars and splitting of fibers on the outer surface in case of ribbed bars, indicating the failure initiation was in the outer fibers of the bars, with higher stresses. Thus, the stress variation across the cross-section of the bar is not uniform which is referred to as shear lag $[W u, 1990]$. This stress variation results in reduction of average tensile stress in the bar. The stress variation increases with the increase in bar diameter, resulting in reduced average stresses in higher diameter bars.

\subsubsection{Test Method Summary}

- Grip Lengths and Adhesive - Variable lengths of steel grips with Pliogrip ${ }^{\mathrm{TM}}$ adhesive were used depending on the diameter of the FRP bar to be tested. A grip length of 8 in (for \#3-\#5 bars), 10 in (for \#6 bars) and 13.3 in (for \#8 bars) was found sufficient to be used on each end of the bar. A preferable grip length of 15" is suggested for \#8 bars [Vijay and GangaRao, 1991]. However, in this test a grip length of \#8 bars was taken to be 13.3" due to specimen length restrictions. These optimum grip lengths for different diameter of bars are summarized in Table 4.2 of this document.

- Bar Diameters - Variable diameters for the same type of bars were tested in tension to determine the effect of diameter on tensile stresses. It was observed that in general, bars with larger diameters show lower tensile stresses due to shear lag effect.

- Loading Rate - The loading rates were adjusted and determined for tension such that the load application and failure of the specimen was gradual. The loading rate for all the 
tension tests ranged between 15-70 ksi per minute, such that the failure of the specimen was reached between 30 seconds to 5 minutes. Loading rates were lower for glass bars and higher for carbon bars based on higher ultimate tensile strength of carbon bars. Suggested loading rate helps in minimizing stress concentration effects due to quick loading and creep effects due to slow loading.

- Standard Deviations - Lower standard deviation values indicate higher consistency in test results associated with a particular test methodology. Due to lower standard deviations $(<7.11 \%)$, this test methodology can be considered as a standardized tension test procedure.

\subsection{SUMMARY AND CONCLUSIONS - FLEXURE TESTS}

Flexure tests were conducted on three types of FRP bars - carbon, glass and aramid. The surface textures of these bars were ribbed and sand coated. Two different types of supports Type A (knife edge support) and Type B (smooth roller support) as described in Chapter 4, were used to conduct these tests. It was, however, observed that the results from flexure tests using support Type A were relatively inconsistent (in terms of standard deviation values) than results from support Type B. Hence, results from support Type A tests were discarded in favor of support Type B and are not included in this summary. The summary of flexure test results is given in Table 9.2 below. 


\subsubsection{Results Summary and Conclusions}

Table 9.2: Summary of Flexure test results for FRP bars on support Type B (L/D=20)

\begin{tabular}{|l|c|c|c|c|}
\hline & $\begin{array}{c}\text { Avg. Max. } \\
\text { Stress (ksi) }\end{array}$ & $\begin{array}{c}\text { Stiffness P- } \delta \\
(\mathbf{m s i})\end{array}$ & $\begin{array}{c}\text { Stiffness } \\
\sigma-\varepsilon(\mathbf{m s i})\end{array}$ & $\begin{array}{c}\text { Stiff \% diff } \\
\text { P- } \delta \text { v/s } \sigma-\varepsilon\end{array}$ \\
\hline \#3 Sand Coated CFRP & $151.4(3.6 \%)$ & $14.82(0.5 \%)$ & $16.85(6.6 \%)$ & $-12.04 \%$ \\
\hline \#3 Sand Coated AFRP & $102.8(2.1 \%)$ & $8.33(4.3 \%)$ & $9.05(6.6 \%)$ & $-7.9 \%$ \\
\hline \#3 Ribbed GFRP & $145.34(2.7 \%)$ & $6.64(7.6 \%)$ & $6.46(5.2 \%)$ & $+2.8 \%$ \\
\hline \#4 Ribbed GFRP & $127.9(5.1 \%)$ & $6.2(1.5 \%)$ & $6.63(3.5 \%)$ & $-6.5 \%$ \\
\hline \#5 Ribbed GFRP & $117.2(1.7 \%)$ & $6.5(1.9 \%)$ & $6.34(4.2 \%)$ & $+2.5 \%$ \\
\hline \#3 Sand Coated GFRP & $107.47(7.3 \%)$ & $5.73(5.3 \%)$ & $7.1(4.3 \%)$ & $-19.3 \%$ \\
\hline \#4 Sand Coated GFRP & $113.2(1.2 \%)$ & $6.05(3.7 \%)$ & $6.4(7.1 \%)$ & $-5.5 \%$ \\
\hline \#5 Sand Coated GFRP & $110.64(0.5 \%)$ & $6.04(2.0 \%)$ & $6.34(1.3 \%)$ & $-4.7 \%$ \\
\hline \#6 Sand Coated GFRP & $98.4(1.1 \%)$ & $5.54(0.4 \%)$ & $5.95(6.9 \%)$ & $-6.9 \%$ \\
\hline
\end{tabular}

Note: $\rightarrow$ Values in parenthesis are standard deviations as a percentage of the avg. value $\rightarrow$ All samples were provided by FAU

- Flexural Stress - Of the three types of bars tested (carbon, glass and aramid) in flexure, carbon bars provided a maximum flexural stress of $151.4 \mathrm{ksi}$ (\#3 bars). Aramid bars provided an average flexural stress $102.8 \mathrm{ksi}$ (\#3 bars). GFRP bars provided an average stress range of 145-98 ksi (\#3-\#6 bars). Of the two types of GFRP bars tested (ribbed and sand coated), ribbed bars gave higher flexural stress values. Ribbed GFRP bars showed reduction in stress with the increase in bar diameter (145 ksi for \#3 to 117 ksi for \#5). This was due to the shear lag phenomenon. However, in case of sand coated GFRP bars, only \#3 and \#6 bars showed this trend, whereas \#4 and \#5 bars showed higher stresses than \#3 and \#6 bars. This may be due to asymmetrical distribution of fibers in \#4 and \#5 bars as compared to \#3 and \#6 bars. Bars with higher fiber volume $\left(\mathrm{v}_{\mathrm{f}}\right.$ 
$=0.7)$ were tested $[W u, 1990]$, which gave higher flexural strength values as compared to the bars tested in this study $\left(\mathrm{v}_{\mathrm{f}}=0.5\right.$ to 0.6 in this study).

- Flexural Stiffness - Of the three types of bars tested in flexure (carbon, glass and aramid), carbon bars provided maximum flexural stiffness of 14.82 with P- $\delta$ method and $16.85 \mathrm{msi}$ with $\sigma-\varepsilon$ method. Aramid bars provided stiffness values of 8.33 with P$\delta$ method and 9.05 msi with $\sigma-\varepsilon$ method. GFRP bars provided the stiffness value range of $5.54-6.64$ msi with P- $\delta$ method and $5.95-7.1$ msi with $\sigma-\varepsilon$ method. Of the two types of GFRP bars tested (ribbed and sand coated), ribbed bars displayed slightly higher stiffness values. In general, stiffness values obtained from stress-strain plots were higher than the values obtained by load-deflection methods. The maximum variation between these values is as high as $19.3 \%$ in case of \#3 sand coated GFRP bars and $12.04 \%$ in case of \#3 sand coated CFRP bar. For bars with \#4-\#6 diameters this variation was lesser than $7.9 \%$.

- Standard Deviation - The maximum standard deviation for all flexure tests on support Type B was $7.6 \%$. This variation was less when compared to the $20.98 \%$ maximum variation in test results observed from tests on support Type A (Table 5.22, Chapter 5).

- Tensile/Flexure stress comparison - Carbon and aramid FRP bars show lower flexural stresses (151.4 and $102.8 \mathrm{ksi}$ respectively), as compared to tensile stresses (256.31 and $173.67 \mathrm{ksi}$ respectively). In general, higher stresses are expected in tensile values under flexure as compared to pure tension. In line with this trend, ribbed and sand coated glass bars (with \#3-\#6 diameter) show higher flexural stresses (98.4-145.34 ksi) when compared to their tensile stresses $(67.19-86.63 \mathrm{ksi})$. The combination of tensile and 
shear stresses under flexural of \#3 CFRP and AFRP bars need to be further investigated including additional tests on higher diameter CFRP and AFRP bars.

- Tensile/Flexure stiffness comparison - Carbon bars show lower (4.3\%) flexural stiffness values (16.85 msi) when compared to tensile stiffness (17.6 msi). Aramid bars, however, show higher $(6.3 \%)$ flexural stiffness values $(9.05 \mathrm{msi})$ as compared to their tensile stiffness $(8.51 \mathrm{msi})$. Glass bars show higher (\% increase varies for specific bar) stiffness values $(5.95-7.1 \mathrm{msi})$ when compared to their tensile stiffness $(5.25-6.8 \mathrm{msi})$.

\subsubsection{Test Method Summary}

- Supports - Two different types of supports - Type A and Type B were used for testing FRP bars in flexure. Tests using Support Type B were finally accepted due to more consistent test results and flexibility of use of the supports. It was noted that support Type B did not cause punching of the specimens at support locations as observed in the case of support Type A.

- L/D Ratio - FRP bars were tested in flexure with different L/D ratios (16, 20, 21 and 40). L/D ratio of 20 provided consistent results. This is within ASTM D790M-93 designated limits of 16-40.

- Bar Diameters - Variable diameters for the same type of bars were tested in flexure to determine the effect of diameter on flexural stresses. It was observed that in general, bars with larger diameters show lower flexural stresses.

- Loading Rate - The loading rates were adjusted and determined for flexure tests such that the load application and failure of the specimen was gradual. The loading rate for all the flexure tests ranged between 15-70 ksi per minute, such that the failure of the 
specimen was reached between 30 seconds to 5 minutes. Loading rates were lower for glass bars and higher for carbon bars due to higher ultimate tensile strength of carbon bars. Suggested loading rate helps in minimizing stress concentration effects due to quick loading and creep effects due to slow loading.

- Standard Deviations - Lower standard deviation values indicate higher consistency in test results associated with a particular test methodology. Due to lower standard deviations $(<7.6 \%)$ of flexure test results conducted using support Type B, this test methodology can be considered as a standardized flexure test procedure.

\subsection{SUMMARY AND CONCLUSIONS - SHEAR TESTS}

Shear tests were performed on two types of FRP bars - carbon and glass. Carbon bars had ribbed surface texture, whereas glass bars with sand coated (with or without helical wraps) and ribbed surface texture were tested. Two different widths of the cutting (shearing) tool 1 " and $1 / 2$ " were used to conduct the tests. Bars were tested in both single and double shear (as described in Chapter 6). The results from shear tests are summarized in Table 9.3.

\subsubsection{Results Summary and Conclusions}

Table 9.3: Summary of shear test results for FRP bars (WVU Samples)

\begin{tabular}{|c|c|c|c|}
\hline Bar Type & $\begin{array}{l}\text { Single Shear } \\
\text { Stress (ksi) }\end{array}$ & $\begin{array}{l}\text { Double Shear } \\
\text { Stress (ksi) }\end{array}$ & $\begin{array}{l}\text { Double Shear } \\
\text { Stress (ksi) }\end{array}$ \\
\hline (Tool Width) & $1 "$ & $1 "$ & $1 / 2 "$ \\
\hline \#3 Ribbed CFRP & $29.23(15.26 \%)$ & $39.25(5.02 \%)$ & $46.93(5.78 \%)$ \\
\hline \#4 Ribbed GFRP & $19.12(18 \%)$ & $23.47(6.31 \%)$ & $27.25(4.41 \%)$ \\
\hline \#4 Sand Coated GFRP & $26.48(16.24 \%)$ & $24.94(6.18 \%)$ & $26.99(4.53 \%)$ \\
\hline
\end{tabular}

(Values in parenthesis are standard deviations as a percentage of the average shear value) 
- Cutting Tool Width - The width of the cutting tool constitutes the effective shear cutting region and determines the effective bending span. Higher width of the cutting tool resulted in lower shear stress due to increased bending effects. Two different widths of cutting tool -1 " and $1 / 2$ " were used. The results with $1 / 2$ " cutting tool gave higher and consistent shear stress when compared to those with the use of 1 " wide cutting tool.

- Single and Double Shear - Single shear results gave lower shear stress (except sand coated GFRP bars) and higher standard deviations as compared to double shear stress results. This was due to the anchor mechanism adopted for each test - anchoring at one end in single shear (similar to a cantilever beam) compared to anchoring at both ends (similar to a fixed beam) for double shear. Due to the anchor mechanisms, bending effects in single shear were more when compared to double shear tests and resulted in lower shear stresses (in single shear).

- Shear Stress - Ribbed CFRP bars showed the maximum shear stress of the three types of bars tested. Ribbed GFRP and sand coated bars showed similar shear stresses in double shear. However, in single shear, sand coated bars showed higher shear stresses as compared to ribbed GFRP bars. There was an increase in shear stress (in double shear) of the bars by $8-20 \%$, when $1 / 2$ " wide cutting tool was used as compared to 1 " wide cutting tool.

- Standard Deviation - Standard deviation values were in the range of $15-18 \%$ for single shear tests, whereas for double shear tests this range was $4.4-6.4 \%$ with both 1 " and $1 / 2$ " wide cutting tools. Hence, it was concluded that double shear tests were comparatively more consistent and accurate of the two shear test methods. 


\subsubsection{Test Method Summary}

- Cutting Tool Width - Two different shearing tool widths - 1" and 1/2" were used for testing FRP bars in shear. Bending response played an important role in the shear strength test data in this research program. Higher bending effect resulted in lower shear strength. Hence it was decided to reduce the effective bending span for the specimens, i.e., by reducing the width of the cutting tool. The cutting tool was reduced to half its width, i.e. to $1 / 2 "$, and the fixtures were accordingly modified.

- Single and Double Shear - FRP bars were tested in single (one cross-section in shear) and double (two cross-sections in shear) shear. Due to increased bending effects, single shear tests gave lower shear stress values as compared to double shear stress values. Standard deviations in single shear tests were higher as compared to those obtained from double shear tests. Hence, double shear test is a more consistent method to determine the shear strength of FRP bars.

- Loading Rate - The loading rates were adjusted and determined for shear tests such that the load application and failure of the specimen was gradual. The loading rate for all the shear tests ranged between 5-15 ksi per minute, such that the failure of the specimen was reached between 30 seconds to 5 minutes. Suggested loading rate helps in minimizing stress concentration effects due to quick loading and creep effects due to slow loading.

- Standard Deviations - Lower standard deviation values indicate higher consistency in test results associated with a particular test methodology. Due to lower standard deviations $(<5.78 \%)$, double shear tests with $1 / 2$ " cutting tool can be considered as a standardized shear test procedure. 


\subsection{SUMMARY AND CONCLUSIONS - BOND TESTS.}

Pull-out tests were performed on two types of FRP bars - carbon and glass. The carbon bars had ribbed surface texture, whereas glass bars had both ribbed and sand coated (with helical wraps) surface texture. The bars were embedded in concrete cylinders. During casting certain length of top and bottom portion of bar was not bonded with concrete. Results obtained from the bond tests are summarized in Table 9.4.

\subsubsection{Results Summary and Conclusions}

Table 9.4: Summary of bond test results on FRP bars (WVU Samples)

\begin{tabular}{|l|c|}
\hline \multicolumn{1}{|c|}{ Bar Type } & Bond Stress (psi) \\
\hline \#3 Ribbed CFRP & $1834 \pm 14.02(0.77 \%)$ \\
\hline \#4 Ribbed GFRP & $1712 \pm 52.2(3.05 \%)$ \\
\hline \#4 Sand Coated GFRP & $1895 \pm 166(8.76 \%)$ \\
\hline
\end{tabular}

(Values in parenthesis indicate standard deviations as a percentage of the average value)

- Bond Stress - Sand coated GFRP bars had the maximum bond stress (1.895 ksi) among the three types of bars tested. The ribbed CFRP (1.834 ksi) and GFRP bars (1.712 ksi) show comparatively lower bond stress.

- Standard Deviation - Though the sand coated bars displayed the maximum bond stress, the standard deviation was $8.76 \%$. Ribbed CFRP bars had the least standard deviation of $0.77 \%$, followed by ribbed GFRP bars with a standard deviation of $3.05 \%$.

- Failure Mode and Bar Slip- All bond test samples failed due to slipping of the FRP bar inside the concrete cylinder, except for one sample where the failure was observed due to splitting of the concrete cylinder. The maximum bar slip inside the concrete recorded was observed to range from 0.068 " to 0.084 “. It was observed that bars with ribbed surface had more slip (maximum of $52.59 \%, 33.94 \%$ and $11.84 \%$ for load ranges $0-500,500-1000$ and 1000-1500 lbs respectively) inside the concrete cylinder as 
compared to bars with sand coated surface. Comparing bars with carbon and glass fibers, it was observed that ribbed GFRP bars give more slip (maximum of $14.52 \%, 35.12 \%$ and $36.97 \%$ for load ranges $0-500,500-1000$ and $1000-1500$ lbs respectively) as compared to ribbed CFRP bars.

\subsubsection{Test Method Summary}

- Embedment of Bars in Concrete - FRP bars were embedded in the concrete cylinders for a length of 3.5 " by bonding foam tubes equally on either sides of the remaining length of the bar not in contact with concrete. Before bonding the foam tubes the non bonded zone of the bar surface was applied with a thin coat of Vaseline ${ }^{\mathrm{TM}}$ to minimize friction with foam and any type of bonding with concrete. The embedment length of 3.5 " was chosen because, with a higher embedment length there is a possibility of tension failure of the FRP bar before bond failure, and with a lower embedment length it becomes difficult to record data with sufficiently accuracy due to bond failure at very low loads.

- Loading Rate - The loading rate for all the bond tests ranged between $250-750$ psi per minute, such that the failure was reached between 30 seconds to 5 minutes. Suggested loading rate helps in minimizing stress concentration effects due to quick loading and creep effects due to slow loading.

- Standard Deviations - Lower standard deviation values indicate higher consistency in test results associated with a particular test methodology. Due to lower standard deviations $(<8.76 \%)$, this test methodology can be considered as a standardized bond test procedure. 


\subsection{SUMMARY AND CONCLUSIONS - MOISTURE ABOSORPTION}

It was observed that the FRP bars absorbed very low quantities of moisture. The maximum \% gain by weight due to moisture absorption was $0.34 \%$ for CFRP bars and the minimum was $0.2 \%$ for the ribbed GFRP bars. It was also observed that the major portion of absorption occurred during initial few weeks. The absorption reduced after this period coming down to almost a stable state of no absorption after a month. The moisture pickup can increase dramatically with increased temperature and matrix cracking [Vijay GangaRao, 1999].

\subsection{SUMMARY AND CONCLUSIONS - FLEXURE ON AGED SAMPLES}

FRP bars were immersed in water and 3\% salt solutions at room and freeze-thaw temperature fluctuations and tested in flexure to evaluate the effect of aging on flexural stresses. Glass bars with ribbed and sand coated surface textures were tested on support Type B (as Type A was rejected in favor of Type B supports as described in Chapter 4). The results obtained are summarized in Table 9.5.

\subsubsection{Results Summary and Conclusions}

Table 9.5: Summary of flexural tests performed on \#4 ribbed and \#4 sand coated GFRP bars under different aging conditions (WVU Specimens)

\begin{tabular}{|c|c|c|c|c|}
\hline \multirow{2}{*}{ Bar Type } & \multicolumn{2}{|c|}{ Aging Conditions } & \multirow{2}{*}{ Maximum Stress (ksi) } & Stiffness (msi) \\
\cline { 2 - 5 } & Solution & Temp. & & \\
\hline \multirow{4}{*}{$\begin{array}{c}\text { \#4 Ribbed } \\
\text { GFRP }\end{array}$} & Unaged & RT & $128.42 \pm 11.78(9.17 \%)$ & $5.58 \pm 0.14(2.51 \%)$ \\
\cline { 2 - 5 } & Water & RT & $127.99 \pm 7.27(5.68 \%)$ & $5.39 \pm 0.41(7.61 \%)$ \\
\cline { 2 - 5 } & 3\% Salt & RT & $129.78 \pm 5.83(4.49 \%)$ & $5.43 \pm 0.46(8.47 \%)$ \\
\cline { 2 - 5 } & Water & FT & $126.64 \pm 10.74(8.48 \%)$ & $5.37 \pm 0.31(5.77 \%)$ \\
\cline { 2 - 5 } & 3\% Salt & FT & $107.6 \pm 6.49(6.03 \%)$ & $5.56 \pm 0.18(3.24 \%)$ \\
\hline \multirow{4}{*}{$\begin{array}{c}\text { \#4 Sand } \\
\text { coated } \\
\text { GFRP }\end{array}$} & Unaged & RT & $75.04 \pm 5.66(7.54 \%)$ & $5.64 \pm 0.3(5.32 \%)$ \\
\cline { 2 - 5 } & Water & RT & $77.07 \pm 5.25(6.81 \%)$ & $5.4 \pm 0.35(6.48 \%)$ \\
\cline { 2 - 5 } & Water & FT & $64.46 \pm 7.42(11.51 \%)$ & $5.08 \pm 0.24(4.72 \%)$ \\
\cline { 2 - 5 } & 3\% Salt & FT & $67.69 \pm 8.47(12.51 \%)$ & $4.96 \pm 0.17(3.43 \%)$ \\
\hline
\end{tabular}

(Values in parenthesis indicate standard deviations as a percentage of the average value. Freeze-thaw temperature $=12$ to $120^{\circ} \mathrm{F}$ ) 
- Stress and Stiffness - The maximum variation in the flexural strength and stiffness of \#4 ribbed GFRP bars due to aging was 20.6\% (129.78 ksi vs $107.6 \mathrm{ksi}$ ) and $3.91 \%$ (5.58 msi vs $5.37 \mathrm{msi}$ ). The maximum variation in the flexural strength and stiffness of \#4 sand coated GFRP bars due to aging was 19.56\% (77.07 ksi vs $64.46 \mathrm{ksi})$ and $13.71 \%$ (5.64 msi vs $4.96 \mathrm{msi}$ ). Hence, it was concluded that stress values deteriorate more as compared to stiffness under aging conditions. Among both types of bars tested, ribbed bars show lesser reduction in stiffness values as compared to sand coated GFRP bars. Both bars however, show similar variations in flexural stress.

- Standard Deviation - The maximum standard deviation for flexural stress values was 9.17\% (except \#4 sand coated GFRP bars in 3\% salt solutions that had $12.51 \%$ of standard deviation). The maximum standard deviation for stiffness results was $8.56 \%$ for all the GFRP bars.

- Effect of Water - \#4 ribbed GFRP bars showed negligible variation in flexural stress values in water solutions both at room temperature and freeze-thaw temperature. Howecer, \#4 sand coated GFRP bars showed a reduction of 5.75\% (75.04 ksi vs 70.96 ksi) in flexure stress when immersed in water at freeze-thaw temperature.

- Effect of Salt water - \#4 ribbed GFRP specimens immersed in salt solution at freezethaw temperature showed a reduction of $19.35 \%$ (128.42 ksi vs $107.6 \mathrm{ksi})$ in stress, and \#4 sand coated specimens immersed in salt solution at freeze-thaw temperature showed a reduction of $16.43 \%(75.04 \mathrm{ksi}$ vs $64.46 \mathrm{ksi})$ in flexural stress values.

- Effect of Freeze-thaw temperature fluctuations - It was observed that freeze-thaw temperature fluctuations reduce the stress of the bars more as compared to room temperature conditions. This is because freeze-thaw variations results in contraction and 
expansion of the fiber-matrix interface due to the difference in thermal coefficient of expansions of fiber $\left(\mathrm{E}\right.$ glass fibers $\left.=2.6 \times 10^{-6} \mathrm{~F}^{-1}[52]\right)$ and matrix $\left(\right.$ Epoxy $=45-60 \mathrm{~F}^{-1}$; Polyester $=30-55 \mathrm{~F}^{-1}[52]$ ). Specimens immersed in salt solution coupled with freezethaw temperature conditions provided the most reduction in flexural stress as compared to unaged specimens.

\subsection{RESEARCH SUMMARY - TEST METHODS}

Tension Test Method: Suitable gripping mechanism with sufficient length and proper adhesive is necessary for conducting tension tests on FRP bars. Grips made of split Schedule

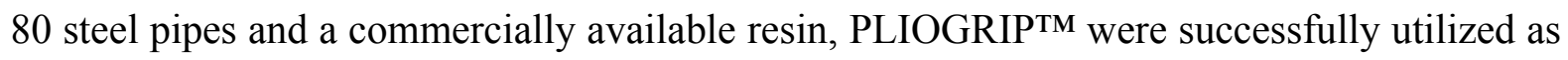
gripping mechanism and adhesive, respectively. It was found that longer length of grips were necessary for higher diameter bars. Grip lengths based on diameter of FRP bars were established to be varying from 8 " to 13.3 " for $\# 3$ to $\# 8$ bars. Strain gages were successfully used in this study to measure strains and evaluate stiffness values. However, available literature indicates both strain gage and extensometer can be successfully used to measure strains [39]. Using the test methodology described in Chapter 4, the maximum standard deviation value for tension test results of FRP bars was 7.11\%.

Flexure Test Method: Three-point bending tests were conducted for different span to diameter (L/D) ratios (16, 20, 21 and 40), using two types of supports, i.e., type A (knifeedge) and type B (smooth roller). Supports with knife edge (Type A) are not recommended for flexure tests. Type B support with rollers as per ASTM D4476-97 showed better 
consistency in test results with lower standard deviations and hence recommended. Also L/D ratio of 20 is recommended due to consistency in results (lower standard deviation) and lesser shear deformation. Strains and deflections were measured using strain-gages and deflection gages, respectively. Stiffness values can be evaluated using either strain or deflection data. The maximum standard deviation value observed for flexure tests results of FRP bars using the test methodology with support Type B as described in Chapter 5 was $7.6 \%$.

Shear Test Method: Available literature indicates lack of comprehensive data on shear strength evaluation of FRP bars, particularly with respect to the type of shear (single and double) and width of the cutting tool. In this study, single and double shear methods were used with the help of two different cutting tools having widths of 1 " and $1 / 2$ ". Double shear tests with $1 / 2$ " wide tool are recommended to achieve consistent results. Using the test methodology described in Chapter 6, the maximum standard deviation value for shear test results of FRP bars was $6.4 \%$.

Bond Test Method: Bond (pullout) tests were conducted on FRP bars by embedding them in concrete cylinders. An embedment length of 3.5" of the bar in the cylinder is recommended to conduct bond tests to avoid premature failure of the bar in tension prior to bond failure. Slip at the unloaded end of the bar was measured using an LVDT. Cantilever beam tests for bond evaluation were not considered due to complexity and cost considerations. Maximum standard deviation value observed for bond tests using the test methodology described in Chapter 7 was $8.76 \%$. 
Moisture Absorption Test Method: Two-inch long bars were cut and sealed at the ends with a thin layer of epoxy (recommended to prevent seepage of water at the cut ends). They were immersed in distilled water and monitored for change in weights.

Flexure Test Method on aged specimens: FRP bars were immersed in water and 3\% salt solutions for over four years at room and freeze-thaw temperature fluctuations. These bars were tested in three-point bending and evaluated for reduction in strength and stiffness as described in "flexure tests".

\subsection{RESEARCH SUMMARY - TEST RESULTS}

Following results were obtained using the test methods described in Chapter 4,5,6,7 and 8 .

Tension tests: The average tensile strengths of different FRP bars were found to be $256 \mathrm{ksi}$ (\#3 ribbed carbon), 83 to $77 \mathrm{ksi}$ (\#4 to \#6 ribbed glass), 82 to $67 \mathrm{ksi}$ (\#4 to \#8 sand coated glass), and $173 \mathrm{ksi}$ (\#3 sand coated aramid). The corresponding stiffness values evaluated from stress-strain plots were $17.6 \mathrm{msi}, 5.25$ to $5.42 \mathrm{msi}, 5.6$ to $6.2 \mathrm{msi}$, and $8.51 \mathrm{msi}$. The strength and stiffness values are a function of bar diameter and fiber volume fraction $\left(\mathrm{v}_{\mathrm{f}}\right)$. The $v_{f}$ of the bars tested in this study varied between $50-60 \%$.

Flexure tests: The flexural strengths of FRP bars were $151 \mathrm{ksi}$ (\#3 sand coated carbon); 145 to $117 \mathrm{ksi}$ (\#3 to\#5 ribbed glass); 113 to $98 \mathrm{ksi}$ (\#3 to \#6 sand coated glass); and $103 \mathrm{ksi}$ (\#3 sand coated aramid). It should be noted that the corresponding tensile strength of \#3 sand coated bar is not available in Table 9.1. Stiffness values evaluated from load-deflection plots 
were $14.82 \mathrm{msi}$ (\#3 sand coated carbon), 6.2 to $6.64 \mathrm{msi}$ (\#3 to \#5 ribbed glass), 5.54 to 6.05 msi (\#3 to \#6 sand coated glass), and $8.33 \mathrm{msi}$ sand (\#3 sand coated aramid). The corresponding stiffness values from stress-strain plots were $16.85 \mathrm{msi}, 6.34$ to $6.63 \mathrm{msi}, 5.95$ to $7.1 \mathrm{msi}$, and $9.05 \mathrm{msi}$. The strength and stiffness values are a function of bar diameter and fiber volume fraction as observed in tension results. Stiffness values calculated from stressstrain plots are slightly higher than those obtained from load-deflection plots.

Shear tests: The shear strength in double shear using 1/2" wide cutting tool of \#3 ribbed carbon bars was observed to be $47 \mathrm{ksi}$ as compared to $27.2 \mathrm{ksi}$ for \#4 ribbed glass and $27 \mathrm{ksi}$ for \#4 sand coated glass bars.

Bond tests: Experimental bond strengths for ribbed carbon, ribbed glass and sand coated glass FRP bars were 1834 psi, 1712 psi and 1895 psi, respectively. Bond strength of FRP bars depended on their surface textures.

Moisture absorption: FRP bars showed low amount of moisture absorption $(<0.34 \%)$ over a period of 298 days indicating lower void content.

Flexure tests on aged specimens: Flexure tests on FRP bars aged for four years showed that a combination of salt and freeze-thaw temperature resulted in maximum stress reduction (20.6\% in \#4 ribbed GFRP and 19.56\% in \#4 sand coated GFRP). 
Standard deviations: Maximum standard deviation values of test results were $7.11 \%, 7.6 \%$, $6.4 \%$ and $8.76 \%$ of average strength/stiffness values for tension, flexure (support type B), double shear, and bond tests, respectively. Based on the data from this research, specifications were developed and submitted to NCHRP-FHWA for consideration as draft AASHTO Standard Test Specifications.

\subsection{RECOMMENDATIONS FOR FUTURE RESEARCH}

Following recommendations are made for future research:

1) Future torsion tests on FRP bars are recommended to determine and compare the torsion values of FRP bars with shear stress values. It should be noted that simple torsion tests on FRP bars, conducted separately in this research (beyond the scope of this work and hence not reported), revealed that they are flexible (ductile) in torsion.

2) Additional tests need to be conducted on CFRP and AFRP bars with different diameters for tensile and flexural stress comparisons.

3) More short and long term tests need to be conducted on CFRP, GFRP and AFRP bars with different resin types (thermoset and thermoplastic) to identify their compatibility and aging behavior.

4) During the course of this work, steel grips were extensively used. However, the grips were not reusable. Developing reusable grips to conduct tension or pull-out tests is recommended.

5) Additional flexural tests need to be conducted to compare stiffness results obtained from load-deflection and stress-strain plot methods.

6) Additional tests are necessary to correlate cylinder pull-out results to cantilever beam test results for bond strength determination. 


\section{REFERENCES}

1. Non-Metallic (FRP) Reinforcement for Concrete Structures, Proceedings of the Third International Symposium on Non-Metallic (FRP) Reinforcement for Concrete Structures (FRPPRCS-3), Vols. I and II, Sapporo, Japan (October 14-16, 1997) 728 pp. and 813 pp.

2. Saadatmanesh, H. and Ehsani, M. R. (Editors), Fiber Composites in Infrastructure, Proceedings of the First International Conference on Composites in Infrastructure, ICCI 96, Tucson, Arizona (January 1996) 1231 pp.

3. Saadatmanesh, H. and Ehsani, M. R. (Editors), Fiber Composites in Infrastructure, Proceedings of the Second International Conference on Composites in Infrastructure, ICCI 98, Vols. I and II, Tucson, Arizona (January 1998) 723 pp. and 783 pp.

4. Non-Metallic (FRP) Reinforcement for Concrete Structures, Proceedings of the Second International RILEM Symposium (FRPPRCS-2), Ghent, Belgium (August 23$25,1995) 714 \mathrm{pp}$.

5. Benmokrane, B. and Rahman, H. (Editors), Durability of Fiber Reinforced Polymer Composites for Construction (FRP), Proceedings of the First International Conference (CDCC'98), Sherbrooke, Canada (August 5-7, 1998) 706 pp.

6. Sen, R., Mariscal, D. and Shahawy, M., "Investigation of S-2 Glass/Epoxy Strand in Concrete", Fiber reinforced Plastic Reinforcement for Concrete Structure, International Symposium, ACI SP-138, 1993, pp. 15-33.

7. Malvar, L. J., "Tensile and Bond properties of GFRP Reinforcing Bars", $A C I$ Materials Journal, Vol. 92, No. 3, 1995, pp. 276-285.

8. Faza, S. S. and GangaRao, H. V. S., "Behavior of Fiber Reinforced Plastic Rebar 
Under Bending", ASCE Structural Congress Abstracts (1991) p. 262.

9. GangaRao, H. and Kumar, S., "Design and Fatigue Response of Concrete Bridge Decks Reinforced with FRP Rebars", Proceedings of the Second International RILEM Symposium (FRPPRCS-2), Non-Metallic (FRP) Reinforcement for Concrete Structures, Ghent (1995) pp. 663-671.

10. Dolan, C., "FRP Development in the United States, Fiber-Reinforced-Plastic Reinforcement for Concrete Structures: Properties and Applications", Developments in Civil Engineering, Vol. 42 (1993) pp. 129-163.

11. Sen, R., Shahawy, M., Rosas, J. and Sukumar, S., "Durability of AFRP Pretensioned Elements in a Marine Environment", ACI Structural Journal, Vol. 95, No. 5 (1998) pp. 578-587.

12. Sen, R., Shahawy, M., Rosas, J. and Sukumar, S., "Durability of AFRP Pretensioned Piles Under Tidal Thermal Cycles”, ACI Structural Journal, Vol. 96, No. 1 (1999) pp. $95-104$.

13. Sasaki, I., Nishizaki, I., Sakamoto. H., Katawaki, K. and Kawamoto, Y. "Durability Evaluation of FRP Cables by Exposure Tests", Proceedings of the Third International Symposium on Non-Metallic (FRP) Reinforcement for Concrete Structures, Japan Concrete Institute, Vol. 2 (October 1997) pp. 131-138.

14. Wu, W. P., "Thermo-mechanical Properties of Fiber Reinforced Plastics (FRP) Bars", Ph.D. Dissertation, West Virginia Morgantown, West Virginia University (1990) 292 pp.

15. Benmokrane, B. and Masmoudi, R. (Editors), "FRP C-Bar as Reinforcing Rod for Concrete Structures”, ACMBS-II, Montreal, Canada (August 1996) pp. 181-188. 
16. Otsuki, N., Seki, H., and Kamiyoshi, M., "Considerations of the Tensile Strength Test Method of FRP", Proceedings of the Third International Symposium on Non-Metallic (FRP) Reinforcement for Concrete Structures (October 1997) pp. 3-9.

17. Tanano, H., Masuda, Y., Sakashita, M., Oono, Y., Nonomura, K., and Satake, K., "Tensile Properties at High Temperatures of Continuous Fiber Bars and Deflections of Continuous Fiber Reinforced Concrete Beams under High-Temperature Loading”, Proceedings of the Third International Symposium on Non-Metallic (FRP) Reinforcement for Concrete Structures, Japan Concrete Institute, Vol. 2 (October 1997) pp. 43-50.

18. Roll, R. D., "Use of GFRP Rebar in Concrete Structures", Advanced Composite Materials in Civil Engineering Structures, Proceedings of the Society of Specialty Conference, ASCE, NY (January 1991) pp. 93-98.

19. Hosny, O., El-Nawawy, E. I. and Mostafa Khalil, V., "Behavior of Concrete Slabs Reinforced with Fiber-Glass Bars", The First Middle East Workshop on Structural Composites, Egypt (June 1996) pp. 267-280.

20. Abdalla, H., El-badry, M. M., and Rizkalla, S., "Deflection of Concrete Slabs Reinforced with Advanced Composite Materials", ACMBS-II, Montreal, Canada (August 1996) pp 201-208.

21. Matthys, S. and Taerwe, L., "Behavior of Concrete Slabs Reinforced with FRP Grids Under Service and Ultimate Loading”, ICCI'96, Proceedings of First International Conference on Composites in Infrastructure, Tuscon, AZ (January 1996) pp.359-373.

22. Razaqpur, A. G. and Ali, M. M., "A New Concept for Achieving Ductility in FRPReinforced Concrete", ICCI'96, Proceedings of First International Conference on 
Composites in Infrastructure, Tuscon, AZ (January 1996) pp.401-413.

23. Faza, S. S. and GangaRao, H. V. S., "Pre- and Post- cracking Deflection Behavior of Concrete Beams Reinforced with Fiber-reinforced Plastic Rebars", ACMBS-I Conference (1992) pp.151-160.

24. Vijay, P. V. and GangaRao, H. V. S., "Development of Fiber Reinforced Plastics for Highway Application: Aging Behavior of Concrete Beams Reinforced with GFRP bars", CFC-WVU Report No. 99-265 (WVDOH RP \#T-699-FRP1) (1999) 202 pp.

25. Maji, A., Orozco, A. and Acree, R., "Fracture Analysis of FRP Reinforced Concrete Beams", Journal of Engineering Mechanics, ASCE, Vol. 127, No. 6 (June 2001) pp. $620-624$.

26. Ehsani, M. R., Saadatmanesh, H. and Tao, S., "Bond Behavior and Design Recommendations for Fiberglass Reinforcing Bars", Proceedings of the First International Conference on Composites in Infrastructure, Tucson, Arizona (1996) pp. $466-477$.

27. Pleimann, L. G., "Strength Modulus of Elasticity and Bond of Deformed FRP Rods", Advanced Composites materials in Civil Engineering Structures, Proceedings of the Specialty Conference, Materials Engineering Division, ASCE (1991) pp. 99-110.

28. Faza, S. S. and GangaRao, H. V. S., "Bending and Bond Behavior of Concrete Beams Reinforced with Plastic Rebars", Transportation Research Record 1290 (1990) pp. 185-193.

29. Daniali, S., "Development Length for Fiber Reinforced Plastic Bars", Advanced Composite Materials in Bridges and Structures, Canadian Society for Civil Engineering (1992) pp. 169-177. 
30. Chaallal, O., Benmokrane B. and Masmoudi, R., "An Innovative Glassfiber Composite Rebar for Concrete Structures", Advanced Composite Materials in Bridges and Structures, Canadian Society for Civil Engineering (1992) pp. 169-177.

31. Al-Dulaijan S. U., "The Effect of Mechanical and Environmental Conditioning on Bond Between FRP Reinforcement and Concrete", Ph.D. Thesis, Department of Civil and Environmental Engineering, The Pennsylvania State University, University Park, PA (1996).

32. Nanni, A., Bakis, C. E. and Mathew, J. A., "Acceleration of FRP Bond Degradation”, Durability of Fiber Reinforced Polymer Composites for Construction (FRP), Proceedings of the First International Conference (CDCC'98), Sherbrooke, Canada (1998) pp. 45-56.

33. Bakis, C. E., Freimanis, A. J. and Nanni A., "Effect of Resin Material on Bond and Tensile Properties of Unconditioned and Conditioned FRP Reinforcement Rods", Durability of Fiber Reinforced Polymer Composites for Construction (FRP), Proceedings of the First International Conference (CDCC'98), Sherbrooke, Canada (1998) pp. 525-535.

34. Fukuyama, H., Sonobe, Y., Fujisawa, M., Kanakubo, T. and Yonemaru, K., "Bond Splitting Strength of Concrete Members Reinforced with FRP Bars", Bond of Fiber Reinforced Plastic (FRP) Rebars and Tendons, ACI Spring Convention, San Francisco, CA (March 1994) pp. 5-8.

35. Benmokrane, B., Tighiouart, B. and Chaallal, O., "Investigation on Bond Performance of FRP Rebars”, Bond of Fiber Reinforced Plastic (FRP) Rebars and Tendons, ACI Spring Convention, San Francisco, CA (March 1994) pp. 1-4. 
36. Khin, M., Matsumoto, S., Harada, T. and Takewaka, K., "Experimental Study on Bond and Anchorage of FRP Rods", Bond of Fiber Reinforced Plastic (FRP) Rebars and Tendons, ACI Spring Convention, San Francisco, CA (March 1994) pp. 13-16.

37. Faza, S. S. and GangaRao, H. V. S., "Behavior of Fiber Reinforced Plastic Rebar Under Bending", ASCE Structures Congress Abstracts (1991), pp. 262.

38. Chaallal, O. and Benmokrane, B., "Physical and Mechanical Performance of an Innovative Glass-Fiber-Reinforced Plastic Rod for Concrete and Grouted Anchorages", Canadian Journal of Civil Engineering, Vol. 20 (1993) pp. 254-268.

39. Chaallal, O., Houde, J., Benmokrane, B. and Aitcin, P. C. "Use of a New Glass-Fiber Rod as Reinforcement for Concrete Structures", Evaluation and Rehabilitation of Concrete Structures and Innovations in Design Proceedings, ACI International Conference, Hong Kong, SP-128, Vol. I (1991) pp. 515-528.

40. Malvar, L. J., et al., "Bond Stress-Slip Characteristics of FRP Rebars", $A C I$ Convention, San Francisco (March 20-25, 1994) pp. 17-20.

41. Hahn, H. T. and Kim, K. S., "Hygroscopic Effects in Aramid Fiber/Epoxy Composite", Journal of Engineering Materials and Technology, Vol. 110 (April 1988) pp. 153-157.

42. Ashbee, K. and Wyatt, R., "Water Damage in Glass Fiber Resin Composites", Proceedings of Royal Society, London, Series A, Vol. 312 (1969) pp. 553-574.

43. GangaRao, H. and Vijay, P. V., "Aging of Structural Composites Under Varying Environmental Conditions", Proceedings of the Third International Symposium on Non-Metallic (FRP) Reinforcement for Concrete Structures, Japan Concrete Institute, Vol. 2 (October 1997) pp. 91-98. 
44. Vijay, P. V., GangaRao, H. V. S., and Kalluri, R., "Hygrothermal Response of GFRP Bars under Different Conditioning Schemes", Durability of Fiber Reinforced Polymer (FRP) Composites for Construction, Sherbrooke, Canada (August 1998) pp. 243-252.

45. Uomoto, T. and Nishimura, T., "Development of New Alkali Resistant Hybrid AGFRP Rod", Proceedings of the Third International Symposium on Non-Metallic (FRP) Reinforcement for Concrete Structures, Japan Concrete Institute, Vol. 2 (October 1997) pp. 67-74.

46. Arockiasamy, M. and Sandepudi, K., "Active Deformation Control of Bridges Prestressed with Aramid Fiber Reinforced Plastic (AFRP) Cables", WPI No. 0510614, Contract No. C-4131, Florida Department of Transportation (August 1994) $276 \mathrm{pp}$.

47. Arockiasamy, M. and Zhuang, M., "Experimental Studies on the Behavior of Concrete Bridges Prestressed with Carbon Fiber Composite Cable", Final Report, New Technology Division, Itochu Corporation, Tokyo, Japan (June 1996) 330 pp.

48. Tannous, F. E. and Saadatmanesh, H., "Durability of AR Glass Fiber Reinforced Plastic Bars", Journal of Composites for Construction, ASCE, Vol. 3, No. 1 (February 1999) pp. 12-19.

49. Gomez, J. and Casto, B., "Freeze-Thaw Durability of Composite Materials", Proceedings of the First International Conference on Composites in Infrastructure, ICCI '96, Tucson, Arizona (January 1996) pp. 947-955.

50. Springer, G. S. (Editor), Environmental Effects on Composite Materials (Vol. I, II, III), Technomic Publishing Company Inc., Lancaster, Pennsylvania (1981) 438 pp. $498 \mathrm{pp}$. 
51. Timoshenko, S., "Strength of Materials", $3^{\text {rd }}$ edition, Kreiger Publishing Company (June 1976) pp 170-175.

52. Chawla, K.K., "Composite Materials: Science and Engineering", $2^{\text {nd }}$ edition, Springer-Verlag New York Inc. (1998) pp 14, 86. 


\section{APPENDIX A}

\section{DRAFT AASHTO TEST PROTOCOLS}

(NOTE: Proposed standards based on the efforts of this research, technical collaboration between other project participants, existing relevant standards by other committees and current literature review.)

\section{A.1. Draft Standard Test Method for Tensile Properties of FRP Rods}

\section{A.1.1. SCOPE}

A.1.1.1 This test method specifies the test requirements for tensile strength, modulus of elasticity and ultimate elongation of FRP rebars used in place of steel reinforcing rebars in concrete.

\section{A.1.2. REFERENCED DOCUMENTS}

\section{A.1.2.1 ASTM Standards \\ D 618 - 96 Standard Practice for Conditioning Plastics for Testing \\ D 3916 - 94 Standard Test Method for Tensile Properties of Pultruded Glass-Fiber Reinforced Plastic Rod \\ E 4 - 01 Standard Practices for Force Verification of Testing Machines.}

\section{A.1.3. SIGNIFICANCE AND USE}

A.1.3.1 This test method for obtaining the tensile strength and modulus is intended for use in laboratory tests in which the principal variable is the size or type of FRP rebars.

A.1.3.2 The test method given here focuses on the FRP rebar itself, excluding the performance of the anchorage. Therefore, failure or pullout at an anchoring section shall be disregarded, and the test findings shall be based solely on test specimens that fail in the test section.
A.1.3.3 This test method is intended to determine the tensile strength, modulus of elasticity and ultimate elongation of FRP rebars for material specifications, research and development, quality control, quality assurance, and structural design and analysis.

\section{A.1.4. TERMINOLOGY}

A.1.4.1 Test section: The portion of a specimen between the anchoring sections of the test specimen.

A.1.4.2 Anchoring section: The end parts of the specimen where an anchorage is fitted to transmit the loads from the testing machine to the test section.

A.1.4.3 Gage length: The distance between two gage points on the test section, over which the percentage of elongation is determined.

A.1.4.4 Anchorage: Device fitted to the anchoring section of a specimen to transmit loads from the testing machine to the test specimen. Refer to "Anchor for Testing FRP Rebars under Monotonic, Sustained, and Cyclic Tension".

A.1.4.5 Tensile capacity: The maximum tensile load carried by test specimen prior to failure.

A.1.4.6 Guaranteed tensile capacity: The average maximum tensile load minus three standard deviations. The tensile capacity for which an FRP manufacturer guarantees it will meet.

A.1.4.7 Ultimate strain: The change in length per unit length corresponding to the tensile capacity.

\section{A.1.5. TEST EQUIPMENT AND REQUIREMENTS}

A.1.5.1 Test machine: The testing machine to be used in the tension test shall generally conform to ASTM Practices E 4. The testing machine shall have a loading capacity in excess of the tensile capacity of the test specimen, and shall preferably be equipped with displacement-rate or load-rate control.

A.1.5.2 Anchor: The anchor specified in "Anchor for Testing FRP Rebars under Monotonic, Sustained, and Cyclic Tension" shall be used. Any of various anchoring devices may be used provided that they are suitable for the geometry of the test specimen, and have the capacity to transmit the loads capable of causing the test specimen to fail at the test section. The anchor shall be constructed so as to transmit loads reliably from the testing machine to the test section, transmitting only axial loads to the test specimen, without transmitting either torsion or flexural force. Refer to "Anchor for Testing FRP Specimens under Monotonic, Sustained, and Cyclic Tension" for attachment of anchors to testing machines.

A.1.5.3 Strain measuring device: Extensometers and strain gages shall be capable of recording all variations in the gage length or specimen 
elongation during testing with an accuracy of not less than $10^{-5}$.

A.1.5.4 Elongation measuring device: In order to determine the modulus of elasticity and ultimate strain of the test specimen, an extensometer or strain gage should be mounted in the center of the test section at a distance from the anchorage at least 8 times the diameter of the FRP rod. The extensometer or strain gage should be properly aligned with the direction of tension. When using an extensometer, the gage length should not be less than 8 times the diameter of the FRP rod. For a stranded FRP rod, the gage length should not be less than 8 times the diameter of the FRP rod, nor less than the strand pitch. An LVDT of at least 50 $\mathrm{mm}$ gage length may be used to measure the displacement on the specimen, at any location between anchors. In cases of FRP rods that may have characteristic deformed pattern lengths greater than 25 $\mathrm{mm}$, the gage length for the LVDT should be at least two times the deformed pattern length.

A.1.5.5 Data acquisition system: The system shall be capable of continuously logging load, strain and displacement at a minimum rate of 2 readings per second. The minimum resolutions shall be $100 \mathrm{~N}$ for load, 100 microstrain for strain, and 0.01 $\mathrm{mm}$ for displacement.

\section{A.1.6. SPECIMEN PREPARATION}

A.1.6.1 Specimens shall be representative of the lot or batch being tested. For grid-type FRP specimen, linear test specimens may be prepared by cutting away extraneous material in such a way as not to affect the performance of the part to be used. Leaving a 2 $\mathrm{mm}$ projection of the crossbars is recommended. Within the gage length of the specimen, no post- production machining, abrading or other such processing is permitted. Such processing may be used in the anchoring sections to promote bond of sample to the anchoring device.

A.1.6.2 During the sampling and preparation of test specimens, all deformation, heating, outdoor exposure to ultraviolet light, possibly causing changes to the material properties of the specimen shall be avoided.

A.1.6.3 The length of the specimen shall be the sum of the length of the test section and the lengths of the anchoring sections. The length of the test section shall not be less than $100 \mathrm{~mm}$, nor shall it be less than 40 times the diameter of the FRP rebar. For FRP rods in twisted strand form, the length shall also be greater than 2 times the strand pitch.

A.1.6.4 The number of specimens shall not be less than five. If the test specimen fails at or slips out of an anchoring section, an additional test shall be performed on a separate specimen taken from the same lot as the failed specimen.

\section{A.1.7. CONDITIONING}

A.1.7.1 Standard Conditioning Procedure- Unless a different environment is specified as part of the experiment, condition the test specimens in accordance with Procedure A of ASTM D 618 and store and test at standard laboratory atmosphere $\left(23 \pm 3^{\circ} \mathrm{C}\right.$ and $50 \pm 10 \%$ relative humidity).

\section{A.1.8. TEST METHOD}

A.1.8.1 When mounting the specimen on the testing machine, care shall be taken to ensure that the longitudinal axis of the specimen coincides with the imaginary line joining the two anchorages fitted to the testing machine.
A.1.8.2 The data acquisition system shall be started a few seconds before starting the loading. The specified rate of loading should be such that the specimen fails in 1 to 10 minutes.

A.1.8.3 The load shall be increased until tensile failure occurs. The strain measurements shall be recorded until the load reaches at least $60 \%$ of the tensile capacity or of the guaranteed tensile capacity.

\section{A.1.9. CALCULATIONS}

A.1.9.1 A load (stress) - strain curve shall be generated from the load (stress) and strain measurements recorded from the extensometer or strain gage readings.

A.1.9.2 The tensile strength shall be calculated according to Eqn. (A.1.1), with a precision to three significant digits.

$$
f_{u}=F_{u} / A
$$

where

$\mathrm{f}_{\mathrm{u}}=$ tensile strength (MPa)

$\mathrm{F}_{\mathrm{u}}=$ tensile capacity $(\mathrm{N})$

$\mathrm{A}=$ cross sectional area of specimen $\left(\mathrm{mm}^{2}\right)$

A.1.9.3 The tensile modulus of elasticity should be taken as a linear regression of the data points from $20 \%$ to $60 \%$ of the tensile strength of the rod. It may be calculated from the difference between the load-strain curve values at $20 \%$ and $60 \%$ of the tensile capacity, obtained from the extensometer or strain gage readings according to Eqn. (A.1.2), and with a precision to three significant digits, provided that the load (stress)-strain curve is linear during this load range. For FRP rods where a guaranteed tensile capacity is given, the values at $20 \%$ and $60 \%$ of the guaranteed tensile capacity may be used.

$$
E A=\frac{P_{1}-P_{2}}{\varepsilon_{1}-\varepsilon_{2}} \quad \ldots(\text { A.1.2) }
$$


where

$\mathrm{E}=$ modulus of elasticity $(\mathrm{MPa})$

$\mathrm{A}=$ cross sectional area $\left(\mathrm{mm}^{2}\right)$ (see "Test Method for Cross Sectional properties of FRP Rods").

$\mathrm{P}_{1}$ and $\varepsilon_{1}=$ load and corresponding strain, respectively, at about $60 \%$ of the ultimate tensile capacity or guaranteed tensile capacity $(\mathrm{N}$ and dimensionless, respectively)

$\mathrm{P}_{2}$ and $\varepsilon_{2}=$ load and corresponding strain, respectively, at about $20 \%$ of the ultimate tensile capacity or guaranteed tensile capacity (N and dimensionless, respectively)

A.1.9.4 Ultimate strain shall be the strain corresponding to the ultimate tensile capacity when the strain gage measurements of the specimen are available up to failure. If extensometer or strain gage measurements are not available up to failure, the ultimate strain shall be calculated from the ultimate tensile capacity and modulus of elasticity according to Eqn. (A.1.3), with a precision to three significant digits.

$$
\varepsilon_{u}=\frac{F_{u}}{E A}
$$

where

$\varepsilon_{\mathrm{u}}=\quad$ ultimate strain (dimensionless)

\section{A.1.10. REPORT}

The test report shall include the following items:

A.1.10.1 The trade name, shape and date of manufacture if available, and lot number of product tested

A.1.10.2 Type of fiber and fiber binding material, volume ratio of fiber

A.1.10.3 Numbers or identification marks of test specimens

A.1.10.4 Designation, nominal diameter, nominal cross sectional area

A.1.10.5 A brief description of the anchorage device, drawings of the anchorage device describing dimensions and materials used

A.1.10.6Date of test, test temperature, loading rate

A.1.10.7 Ultimate tensile capacity for each test specimen, averages and standard deviations for ultimate tensile capacity and tensile strength

A.1.10.8 Tensile modulus of elasticity for each test specimen, means and standard deviations for ultimate tensile capacity and tensile strength

A.1.10.9 Ultimate strain for each test specimen, if measured, averages, and standard deviations, if measured

A.1.10.10 Stress (load) strain curve for each test specimen

A.1.10.11 A brief description, with photographs and sketches if necessary, of the postfailure appearance of each specimen. Report anomalous failure modes observed during testing or anomalous post-failure appearances of any specimens

\section{A.2. Draft Standard Test Method for Flexural Properties of FRP Rods}

\section{A.2.1. SCOPE}

A.2.1.1 This test method specifies the test requirements for flexural properties of FRP rods used in place of steel reinforcement or pre-stressing tendon in concrete.

\section{A.2.2. REFERENCED DOCUMENTS}

D 4476 -97 Standard Test Method for Flexural Properties of Fiber Reinforced Pultruded Plastic Rods.

E4 Standard Practices for Force Verification of Testing Machines.

Japan Society of Civil
Engineers (JSCE) 1997. Recommen-dation for Design and Construction of Concrete Structures Using Continuous Fiber Reinforced Materials, Concrete Engineering Series 23, Ed. A. Machida, Research Committee on Continuous Fiber Reinforcing Materials, Tokyo, Japan, p. 325.

\section{A.2.3. SIGNIFICANCE AND USE}

A.2.3.1 This test method is intended for use in laboratory tests in which the principal variable is the size or type of FRP rods for obtaining the flexural tensile properties.

A.2.3.2 This test method describes the determination of the flexural properties of fiber reinforced pultruded plastic rods. These properties are needed for research and development, quality control, quality assurance, and structural analysis and design.

A.2.3.3 Flexural properties may vary with specimen depth, temperature, atmospheric conditions and rate of loading.

\section{A.2.4. TERMINOLOGY}

A.2.4.1 Test section: The test section shall be the distance between center to center of the support. 
A.2.4.2 Bending tensile capacity: Load at the instant of failure of the test specimen.

A.2.4.3 Ultimate strength in bending: The ultimate stress in the outer fibers at midspan of the specimen.

A.2.4.4 Guaranteed bending capacity: The flexural load minus three times the standard deviation shall be guaranteed by the manufacturer.

\section{A.2.5. TEST EQUIPMENT AND REQUIREMENTS}

A.2.5.1 The testing machine must include a loading device, load indicator, supports and loading nose. The testing machine must also have a structure capable of continuing the test up to the flexure failure. Fig. A.2.1 shows the schematic of flexural test.

A.2.5.2 The loading device shall have a loading capacity in excess of the tensile capacity of the test specimen, and shall be capable of applying load at the required loading rate.

A.2.5.3 Load indicator must be capable of displaying loads with an accuracy of not less than $1 \%$ of the failure load, up to failure of the test specimen.

A.2.5.4 The support anvil shall be suited to the geometry of the test specimen, and shall be capable of accurately transmitting loads from the testing machine to the test specimen. It shall be structured so as to transmit flexural force only to the test specimen, without transmitting either torsion or axial force.

A.2.5.5 The loading nose shall have cylindrical surface. In order to avoid excessive indentations or failure due to stress concentration directly under the loading nose, the radius of the nose shall be at least $6.4 \mathrm{~mm}(1 / 4$ in.) for all specimens. Larger-radius noses are recommended, if significant indentation or compressive failure occurs. The specimen shall be prevented from contacting the sides of the nose by having sufficiently large curvature of the loading nose.

\section{A.2.6. SPECIMEN PREPARATION}

A.2.6.1 Specimen shall be representative of the lot or batch being tested. Test specimen shall, as a rule, not be subjected to any processing. For grid-type FRP specimen, linear test specimens shall be prepared by cutting away extraneous material in such a way as not to affect the performance of the part to be used. It is recommended to leave a $2 \mathrm{~mm}$ projection of the crossbars.

A.2.6.2 The length of the test specimen shall be the length of the test section, which shall be 16 to 24 times the diameter of the rod. In addition to it, an overhang of $10 \%$ of the supported span shall be allowed on each support.

A.2.6.3 The number of test specimens shall not be less than five for each test condition.

\section{A.2.7. CONDITIONING}

A.2.7.1 Standard Conditioning Procedure- Unless a different environment is specified as part of the experiment, tests shall be carried out at a standard laboratory atmosphere $\left(23 \pm 3{ }^{\circ} \mathrm{C}\right.$ and $50 \pm 10 \%$ relative humidity).

A.2.7.2 Preconditioning in other environments to simulate specified conditions and durations is permissible.

A.2.7.3 Testing in other environmental conditions is permissible.

\section{A.2.8. TEST METHOD}

A.2.8.1 When mounting the test specimen on the testing machine, care shall be taken to ensure that the load is applied at midspan of the test specimen.

A.2.8.2 In order to determine modulus of elasticity in bending and maximum strain in outer fibers of the test specimen, strain gages shall be mounted in the extreme tensile fiber in the test section close to midspan and LVDT at midspan of the test specimen.

A.2.8.3 The data acquisition system shall be started a few seconds before starting the loading. The applied load, extreme fiber strain and deflection at center shall be recorded by the data acquisition system.

A.2.8.4 Loading shall be continued until the failure of the test specimen. Load and failure location shall be measured and recorded at the time of failure.

\section{A.2.9. CALCULATION}

A.2.9.1 The material properties of FRP rod shall only be assessed on the basis of the test specimen undergoing failure in flexure within the test section.

A.2.9.2 The average, maximum, minimum, and standard deviation of the bending tensile capacity shall be calculated.

The maximum stress and strain in the outer fibres shall be calculated according to Eq. (A.2.1) and Eq. (A.2.2), respectively

$$
\begin{aligned}
& \sigma=\frac{P \times L \times C}{4 \times I} \ldots(\text { A.2.1) } \\
& \varepsilon=\frac{12 \times C \times Y}{L^{2}} \ldots(\text { A.2.2) }
\end{aligned}
$$

Also, the modulus of elasticity in bending can be calculated as follows:

$$
\mathrm{E}=\frac{P \times L^{3}}{48 \times I \times Y} \ldots \text { (A.2.3) }
$$

Where;

$\sigma=$ maximum fiber stress 
$\left(\mathrm{N} / \mathrm{mm}^{2}\right)$

$\varepsilon=$ maximum strain $(\mathrm{mm} / \mathrm{mm})$

$\mathrm{P}=$ ultimate load applied at

midspan of the test specimen $(\mathrm{N})$

$\mathrm{C}=$ distance from the centriod of

the section of the bars with the outer fiber (mm)

$\mathrm{Y}=$ maximum deflection at load under consideration $(\mathrm{mm})$

$\mathrm{I}=$ moment of inertia $\left(\mathrm{mm}^{4}\right)$

$\mathrm{L}=$ center-to-center distance between the supports ( $\mathrm{mm}$ ).

The location and mode of failure shall be observed and recorded for each test specimen.

\section{A.2.10. REPORT}

The test report shall include the following items:

A.2.10.1 Name of FRP rod and shape and date of manufacture of FRP rod.

A.2.10.2 Type of fiber and fiber binding material, volume ratio of fiber.

A.2.10.3 Numbers identification marks of test specimens.

A.2.10.4 Designation, nominal diameter, and nominal cross- section area.

A.2.10.5 Date of test, test temperature, loading rate.

A.2.10.6 Condition of surface of FRP rod (material, thickness, configuration etc. of any coating, etc.).

A.2.10.7Bending tensile capacity for each test specimen, maximum strains, modulus of elasticity, average values and standard deviations.

A.2.10.8 Location and mode of failure for each test specimen.

Figure A.2.1 Test setup

\section{A.3. Draft Standard Test Method for Shear Properties of FRP Rod}

\section{A.3.1. SCOPE}

USE

A.3.1.1 This test method specifies the test requirements for determining the shear properties of FRP rods used in place of steel reinforcement or prestressing tendon in concrete by direct application of double shear.

\section{A.3.2. REFERENCED DOCUMENTS}

D 618 - 96 Standard Practice for Conditioning Plastics for Testing

E 4 - 01 Standard Practices for Force Verification of Testing Machines.

\section{A.3.3. SIGNIFICANCE AND}

A.3.3.1 This test method for transverse shear strength is intended for use in laboratory tests in which the principal variable is the size or type of FRP rods. This test method establishes values of shear strength for material specifications, quality control, quality assurance, research and development, and may also be used for structural design purposes.

A.3.3.2 The transvese shear strength shall be measured according to the method given here, in keeping with the intended purposes.

\section{A.3.4. TERMINOLOGY}

A.3.4.1 Double Shear Strength: The shear stress at maximum load in which the planes of fracture are perpendicular to the longitudinal axis of the specimen.

\section{A.3.5. TEST EQUIPMENT AND REQUIREMENTS}

A.3.5.1 The testing machine shall generally conform to ASTM Practices E 4 and have a loading capacity in excess of the tensile capacity of the specimen and shall be capable of applying load at the required loading rate. The testing machine should also be capable of giving readings of loading accurate to within $1 \%$ throughout the test.

A.3.5.2 Figure A.3.1 shows a typical test set-up. It consists of sample holder, one upper blade, 
and two lower blades. The sample holder has dimensions of $230 \mathrm{~mm}$ long, $100 \mathrm{~mm}$ wide, and $110 \mathrm{~mm}$ high, and a longitudinal V-shape cut for placing FRP samples and a rectangle cut for holding upper and lower blades in the center of its top part. There are several sets of blades with different sizes of half-ring cuts for different diameters of FRP rods.

A.3.5.3 The shear testing apparatus shall be made of steel and constructed so that a rodshaped specimen is sheared on two planes more or less simultaneously by two blades (edges) converging along the faces perpendicular to the longitudinal axis of the test specimen. The gap in the axis direction between the upper and lower blades shall not be greater than $0.5 \mathrm{~mm}$, and shall be made as small as possible.

\section{A.3.6. SPECIMEN PREPARATION}

A.3.6.1 Test specimens shall be representative of the lot or batch being tested and, as a rule, shall not be subjected to any processing. For grid-type FRP rods, linear test specimens shall be prepared by cutting away extraneous material in such a way as not to affect the performance of the part to be tested. Test specimens shall be as straight as possible; severely bent pieces shall not be used.

A.3.6.2 During the sampling and preparation of test specimens, all deformations, heating, outdoor exposure to ultraviolet light, etc. causing changes to the material properties of the test specimen, shall be avoided.

A.3.6.3 Test specimens shall be $300 \mathrm{~mm}$ long regardless of the diameter of the FRP rods.
A.3.6.4 The number of test specimens shall not be less than five. If a specimen shows significant pullout of fibers, indicating that failure is not due to shear, an additional test shall be performed on a separate test specimen taken from the same lot as the failed specimen.

\section{A.3.7. CONDITIONING}

A.3.7.1 Standard Conditioning Procedure: The specimens shall be conditioned in accordance with Procedure A of ASTM D 618; and shall be stored and tested at the standard laboratory atmosphere $\left(23 \pm 3{ }^{\circ} \mathrm{C}\right.$ and $50 \pm$ $10 \%$ relative humidity), unless a different environment is specified as part of the experiment.

\section{A.3.8. TEST METHOD}

A.3.8.1 The test specimen shall be mounted in the center of the shear apparatus, touching the upper loading device. No gap shall be visible between the contact surface of the loading device and the test specimen.

A.3.8.2 The loading rate shall be such that the shear stress increases at a rate of 30-60 $\mathrm{MPa}$ per minute. Load shall be applied uniformly without subjecting the test specimen to shock.

A.3.8.3 Loading shall be continued until the test specimen fails. The failure load shall be recorded with a precision to three significant digits. It shall be noted that loading may decrease temporarily, due to the presence of two rupture faces.

\section{A.3.9. CALCUlation}

A.3.9.1 Failure, whether it is due to shear or not, shall be determined by visual inspection. If pullout of fibers is obvious, the data shall be disregarded and additional tests shall be performed until the number of test specimens failing due to shear is not less than five.

A.3.9.2 Shear strength shall be calculated according to Eq. (A.3.1) with a precision to three significant digits.

$$
\tau=\frac{\mathrm{P}}{2 \mathrm{~A}} \ldots(\mathrm{A} .3 .1)
$$

Where,

$\tau=$ shear strength $(\mathrm{MPa})$

$\mathrm{P}=$ shear failure load $(\mathrm{N})$

$\mathrm{A}=$ cross sectional area of test specimen $\left(\mathrm{mm}^{2}\right)$

\section{A.3.10. REPORT}

The test report shall include the following items:

A.3.10.1 Name of FRP rod and shape, and date of manufacture of FRP rod if available, and lot number of product tested.

A.3.10.2 Type of fiber and fiber binding material, volume ratio of fiber
A.3.10.3 Numbers
identification marks of test specimens

A.3.10.4 Designation, nominal diameter and maximum cross sectional area

A.3.10.5 Date of test, test temperature, loading rate

A.3.10.6 Condition of surface of FRP rod (material, thickness, configuration, any coating, etc.)

A.3.10.7 Distance between shear failure faces

A.3.10.8 Shear failure load for each test specimen, average shear failure load and shear strength and standard deviation.

A.3.10.9 Failure mode of each test specimen 


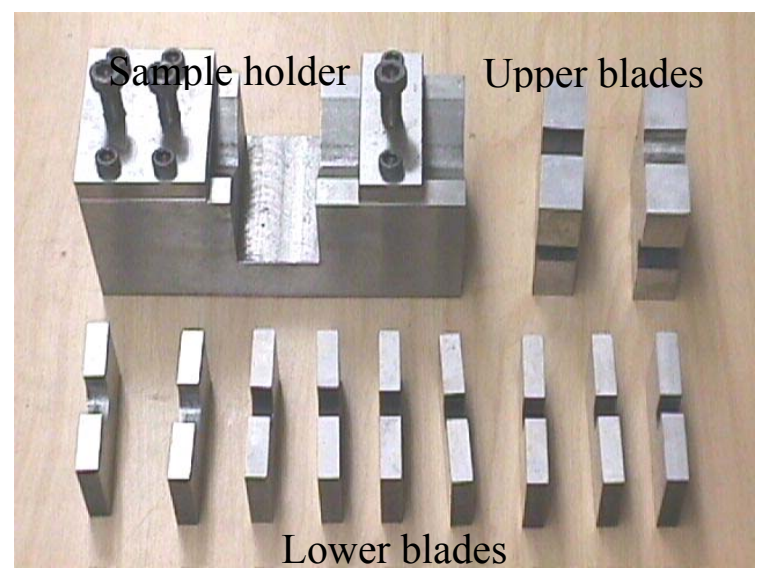

(a) Pieces of the apparatus

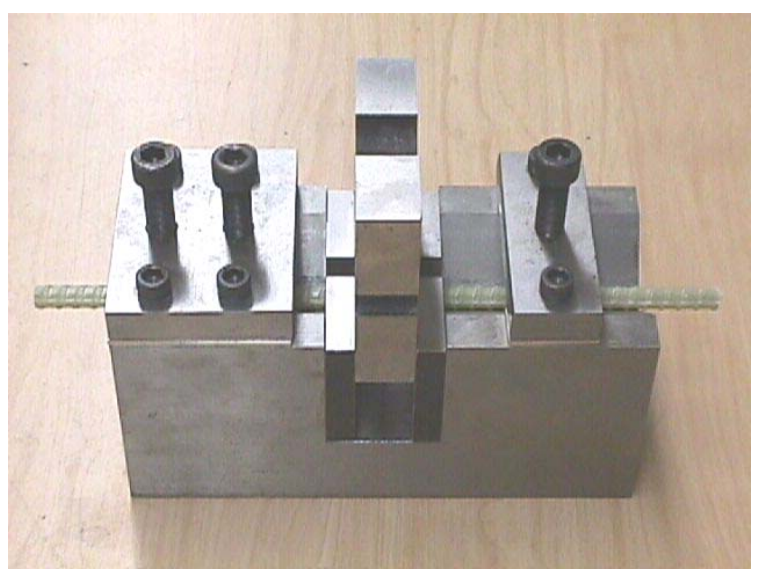

(b) Overview of test setup

Figure A.3.1 Double shear testing machine

\section{A.4. Draft Standard Test Method for Bond Strength of FRP Rods by}

\section{Pullout Testing}

\section{A.4.1. SCOPE}

A.4.1.1 This test method specifies the test requirements for determining the bond strength of FRP rods used in place of steel reinforcing bars in concrete by pull out testing.

\section{A.4.2. REFERENCED DOCUMENTS}
A.4.2.1 ASTM Standards
A 944 - 95 Standard Test Method for Comparing Bond Strength of Steel Reinforcing Bars to Concrete Using Beam- End Specimens
C 39 - 94 Standard Test Method for Compressive Strength of Cylindrical Concrete Specimens.
C 143 - 90a Standard Test Method for Slump of Hydraulic Cement Concrete.

C 192 - 95 Standard Practice for Making and Curing Concrete Test Specimens in the Laboratory.

C 234 - 91a Standard Test Method for Comparing Concrete on the Basis of the Bond Developed with Reinforcing Steel.

C 293 - 79 Standard Test Method for Flexural Strength of Concrete (Using Simple Beam With Center-Point Loading)

C $511-85 \quad$ Standard Specification for Moist Cabinets, Moist Rooms, and Water Storage Tanks Used in the testing of Hydraulic Cements and

C 617 - 87 Standard Practice for Capping Cylindrical Concrete Specimens

D 618 - 96 Standard Practice for Conditioning Plastics for Testing Concrete

\section{E 4 - 01 Standard Practices for Force Verification of Testing Machines.}

\section{A.4.3. SIGNIFICANCE AND USE}

A.4.3.1 This test method for measuring bond strength by pullout testing is intended for use in laboratory tests in which the principal variable is the size or type of FRP rods. The test method should not be used to establish design bond values and development lengths for FRP rods embedded in concrete.

A.4.3.2 This test method is intended to determine bond behavior for material specifications, research and development, and quality assurance. The bond behavior will be specimen configuration dependent, which may affect both analysis and design. It shall be measured according to the method 
given here, in keeping with the intended purposes. The primary test result is the bond strength of the test specimen to normalweight concrete, which is an important factor to be considered in the use of FRP rods as reinforcing bars.

A.4.3.3 This test method may also be used to determine the conformance of a product or a treatment to a requirement relating to its effect on the bond developed between FRP rod and concrete. The result obtained from this test method should be used only for comparative purposes to compare parameters or variables of bond strength. The method may be used to establish longterm environmental effects on bond to concrete, including environmental reduction factors for FRP bars embedded in concrete.

\section{A.4.4. TERMINOLOGY}

A.4.4.1 Circumference: The length of the FRP rod, which forms the basis for calculation of bond strength; determined separately for each FRP rod.

A.4.4.2 Bonded Length: The length of the test rod that is in contact with concrete.

\section{A.4.5. TEST EQUIPMENT AND REQUIREMENTS}

A.4.5.1 The testing machine for pullout tests shall generally conform to ASTM Practices E-4 and be capable of accurately applying the prescribed load. The load shall be applied to the reinforcement bar at a rate not greater than $22 \mathrm{kN}$ (5,000 lbf) per minute or at the no-load speed of the testing machine head not greater than $1.27 \mathrm{~mm}$ (0.05 in.) per minute, depending on the type of testing machine used and the means provided for ascertaining or controlling speeds.

A.4.5.2 The loading plate
(Figure A.4.3) shall be a machined steel plate at least 200 $\mathrm{mm}$ square and $20 \mathrm{~mm}$ thick, and have a hole drilled through its center to accommodate the FRP rod with sufficient clearance.

A.4.5.3 The loading end of the FRP rod shall be fitted with an anchorage capable of transmitting loads until the rod is pulled out of the concrete by a bond failure. The load transmission device shall transmit axial loads only to the FRP rods, without transmitting either torsion or flexural forces.

A.4.5.4 The displacement meters fitted to both the free and loaded ends of the FRP rod shall be LVDTs or similar apparatuses, reading accurately to $0.01 \mathrm{~mm}$. Provisions for bending compensation shall be made. Three displacement gages (LVDT) at 120-degree intervals or two gages at 180-degree intervals at each end of the bar are recommended.

A.4.5.5 Molds for bond test specimens will be of two types: for $200 \mathrm{~mm}$ concrete cubes each containing a vertically embedded rod, and for 200 by 200 by 400 $\mathrm{mm}$ prisms each containing two horizontally embedded rods. The molds preferably shall be made of metal, not less than $6 \mathrm{~mm}$ thick. The molds shall be watertight and be constructed for easy removal without disturbance of embedded rods.

\section{A.4.6. SPECIMEN PREPARATION}

A.4.6.1 FRP rod specimens shall be representative of the lot or batch being tested. Each specimen shall be cut into 1200 $\mathrm{mm}$ long sections and assembled with an anchor at one end (see "Anchor for Testing FRP Rebars under Monotonic, Sustained and Cyclic Tension"). The test specimens shall be either one of the two types: one containing one FRP rod embedded vertically (Figure A.4.1), and the other containing two FRP rods embedded horizontally (Figure A.4.2). Five specimens of each type shall constitute a set of test specimens. If a test specimen is found to have failed or slipped at an anchoring section, or to have split the concrete cover, an additional test shall be performed on a separate test specimen taken from the same lot as the failed specimen.

A.4.6.2 Specimens for vertically embedded bar (Figure A.4.1): These specimens shall consist of concrete cubes, 200 $\mathrm{mm}$ (8 in.) on each edge, with a single FRP rod embedded vertically along a central axis in each specimen. The rod shall project upward from the top face a sufficient length to extend through the bearing blocks and the support of the testing machine and provide an adequate length to be gripped for application of load. The cover shall not be less than 5 $\mathrm{d}_{\mathrm{b}}$, to avoid splitting of the concrete cover. If splitting failure of concrete occurs, a larger prism of $300 \mathrm{~mm}$ is then required and new tests should be performed.

A.4.6.3 Specimens for horizontally embedded bars (Figure A.4.2): These specimens shall consist of concrete prisms $200 \times 200 \times 400 \mathrm{~mm}(8 \times 8 \times 16$ in.) with the longer axes in the vertical direction. Two rods shall be embedded in each specimen, perpendicular to the longer axis and parallel to and equidistant from the sides of the prism. In the vertical direction, one rod shall be located with its axis $100 \mathrm{~mm} \mathrm{(4}$ in.) from the bottom of the prism, and the other with its axis 300 $\mathrm{mm}$ (12 in.) from the bottom. Both rods shall project from the sides of the specimen located at distances similar to those for vertical specimens. A triangular groove shall be formed on each of 
the two opposite sides of the prism parallel to the rods and at the mid-height of the prism. These grooves shall be at least 13 $\mathrm{mm}$ (1/2 in.) deep, measured perpendicular to the surface of the concrete. The grooves are to facilitate breaking of the prism into two test specimens at this weakened plane, prior to performing the bond tests.

A.4.6.4 The bonded length of the FRP rod shall be a minimum of five times the diameter of the FRP rod. If the bonded length as defined above is considered not to represent the bonding characteristics of the FRP rod, the bond length may be extended as appropriate. Outside of the bonded section, the embedded bar shall be sheathed with PVC or other suitable material to prevent bonding. At the free end, rods shall protrude a distance either sufficient to attach two LVDTs as shown in Fig. A.4.3, or of $10 \mathrm{~mm}$ as shown in Fig. A.4.5.

A.4.6.5 The molds for bond test specimens shall be in accordance with ASTM C 234. Special care shall be taken as follows:

A.4.6.5.1 The opening in the form through which the FRP rod is inserted shall be sealed using oil, putty, or similar materials, to prevent ingress of water, etc.

A.4.6.5.2 The orientation of the specimen shall not be changed until the form is removed.

A.4.6.6 Prior to casting the test specimens, coat the inside surface of the molds with a thin film of mineral oil, petroleum jelly, or stearic acid paste. The following procedures are recommended for placement of concrete in the molds, unless another wellestablished method is employed instead.

A.4.6.6.1 For the $200 \mathrm{x}$ $200 \times 400-m m(8 \times 8 \times 16$-in.) prisms, place the concrete in four layers of approximately equal thickness and rod each layer 25 times with a $16 \mathrm{~mm}$ (5/8 in.) diameter tamping rod.

A.4.6.6.2 For the 200-mm (8-in.) cubes, place the concrete in four layers of approximately equal thickness and rod each layer 25 times with a $16 \mathrm{~mm}$ (5/8 in.) diameter tamping rod.

A.4.6.6.3 After the top layer has been consolidated, strike off the surface with a trowel and protect against moisture evaporation by one of the acceptable methods described in paragraph 7.1, on Covering after Finishing, of ASTM C 192. Care shall be taken that evaporation does not take place in the area adjacent to the protruding FRP rod for vertically cast specimens.

A.4.6.6.4 The concrete shall be a standard mix, with coarse aggregates having a maximum dimension of 20 to 25 $\mathrm{mm}$. It shall be batched and mixed in accordance with the applicable portions of ASTM C 192. The concrete shall have slump of $10 \pm 2 \mathrm{~cm}$ in accordance with ASTM C 143, and the compressive strength at 28 days shall be $30 \pm 3 \mathrm{MPa}$ for bond testing in accordance with ASTM C 39. A minimum of five standard 150 x 300-mm (6 x 12in.) or $100 \times 200-\mathrm{mm}(4 \times 8$-in $)$ control cylinders shall be made for determining compressive strength from each batch of concrete.

A.4.6.6.5 Molds shall not be removed from the specimens earlier than 20 hours after casting. Extreme care shall be taken to prevent striking or otherwise disturbing the FRP rods. Immediately after removing the molds, specimens shall be cured in accordance with ASTM C 511 until the time of test. Specimens shall be tested at an age of 28 days.

A.4.6.6.6 When the specimens are between 7 and 14 days old, the $200 \times 200 \times 400-\mathrm{mm}$ ( $8 \times 8 \times 16$-in.) prisms shall be broken in half to form two 200$\mathrm{mm}$ (8-in.) cubes. Specimens shall be broken as simple beams with center-point loading in accordance with ASTM C 293. The two triangular grooves in the upper and lower faces of the prisms shall be located at midspan. The load shall be applied to a 19-mm (3/4-in.) diameter bar laid in the upper groove until fracture occurs. Care shall be taken not to strike or otherwise disturb the FRP rods during the operation.

A.4.6.6.7 The surface of the $200 \mathrm{~mm}$ (8 in.) cube containing the vertically embedded rod shall be capped, so as to utilize it as the bearing surface in the pullout test. The applicable portions of ASTM C 617 , relative to capping materials and procedures, shall be used.

\section{A.4.7. TEST CONDITIONS}

A.4.7.1 Unless a different testing environment is specified as part of the experiment, the pullout tests shall be conducted at standard laboratory atmosphere $\left(23 \pm 3^{\circ} \mathrm{C}\right.$ and $50 \pm 10 \%$ relative humidity).

A.4.7.2 Preconditioning of FRP rod specimens before casting in concrete, such as postproduction machining, abrading or other such processing, is permitted, but should be reported.

\section{A.4.8. TEST METHOD}

A.4.8.1 The specimen shall be mounted in the testing machine in one of the following two test setups.

A.4.8.1.1 The capped or bearing surface of the cube from which the long end of the rod projects shall be in contact with the bearing block assembly in accordance with paragraph 4.3 of 
ASTM C 234. The spherically seated bearing block shall rest on a support, which transfers the reaction from this block to the load cell of the testing machine. The projecting FRP rod shall extend through the bearing block assembly and the support, and the anchorage shall be gripped for tension by the jaws of the testing machine (Fig. A.4.3).

A.4.8.1.2 The concrete cube should be seated on a slotted steel tube and fixed on the stationary head of the testing machine as shown in Fig. A.4.4. Three LVDTs at the loaded end and one LVDT at the free end are attached to measure the slips of the FRP rod, as shown in Figs. A.4.4 and A.4.5. The anchor should be gripped on the moving head of the testing machine for tension by the jaws of the testing machine.

A.4.8.2 The testing apparatus shall be assembled with the specimen. The distance between the bearing face of the concrete and the horizontal plane passing through the point on the FRP rod, where the cross bar of the device for measuring slip plus elongation is attached, shall be recorded to the nearest 0.1 of the smallest scale of the meter. The elongation of the FRP rod over this distance shall be calculated and deducted from the measured slip plus elongation to obtain the loadedend slip. Moreover, free-end slip shall also be measured to the nearest $0.5-\mathrm{mm}$ (0.02-in).

A.4.8.3 The load shall be applied to the FRP rod at a rate of 10-20 MPa per minute, or at a testing machine head speed not greater than $1.27 \mathrm{~mm}$ per minute (0.05 in. per minute).

A.4.8.4 The applied load and the LVDT readings shall be read and recorded at a sufficient number of intervals throughout the test to provide at least 15 readings by the time a slip of 0.25 $\mathrm{mm}(0.010 \mathrm{in}$.) has occurred at the loaded end of the FRP rod. The slippage of the free-end shall be recorded in increments of 0.01 $\mathrm{mm}$, together with the corresponding applied load.

A.4.8.5 The loading and readings shall be continued at appropriate intervals until (i) rupture of the FRP rod occurs, (ii) the enclosing concrete splits, or (iii) slippage of at least $2.5 \mathrm{~mm}$ ( 0.10 in.) occurs at the loaded end of the embedded length.

\section{A.4.9. CALCULATIONS}

A.4.9.1 Five valid test specimens are required. A valid specimen is the one that: (1) does not fail in or slip out of the anchoring section, (2) does not create splitting of cracking of the concrete cube.

A.4.9.2 The average bond stress shall be calculated according to Eq. (A.4.1) and reported with a precision to three significant digits, and the curves for the pullout or bond stress versus slippage at both free-end and loaded-end displacement for each test specimen shall be plotted.

$$
\tau=\frac{F}{C_{b} \cdot l} \ldots(\text { A.4.1) }
$$

where

$\tau=$ average bond stress (MPa)

$\mathrm{F}=$ tensile load $(\mathrm{N})$

$C_{b}=$ circumference of FRP rod (mm) and

$1=$ bonded length ( $\mathrm{mm})$

A.4.9.3 Average bond stresses causing slippage of $0.05 \mathrm{~mm}, 0.10$ $\mathrm{mm}$, and $0.25 \mathrm{~mm}$ at the free end and the loaded end shall be calculated, along with the maximum bond stress at failure.

A.4.9.4 At each load level, the slip at the loaded end shall be calculated as the average of the readings of the LVDTs, minus the elongation of the FRP rod in the length between the top surface of bonded length and the point of attachment of the measuring device on FRP rod, the latter being calculated as follows:

$$
S_{c}=\frac{P L_{c}}{E A}
$$

where

$\mathrm{S}_{\mathrm{c}}=$ elastic elongation $(\mathrm{mm})$

$\mathrm{P}=$ tensile load $(\mathrm{N})$

$\mathrm{L}_{\mathrm{c}}=$ length between the top surface of bonded length and the point of attachment of the measuring device on FRP rod (mm) (see Fig. A.4.3)

$\mathrm{E}=$ modulus of elasticity of FRP $\operatorname{rod}(\mathrm{MPa})$ and

$\mathrm{A}=$ nominal cross sectional area $\left(\mathrm{mm}^{2}\right)$

\section{A.4.10. REPORT}

The test report shall include the following items:

A.4.10.1 Properties of the concrete

A.4.10.1.1 The mix proportions of cement, fine aggregate, coarse aggregate, admixture (if any used), and the water-cement ratio

A.4.10.1.2 Slump of freshly mixed concrete as determined in accordance with ASTM C 143

A.4.10.1.3 Twenty-eight day strength of control cylinders as determined in accordance with ASTM C 39

A.4.10.1.4 Any deviation from the stipulated standards in such aspects as mixing, curing, dates of demolding and testing of control cylinders

A.4.10.2 Properties of the FRP $\operatorname{rod}$

A.4.10.2.1 The trade name, date of manufacture, and shape of FRP rod

A.4.10.2.2 Type of fiber and fiber binding material, fiber volume fraction, type of surface treatment of FRP

A.4.10.2.3 Designation, nominal diameter, nominal cross sectional area

A.4.10.2.4 Modulus of elasticity and ultimate tensile strength as determined in 
accordance with 'Standard Test Method for Tensile Properties of FRP Rods'.

A.4.10.2.5 A close-up photograph of the rods showing surface deformations and characteristics

A.4.10.3 Numbers identification marks of test specimens

A.4.10.4 Date of test, test temperature, loading rate

A.4.10.5 Dimensions of test specimens, bonded length of FRP rod.

A.4.10.6 A brief description of the gripping device

A.4.10.7 Average bond stress causing slippage at the free end of $0.05 \mathrm{~mm}, 0.10 \mathrm{~mm}$ and $0.25 \mathrm{~mm}$ for each specimen

A.4.10.8 Average bond stress causing slippage at the loaded end at intervals of values from 0 to $0.25 \mathrm{~mm}$ for each test specimen

A.4.10.9 Maximum bond stress, failure mode and averages for each test specimen.

A.4.10.10 Bond stressslippage displacement (free-end and loaded end) curves for each test specimen
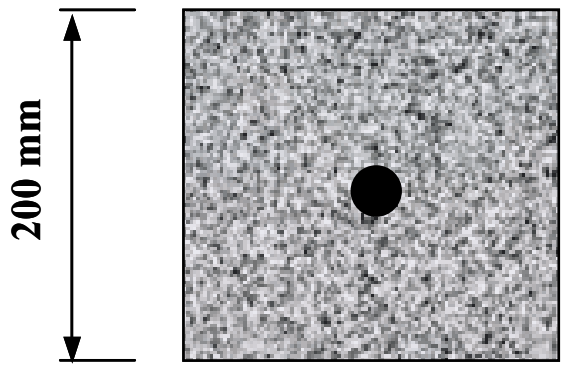

$200 \mathrm{~mm}$
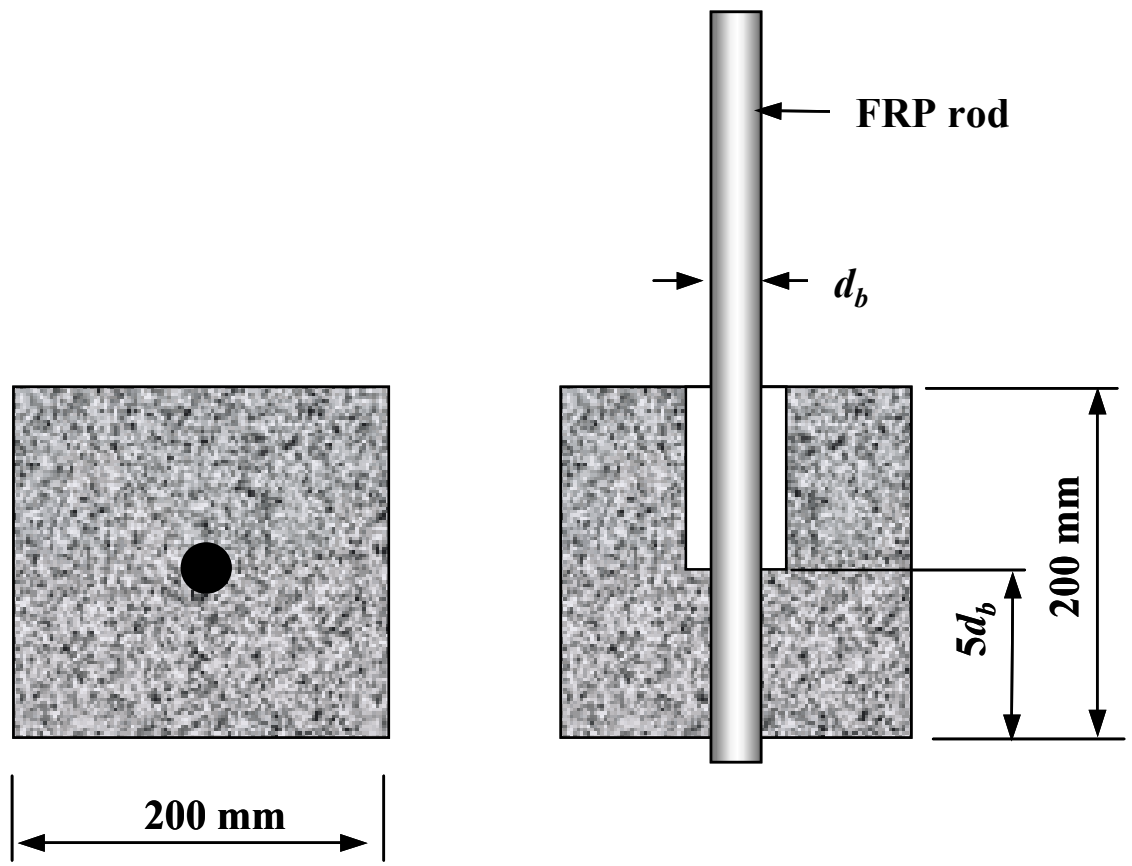

Figure A.4.1. Vertical bond test specimen 

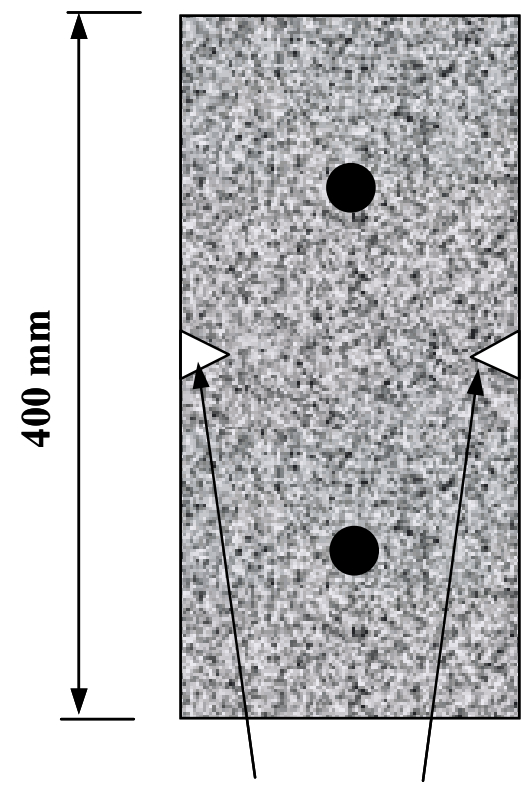

Triangular grooves $13 \mathrm{~mm}$ deep

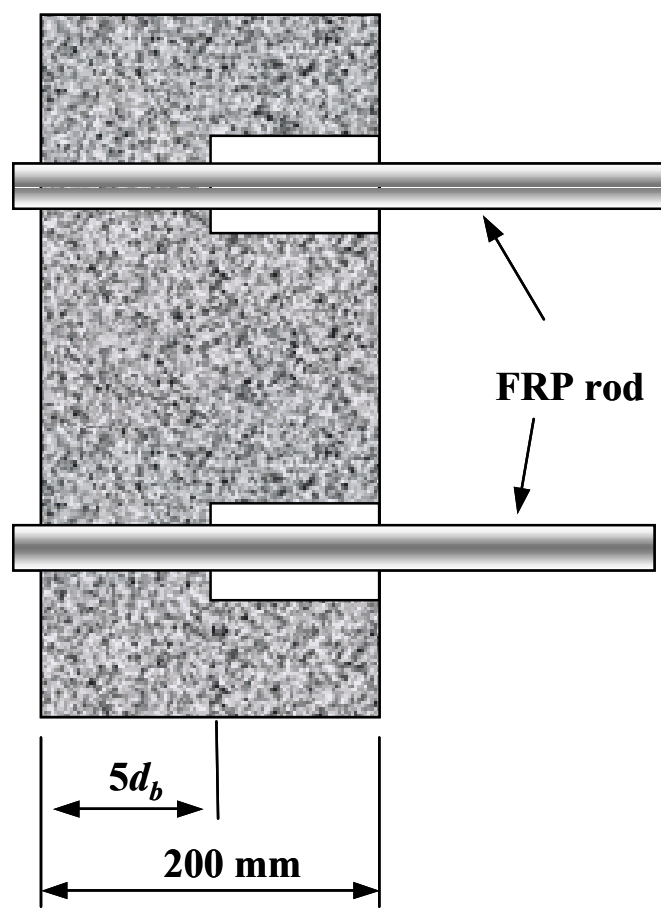

Figure A.4.2 Horizontal bond test

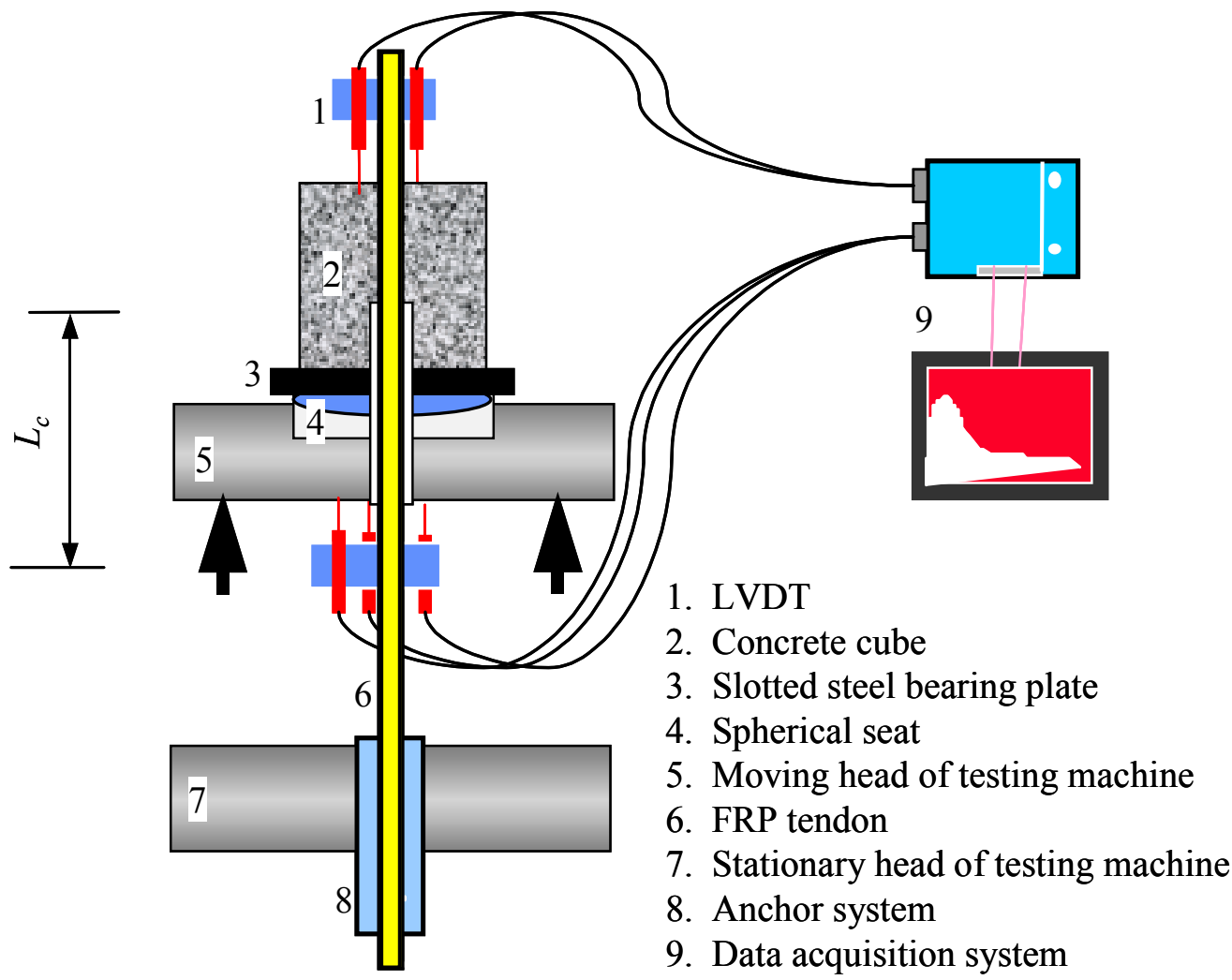


Figure A.4.3 Schematic details of bond test setup 1

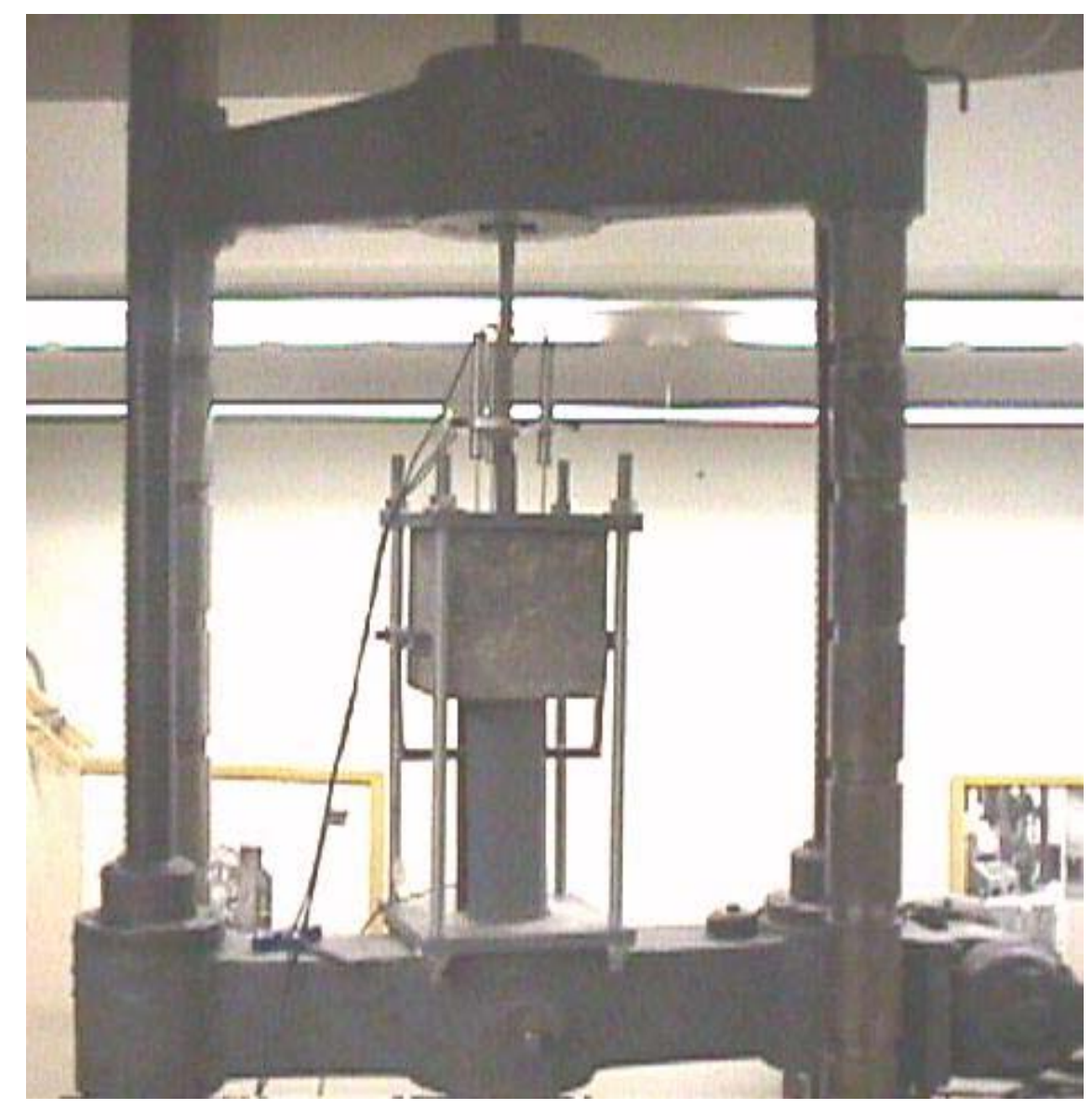

Figure A.4.4 Typical bond test setup 2

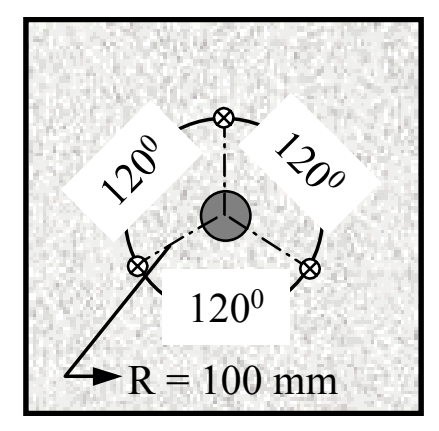

$\otimes$ LVDT

(a)

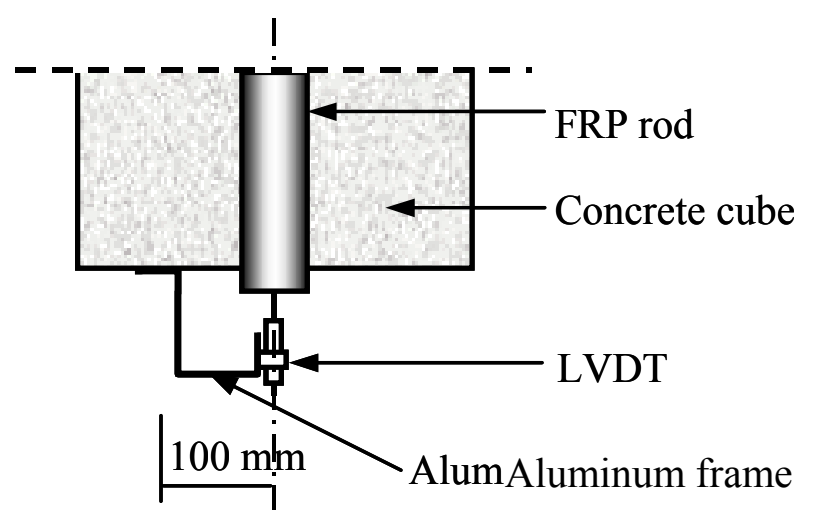

(b)

Figure A.4.5 Typical positions of LVDTs at the surface of the concrete cube: (a) plan view of LVDTs at the top surface, and (b) vertical view of LVDTs at the bottom surface 


\section{A.5. Draft Standard Test Method for Moisture Absorption of FRP Rods}

\section{A.5.1. SCOPE}

A.5.1.1 This test procedure specifies the method for determining the relative rate of water absorption for an FRP rod.

\section{A.5.2. REFERENCED DOCUMENTS}

\author{
A.5.2.1 ASTM Standard \\ D570 - 98 Standard Test \\ Method for Water \\ Absorption of Plastics
}

\section{A.5.3. SIGNIFICANCE AND USE}

A.5.3.1 The exposure to water or humid condition could have a direct effect on the electrical and mechanical properties of FRP rebars. The rate of water absorption is an indication of the receptivity of the FRP rebars to such conditions. This test method for determining the rate of water absorption serves as a control test insuring the uniformity of FRP rebars.

A.5.3.2 Ideal diffusion of liquids into polymers is a function of the square root of immersion time. Time of saturation depends on the specimen thickness.

\section{A.5.4. TERMINOLOGY}

A.5.4.1 The absorption is defined as the weight gained by a specimen after being immersed in water for a specific length of time.

\section{A.5.5. APPARATUS}

A.5.5.1 High precision balance- an analytical balance of 0.0001 g accuracy

\section{A.5.6. TEST SPECIMEN}

A.5.6.1 Specimen shall be representative of the lot or batch being tested. Test specimen shall not be subjected to any processing.

A.5.6.2 During the sampling and preparation of the FRP test specimen, all deformation, heating, outdoor exposure to ultraviolet light, etc., which cause changes to the material properties of the test specimen shall be avoided.

A.5.6.3 The length of the test specimen shall be $25.4 \mathrm{~mm}$ (1in.) long for rods $25.4 \mathrm{~mm}$ in diameter or under and $12.7 \mathrm{~mm}(1 / 2 \mathrm{in}$.) longer than the diameter for larger-diameter of the finished rod.

A.5.6.4 The two end cut faces of the test specimen shall be sealed by epoxy resin.

\section{A.5.7. CONDITIONING}

A.5.7.1 The specimens should be cleaned with water using a plastic brush to remove any contamination or dust. The clean specimen shall then be dried in a vacuum chamber at room temperature.

\section{A.5.8. NUMBER SPECIMENS}

A.5.8.1 The number of test specimens shall not be less than five in order to obtain satisfactory average and standard deviation.

\section{A.5.9. TEST PROCEDURE}

A.5.9.1 The conditioned, cleaned and dried specimens shall be placed in a container of distilled water maintained at a temperature of $23 \pm 3{ }^{\circ} \mathrm{C}(73 \pm 5$ $\left.{ }^{\circ} \mathrm{F}\right)$.

A.5.9.2 A specimen shall be weighed several times in a microbalance with an accuracy of $0.1 \mathrm{mg}$ until a constant weight is reached.

\section{A.5.10. RECONDITIONING}

A.5.10.1 When materials are known or suspected to contain any appreciable amount of watersoluble ingredient, the specimens, after immersion, shall be weighed, and then reconditioned for the same time and temperature as in the original drying period.

\section{A.5.11. CALCULATIONS}

A.5.11.1 Percentage increase in weight during immersion is calculated to the nearest $0.01 \%$ as follows.

Increase in weight, $\%=$

wet weight - conditioned weight

conditioned weight

\section{A.5.12. REPORT}

The test report shall include the

following items:

A.5.12.1 The trade name, date of manufacture, and shape of FRP rebar.

A.5.12.2 Type of fiber binding material, and volume ratio of fibers.

A.5.12.3 Numbers or identification marks of test specimens.

A.5.12.4 Designation, nominal diameter, and nominal cross sectional area. 
A.5.12.5 Date of testing, graph of the increase in weight conditioning time and shall be plotted as a function of temperature at the time of testing. the square root of each immersion A.5.12.6 Immersion time and procedure.

A.5.12.7 Percentage of increase in weight during immersion. A time. The initial slope of this graph is proportional to the diffusion constant of water in FRP rod. The plateau region with little or no change in weight as a function of the square root of immersion time represents the saturation water content of a FRP rebar. 


\section{APPENDIX B - PLOTS}

\section{B.1 Stress-strain plots for tension tests - Ribbed CFRP - \#3 (Refer Table 4.3, Chapter 4, Section 4.3.1)}

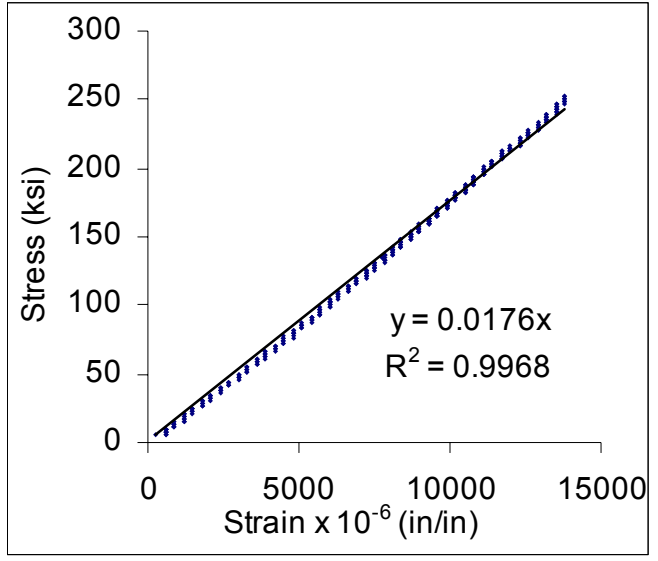

Sample 1

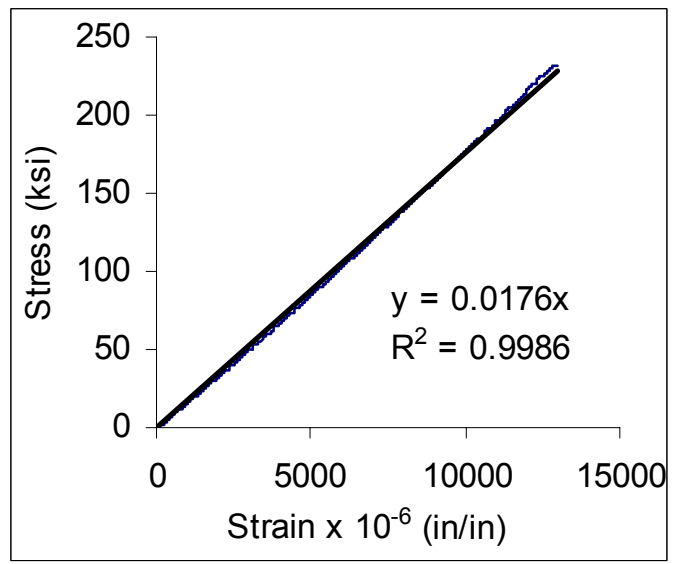

Sample 3

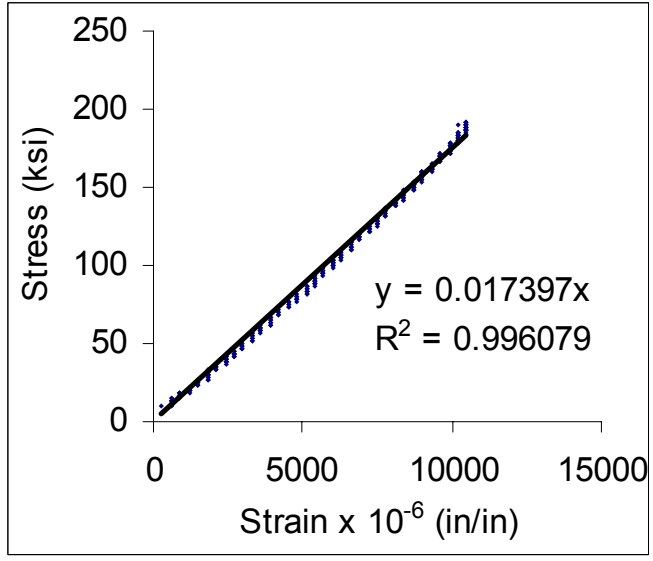

Sample 2

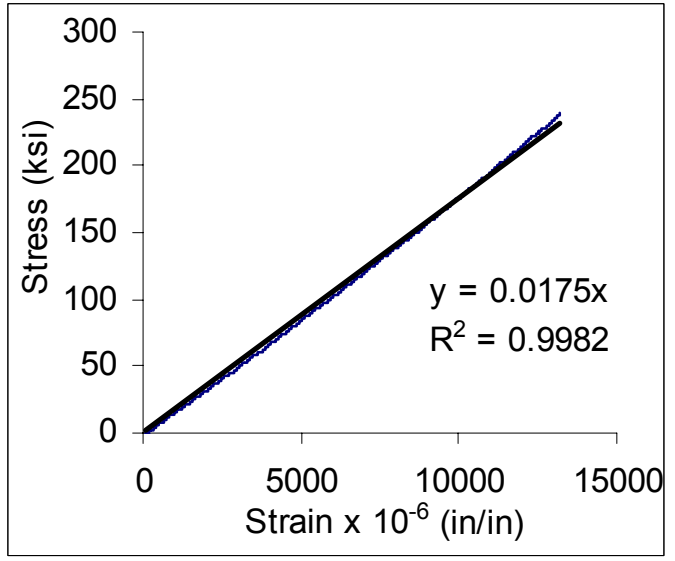

Sample 4

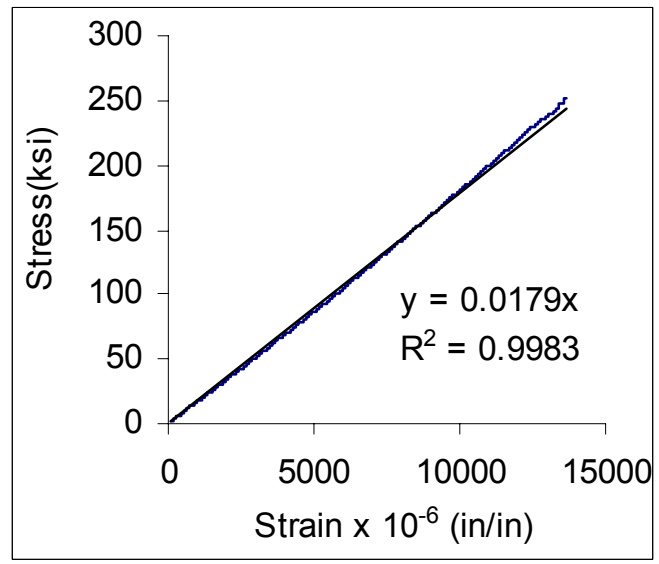

Sample 5 
B.2 Stress-strain plots for tension tests - Ribbed GFRP - \#4 WVU (Refer Table 4.4, Chapter 4, Section 4.3.2)

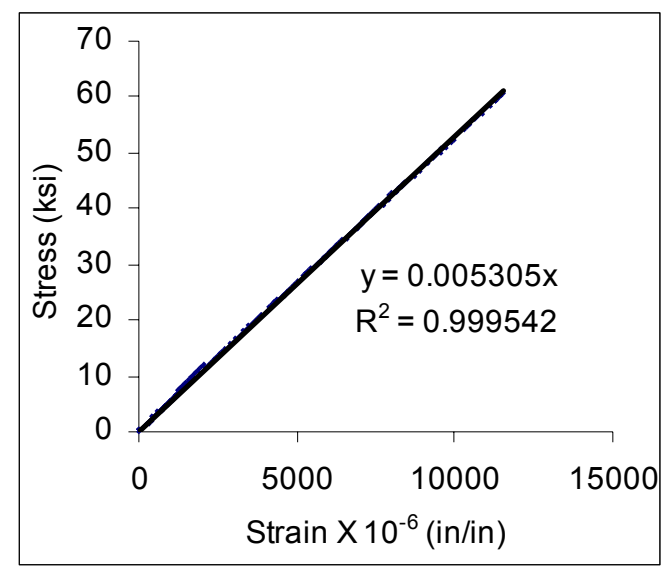

Sample 1

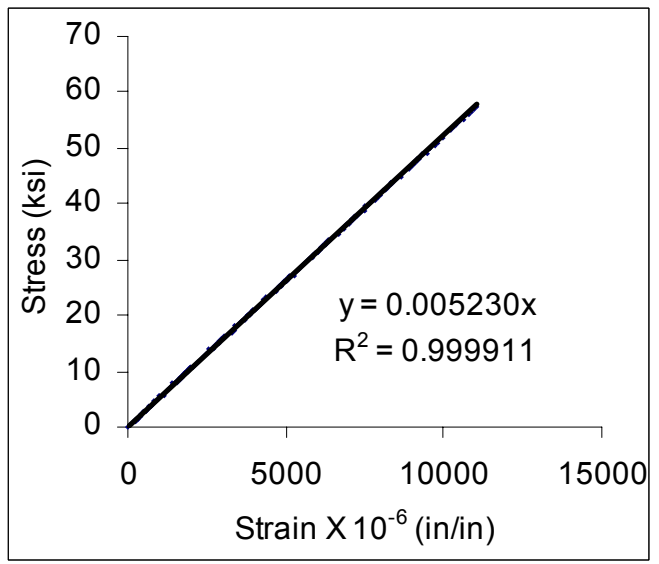

Sample 3

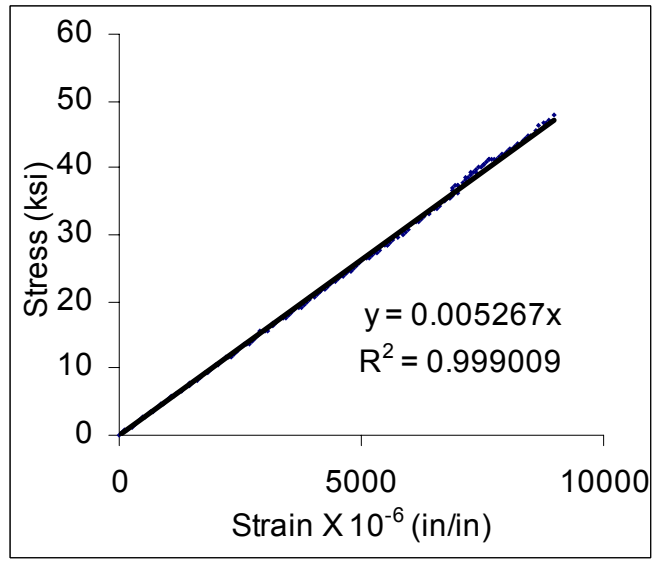

Sample 2

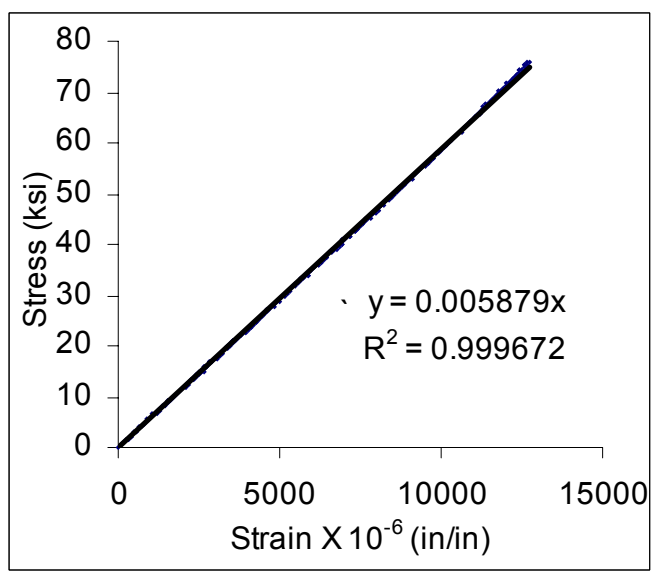

Sample 4

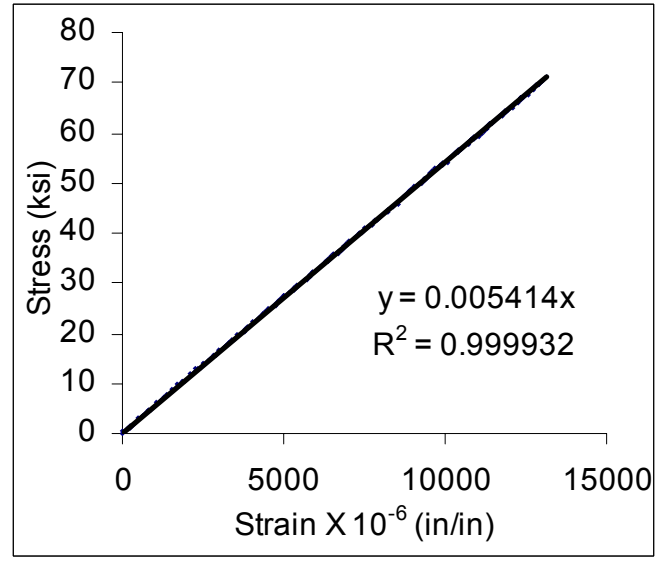

Sample 5 
B.3 Stress-strain plots for tension tests - Ribbed GFRP - \#4 FAU (Refer Table 4.5, Chapter 4, Section 4.3.2)

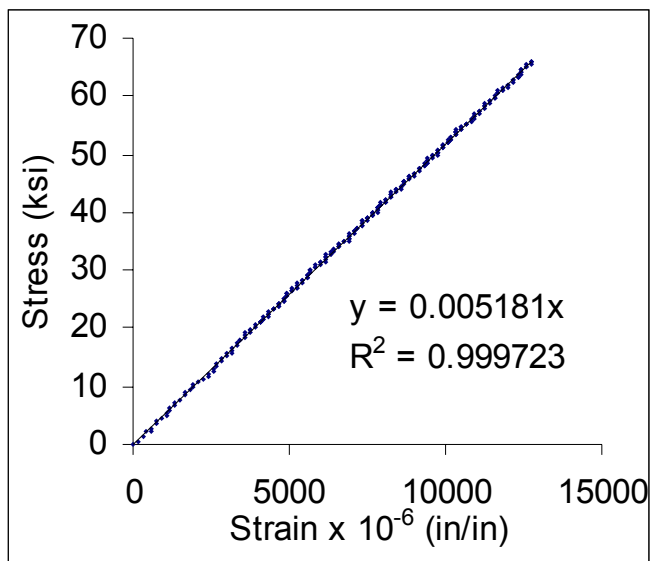

Sample TC1

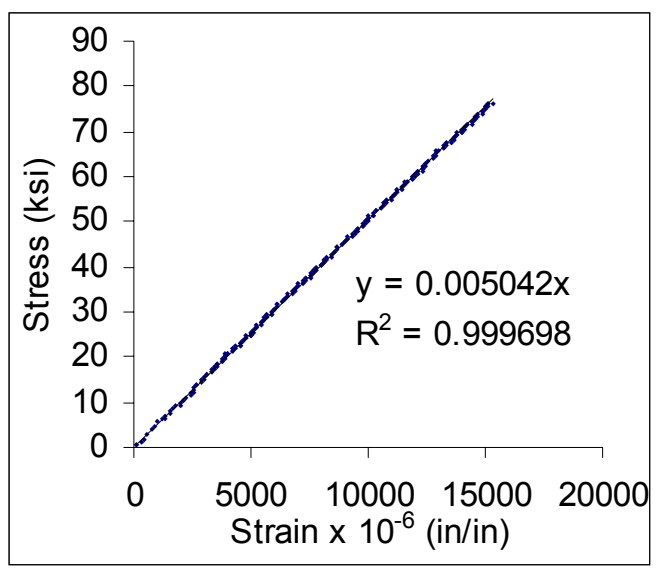

Sample TC2

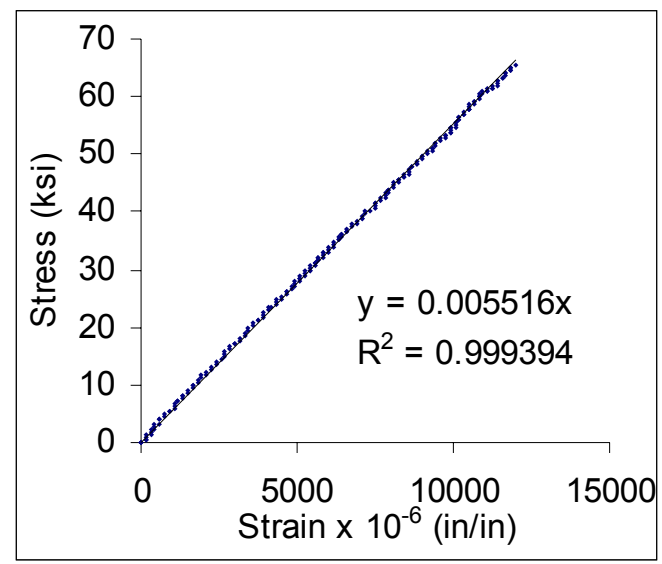

Sample TC3

B.4 Stress-strain plots for tension tests - Sand Coated GFRP - \#4 WVU (Refer Table 4.7, Chapter 4, Section 4.3.3)

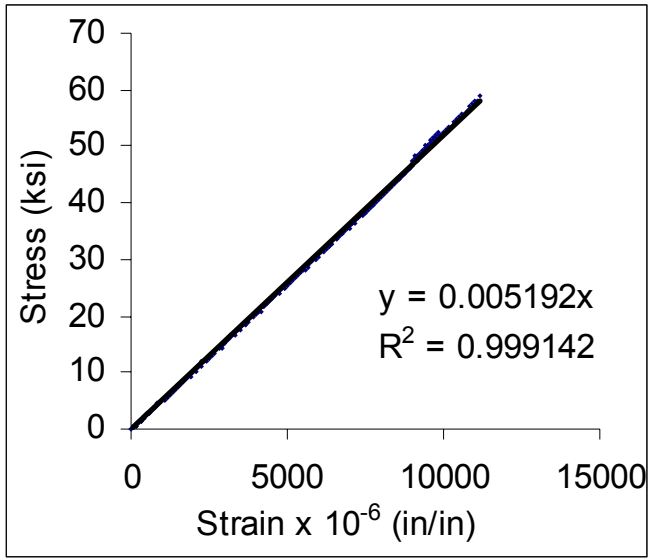

Sample 1

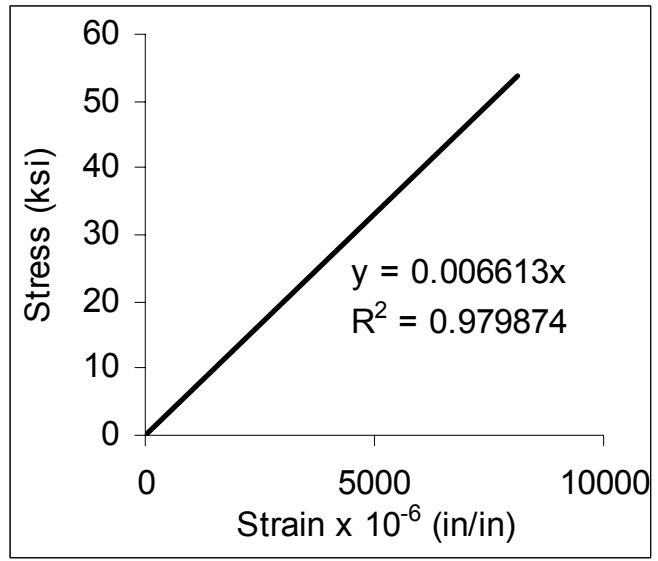

Sample 2 
B.5 Stress-strain plots for tension tests - Sand Coated GFRP - \#5 FAU (Refer Table 4.8, Chapter 4, Section 4.3.3)

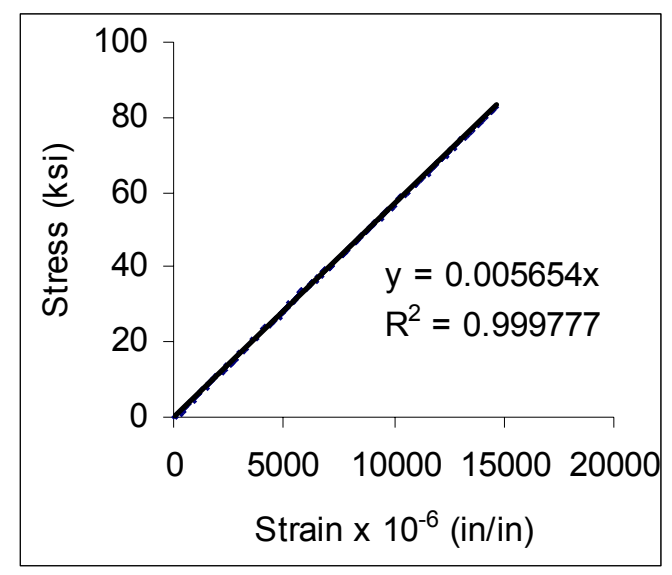

TA1

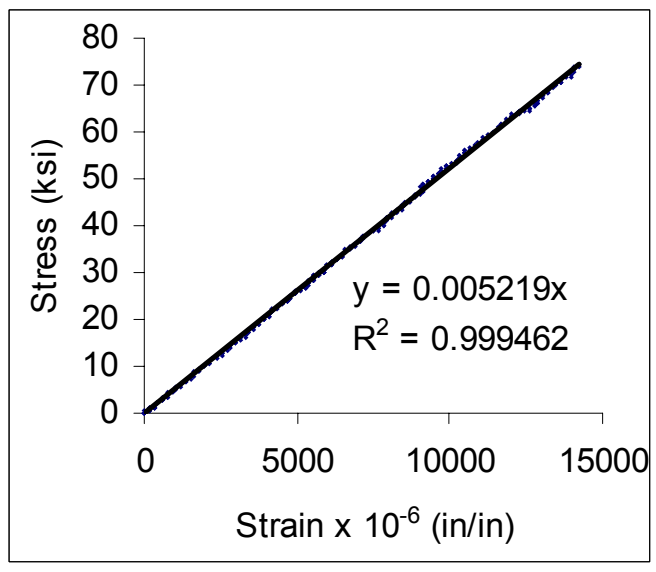

TA2

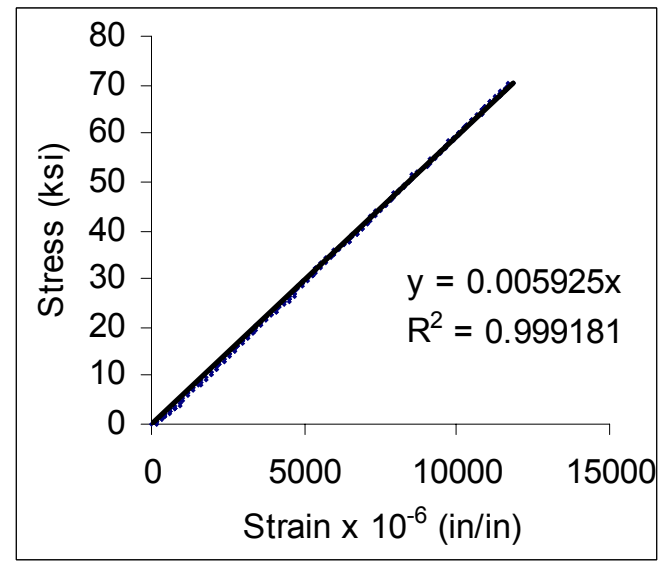

TA3

B.6 Stress-strain plots for tension tests - Sand Coated AFRP - \#3 FAU (Refer Table 4.10, Chapter 4, Section 4.3.4)

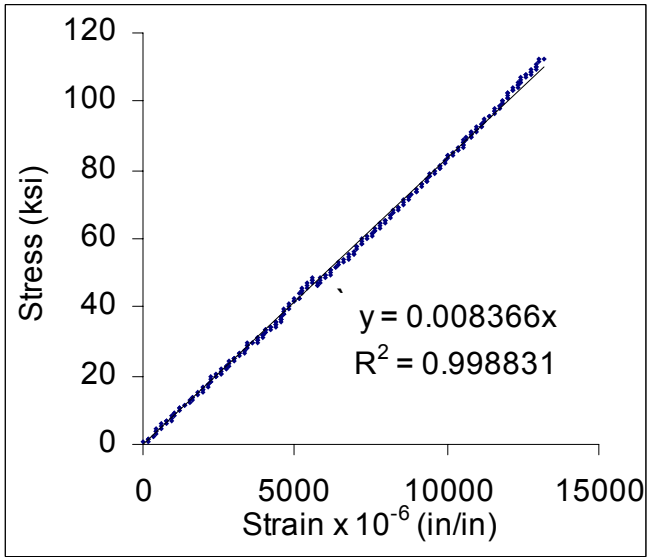

TD1

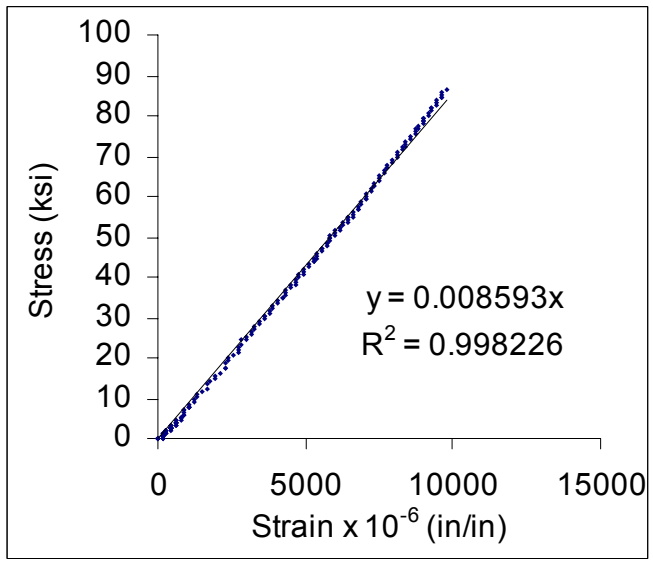

TD2 


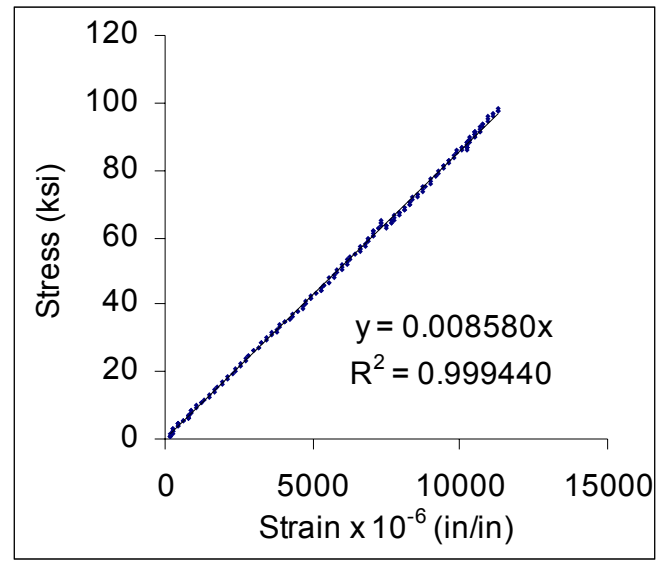

TD3

\section{B.7 Load-deflection plots for flexure tests on support type A - Ribbed CFRP - \#3 (Refer} Table 5.8, Chapter 5, Section 5.3.3)

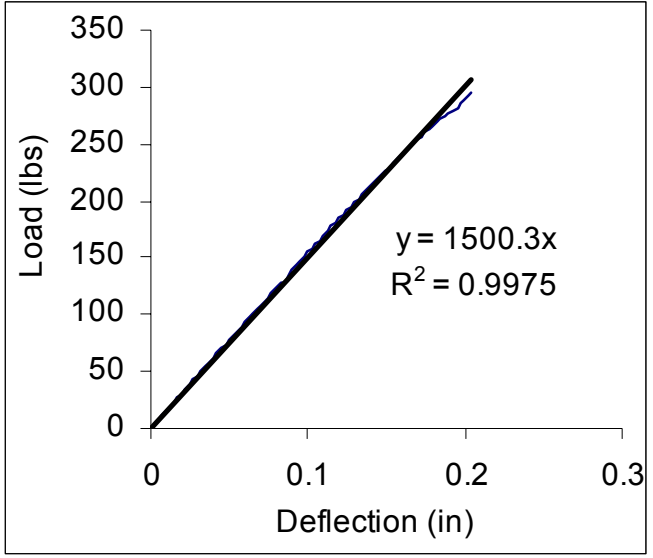

Sample 1

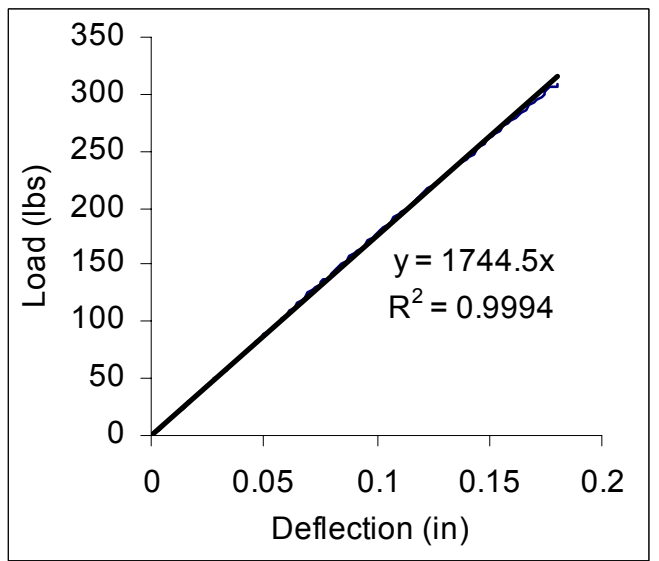

Sample 3

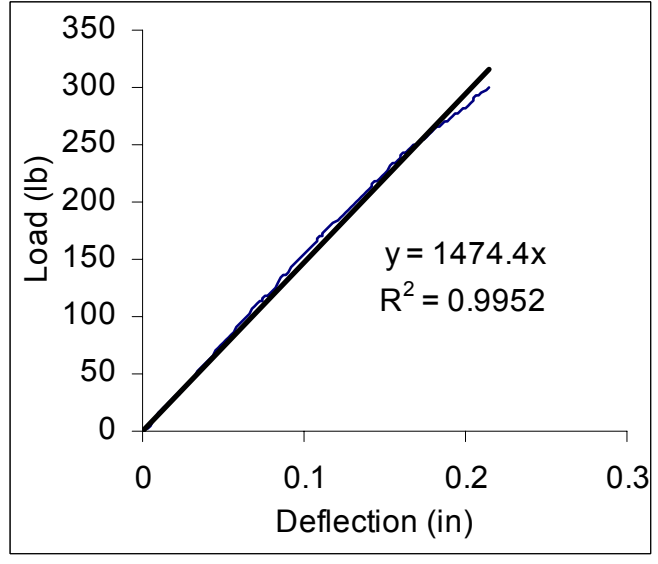

Sample 2

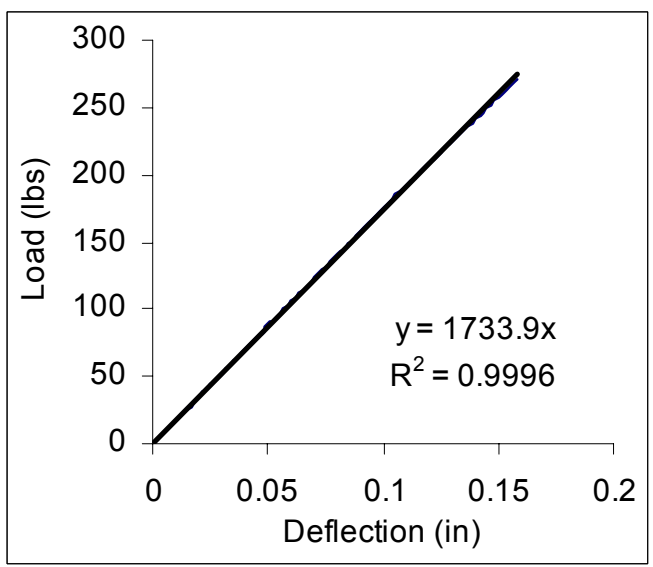

Sample 4 


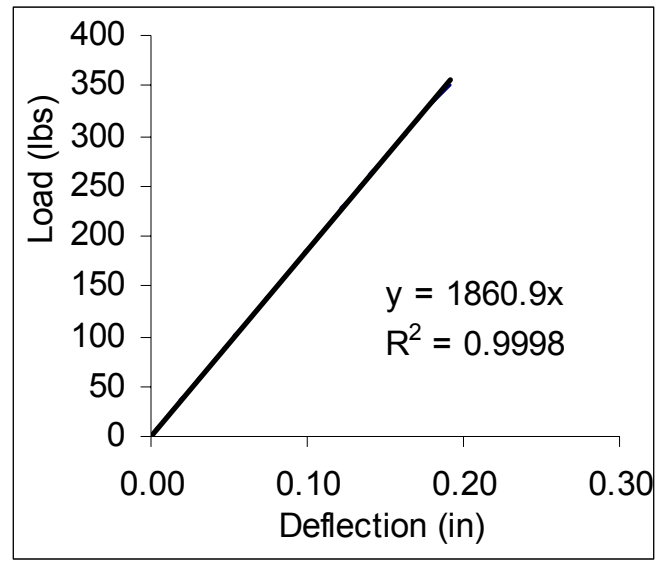

Sample 5

B.8 Load-deflection plots for flexure tests on support type A - Ribbed GFRP - \#4 (Refer Table 5.2 and 5.3, Chapter 5, Section 5.3.1)

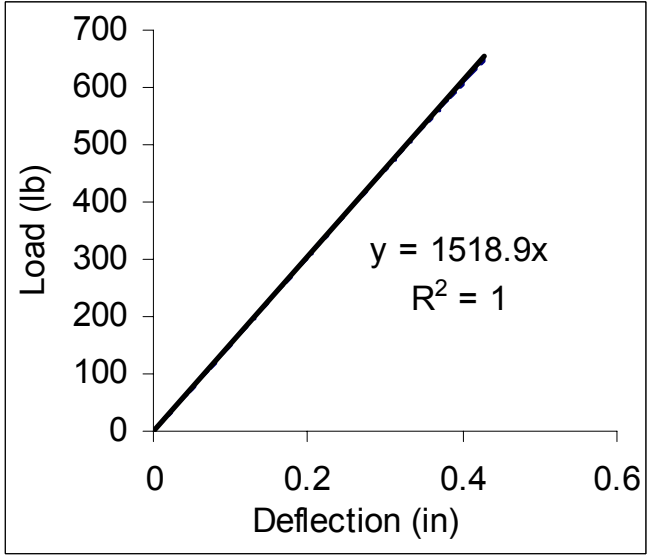

Sample 4

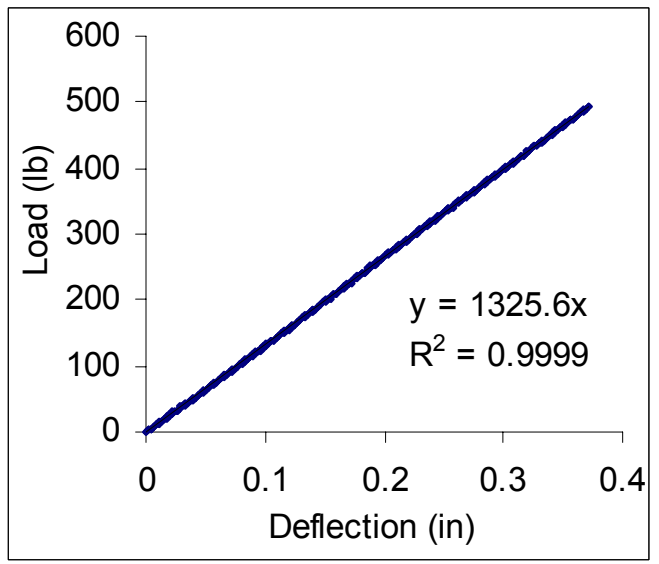

Sample 6

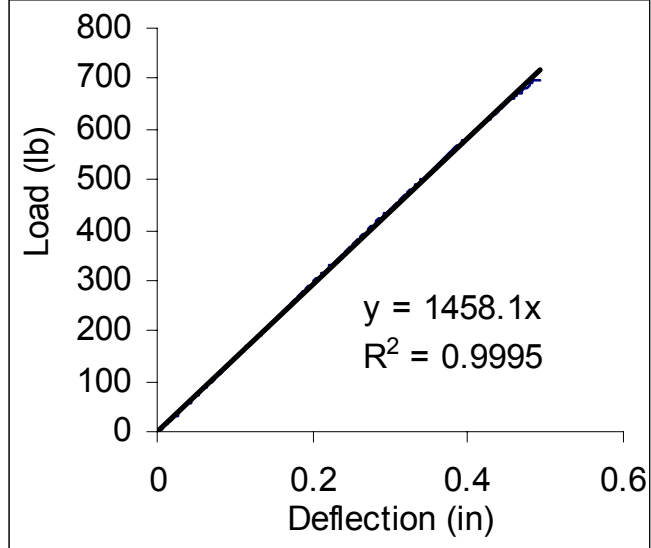

Sample 5

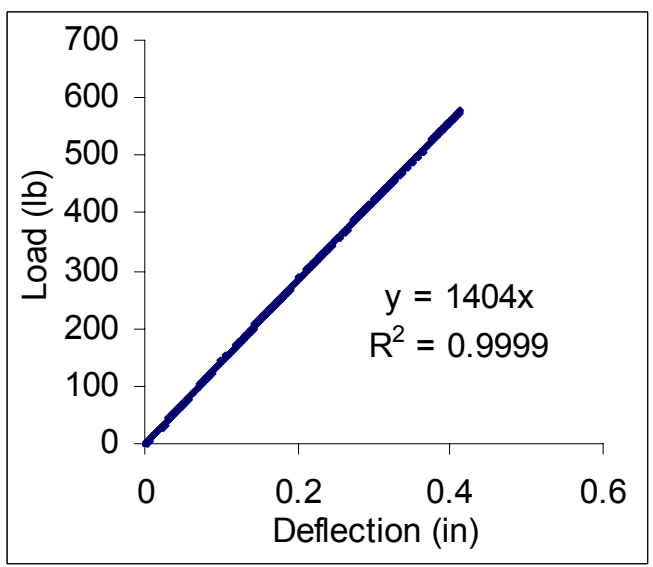

Sample 7 


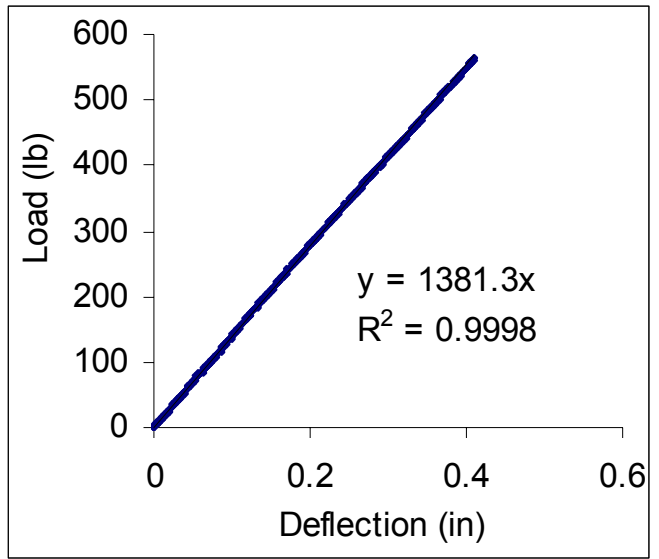

Sample 8

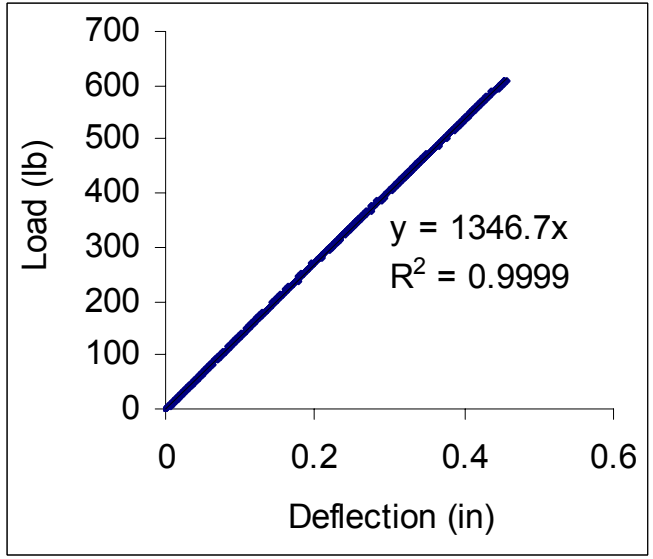

Sample 9

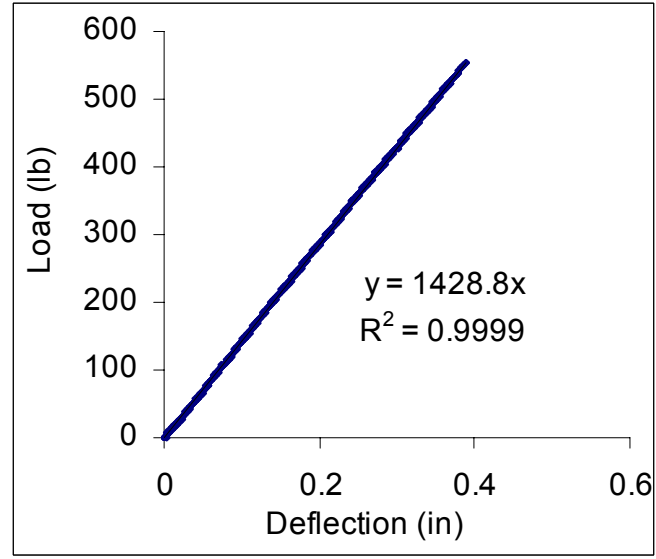

Sample 10

B.9 Stress-strain plots for flexure tests on support type A - Ribbed GFRP - \#4 (Refer Table 5.3, Chapter 5, Section 5.3.1)

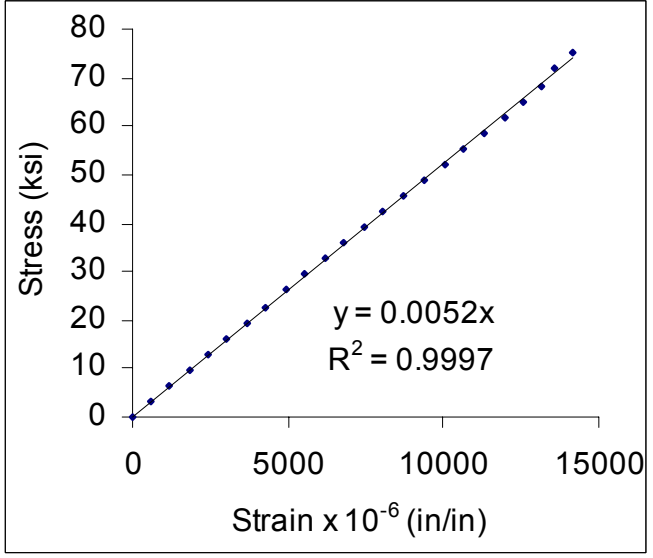

Sample 8

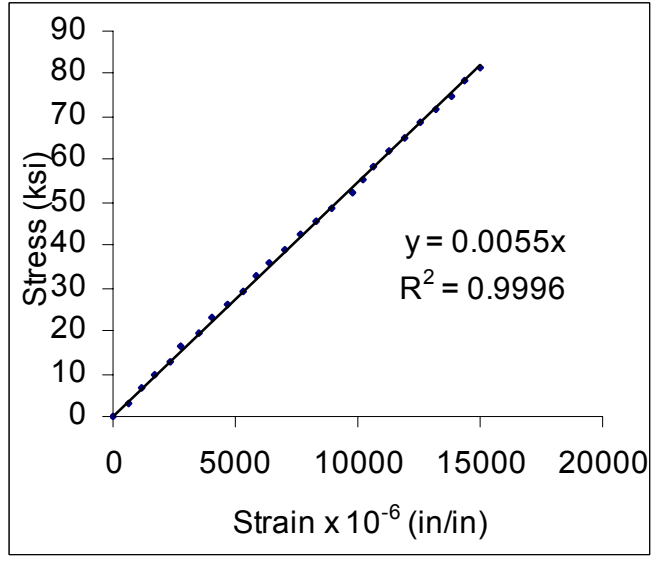

Sample 10 
B.10 Load-deflection plots for flexure tests on support type A - Sand Coated GFRP - \#4 (Refer Table 5.5 and 5.6, Chapter 5, Section 5.3.2)

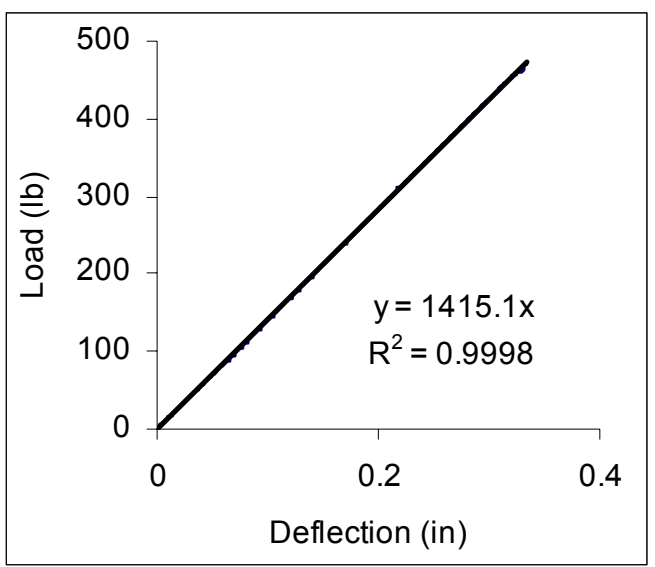

Sample 4

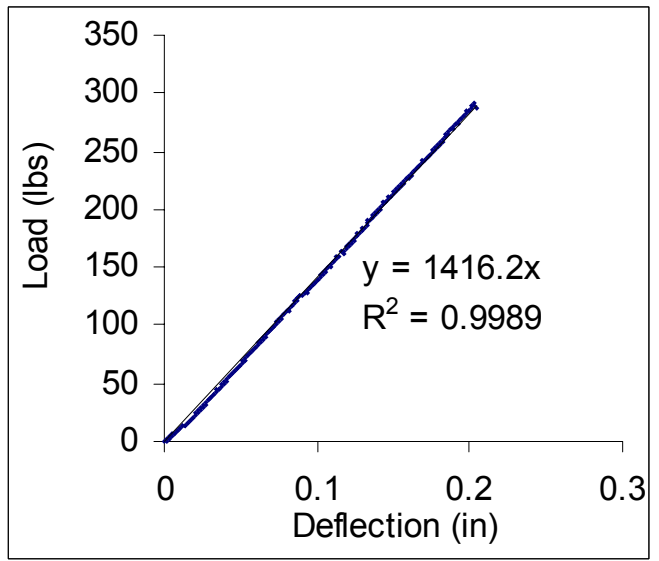

Sample 6

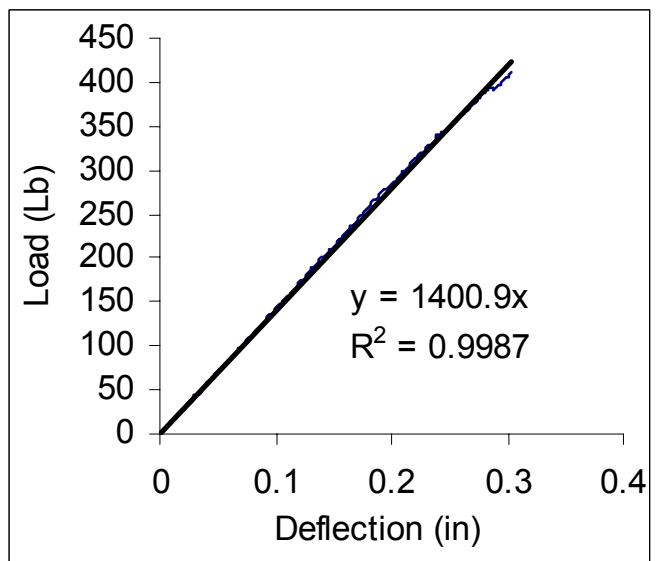

Sample 5

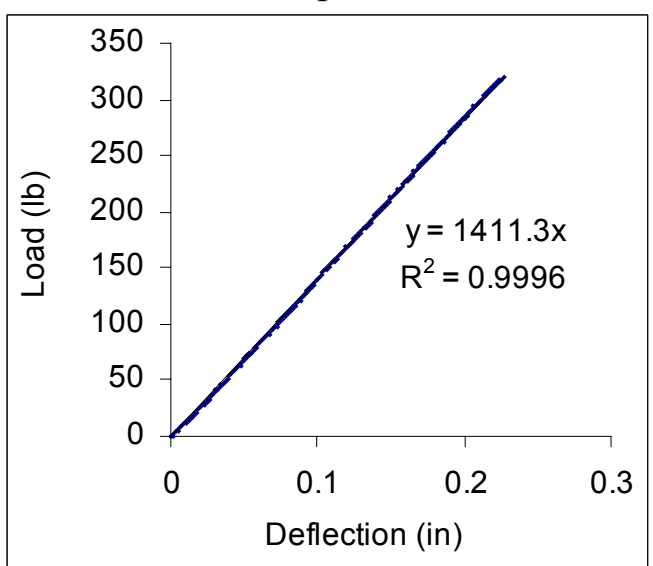

Sample 7

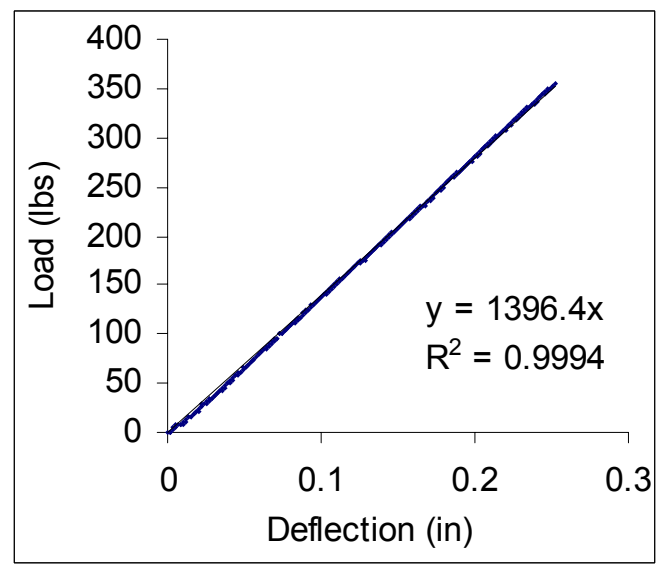

Sample 8 
B.11 Stress-strain plots for flexure tests on support type A - Sand Coated GFRP - \#4 (Refer Table 5.6, Section 5.3.2)

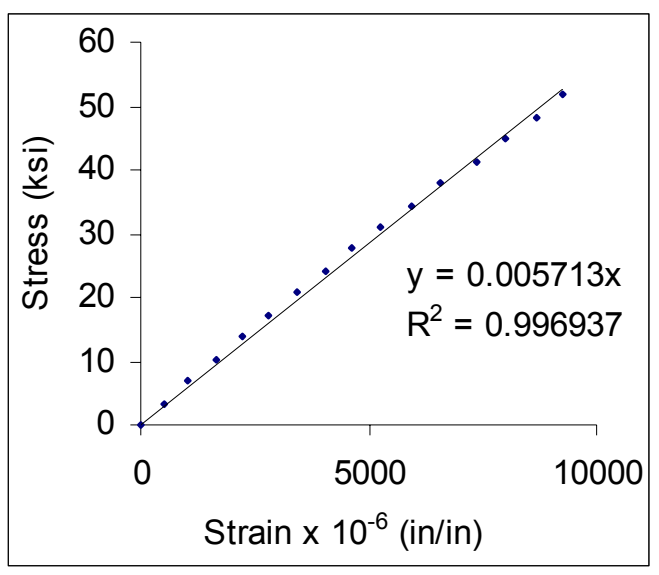

Sample 6

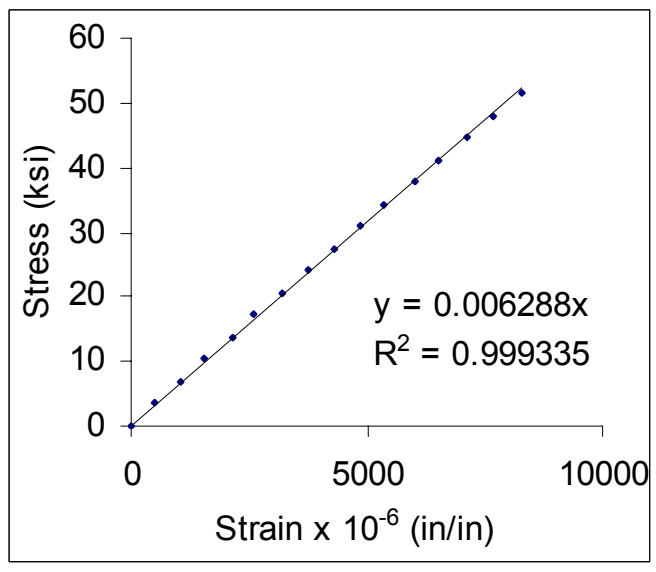

Sample 7

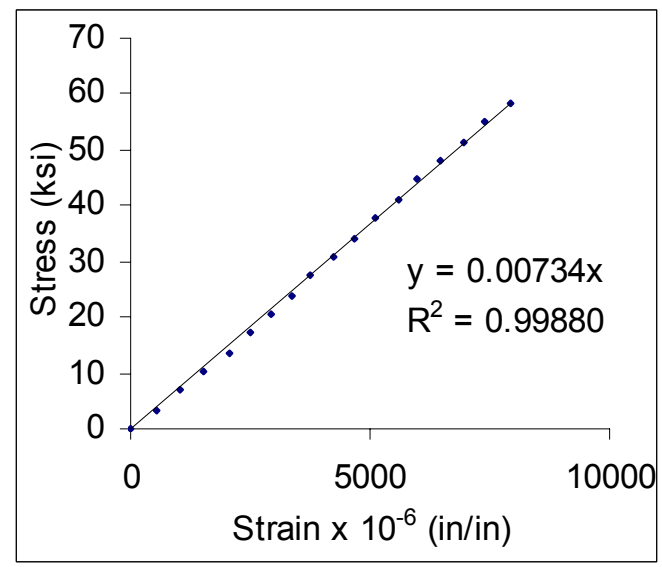

Sample 8

B.12 Load-deflection plots for flexure tests on aged bars - Ribbed GFRP - \#4 (Refer Table 8.5, Chapter 8, Section 8.5.1)

(Note: Only maximum and minimum slopes of the plots given)

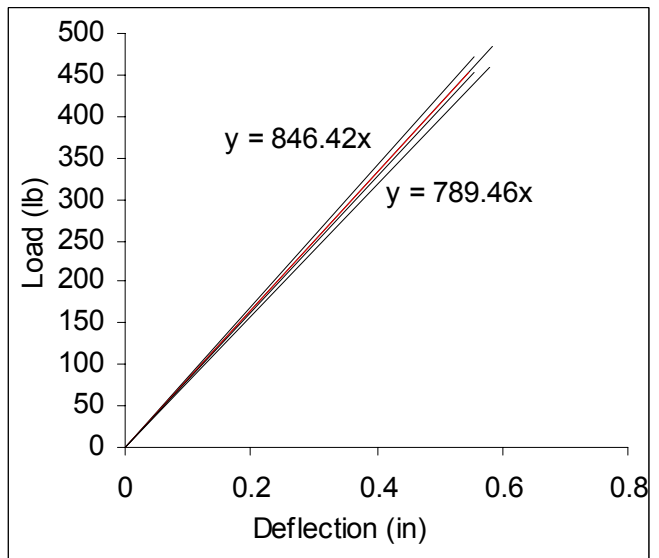

Unaged bars

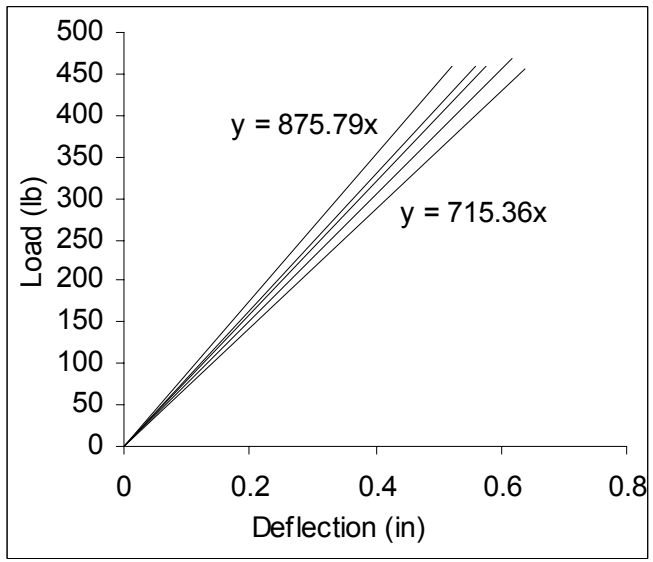

Water solution at room temp 


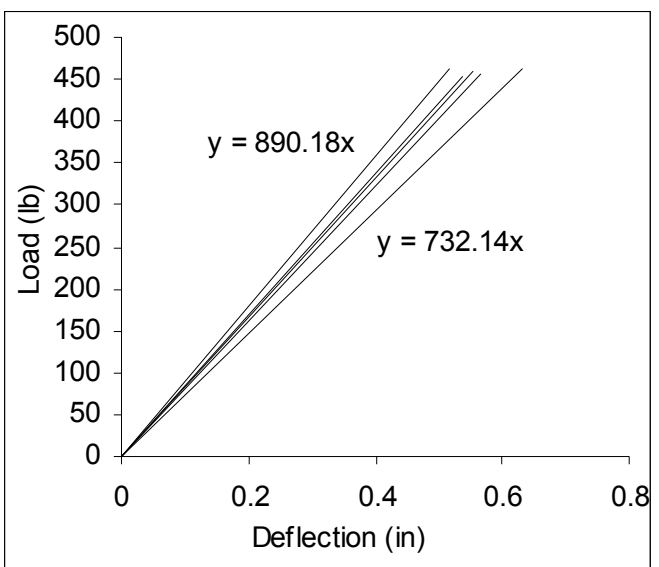

$3 \%$ Salt soln. at room temp

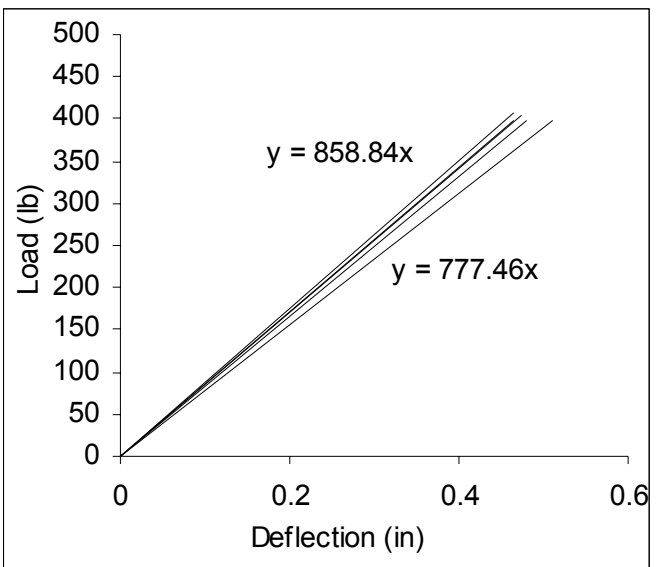

Water soln. with freeze-thaw temp fluctiations

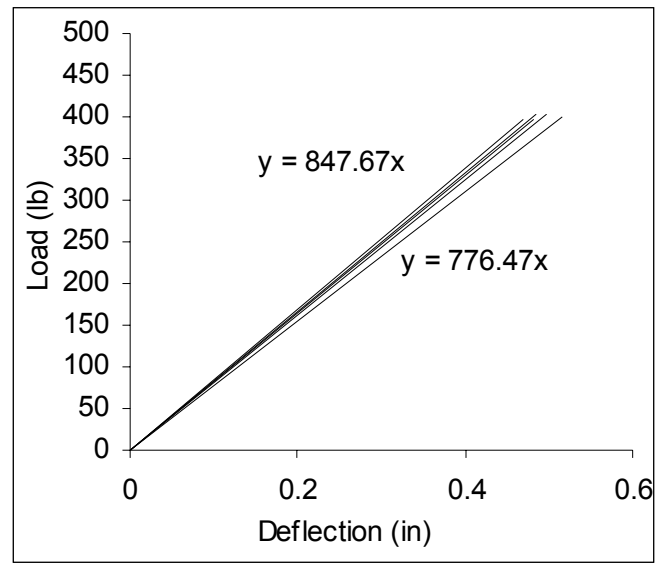

$3 \%$ Salt soln. with freeze-thaw temp fluctuations

\section{B.13 Load-deflection plots for flexure tests on aged bars - Sand Coated GFRP - \#4 (Refer Table 8.7, Chapter 8, Section 8.5.2)}

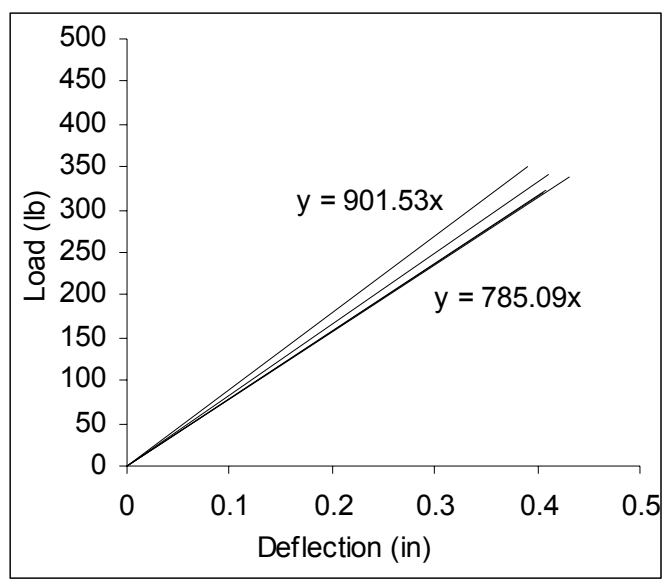

Unaged bars

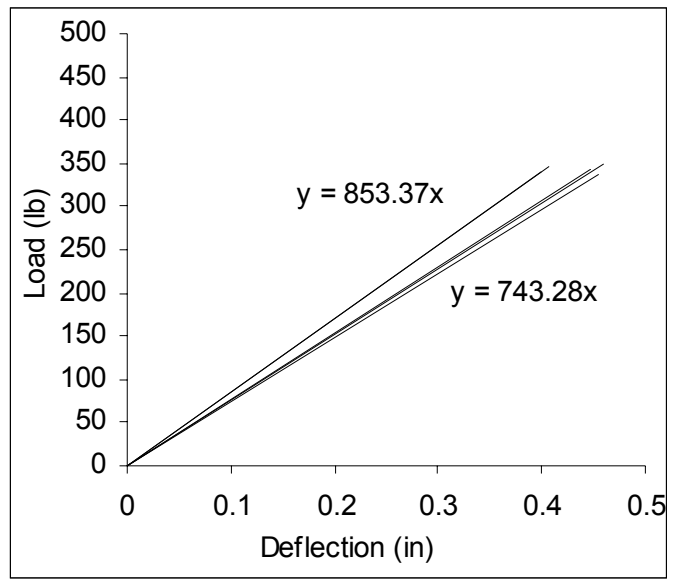

Water solution at room temp 

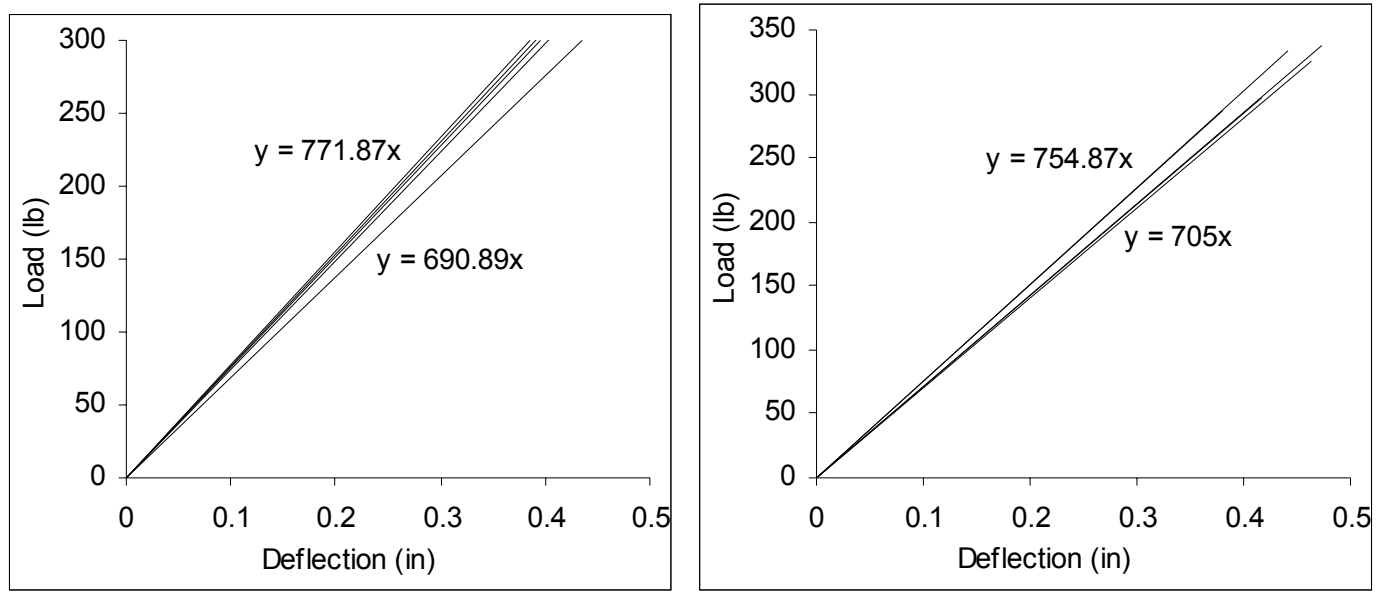

$3 \%$ Salt soln at room temp

Water soln with freeze-thaw temp fluctiations

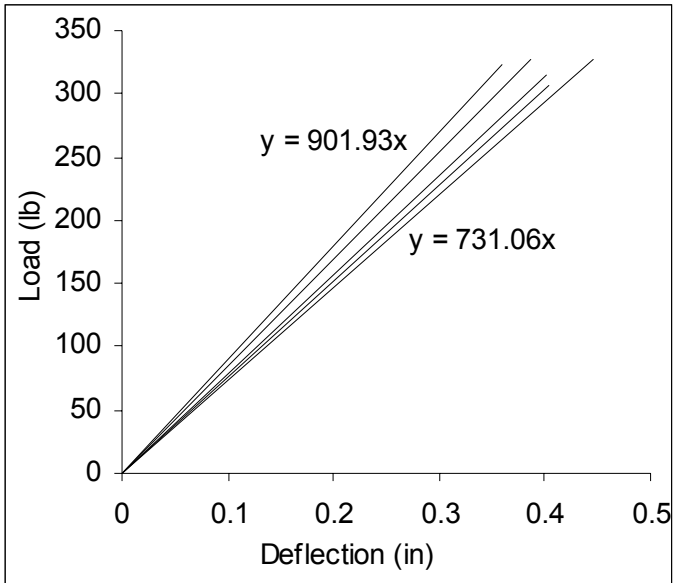

3\% Salt soln with freeze-thaw temp fluctuations

\section{B.14 Load-slip plots for bond tests (Refer Table 7.6, Chapter 7, Section 7.3)}

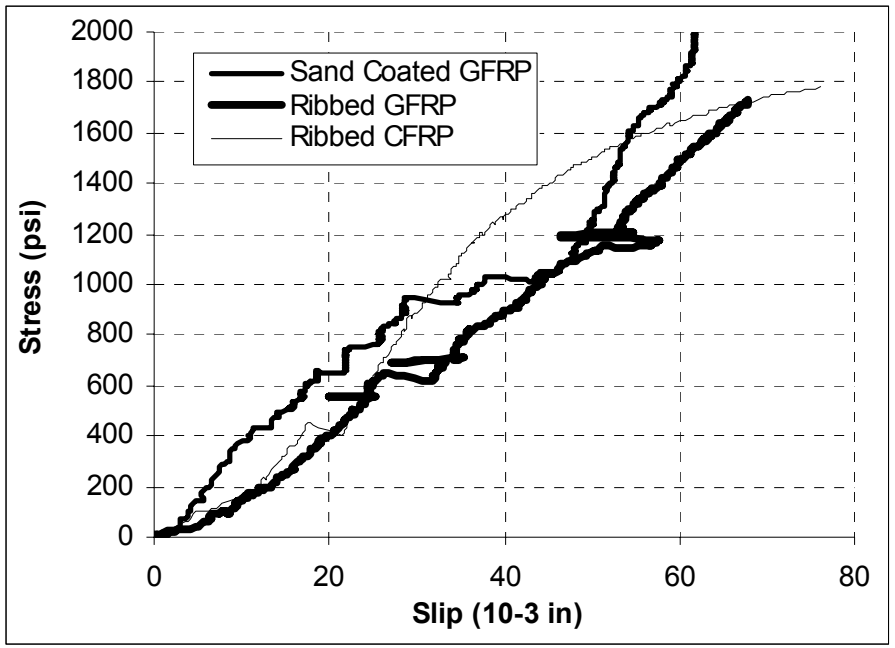

B.15 Moisture absorption plots for FRP bars (Refer Table 8.2, Chapter 8, Section 8.3) 


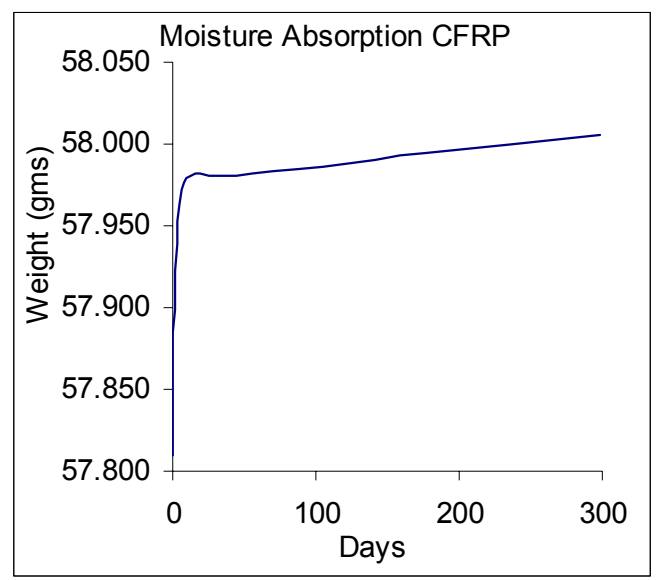

CFRP Ribbed \#3 bars

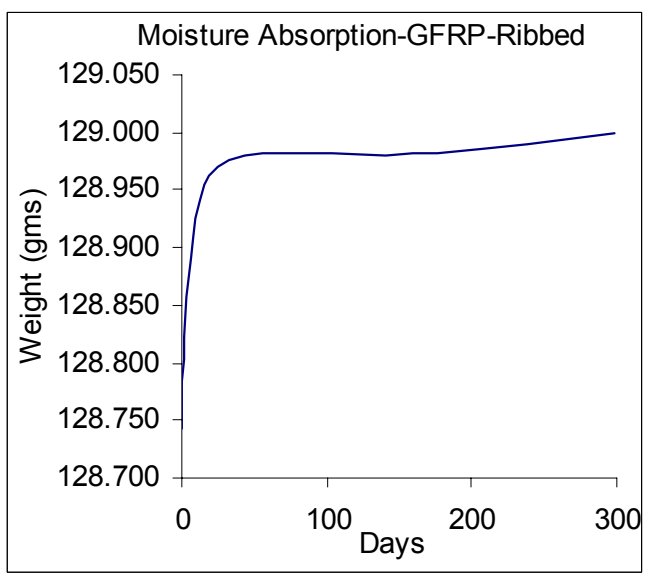

GFRP Ribbed \#4 bars

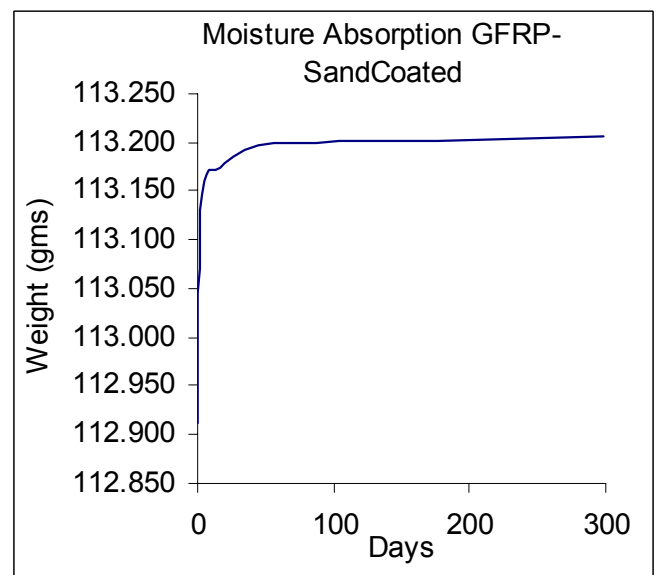

GFRP Sand Coated \#4 bars 


\section{APPENDIX C}

\section{Shear Deflections in bars under Flexure}

The deflections recorded during flexure tests in Chapter 5 are mainly due to flexure. The stiffness (E) value was calculated based on considering the deflections as entirely due to flexure (Chapter 5). However, if the small amount deflection due to shear is subtracted from the total deflections recorded, there is a marginal increase in the calculated E value. Effect of bending span to diameter ratio (L/D) of the bars on shear deflection is discussed later in this appendix.

Deflection due to bending (3 point bending, simply supported) is given by,

$$
\delta_{b}=\frac{P L^{3}}{48 E I}
$$

where,

$\mathrm{P}=$ Load applied,

$\mathrm{L}=$ Test span or the distance between the center of two support locations,

$\mathrm{E}=$ Stiffness of the bar tested, and

$\mathrm{I}=$ Moment of Inertia of cross-section of the bar tested.

Deflection due to shear is given by [51],

$$
\delta_{s}=\frac{\alpha P L}{4 G A}
$$

where,

$\alpha=$ shear correction factor $=4 / 3$ for circular cross sections [51],

$\mathrm{G}=$ Shear Modulus of the bar $=0.71 \mathrm{msi}[14]$, and

$\mathrm{A}=$ Area of cross-section of the bar tested. 
Table C-1: Theoretical Flexure and Shear Deflections

$($ Stiffness $(E)=6$ msi; Shear Modulus $(G)=0.71$ msi; Shear Correction Factor $(\alpha)=4 / 3$;

Load (P) lbs = $400 \mathrm{lbs}$.

\begin{tabular}{|c|c|c|c|c|c|c|c|c|}
\hline $\begin{array}{l}\text { Dia } \\
\text { (D) }\end{array}$ & Area (A) & $\begin{array}{l}\text { Moment of } \\
\text { Inertia (I) }\end{array}$ & $\begin{array}{c}\text { Span } \\
\text { (L) }\end{array}$ & (L/D) & $\begin{array}{c}\text { Flexure } \\
\text { Deflection } \\
\left(\delta_{b}\right) \\
\end{array}$ & $\begin{array}{c}\text { Shear } \\
\text { Deflection } \\
\left(\delta_{\mathrm{s}}\right) \\
\end{array}$ & $\begin{array}{c}\text { Total } \\
\text { Deflection } \\
(\Delta) \\
\end{array}$ & $\begin{array}{c}\% \\
\text { Shear } \\
\left(\delta_{\mathrm{s}} / \Delta\right) \\
\end{array}$ \\
\hline in & in $^{2}$ & in $^{4}$ & in & & in & in & in & \\
\hline 0.375 & 0.1104467 & 0.0009707 & 3.75 & 10 & 0.0754 & 0.006376 & 0.08183 & 7.8 \\
\hline 0.375 & 0.1104467 & 0.0009707 & 4.6875 & 12.5 & 0.14736 & 0.00797 & 0.155336 & 5.14 \\
\hline 0.375 & 0.1104467 & 0.0009707 & 5.625 & 15 & 0.25465 & 0.009564 & 0.264212 & 3.62 \\
\hline 0.375 & 0.1104467 & 0.0009707 & 6.5625 & 17.5 & 0.40437 & 0.011158 & 0.41553 & 2.69 \\
\hline 0.375 & 0.1104467 & 0.0009707 & 7.5 & 20 & 0.60361 & 0.012752 & 0.61636 & 2.07 \\
\hline 0.375 & 0.1104467 & 0.0009707 & 8.4375 & 22.5 & 0.85944 & 0.014346 & 0.87378 & 1.65 \\
\hline 0.375 & 0.1104467 & 0.0009707 & 9.375 & 25 & 1.179 & 0.01594 & 1.194866 & 1.34 \\
\hline 0.375 & 0.1104467 & 0.0009707 & 15 & 40 & 4.829 & 0.025504 & 4.85438 & 0.53 \\
\hline 0.5 & 0.19635 & 0.003068 & 5 & 10 & 0.05659 & 0.004782 & 0.06137 & 7.8 \\
\hline 0.5 & 0.19635 & 0.003068 & 6.25 & 12.5 & 0.11052 & 0.005978 & 0.1165 & 5.14 \\
\hline 0.5 & 0.19635 & 0.003068 & 7.5 & 15 & 0.191 & 0.007173 & 0.19816 & 3.62 \\
\hline 0.5 & 0.19635 & 0.003068 & 8.75 & 17.5 & 0.3033 & 0.00837 & 0.31165 & 2.69 \\
\hline 0.5 & 0.19635 & 0.003068 & 10 & 20 & 0.45271 & 0.009564 & 0.46227 & 2.07 \\
\hline 0.5 & 0.19635 & 0.003068 & 11.25 & 22.5 & 0.64458 & 0.01076 & 0.65534 & 1.65 \\
\hline 0.5 & 0.19635 & 0.003068 & 12.5 & 25 & 0.8842 & 0.011955 & 0.89615 & 1.34 \\
\hline 0.5 & 0.19635 & 0.003068 & 20 & 40 & 3.62166 & 0.01913 & 3.64079 & 0.53 \\
\hline 0.625 & 0.3068 & 0.0075 & 6.25 & 10 & 0.045271 & 0.00382 & 0.0491 & 7.8 \\
\hline 0.625 & 0.3068 & 0.0075 & 7.8125 & 12.5 & 0.08842 & 0.00478 & 0.0932 & 5.14 \\
\hline 0.625 & 0.3068 & 0.0075 & 9.375 & 15 & 0.15279 & 0.00574 & 0.15853 & 3.62 \\
\hline 0.625 & 0.3068 & 0.0075 & 10.9375 & 17.5 & 0.242623 & 0.0067 & 0.2493 & 2.69 \\
\hline 0.625 & 0.3068 & 0.0075 & 12.5 & 20 & 0.362166 & 0.00765 & 0.36982 & 2.07 \\
\hline 0.625 & 0.3068 & 0.0075 & 14.0625 & 22.5 & 0.515662 & 0.00861 & 0.52427 & 1.65 \\
\hline 0.625 & 0.3068 & 0.0075 & 15.625 & 25 & 0.707355 & 0.00956 & 0.71692 & 1.34 \\
\hline 0.625 & 0.3068 & 0.0075 & 25 & 40 & 2.89733 & 0.015302403 & 2.91263 & 0.53 \\
\hline
\end{tabular}




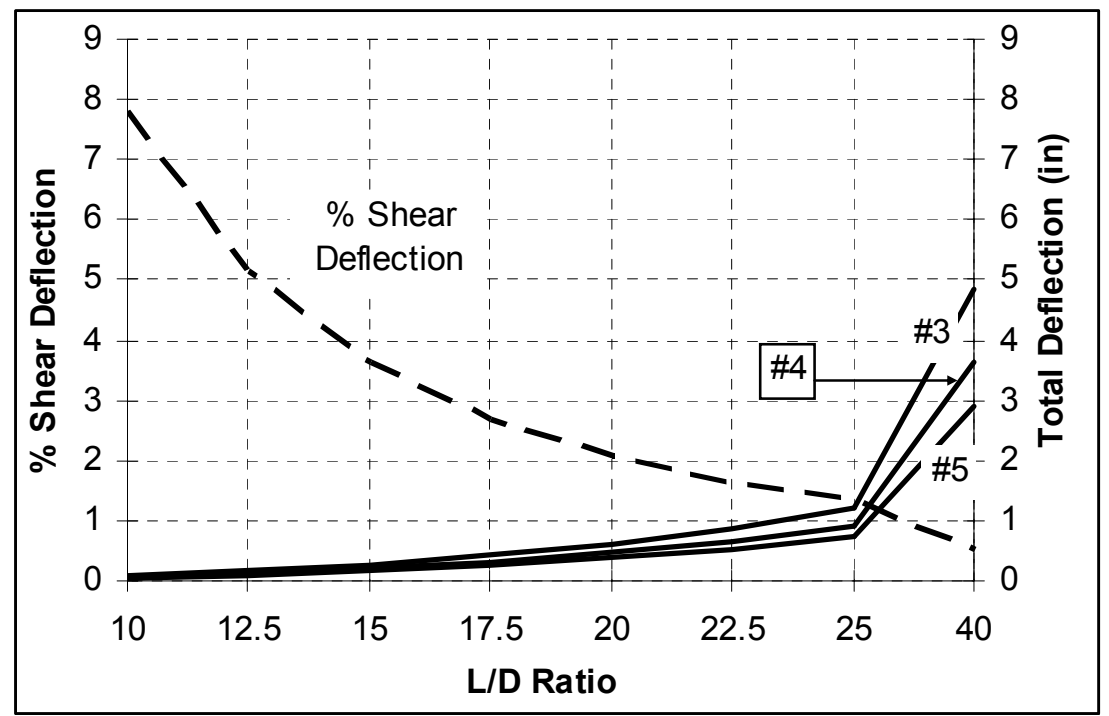

Fig. C-1: L/D ratio vs Percentage Shear Deflections and Total Deflections

(For $P=400 \mathrm{lbs} ; E=6 \mathrm{msi}$; $G=0.71 \mathrm{msi}$; and Shear Correction Factor $\alpha=4 / 3$ )

Hence the total deflection $(\Delta)$ due to both bending and shear is given by,

$$
\Delta=\frac{P L^{3}}{48 E I}+\frac{\alpha P L}{4 G A} \ldots \ldots \ldots \ldots \ldots \ldots \ldots(\mathrm{c}-3)
$$

The shear deflections, considering load $\mathrm{P}=400$ (approximate maximum load taken by GFRP bars in flexure in this study), $\mathrm{G}=0.71[14], \mathrm{E}=6 \mathrm{msi}$ (approximate $\mathrm{E}$ value of GFRP bars in this research), $\alpha=4 / 3$ for circular cross sections [51], for different diameters of bars and span-to-diameter (L/D) ratios are given in Table C-1. Results from Table C-1 are plotted in Fig C-1.

As observed from Fig C-1, shear defection contributes $7.8 \%$ of total deflection with an L/D ratio of 10 . With an $\mathrm{L} / \mathrm{D}$ ratio of 20 , the shear deflection is reduced to $2.07 \%$ of the total deflection. Hence higher the L/D ratio, lesser is the percentage shear deflection. 
From above observations, the $\mathrm{L} / \mathrm{D}$ ratio to be adopted for experimental purposes would be such that the deflection of the bar is sufficiently elastic, the shear deflection is less, and the total deflection produced is measurable to a sufficient accuracy. Hence, the region with L/D ratio of 20 used in this research is a better choice because of lesser percentage shear deflection.

\section{Why should shear deflection be less?}

The experimental deflection $\left(\Delta_{\mathrm{e}}\right)$ recorded from flexure tests is used to calculate the stiffness value $(\mathrm{E})$ of the bar using Eq c-4,

$$
E=\frac{P L^{3}}{48 \Delta_{e} I} \ldots \ldots \ldots \ldots \ldots \ldots \ldots(\mathrm{c}-4)
$$

However, $\Delta_{\mathrm{e}}$ contains both flexural and shear deflections. From Table C-1, the shear deflection is $2 \%$ of the total deflection for an $\mathrm{L} / \mathrm{D}$ ratio of 20 . Hence the actual flexure deflection $\left(\Delta_{\mathrm{a}}\right)$ is 0.98 times $\Delta_{\mathrm{e}}$. Substituting $\Delta_{\mathrm{a}}=0.98 \Delta_{\mathrm{e}}$ in Eq. c-4, the actual stiffness $\left(\mathrm{E}_{\mathrm{a}}\right)$ value becomes,

$$
E_{a}=\frac{P L^{3}}{48 \Delta_{a} I}=\frac{P L^{3}}{48\left(0.98 \Delta_{e}\right) I}=\frac{1.02 P L^{3}}{48 \Delta_{e} I}=1.02 E
$$

There is an increase of $2 \%$ in the corrected stiffness value $E_{a}$ as compared to $E$, when shear deflection is subtracted. Hence lower the contribution of shear in total deflection, lower is the variation in calculated and actual stiffness values. 